\title{
Redes complexas de expressão gênica: síntese, identificação, análise e aplicações
}

\author{
Fabrício Martins Lopes \\ TESE APRESENTADA \\ $\mathrm{AO}$ \\ Programa INTERUNidADES EM BIOINFORMÁTICA \\ DA \\ UNIVERSIDADE DE SÃO PAULO \\ PARA \\ OBTENÇÃO DO TÍTULO \\ $\mathrm{DE}$ \\ DOUTOR EM CIÊNCIAS
}

\author{
Programa: Doutorado em Bioinformática \\ Orientador: Prof. Dr. Roberto M. Cesar Jr. \\ Coorientadora: Profa ${ }^{\text {a }}$ Dra. Marie-Anne Van Sluys
}
Durante o desenvolvimento deste trabalho o autor recebeu auxílio financeiro da UTFPR/CAPES(PICDT)





\title{
Redes complexas de expressão gênica: síntese, identificação, análise e aplicações
}

\author{
Este exemplar corresponde à redação \\ final da tese submetida à comissão julgadora \\ apresentado por Fabrício Martins Lopes \\ ao Programa Interunidades de Doutorado \\ em Bioinformática da Universidade de São Paulo.
}

Banca Examinadora:

- Prof. Dr. Roberto Marcondes Cesar Jr. - IME-USP.

- Prof. Dr. David Corrêa Martins Jr. - CMCC-UFABC.

- Prof. Dr. Eduardo Moraes Rego Reis - IQ-USP.

- Profa . Dra. Helena Paula Brentani - FM-USP.

- Prof. Dr. Junior Barrera - FFCLRP-USP.

- Prof. Dr. Roberto Hirata Jr - IME-USP. 

"A vida é muito curta para que possamos nos interessar por tudo, mas convém concentrar nosso interesse em todas as coisas que possam preencher nossos dias."

Bertrand Russell 
Aos meus queridos pais

Orlando e Izaura, minha esposa Daniela e a meus antepassados. 


\section{Agradecimentos}

Em primeiro lugar, agradeço a Deus por ter me dado inspiração, saúde e persistência para desenvolver este trabalho.

À minha esposa, Daniela, por seu apoio, carinho, respeito, incentivo, companheirismo e amor. Além de ter acreditado em meu sonho e encarado esse desafio comigo, ainda proveu nosso maior presente, nosso primeiro filho, Enzo. Dani você é especial para mim!

Aos meus pais, Orlando e Izaura, e ao meu irmão Christian, pelo incentivo, confiança, apoio e carinho incondicionais.

Ao ex-orientador e amigo Luís Augusto Consularo que participou ativamente de meus primeiros passos na pesquisa. Seu exemplo, conhecimento e generosidade em me ensinar durante o mestrado foi determinante para eu continuar os estudos, que levou ao desenvolvimento deste trabalho.

Ao Roberto M. Cesar Jr, por ter confiado em minha capacidade e me aceito como seu aluno de doutorado. Suas ideias e atitudes sempre positivas, além de seu conhecimento e sua dedicação ao ensino e à pesquisa, foram fundamentais para o desenvolvimento deste trabalho. Valeu Roberto!

À Marie-Anne Van Sluys por ter aceitado o convite em co-orientar este trabalho e, ter participado efetivamente do seu desenvolvimento, especialmente em sua finalização.

Aos professores Nina Hirata, Roberto Hirata e Ronaldo Hashimoto pela participação efetiva em minha formação durante o período de doutorado.

Aos demais colaboradores dessa pesquisa. Ao professor Luciano da Fontoura Costa, David C. Martins Jr, Andreia O. Latorre, Evaldo A. de Oliveira e Junior Barrera por todas as contribuições realizadas no desenvolvimento deste trabalho e, em particular, ao David e ao Evaldo pela cuidadosa revisão de algumas partes dessa tese.

Ao amigo Yossi Zana por seu apoio e acolhida quando cheguei ao laboratório, tornando minha adaptação ao ambiente muito rápida e agradável.

Aos amigos do laboratório, David da Silva Pires, Jesús Mena-Chalco, Jihan Zoghbi, André Kashiwabara, Alexandre Paschoal, Ana Beatriz, Talita Perciano, Fábio Vicente, Silvia Pinto, Silvio de Faria, Daniel Dantas, Alexandre Noma, Arnaldo Lara e Carlos Higa pelos momentos agradáveis, discussões e reflexões que tornaram o desenvolvimento das atividades cotidianas mais divertida e a convivência no laboratório muito agradável.

Aos membros da CPG-Bioinfo pela oportunidade de aprendizado durante minha participação como representante discente e na organização dos cursos de verão em bioinformática, em especial ao Prof. Alan M. Durham e à Profa. Helaine Carrer.

Aos amigos da UTFPR pelo apoio em proporcionar um período de licença de minhas atividades acadêmicas que foi fundamental para o desenvolvimento deste trabalho.

À Patricia Martorelli por ter me ajudado em todos os problemas burocráticos na CPG-Bionfo. 
À CAPES (PICDT) e à UTFPR pelo apoio financeiro que tornaram possível o desenvolvimento deste trabalho. 


\section{Resumo}

Os avanços na pesquisa em biologia molecular e bioquímica permitiram o desenvolvimento de técnicas capazes de extrair informações moleculares de milhares de genes simultaneamente, como DNA Microarrays, SAGE e, mais recentemente RNA-Seq, gerando um volume massivo de dados biológicos. O mapeamento dos níveis de transcrição dos genes em larga escala é motivado pela proposição de que o estado funcional de um organismo é amplamente determinado pela expressão de seus genes. No entanto, o grande desafio enfrentado é o pequeno número de amostras (experimentos) com enorme dimensionalidade (genes). Dessa forma, se faz necessário o desenvolvimento de novas técnicas computacionais e estatísticas que reduzam o erro de estimação intrínseco cometido na presença de um pequeno número de amostras com enorme dimensionalidade. Neste contexto, um foco importante de pesquisa é a modelagem e identificação de redes de regulação gênica (GRNs) a partir desses dados de expressão. O objetivo central nesta pesquisa é inferir como os genes estão regulados, trazendo conhecimento sobre as interações moleculares e atividades metabólicas de um organismo. Tal conhecimento é fundamental para muitas aplicações, tais como o tratamento de doenças, estratégias de intervenção terapêutica e criação de novas drogas, bem como para o planejamento de novos experimentos. Nessa direção, este trabalho apresenta algumas contribuições: (1) software de seleção de características; (2) nova abordagem para a geração de Redes Gênicas Artificiais (AGNs); (3) função critério baseada na entropia de Tsallis; (4) estratégias alternativas de busca para a inferência de GRNs: SFFS-MR e SFFS-BA; (5) investigação biológica das redes gênicas envolvidas na biossíntese de tiamina, usando a Arabidopsis thaliana como planta modelo. O software de seleção de características consiste de um ambiente de código livre, gráfico e multiplataforma para problemas de bioinformática, que disponibiliza alguns algoritmos de seleção de características, funções critério e ferramentas de visualização gráfica. Em particular, implementa um método de inferência de GRNs baseado em seleção de características. Embora existam vários métodos propostos na literatura para a modelagem e identificação de GRNs, ainda há um problema muito importante em aberto: como validar as redes identificadas por esses métodos computacionais? Este trabalho apresenta uma nova abordagem para validação de tais algoritmos, considerando três aspectos principais: (a) Modelo para geração de Redes Gênicas Artificiais (AGNs), baseada em modelos teóricos de redes complexas, os quais são usados para simular perfis temporais de expressão gênica; (b) Método computacional para identificação de redes gênicas a partir de dados temporais de expressão; e (c) Validação das redes identificadas por meio do modelo AGN. O desenvolvimento do modelo AGN permitiu a análise e investigação das características de métodos de inferência de GRNs, levando ao desenvolvimento de um estudo comparativo entre quatro métodos disponíveis na literatura. A avaliação dos métodos de inferência levou ao desenvolvimento de novas metodologias para essa tarefa: (a) uma função critério, baseada na entropia de Tsallis, com objetivo de inferir os inter-relacionamentos gênicos com maior precisão; (b) uma estratégia alternativa de busca para a inferência de GRNs, chamada SFFS-MR, a 
qual tenta explorar uma característica local das interdependências regulatórias dos genes, conhecida como predição intrinsecamente multivariada; e (c) uma estratégia de busca, interativa e flutuante, que baseia-se na topologia de redes scale-free, como uma característica global das GRNs, considerada como uma informação a priori, com objetivo de oferecer um método mais adequado para essa classe de problemas e, com isso, obter resultados com maior precisão. Também é objetivo deste trabalho aplicar a metodologia desenvolvida em dados biológicos, em particular na identificação de GRNs relacionadas a funções específicas de Arabidopsis thaliana. Os resultados experimentais, obtidos a partir da aplicação das metodologias propostas, mostraram que os respectivos ganhos de desempenho foram significativos e adequados para os problemas a que foram propostos.

Palavras-chave: reconhecimento de padrões, seleção de características, entropia, entropia de Tsallis, redes de regulação gênica, inferência de redes, validação, redes complexas. 


\section{Abstract}

Thanks to recent advances in molecular biology and biochemistry, allied to an ever increasing amount of experimental data, the functional state of thousands of genes can now be extracted simultaneously by using methods such as DNA microarrays, SAGE, and more recently RNA-Seq, generating a massive volume of biological data. The mapping of gene transcription levels at large scale is motivated by the proposition that information of the functional state of an organism is broadly determined by its gene expression. However, the main limitation faced is the small number of samples (experiments) with huge dimensionalities (genes). Thus, it is necessary to develop new computational and statistics techniques to reduce the inherent estimation error committed in the presence of a small number of samples with large dimensionality. In this context, particularly important related investigations are the modeling and identification of gene regulatory networks from expression data sets. The main objective of this research is to infer how genes are regulated, bringing knowledge about the molecular interactions and metabolic activities of an organism. Such a knowledge is fundamental for many applications, such as disease treatment, therapeutic intervention strategies and drugs design, as well as for planning high-throughput new experiments. In this direction, this work presents some contributions: (1) feature selection software; (2) new approach for the generation of artificial gene networks (AGN); (3) criterion function based on Tsallis entropy; (4) alternative search strategies for GRNs inference: SFFS-MR and SFFS-BA; (5) biological investigation of GRNs involved in the thiamine biosynthesis by adopting the Arabidopsis thaliana as a model plant. The feature selection software is an open-source multiplataform graphical environment for bioinformatics problems, which supports many feature selection algorithms, criterion functions and graphic visualization tools. In particular, a feature selection method for GRNs inference is also implemented in the software. Although there are several methods proposed in the literature for the modeling and identification of GRNs, an important open problem regards: how to validate such methods and its results? This work presents a new approach for validation of such algorithms by considering three main aspects: (a) Artificial Gene Networks (AGNs) model generation through theoretical models of complex networks, which is used to simulate temporal expression data; (b) computational method for GRNs identification from temporal expression data; and (c) Validation of the identified AGN-based network through comparison with the original network. Through the development of the AGN model was possible the analysis and investigation of the characteristics of GRNs inference methods, leading to the development of a comparative study of four inference methods available in literature. The evaluation of inference methods led to the development of new methodologies for this task: (a) a new criterion function based on Tsallis entropy, in order to infer the genetic inter-relationships with better precision; (b) an alternative search strategy for the GRNs inference, called SFFS-MR, which tries to exploit a local property of the regulatory gene interdependencies, which is known as intrinsically multivariate prediction; and (c) a search strategy, 
interactive and floating, which is based on scale-free network topology, as a global property of the GRNs, which is considered as a priori information, in order to provide a more appropriate method for this class of problems and thereby achieve results with better precision. It is also an objective of this work, to apply the developed methodology in biological data, particularly in identifying GRNs related to specific functions of the Arabidopsis thaliana. The experimental results, obtained from the application of the proposed methodologies, indicate that the respective performances of each methodology were significant and adequate to the problems that have been proposed.

Keywords: pattern recognition, feature selection, entropy, Tsallis entropy, gene regulatory networks, network inference, validation, complex networks. 


\section{Sumário}

Lista de Abreviaturas $\quad$ xiii

Lista de Símbolos $\quad$ Xv

Lista de Figuras $\quad$ xvii

Lista de Tabelas $\quad$ xxi

1 Introdução $\quad 1$

1.1 Motivação . . . . . . . . . . . . . . . . . . . . . . . . . . 1

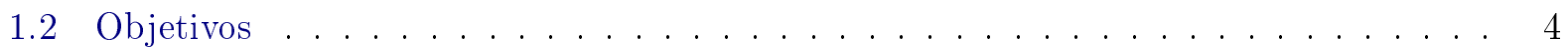

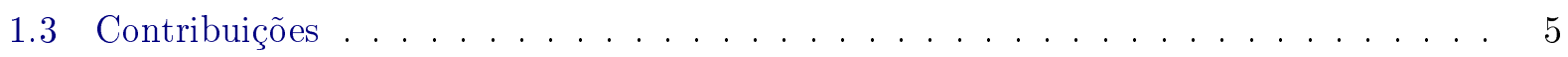

1.4 Organização do Trabalho . . . . . . . . . . . . . . . . . 6

$\begin{array}{lll}2 & \text { Revisão Bibliográfica } & 7\end{array}$

2.1 Dados de Expressão Gênica . . . . . . . . . . . . . . . . . . 7

2.2 Pré-processamento dos Dados . . . . . . . . . . . . . . . . . . . 10

2.3 Modelagem e Simulação de Redes de Regulação Gênica . . . . . . . . . . . . . . . . 11

2.3.1 Modelos Baseados em Grafos . . . . . . . . . . . . . . . . . . . 12

2.3 .2 Redes Booleanas . . . . . . . . . . . . . . . . . . . 13

2.3 .3 Redes Bayesianas . . . . . . . . . . . . . . . . . . . . . 15

2.3.4 Redes Booleanas Probabilísticas . . . . . . . . . . . . . . . . . 16

2.3.5 Redes Gênicas Probabilísticas . . . . . . . . . . . . . . . . 18

2.4 Seleção de Características . . . . . . . . . . . . . . . . . . . . . . . . . . . . . . . . . .

2.4 .1 Busca Sequencial para Frente $(\mathrm{SFS}) \ldots \ldots \ldots \ldots \ldots$. . . . . . . . 21

2.4 .2 Busca Sequencial Flutuante para Frente (SFFS) . . . . . . . . . . . . . . 21

2.5 Entropia e Informação Mútua . . . . . . . . . . . . . . . . . . . . . 23

2.5.1 Entropia Generalizada de Tsallis . . . . . . . . . . . . . . 25

2.6 Inferência de Redes . . . . . . . . . . . . . . . . . . . . . . 28

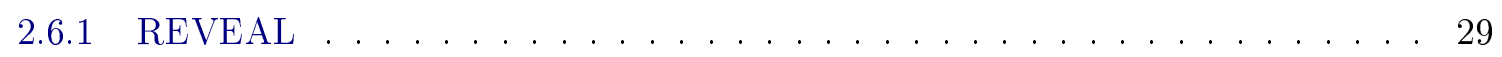

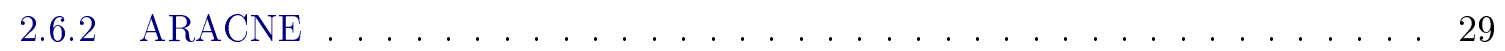

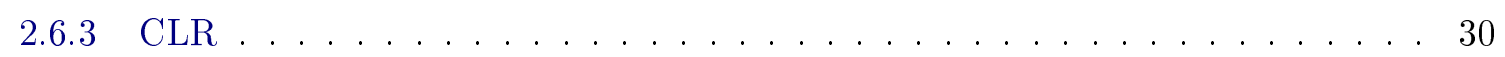

2.6 .4 MRNET . . . . . . . . . . . . . . . . . . . . 30

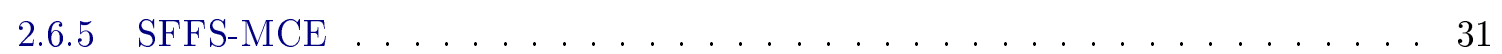

2.7 Genes de Predição Intrinsecamente Multivariada ～. . . . . . . . . . . . . . . 31

2.8 Redes Complexas . . . . . . . . . . . . . . . . . . . . . . 33 
2.8.1 Redes Aleatórias . . . . . . . . . . . . . . . . . . . 34

2.8.2 Redes Small-World . . . . . . . . . . . . . . . . . . . 34

2.8 .3 Redes Scale-Free . . . . . . . . . . . . . . . . . 35

2.8 .4 Redes Geográficas . . . . . . . . . . . . . . . 36

3 Materiais e Métodos $\quad 39$

3.1 Síntese: Modelo Conceitual de Redes Gênicas Artificiais (AGNs) . . . . . . . . . . . . 40

3.1 .1 Topologias das AGNs . . . . . . . . . . . . . . . . . 40

3.1 .2 Funções de Transição . . . . . . . . . . . . . . . . . . . . . . . . . . . . . 41 41

3.1.3 Simulação de Perfis Temporais de Expressão Gênica . . . . . . . . . . . . . . 43

3.2 Identificação: Inferência de Redes . . . . . . . . . . . . . . . . . . . . 44

3.2.1 Função Critério Baseada na Entropia de Tsallis . . . . . . . . . . . . . . . 46

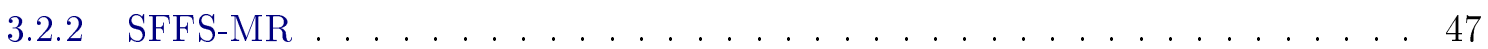

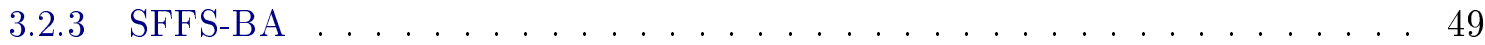

3.3 Análise: Medidas de Similaridade Topológicas . . . . . . . . . . . . . . . . . . . 54

3.4 Aplicações: Investigação Biológica . . . . . . . . . . . . . . . . . . . 55

4 Resultados $\quad \mathbf{5 9}$

4.1 Redes Gênicas Artificiais (AGNs) . . . . . . . . . . . . . . . . . . . 59

4.2 Estudo Comparativo entre Métodos de Inferência de GRNs . . . . . . . . . . . . 66

4.3 Função Critério Baseada na Entropia de Tsallis . . . . . . . . . . . . . . . . . . 68

4.4 Algoritmo de busca SFFS-MR . . . . . . . . . . . . . . . . . 76

4.5 Algoritmo de busca SFFS-BA . . . . . . . . . . . . . . . . . . 78

4.6 Investigação Biológica . . . . . . . . . . . . . . . . . . . 82

5 Considerações Finais e Direcionamentos $\quad 89$

$\begin{array}{ll}\text { A Trabalhos produzidos } & 95\end{array}$

$\begin{array}{ll}\text { Referências Bibliográficas } & 97\end{array}$

$\begin{array}{ll}\text { Índice Remissivo } & 109\end{array}$ 


\title{
Lista de Abreviaturas
}

\author{
AGI Arabidopsis Genome Initiative. \\ AGN Rede Gênica Artificial (Artificial Gene Network). \\ ARACNE (Algorithm for the Reconstruction of Accurate Cellular NEtworks). \\ ATP \\ Adenosina Trifosfato (Adenosine Triphosphate). \\ BA Modelo de redes livre de escala (scale-free) de Barabási-Albert. \\ BN Rede Booleana (Boolean Network). \\ cDNA DNA complementar (complementary DNA). \\ CLR (Context Likelihood of Relatedness). \\ CoD Coeficiente de Determinação (Coefficient of Determination). \\ DAG Grafo Acíclico Dirigido (Directed Acyclic Graph). \\ DNA Ácido Desoxirribonucleico (Deoxyribonucleic Acid). \\ dNTPs Desoxirribonucleotídeos Trifosfatados (Deoxyribonucleotide Triphosphate). \\ DREAM Diálogo para Avaliações de Métodos de Engenharia Reversa \\ (Dialogue for Reverse Engineering Assessments and Methods). \\ ER Modelo de redes aleatórias (uniformly-random) de Erdös-Rényi. \\ GN Modelo de redes geográficas (geographical networks) de Gastner-Newman. \\ GRN Rede de Regulação Gênica (Gene Regulatory Network). \\ GSP Processamento de Sinais Genômicos (Genomic Signal Processing). \\ IMP Predição Intrinsecamente Multivariada \\ (Intrinsically Multivariate Prediction). \\ KEGG Kyoto Encyclopedia of Genes and Genomes. \\ MCE Entropia Condicional Média (Mean Conditional Entropy). \\ mRNA Ácido Ribonucleico Mensageiro (Messenger Ribonucleic Acid). \\ MRNET Redes de Redundância Mínima (Minimum Redundancy Networks). \\ PBN Rede Booleana Probabilística (Probabilistic Boolean Network). \\ PCR Reação em Cadeia da Polimerase (Polymerase Chain Reaction). \\ RBN Rede Booleana Aleatória (Random Boolean Network). \\ RNA Ácido Ribonucleico (Ribonucleic Acid). \\ SAGE Análise Serial da Expressão Gênica (Serial Analysis of Gene Expression). \\ SFFS Busca Sequencial Flutuante para Frente \\ (Sequential Forward Floating Selection). \\ SFFS-BA Busca Sequencial Flutuante para Frente - Barabási-Albert \\ (Sequential Forward Floating Selection - Barabási-Albert).
}


SFFS-MCE Busca Sequencial Flutuante para Frente - Entropia Condicional Média (Sequential Forward Floating Selection - Mean Conditional Entropy).

SFFS-MR Busca Sequencial Flutuante para Frente com Múltiplas Raízes (Sequential Forward Floating Selection - Multiple Roots).

SFS Busca Sequencial para Frente (Sequential Forward Selection).

TAIR The Arabidopsis Information Resource.

TPP Tiamina Pirofosfato (thiamine pyrophosphate).

WS Modelo de redes mundo pequeno (small-world) de Watts-Strogatz. 


\section{Lista de Símbolos}

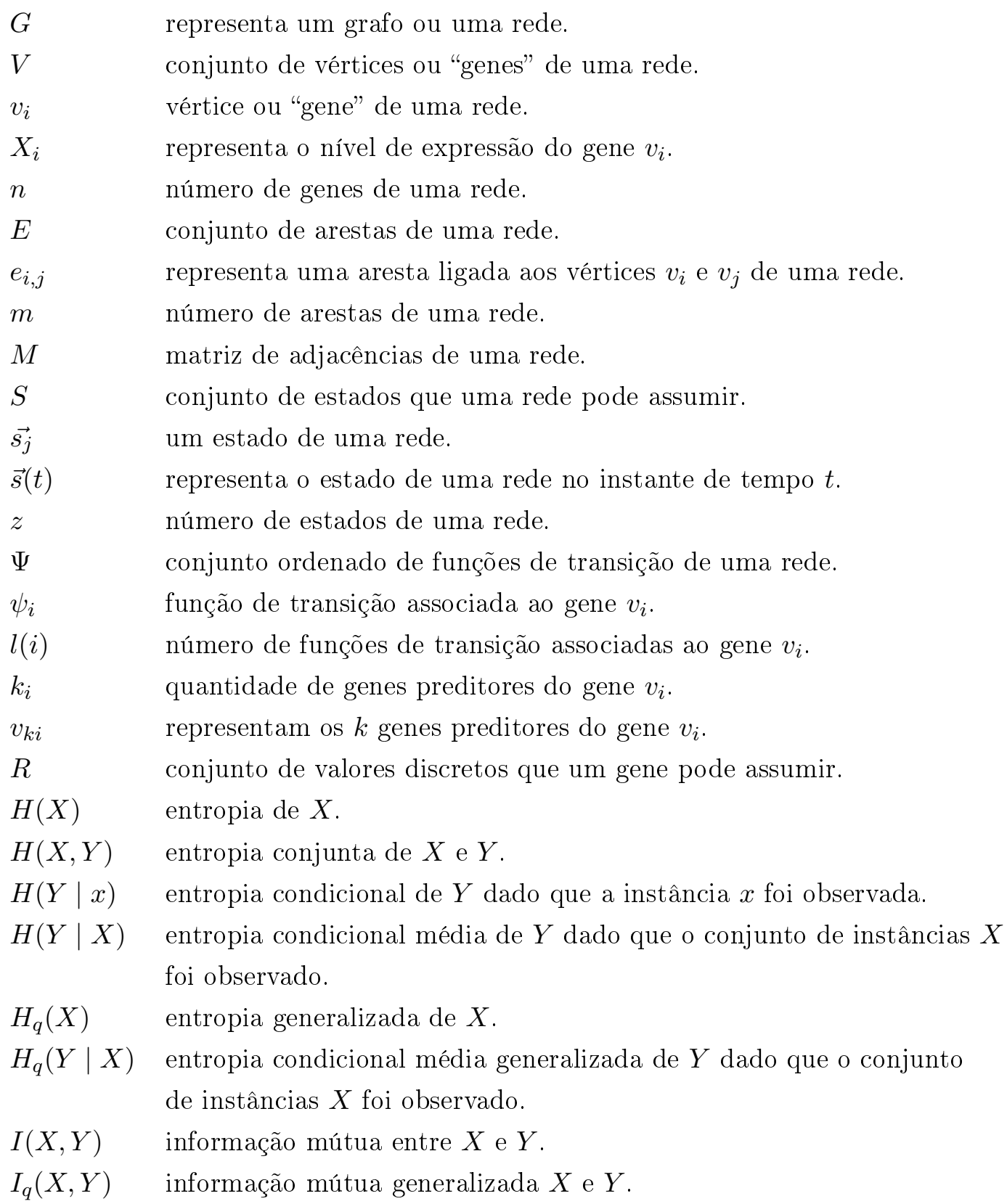




\section{Lista de Figuras}

1.1 Visão geral do fluxo de informações adotado na elaboração deste trabalho. . . . . . . 6

2.1 Um esquema geral de um DNA microarray. O mRNA é extraído tanto das células normais (controle) quanto das células experimentais (caso de interesse). Utilizando a transcriptase reversa, o mRNA é transformado em cDNA, sendo marcados com cores fluorescentes. O cDNA é exposto ao microarray, no qual estão os genes de interesse (spots). O microarray é digitalizado e o sinais fluorescentes dos spots são convertidos para uma escala numérica de intensidade. . . . . . . . . . . . . . . 9

2.2 Exemplo de um dígrafo com 5 vértices (a) e sua matriz de adjacências (b). Cada elemento igual a 1 na matriz de adjacências representa um relacionamento regulatório entre dois vértices do dígrafo. . . . . . . . . . . . . . . . . . . . . . . . 13

2.3 Exemplo de uma BN contendo 3 genes. (a) representação na forma de um dígrafo, (b) Funções Booleanas, (c) Tabela de transição de estados e (d) Diagrama de transição de estados (adaptada de [Kelemen et al., 2008]) . . . . . . . . . . . . . . . . . 14

2.4 Exemplo de rede Bayesiana contendo 5 vértices. . . . . . . . . . . . . . . . . . . . 16

2.5 Fluxograma simplificado do algoritmo SFFS [Lopes et al., 2008c] (adaptado de [Somol et al., 1999]). $K$ se refere ao tamanho do subconjunto que representa a solução atual e $d$ se refere ao tamanho do subconjunto da solução final desejada (condição de parada do algoritmo). . . . . . . . . . . . . . . . . . . . 22

2.6 O histograma (a) configura uma situação em que $Y$ é bem predito por $x$ porque a massa de probabilidades condicionais está concentrada em $Y=1$ (entropia condicional baixa). Já para o histograma (b), a massa de probabilidades está espalhada ao longo das classes, o que faz com que o padrão $x$ não seja um bom preditor do comportamento de $Y$ (entropia condicional alta) (figura adaptada de [Martins-Jr., 2008]) . . . . . . . . . . . . . . . . . . . . . 24

2.7 Diagrama de Venn com a representação das relações entre entropia, entropia condicional, entropia conjunta e informação mútua, considerando duas variáveis. . . . . . . 25

2.8 Entropia generalizada de Tsallis $H_{q}$ como uma função da probabilidade $P(x=1)$, considerando genes binários, $X \in\{0,1\}$. De cima para baixo, as curvas de entropia foram obtidas com o parâmetro entrópico $q$ definido como: 0.1, 0.25, 0.5, 1.0, 1.5,

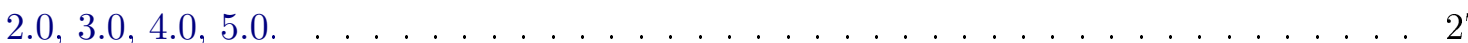

2.9 Lei de potência em função do número de conexões $k$. De cima para baixo, as curvas de lei de potência foram obtidas com o parâmetro $\gamma$ definido como: $0,5,1,1,5,2$,

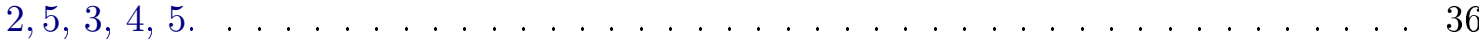


3.1 Exemplo de uma função de transição Booleana representada como um circuito lógico (a) e como uma tabela de regras (b), as quais definem a dinâmica dos sinais de expressão de um gene alvo $v_{i}$ no instante de tempo $t+1$ baseando-se nos valores de seus preditores $v_{1 i}(t), v_{2 i}(t), \ldots, v_{k i}(t),(k=3)$ no instante de tempo $t$. . . . . . .

3.2 Exemplo de diagrama de estados de uma AGN. Cada vértice representa um estado

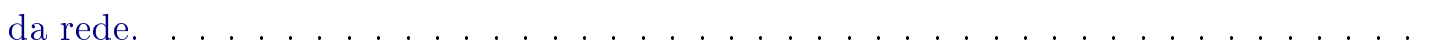

3.3 Comportamento da função critério considerando-se a inclusão de novos preditores no subconjunto de preditores. Na figura assume-se a minimização do valor da função critério, i.e., seu valor ótimo é zero. . . . . . . . . . . . . . . . . 5

3.4 Captura da tela inicial do programa de integração de dados e visualização das redes inferidas. . . . . . . . . . . . . . . . . . .

4.1 Medida de similaridade obtida pelo aumento do grau médio de conexões (arestas) por gene (vértice), i.e., $\langle k\rangle$, (a) considerando todos os genes de cada rede e (b) considerando apenas $10 \%$ dos genes mais conectados de cada rede, i.e., hubs. . . . . .

4.2 Medida de similaridade obtida pelo aumento do número de instantes de tempo da expressão temporal (tamanho do sinal), (a) considerando todos os genes da rede ER e (b) considerando apenas $10 \%$ dos genes mais conectados da rede ER, i.e., hubs. . .

4.3 Medida de similaridade obtida pelo aumento do número de instantes de tempo da expressão temporal (tamanho do sinal), (a) considerando todos os genes da rede WS e (b) considerando apenas $10 \%$ dos genes mais conectados da rede WS, i.e., hubs. . .

4.4 Medida de similaridade obtida pelo aumento do número de instantes de tempo da expressão temporal (tamanho do sinal), (a) considerando todos os genes da rede BA e (b) considerando apenas $10 \%$ dos genes mais conectados da rede BA, i.e., hubs. . .

4.5 Medida de similaridade obtida pelo aumento do número de instantes de tempo da expressão temporal (tamanho do sinal), (a) considerando todos os genes da rede GN e (b) considerando apenas $10 \%$ dos genes mais conectados da rede GN, i.e., hubs. . .

4.6 Distribuições dos graus de entrada e saída, obtidos a partir das AGNs e das redes inferidas, considerando-se a distribuição média das conexões das redes sobre todas as variações de tamanho de sinal e grau médio $\langle k\rangle \ldots \ldots \ldots \ldots$. . . . . . . .

4.7 Medida de similaridade obtida pelo aumento do grau médio de conexões (arestas) por gene (vértice), i.e., $\langle k\rangle$, considerando-se os métodos de inferência ARACNE, MRNET, CLR e SFFS-MCE, aplicados ao modelo de redes aleatórias de Erdös-Rényi (ER). A medida de similaridade aplicada neste resultado é dada por Similaridade = $\sqrt{\text { Sensibilidade } \times \text { Especificidade }}$, entre as AGNs e as redes inferidas pelos respectivos métodos. . . . . . . . . . . . . . . . . . . . . . .

4.8 Medida de similaridade obtida pelo aumento do grau médio de conexões (arestas) por gene (vértice), i.e., $\langle k\rangle$, considerando-se os métodos de inferência ARACNE, MRNET, CLR e SFFS-MCE, aplicados ao modelo de redes scale-free de Barabási-Albert (BA). A medida de similaridade aplicada neste resultado é dada por Similaridade = $\sqrt{\text { Sensibilidade } \times \text { Especificidade }}$, entre as AGNs e as redes inferidas pelos respectivos métodos. . . . . . . . . . . . . . . . . . . . . 
4.9 Medida de similaridade entre as AGNs e as redes inferidas obtida em função da variação do parâmetro entrópico $q$, considerando-se os graus médios de conectividade $1 \leqslant\langle k\rangle \leqslant 5$ : (a) redes aleatórias de Erdös-Rényi (ER) e (b) redes scalefree de Barabási-Albert (BA). A similaridade aplicada neste resultado é dada por Similaridade $=\sqrt{P P V \times \text { Especificidade }}$, considerando-se os resultados médios sobre 50 execuções e redes contendo 100 genes. . . . . . . . . . . . . . . .

4.10 Curvas das frequências normalizadas das melhores taxas de similaridade obtidas em função do parâmetro $q$, para cada gene alvo e grau médio de conexões $(1 \leqslant$ $\langle k\rangle \leqslant 5$ ): (a) redes aleatórias de Erdös-Rényi (ER) e (b) redes scale-free de BarabásiAlbert (BA). A similaridade aplicada neste resultado é dada por Similaridade $=$ $\sqrt{P P V \times \text { Especificidade, }}$ considerando-se os resultados médios sobre 50 execuções e redes contendo 100 genes. . . . . . . . . . . . . . . . . . . . .

4.11 Medida de similaridade entre as redes DREAM e as redes inferidas obtida em função da variação do parâmetro entrópico $q$, considerando-se os resultados médios de cada rede DREAM: (a) contendo 10 genes e (b) contendo 100 genes. A similaridade aplicada neste resultado é dada por Similaridade $=\sqrt{P P V \times \text { Especificidade }}$, considerando-se os resultados médios sobre as redes DREAM. . . . . . . . . . . 72

4.12 Curvas das frequências normalizadas das melhores taxas de similaridade obtidas em função do parâmetro $q$, considerando-se os resultados médios de cada rede DREAM: (a) contendo 10 genes e (b) contendo 100 genes. A similaridade aplicada neste resultado é dada por Similaridade $=\sqrt{P P V \times \text { Especificidade }}$, considerando-se os resultados médios sobre das redes DREAM

4.13 Medida PPV obtida pela inferência das redes considerando-se os algoritmos SFS, SFFS e SFFS-MR, aplicados sobre diferentes tamanhos de perfis de expressão temporal. Os valores de PPV representam os valores médios sobre 50 execuções, i.e., 50 AGNs e suas respectivas inferências. . . . . . . . . . . . . . . . . 77

4.14 Medida de similaridade obtida pela inferência das redes considerando-se os algoritmos SFS, SFFS e SFFS-MR, aplicados sobre diferentes complexidades de redes, em termos do número médio de conexões por gene $\langle k\rangle$. A similaridade aplicada neste resultado é dada por Similaridade $=\sqrt{P P V \times \text { Sensibilidade }}$, considerando-se os resultados médios sobre 50 execuções e redes contendo 20 genes. . . . . . . . . . . . . 78

4.15 Medida de similaridade obtida pela inferência das redes considerando-se os algoritmos SFS, SFFS e SFFS-BA, aplicados sobre diferentes tamanhos de perfis de expressão temporal. Os valores de PPV representam os valores médios sobre 50 execuções, i.e., 50 AGNs e suas respectivas inferências. A similaridade aplicada neste resultado é dada por Similaridade $=\sqrt{P P V \times \text { Sensibilidade }}$, considerando-se os resultados médios sobre 50 execuções e redes contendo 100 genes. . . . . . . . . . . . . . . 80

4.16 Medida de similaridade obtida pela inferência das redes considerando-se os algoritmos SFS, SFFS e SFFS-BA, aplicados sobre diferentes complexidades de redes, em termos do número médio de conexões por gene $\langle k\rangle$. A similaridade aplicada neste resultado é dada por Similaridade $=\sqrt{P P V \times \text { Sensibilidade }}$, considerando-se os resultados médios sobre 50 execuções e redes contendo 20 genes. . . . . . . . . . . . . 
4.17 Redes inferidas a partir de dados temporais de expressão da raiz de Arabidopsis thaliana a partir do método SFFS-MR, considerando duas formas de quantização dos dados: (a) utilizando-se os níveis máximos positivos e mínimos negativos e (b) considerando-se os valores positivos e negativos médios. . . . . . . . . . . . . 84

4.18 Redes inferidas a partir de dados temporais de expressão da folha de Arabidopsis thaliana a partir do método SFFS-MR, considerando duas formas de quantização dos dados: (a) utilizando-se os níveis máximos positivos e mínimos negativos e (b) considerando-se os valores positivos e negativos médios. . . . . . . . . . . . . 85

4.19 Preditores do gene thi1 a partir de dados temporais de expressão de Arabidopsis thaliana a partir do método SFFS-MR, considerando: (a) utilizando-se os níveis médios das expressões da folha, (b) utilizando-se os níveis máximos das expressões da folha, (c) utilizando-se os níveis médios das expressões da raiz, (d) utilizando-se os níveis máximos das expressões da raiz. . . . . . . . . . . . . . . . . . . . . 86 


\section{Lista de Tabelas}

2.1 Exemplo de tabela contendo as probabilidades condicionais de um vértice de uma rede Bayesiana. A probabilidade do vértice $v_{3}$ estar inativo dado que $v_{1}$ está ativo e $v_{2}$ está inativo é $P\left(v_{3}=0 \mid v_{1}=1, v_{2}=0\right)=0.8 \ldots \ldots \ldots \ldots \ldots$

2.2 Exemplo de uma distribuição de probabilidade conjunta entre o gene alvo $Y$ e os dois preditores $X_{1}$ e $X_{2}$ que formam um conjunto de predição intrinsecamente multivariada $\left(I_{Y}(\mathbf{X})=0.6\right.$, usando o $\mathrm{CoD}$ como função critério $) \ldots \ldots \ldots \ldots$

3.1 Matriz de confusão exibindo as medidas usadas para quantificar a similaridade entre a matriz de adjacências de uma AGN (A) e a matriz de adjacências de uma rede identificada $(\mathrm{B}),(\mathrm{TP}=$ verdadeiro positivo, $\mathrm{FN}=$ falso negativo, $\mathrm{FP}=$ falso positivo, $\mathrm{TN}=$ verdadeiro negativo.$\ldots \ldots \ldots \ldots \ldots 4$

3.2 Descrição dos grupos de genes alvo considerados para a geração das GRNs a partir de dados de expressão temporal de Arabidopsis thaliana. . . . . . . . . . . . 57

4.1 Médias das curvas de frequências da Figura $4.10 \ldots \ldots \ldots$. . . . . . . . . . 71

4.2 Resultados obtidos pela inferência de redes, aplicando o parâmetro entrópico $q=2,5$ (sub extensivo) comparado com a entropia de Shannon (extensiva, com $q=1$ ): (a) redes aleatórias de Erdös-Rényi (ER) e (b) redes scale-free de Barabási-Albert (BA). 74

4.3 Exemplo das mudanças nos preditores inferidos a partir da aplicação de diferentes valores para o parâmetro entrópico q: (a) distribuições de probabilidade que, em geral, levam a um preditor errado e (b) distribuições de probabilidade que, em geral, levam a um preditor correto. . . . . . . . . . . . . . . . . 75

4.4 Preditores inferidos para o gene thi1 que possuem função organelar. . . . . . . . . 87 


\section{Capítulo 1}

\section{Introdução}

\subsection{Motivação}

Um organismo vivo pode ser visto como uma rede de moléculas conectadas por reações químicas. O mecanismo de regulação destas reações é composto por um complexo sistema de envio e recepção de sinais (RNAs), o qual tem sido alvo de investigação com o objetivo de se indicar os mecanismos de controle celular e as relações entre diversas entidades biológicas envolvidas, e.g., genes, RNAs e proteínas. No entanto, existe muito ainda a ser descoberto sobre as relações funcionais dos mecanismos de controle, e.g., níveis de transcrição e proteínas, no sistema regulatório.

Um caminho que pode levar a um melhor entendimento desses mecanismos de controle regulatório é considerar a evolução temporal dos níveis de expressão gênica, i.e., sua dinâmica. Em particular, o desenvolvimento de técnicas massivas de extração de informação molecular, como por exemplo os DNA Microarrays [Shalon et al., 1996], SAGE (do inglês Serial Analysis of Gene Expression) [Velculescu et al., 1995] e mais recentemente os RNA-Seq [Wang et al., 2009], tornaram possível estimar o nível de expressão de milhares de genes simultaneamente e em múltiplos instantes de tempo. Consequentemente, o volume de dados de transcrição disponíveis de uma grande variedade de espécies teve um significativo crescimento nos últimos dez anos.

No contexto dos perfis de expressão, um grande desafio de pesquisa enfrentado é o grande número de variáveis (genes), na ordem dos milhares, para apenas poucos experimentos disponíveis (amostras), na ordem das dezenas. Com o objetivo de descobrir os inter-relacionamentos entre essas variáveis, é necessário um grande esforço no desenvolvimento de novas técnicas computacionais e estatísticas que reduzam o erro de estimação intrínseco cometido na presença de um pequeno número de amostras com enorme dimensionalidade.

Devido a esse fato, recuperar com precisão o inter-relacionamento entre os genes, formando uma rede de regulação gênica (GRNs, do inglês Gene Regulatory Networks) [Hovatta et al., 2005, Shmulevich and Dougherty, 2007] a partir dos perfis de expressão, é um problema em aberto. Outros fatores que também dificultam esta tarefa estão associados à falta de informação sobre o organismo biológico de interesse, a alta complexidade das redes de inter-relacionamento produzidas e ao ruído intrínseco das medidas de expressão. Dessa forma, o problema a ser abordado consiste em descobrir o inter-relacionamento entre as entidades biológicas envolvidas em um mesmo processo. A descoberta desses relacionamentos pode levar à caracterização de uma diversidade de funções biológicas e também à descoberta da dinâmica das atividades moleculares. É de suma importância entender como muitos dos processos biológicos ocorrem e na maioria dos casos, como prevenir que 
eles aconteçam, como é o caso das doenças.

A inferência, também conhecida como engenharia reversa, de GRNs a partir de perfis de expressão é fundamentada no dogma central da biologia molecular, no qual existe a premissa de que o estado funcional de um organismo é amplamente determinado pela sua expressão gênica [D'Haeseleer et al., 1999, Nelson and Cox, 2004, Voet et al., 2005]. Logo, se a variação dos níveis de expressão ao longo do tempo for mapeado por meio de GRNs, é possível indicar informações como: diferentes vias regulatórias, ciclo celular, mapeamento de alterações provocadas por estímulos e como modelo de representação da atividade molecular. Desta forma, recuperar uma GRN, a partir de expressões gênicas temporais, representa um importante desafio na pesquisa em bioinformática, inclusive motivando o projeto DREAM (do inglês Dialogue for Reverse Engineering Assessments and Methods) [DREAM, 2009].

Em geral, a validação das redes inferidas [Dougherty, 2007] requer conhecimento sobre as reais conexões entre os genes e seus relacionamentos funcionais, os quais são frequentemente desconhecidos ou incompletos. Dessa forma, não é possível garantir a qualidade das redes inferidas, deixando uma importante questão em aberto: como validar as GRNs identificadas por métodos computacionais? Uma maneira objetiva para testar o desempenho de tais algoritmos é submetê-los a modelos de redes que são completamente conhecidos [Mendes et al., 2003, Lopes et al., 2008a]. Ao adotar modelos de redes gênicas simuladas (in silico), o qual representa uma outra vertente da biologia sintética, como a baseada na recém construção de um genoma sintético [Gibson et al., 2010], os relacionamentos entre os genes passam a ser conhecidos, abrindo possibilidade de investigar não só a inferência desses relacionamentos, mas também outras informações como, por exemplo, a topologia dessas redes, a dinâmica do sistema, funções critério usadas para definir a ligação entre os genes e os algoritmos de busca utilizados.

Tentando identificar alguns dos princípios matemáticos fundamentais de grandes redes de interação gênica, Kauffman [Kauffman, 1969, Kauffman, 1993] propôs usar "genes" binários e funções Booleanas para descrever o comportamento das GRNs. Em seu trabalho, a dinâmica de uma GRN é definida por circuitos lógicos. Mais especificamente, para cada gene desta rede é selecionado aleatoriamente um conjunto de genes preditores, os quais passam a compor um circuito lógico de funções Booleanas. Logo, o valor do gene alvo é definido pela aplicação desse circuito lógico aos valores dos seus preditores. Esse modelo é conhecido na literatura como Redes Booleanas (BNs, do inglês Boolean Networks) ou Redes Booleanas Aleatórias (RBNs, do inglês Random Boolean Networks).

Após o trabalho pioneiro de Kauffman, vários outros métodos foram propostos para modelar e identificar GRNs a partir de dados de expressão gênica [Liang et al., 1998, Weaver et al., 1999, Butte and Kohane, 2000, Keles et al., 2002,Shmulevich et al., 2002a, Kim et al., 2002, Soinov et al., 2003, Zhou et al., 2004, Margolin et al., 2006, Barrera et al., 2007, Trepode et al., 2007, Faith et al., 2007, Meyer et al., 2008, Zhao et al., 2008, Andrecut and Kauffman, 2008, Andrecut et al., 2008]. Revisões podem ser encontradas nos trabalhos [D'haeseleer et al., 2000, de Jong, 2002, Styczynski and Stephanopoulos, 2005, Schllit and Brazma, 2007, Markowetz and Spang, 2007, Karlebach and Shamir, 2008, Hecker et al., 2009, Xiao, 2009, de Smet and Marchal, 2010, Marbach et al., 2010], os quais apresentam as ideias centrais de métodos de inferência de GRNs e respectivas modelagens matemáticas adotadas.

Embora o formalismo Booleano seja aparentemente simples, esse modelo tem sido usado para descrever qualitativamente o comportamento global das GRNs. Essa propriedade permite a análise 
de conjuntos de dados de uma forma global, apresentando algumas características de GRNs reais [Kauffman et al., 2003,Serra et al., 2004,Shmulevich et al., 2005], tais como: funções de canalização, número de conexões por gene, variação da dinâmica ao nocautear genes, estabilidade da rede, entre outras. As BNs foram aplicadas com sucesso na modelagem e simulação de algumas redes e processos biológicos, tais como Drosophila melanogaster [Sánchez and Thieffry, 2001, Albert and Othmer, 2003], ciclo celular de levedura [Li et al., 2004, Davidich and Bornholdt, 2008], Arabidopsis thaliana [Espinosa-Soto et al., 2004, Li et al., 2006], Saccharomyces cerevisiae [Li and Lu, 2005], ciclo celular de mamíferos [Faure et al., 2006] e genomas artificiais [Quayle and Bullock, 2006].

Logo, as BNs são modelos discretos que possuem uma escala mais "grossa" se comparados com os modelos contínuos, tal como o modelo baseado em equações diferenciais ordinárias, havendo desvantagens e vantagens entre as duas abordagens. As BNs são modelos mais simples, sendo empregados para caracterizar os sistemas biológicos de maneira qualitativa e global, sua principal desvantagem é a perda de informação decorrente da discretização dos dados. Por outro lado, modelos de GRNs baseados em equações diferenciais [Chen et al., 1999, Mendes et al., 2003, de Jong et al., 2003, Van den Bulcke et al., 2006, Haynes and Brent, 2009] permitem a geração da dinâmica das redes de forma detalhada. No entanto, a determinação dos parâmetros para a inferência dessas redes exige dados de alta qualidade e em quantidade muito maior do que são geralmente disponíveis [Wahde and Hertz, 2000, Karlebach and Shamir, 2008]. Uma discussão a respeito de modelagem contínua ou discreta pode ser encontrada em [Ivanov and Dougherty, 2006].

Neste contexto, as BNs representam um modelo adequado para generalizar e capturar o comportamento dos sistemas biológicos em alto nível (qualitativo), em face do número limitado de experimentos (amostras), da grande dimensão de variáveis (genes) e da natureza ruidosa das medidas de expressão.

Embora as BNs sejam úteis em vários casos, uma limitação importante é o seu determinismo inerente, que faz a suposição de um ambiente sem incerteza. Por outro lado, é importante considerar uma célula como um sistema aberto, o qual pode receber estímulos externos. Dependendo das condições externas em um dado instante de tempo, a célula pode alterar sua dinâmica [Shmulevich and Dougherty, 2007]. Neste contexto, foi desenvolvido uma nova abordagem para a geração de Redes Gênicas Artificiais (AGNs, do inglês Artificial Gene Networks), com o objetivo de investigar algumas propriedades das GRNs e dos métodos de inferência sob certas hipóteses.

A AGN proposta neste trabalho foi desenvolvida tomando por base as Redes Booleanas Probabilísticas (PBNs, do inglês Probabilistic Boolean Networks) [Shmulevich et al., 2002a, Shmulevich et al., 2002b], as quais preservam as propriedades conhecidas das BNs e evitam sua rigidez determinística. Esse modelo permite o estudo e identificação das propriedades de alto nível das redes gênicas e suas interações, sem a necessidade de descrições bioquímicas detalhadas como adotado por outros trabalhos que analisam métodos de inferência de GRNs [de la Fuente et al., 2004,Bansal et al., 2007, Soranzo et al., 2007].

A topologia do modelo AGN proposto neste trabalho baseia-se nos modelos teóricos de redes complexas [Albert and Barabási, 2002,Newman, 2003, Costa et al., 2007]. A dinâmica de uma AGN é obtida pela aplicação das funções Booleanas probabilísticas, as quais simulam os perfis de expressão de acordo com a topologia gerada, i.e., genes regulatórios ou preditores impostos pela aplicação do modelo topológico.

Uma vez gerados os perfis de expressão simulados, eles podem ser aplicados para investigar as 
redes inferidas e o comportamento dos métodos de inferência quanto submetidos a certas condições de interesse. Uma técnica de reconhecimento de padrões comumente usada para inferir GRNs é a seleção de características [Jain et al., 2000, Theodoridis and Koutroumbas, 2008]. Alguns métodos de inferência de GRNs que aplicam a técnica de seleção de características foram propostos na literatura [Liang et al., 1998, Butte and Kohane, 2000, Hashimoto et al., 2004, Peng et al., 2005, Margolin et al., 2006, Rao et al., 2007, Faith et al., 2007, Barrera et al., 2007, Zhao et al., 2008, Dougherty et al., 2008]. Dessa forma, após o desenvolvimento de um estudo comparativo [Lopes et al., 2009b], foi escolhido o método de inferência de GRNs descrito em [Barrera et al., 2007] como alvo de investigação neste trabalho. Um método de seleção de características é composto basicamente por duas partes: um algoritmo de busca e uma função critério, os quais são apresentados nas Seções 2.4 e 2.5, respectivamente.

Por meio da investigação do método de inferência adotado e tendo em vista as limitações enfrentadas pelos métodos de inferência de GRNs em geral, além da geração das AGNs, apresentada na Seção 3.1, foram desenvolvidas novas metodologias para inferência de GRNs: uma nova função critério baseada na teoria da informação e dois novos algoritmos de busca, um baseado nas estruturas locais e outro baseado na estrutura global das redes biológicas, os quais são apresentados na Seção 3.2. As metodologias desenvolvidas neste trabalho foram aplicadas em dados biológicos, usando a Arabidopsis thaliana como planta modelo, apresentados na Seção 3.4.

\subsection{Objetivos}

O objetivo deste trabalho é investigar os aspectos que envolvem a inferência de GRNs, incluindo sua síntese, identificação, análise e aplicações. O primeiro aspecto a ser explorado das GRNs é a sua síntese, ou seja, a identificação e implementação de um modelo que represente as características globais e que permita uma análise qualitativa das GRNs. Dessa forma, um dos objetivos deste trabalho é o desenvolvimento de um modelo que permita a síntese de GRNs, a geração de perfis de expressão e a validação de métodos de inferência.

O segundo aspecto a ser explorado é diretamente relacionado com a identificação (inferência) de GRNs a partir de dados de expressão gênica. Neste caso, o objetivo é identificar um método de inferência de GRNs que seja alvo de investigação deste trabalho, envolvendo o estudo de seu comportamento em relação a fatores como diferentes tamanhos dos perfis de expressão temporal, presença de ruído ou perturbações, complexidade da rede, entre outras.

Com base nestas investigações, espera-se o desenvolvimento de novas metodologias para inferência de GRNs, no que diz respeito a melhoria no processo de identificação das redes, levando a métodos mais especializados de forma que a inferência da topologia ocorra com maior precisão.

O terceiro aspecto é ligado a análise das GRNs, no qual espera-se a aplicação de uma metodologia para verificar os resultados obtidos pelos métodos de inferência de redes. O objetivo nesta etapa é quantificar a semelhança entre a topologia da rede inferida e uma rede conhecida. Para esta tarefa é proposta a adoção das medidas de similaridade apresentadas em [Dougherty, 2007]. A análise das redes inferidas é uma etapa essencial na investigação dos métodos de inferência, bem como para indicar o comportamento da metodologia aplicada no processo de inferência quando submetido a variações na entrada de dados e de seus parâmetros. É esperado que esta etapa também seja determinante para a realimentação das informações e o possível desenvolvimento de novas 
metodologias no contexto da inferência de GRNs.

Por final, também é objetivo deste trabalho a aplicação de metodologias de inferência de GRNs a partir de dados reais. Nesta etapa é proposta a investigação da inferência no contexto biológico com objetivo de identificar redes gênicas envolvidas na biossíntese de tiamina, considerando algumas vias metabólicas de interesse: respiração, fotossíntese e glicólise, usando a Arabidopsis thaliana como planta modelo.

\subsection{Contribuições}

As principais contribuições deste trabalho, além de uma breve revisão bibliográfica sobre os diversos conceitos e teorias aplicados (Capítulo 2), foram os seguintes:

- Implementação de um ambiente gráfico multiplataforma (Java) de código livre, o qual disponibiliza algumas técnicas de seleção de características por meio de diferentes algoritmos e funções critério. Também são disponibilizados nesse software métodos para a normalização dos dados, classificação, validação e ferramentas de visualização dos resultados e redes inferidas. Embora o objetivo desse software seja aplicações de bioinformática, ele pode ser usado em problemas de seleção de características de forma geral. O desenvolvimento deste projeto [Lopes et al., 2008c,Lopes et al., 2008b] contou com a colaboração do Prof. Dr. David Corrêa Martins Jr. Em particular, foi implementado nesse software o método de identificação de redes apresentado na Seção 2.6.5 e os algoritmos de seleção de características apresentados na Seção 2.4. O software desenvolvido está disponível no Google Code http://code.google.com/p/dimreduction/ e no Source Forge: http://sourceforge.net/projects/dimreduction/.

- Formalização do modelo AGN, o qual foi inicialmente proposto [Lopes et al., 2008a] em colaboração com o Prof. Dr. Luciano da F. Costa, o qual aplicava a abordagem determinística das BNs e apenas os modelos topológicos de redes complexas aleatório e scale-free. Em seguida, o modelo AGN evoluiu e passou a adotar a abordagem probabilística proposta nas PBNs e também a incorporar novos modelos topológicos small-world e geográficos. Essa evolução também foi desenvolvida em colaboração com o Prof. Dr. Luciano da F. Costa [Lopes et al., 2011a], gerando um software livre e multiplataforma (Java) para a geração das AGNs, oferecendo alguns parâmetros de personalização das redes ao usuário. O software desenvolvido está disponível no Google Code: http://code.google.com/p/jagn/. O desenvolvimento e formalização do modelo AGN é apresentado na Seção 3.1.

- Desenvolvimento de um estudo comparativo entre métodos de inferência de GRNs em colaboração com o Prof. Dr. David C. Martins Jr.. Nesse projeto, foi realizada uma análise comparativa entre quatro métodos de inferência de redes [Lopes et al., 2009b] baseados na informação mútua. Os métodos utilizados nesse estudo comparativo são apresentados na Seção 2.6.

- Investigação sobre a sensibilidade da entropia de Tsallis aplicada na inferência de GRNs. Este projeto foi desenvolvido em colaboração com o Dr. Evaldo A. de Oliveira, no qual foram identificadas algumas propriedades na entropia generalizada de Tsallis que levaram a resultados mais precisos na inferência de GRNs, reduzindo drasticamente o número de falsos positivos. 
Nesse contexto, foi proposta uma nova função critério baseada na entropia de Tsallis [Lopes et al., 2009a, Lopes et al., 2011b], a qual é apresentada na Seção 3.2.1.

- Formalização de dois novos algoritmos de busca, baseados no algoritmo SFFS. O desenvolvimento desses algoritmos foi o resultado do trabalho em colaboração com o Prof. Dr. David C. Martins Jr. e o Prof. Dr. Junior Barrera. O primeiro algoritmo proposto assume como hipótese a relação de predição intrinsecamente multivariada entre os preditores e o gene alvo, incorporando essa suposição no algoritmo de busca como uma informação a priori da estrutura local das conexões gênicas [Lopes et al., 2010]. Por outro lado, no segundo algoritmo proposto é assumida uma outra hipótese como informação a priori, na qual a topologia da rede procurada é uma scale-free, com o objetivo de incluir uma informação global da rede para guiar o processo de busca e inferência da topologia de forma mais precisa [Lopes et al., 2011c].

- Investigação biológica envolvendo a Arabidopsis thaliana como planta modelo. O desenvolvimento desse projeto foi realizado em colaboração com a Profa. Dra. Marie-Anne Van Sluys, coorientadora desta tese de doutorado, e com o Kleber Alves Gomes, doutorando do programa interunidades de pós-graduação em Biotecnologia. Neste projeto o objetivo é identificar redes gênicas envolvidas na biossíntese de tiamina, considerando três vias metabólicas de interesse: respiração, fotossíntese e glicólise. Além da identificação das GRNs, foi desenvolvido neste projeto um software livre e multiplataforma (Java) que disponibiliza um ambiente gráfico para visualização das redes e disponibiliza também dados biológicos de bancos de dados públicos sobre os genes da rede de forma integrada. Este software está em fase de conclusão e também será disponibilizado em um repositório público como um software de livre uso como nos dois casos anteriores. Esse projeto, bem como os dados utilizados e o software produzido são apresentados na Seção 3.4.

\subsection{Organização do Trabalho}

Este trabalho segue com a contextualização da área de aplicação através de uma revisão bibliográfica encontrada no Capítulo 2. A metodologia proposta é apresentada no Capítulo 3 e no Capítulo 4 são apresentados os resultados obtidos com a aplicação das novas metodologias desenvolvidas. No Capítulo 5 são apresentadas algumas conclusões e direcionamentos para a continuidade deste trabalho.

A Figura 1.1 apresenta uma visão geral deste trabalho e suas etapas.

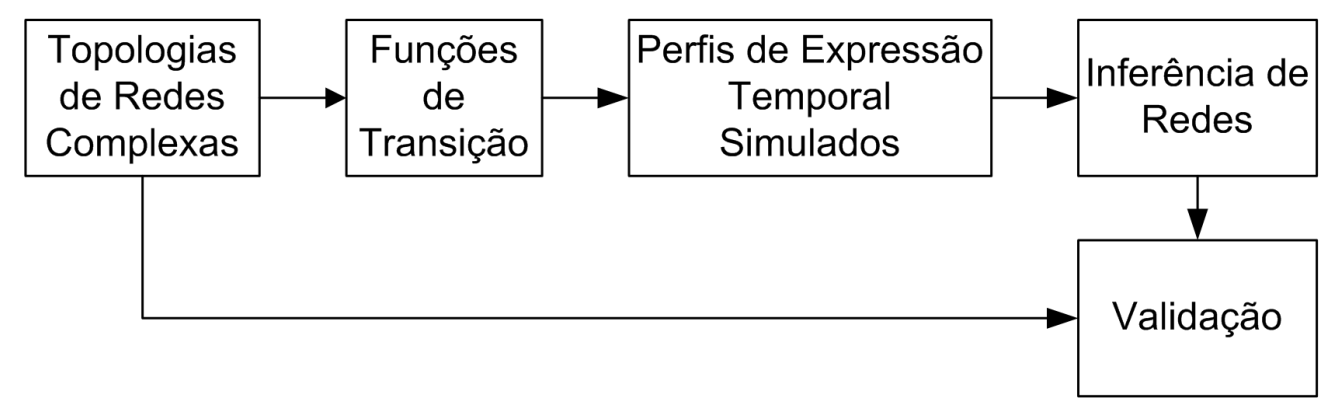

Figura 1.1: Visão geral do fluxo de informações adotado na elaboração deste trabalho. 


\section{Capítulo 2}

\section{Revisão Bibliográfica}

Neste capítulo, são apresentados alguns conceitos importantes para a compreensão deste trabalho. As primeiras duas seções tratam de como os dados de expressão gênica são gerados pela técnica de DNA microarrays e do pré-processamento desses dados, em seguida é apresentada uma revisão sobre modelagem e simulação de redes de regulação gênica (GRNs) [Hovatta et al., 2005]. Neste trabalho, são considerados apenas os métodos que representam a expressão (estado) dos genes por valores discretos. A Seção 2.4 trata da técnica de seleção de características frequentemente adotada nos modelos de inferência de GRNs e, em particular, neste trabalho. Na Seção 2.5, são apresentados conceitos da teoria de informação, como entropia e informação mútua, frequentemente adotados como função critério por métodos de inferência de redes e, em particular, pelos métodos descritos na Seção 2.6. Na Seção 2.7, é apresentada uma classe de propriedades, conhecida como predição intrinsecamente multivariada (IMP), a qual está diretamente relacionada com a inferência de GRNs e com os algoritmos propostos no próximo capítulo, nas Seções 3.2.2 e 3.2.3. Este capítulo é finalizado pela Seção 2.8 com uma revisão sobre teoria de redes complexas, apresentando os principais modelos de redes complexas e suas características.

\subsection{Dados de Expressão Gênica}

Ao sequenciar o genoma de um organismo, encontra-se os genes que codificam as proteínas sem que exista evidência estrutural de interação entre os produtos codificados. Nestes casos, outras abordagens precisam ser usadas para gerar informação sobre a função do gene. Determinar em quais tecidos um gene está ativo, ou quais circunstâncias causam o aparecimento da proteína produzida por este gene, pode ser uma informação muito importante [Nelson and Cox, 2004].

Um abordagem amplamente utilizada para estudar estes padrões são os DNA microarrays [Shalon et al., 1996] também conhecidos como DNA chips, os quais permitem verificar, de forma rápida e simultânea, os níveis de expressão de milhares de genes. No entanto, a extração dos níveis de expressão requer o desenvolvimento e aplicação de vários protocolos a serem usados nos laboratórios, bem como o desenvolvimento de bancos de dados e programas para sua manipulação e análise. Dessa forma, a escolha dos protocolos e algoritmos para a geração e análise dos dados são cruciais.

De forma geral, a produção dos dados de expressão utilizando a tecnologia de DNA microarrays se inicia pela identificação de segmentos de DNA (Ácido desoxirribonucleico) de genes conhecidos, os quais são amplificados por PCR (Reação em Cadeia da Polimerase) e colocados em uma superfície sólida. Durante a amplificação por PCR, uma amostra de DNA é separada em fitas simples e 
incubadas com DNA polimerase, dNTPs, e dois oligonucleotídeos (primers), cujas sequências flanqueiam (ficam nas extremidades) do segmento de DNA de interesse. Os primers direcionam a DNA polimerase para sintetizar as fitas complementares do DNA alvo [Voet et al., 2005]. Cada etapa deste processo dobra a quantidade do DNA de interesse, e pode ser repetida até que se tenha a quantidade desejada de DNA.

Após a amplificação, pequenas quantidades de solução de DNA são depositadas em posições exatas (spots) de uma superfície sólida (array). Muitas milhares de amostras (spots) são depositadas nesta superfície contendo apenas poucos centímetros quadrados, formando uma matriz ou microarranjo (microarray) [Nelson and Cox, 2004]. Uma vez construída esta matriz com a fixação dos trechos de DNA nos spots, o microarray pode ser usado para analisar amostras de transcritos (mRNA) produzidos por uma célula, tecido ou outras amostras biológicas de interesse. Os mRNAs são convertidos para cDNAs por um processo conhecido como transcriptase reversa. Os cDNAs são marcados fisicamente com a adição de um nucleotídeo contendo um fluoróforo que brilha ao ser excitado por luz de comprimento de onda específico. Este fluoróforo tem função análoga a um corante. Os cDNAs rotulados são hibridizados com as amostras contidas no DNA microarray. Os cDNAs não hibridizados são removidos por um processo de lavagem do microarray. No microarray resultante, cada spot apresenta uma intensidade de fluorescência que indica a quantidade de mRNA hibridizado com os segmentos de DNA presentes neste spot, e consequentemente, indicam o nível de expressão gênica (atividade) deste gene em uma condição de interesse.

Os microarrays podem ser de duas formas: single-channel microarrays ou two-channel microarrays. Os single-channel microarrays ou one-color microarrays, utilizam apenas um corante como marcador e assim, produzem níveis absolutos de expressão gênica. Já os two-channel microarrays ou two-color microarrays, utilizam dois corantes fluorescentes distintos, um verde (Cy3) e outro vermelho (Cy5), os quais são aplicados em duas amostras diferentes. Estas amostras são misturadas e hibridizadas em um mesmo microarray, em um processo conhecido como hibridização competitiva. Este processo permite comparar os níveis de expressão gênica destas amostras, em geral amostras de tecido saudável versus tecido doente ou células submetidas a algum tratamento versus células sem tratamento, entre outras. Os spots fluorescentes na cor verde representam mRNAs mais abundantes em uma condição e os fluorescentes vermelhos representam mRNAs mais abundantes em outra condição. Os mRNAs com relação de equilíbrio entre os mRNAs das duas amostras apresentam fluorescência amarela.

A Figura 2.1 exibe um exemplo do processo de geração de um DNA microarray.

Os microarrays podem ser produzidos observando a evolução de um tecido ou cultura de células de interesse ao longo do tempo. Isto ocorre utilizando-se amostras do material biológico a cada intervalo de tempo para a construção de um novo microarray, gerando amostras temporais de expressão gênica.

O surgimento dos DNA microarrays gerou uma quantidade massiva de perfis de expressão gênica, aumentando também de forma surpreendente o número de sequências genômicas em bancos de dados públicos. Embora a tecnologia dos DNA microarrays seja indicada para uma ampla variedade de aplicações, como indicado em [Hoheisel, 2006], neste trabalho essa tecnologia é limitada ao escopo de geração dos perfis de expressão gênica e sua análise.

No entanto, deve-se ter cuidado ao analisar dados gerados pela tecnologia dos DNA Microarrays. Em especial, um passo muito importante é aplicar um ajuste nas intensidades com objetivo de 


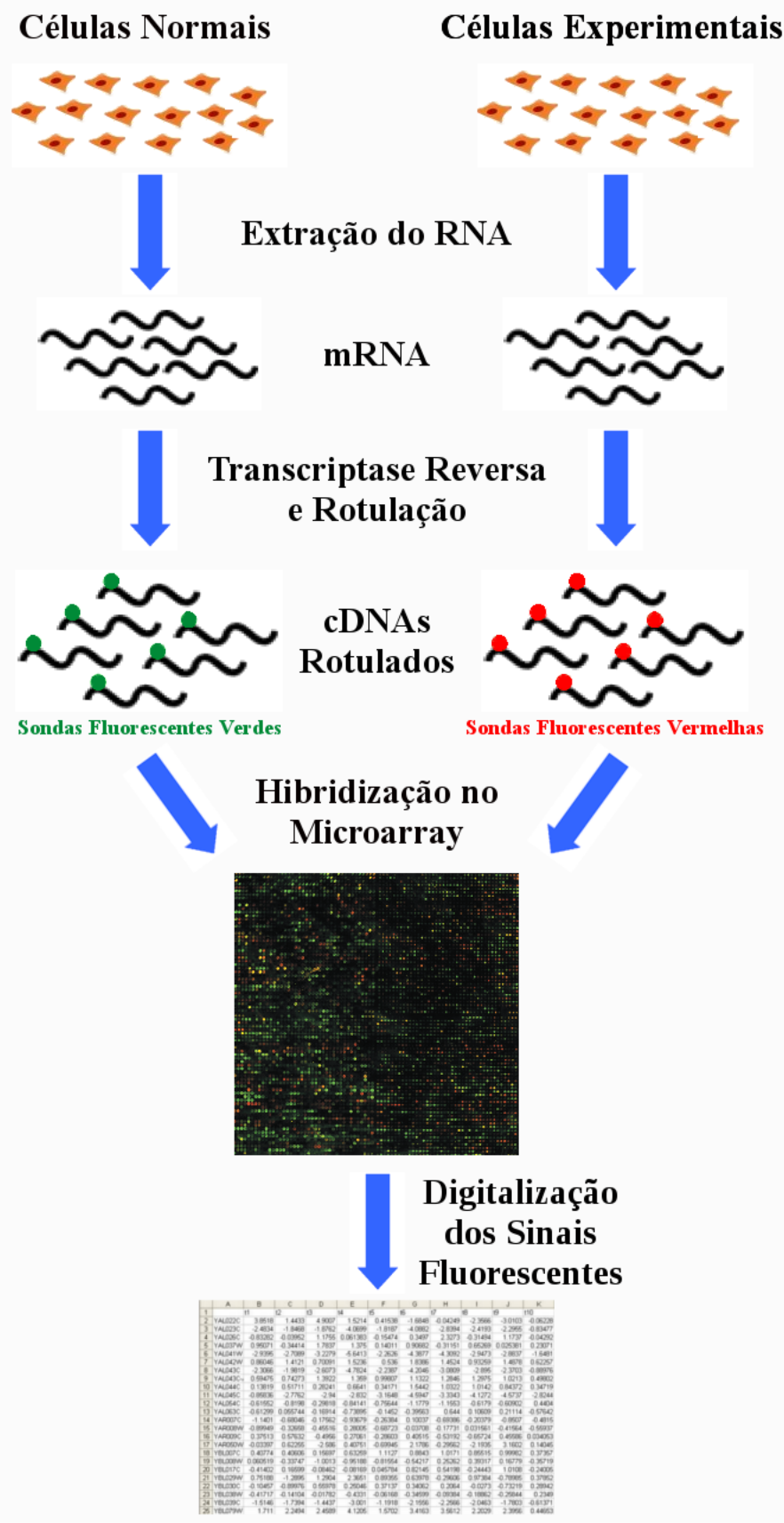

Figura 2.1: Um esquema geral de um DNA microarray. O mRNA é extraído tanto das células normais (controle) quanto das células experimentais (caso de interesse). Utilizando a transcriptase reversa, o $m R N A$ é transformado em cDNA, sendo marcados com cores fluorescentes. O cDNA é exposto ao microarray, no qual estão os genes de interesse (spots). O microarray é digitalizado e o sinais fluorescentes dos spots são convertidos para uma escala numérica de intensidade.

corrigir pequenas distorções, tornando as comparações biológicas entre diferentes spots mais significativas. Esse passo é conhecido como normalização dos dados. Existem vários fatores que tornam a normalização dos dados necessária, incluindo o uso de quantidades diferentes de RNA no início da amplificação, diferenças na eficiência da rotulação ou de deteç̧ão entre os corantes fluorescentes usados e o viés sistemático das medidas dos níveis expressão, o qual pode envolver o comprimento da sequência, corante utilizado, posição do spot no array, entre outros. Logo, o processo de normalização procura remover essas variações que afetam os níveis de expressão gênica. No entanto, é importante mencionar que ele não corrige as variações biológicas [dos Santos and Liu, 2007]. 
Outras fontes de variabilidade experimentais dos DNA Microarrays estão associadas com o processo de fabricação (diferentes fornecedores), geração das amostras biológicas, variabilidade técnica entre os protocolos adotados e especialmente no processamento das imagens dos arrays e obtenção dos níveis de expressão a partir das intensidades de fluorescência dos spots.

Uma revisão sobre a geração dos dados de expressão utilizando a tecnologia DNA microarrays, protocolos envolvidos, suas etapas, características e diferenças entre plataformas, incluindo um estudo comparativo entre os cinco principais fornecedores comerciais (Affymetrix, Agilent, Applied Biosystems, GE Healthcare e Illumina), pode ser encontrada em [dos Santos and Liu, 2007]. É importante destacar que uma lista contendo vários produtos comerciais para a geração de dados de expressão, incluindo os softwares para análise dos dados gerados está disponível em http://www. nature.com/nature/journal/v442/n7106/pdf/4421071a.pdf.

Finalmente, o foco desta tese está na análise e interpretação dos dados de expressão após sua conversão para uma escala numérica como indicado na Figura 2.1, i.e., matriz de dados, na qual normalmente os genes estão dispostos nas linhas e as medidas de expressão ficam nas colunas dessa matriz.

\subsection{Pré-processamento dos Dados}

Uma questão crítica na análise de dados de expressão é o seu pré-processamento. Dependendo da função critério, um passo de quantização de dados pode ser necessário caso os dados de entrada original não sejam discretos, como é o caso das medidas de expressão apresentados na seção anterior.

A quantização geralmente requer uma normalização dos dados [Fujita, 2007]. Neste trabalho, a transformação normal foi adotada. Ela consiste em subtrair do sinal (perfil de expressão) sua média e dividir pelo seu desvio padrão. Formalmente, para cada sinal $g(t)$, a transformação normal é dada por:

$$
\eta[g(t)]=\frac{g(t)-E[g(t)]}{\sigma[g(t)]},
$$

na qual $E[g(t)]$ e $\sigma[g(t)]$ são, respectivamente, a média e o desvio padrão de $g(t)$.

Uma vez tendo os dados normalizados, foi adotada neste trabalho duas formas para a quantização dos dados e, em ambas considerando que $g$ é uma variável e $g(t)$ uma amostra dessa variável. A quantização do sinal normalizado de expressão é um mapeamento dos níveis contínuos de expressão em $k$ níveis qualitativos de expressão $\{0,1, \ldots, k-1\}$ [Lopes et al., 2008c]. Esse mapeamento é realizado por meio de um limiar que divide um dado espaço de valores em $k$ intervalos. Dado um valor contínuo $r$ de $\eta[g(t)]$, ele é mapeado para um valor inteiro $i-1$, no qual $i$ é o $i$-th intervalo ao qual $r$ pertence. A primeira forma adotada foi dividir o espaço de valores numéricos de $g$ em $k$ níveis, utilizando-se seus máximos positivos e mínimos negativos. A segunda forma adotada foi dividir esse espaço numérico considerando-se os valores positivos e negativos médios. Em geral, nesta segunda forma o limiar adotado tende a ser menor e portanto mais permissivo para que o valor de expressão seja considerado na faixa mais alta (ou mais baixa) de valores. Por outro lado, quando adotados os valores máximos, o limiar tende a ter um valor numérico maior e, dessa forma, mais restritivo ao mapear o valor de expressão para os níveis quantizados mais altos (ou baixos). 


\subsection{Modelagem e Simulação de Redes de Regulação Gênica}

A vida de um organismo depende de várias vias metabólicas, as quais são reguladas por redes de expressões gênicas. O mecanismo de regulação dessas vias envolve um sistema complexo com muitos sinais enviados e recebidos. A natureza de sinais capaz de modificar uma rede de regulação gênica é diversa. Entre esses sinais, estão os RNAs produzidos pela expressão de genes e as proteínas produzidas pela tradução de mRNAs pelo ribossomo. Proteínas agem como sinais de resposta que controlam a transcrição dos genes. Sinais enviados, em forma de enzimas, agem como controle das vias metabólicas. Nessas redes, a expressão de cada gene depende de sua própria expressão e dos níveis de expressão de outros genes em um tempo anterior. Assim, essa rede complexa de expressões pode ser modelada por um sistema dinâmico [Hovatta et al., 2005].

Um processo dinâmico pode ser visto como um processo que se altera ao longo do tempo. Células vivas são intrinsecamente dinâmicas [Fall et al., 2002]. Com o objetivo de descobrir como os genes estão relacionados na dinâmica dos processos celulares, o escopo do trabalho precisa ser mais abrangente do que apenas analisar sequências de nucleotídeos. A geração de dados por $D N A$ microarrays (Seção 2.1) permite medir os níveis de expressão dos genes ao longo do tempo e em escala genômica, produzindo uma grande quantidade de dados.

A expressão gênica é um processo complexo e regulado em várias etapas, o qual recebe o nome de sistemas de regulação gênica [de Jong, 2002]. Neste sistema, as relações regulatórias entre os genes são estruturadas na forma de uma rede, na qual as arestas que ligam os genes (vértices) representam uma interação entre eles. Existe muito a ser aprendido sobre o funcionamento de sistemas regulatórios. Neste sentido, o entendimento dos complexos padrões apresentados pelo comportamento dos genes e a identificação de suas interações em uma rede de regulação representam grandes desafios científicos. Análise e simulações computacionais podem gerar hipóteses de predições mais restritas, as quais devem ser confirmadas ou refutadas em bancada utilizando-se dados reais. Dado o volume de dados gerados por técnicas como os DNA microarrays, o desenvolvimento de ferramentas experimentais e métodos formais para a modelagem e simulação de processos de regulação gênica são indispensáveis.

Em geral, sistemas de regulação gênica envolvem muitos genes conectados por interações positivas (ativação) ou negativas (repressão). Métodos formais podem ser aplicados para representar a estrutura e o comportamento de sistemas regulatórios. Em especial, métodos de modelagem permitem a análise de sistemas regulatórios gênicos grandes e complexos. Outro aspecto importante é que estes modelos também permitem a simulação de uma grande variedade de condições experimentais [de Jong, 2002].

Devido à complexidade dos organismos, atualmente existem na literatura várias abordagens propostas para a modelagem e identificação de GRNs. As principais abordagens para a modelagem de GRNs são as Redes Booleanas [Kauffman, 1969], Equações Diferenciais [Chen et al., 1999], Redes Bayesianas [Friedman et al., 2000] e Redes Gênicas Probabilísticas. As Redes Booleanas, e sua versão estocástica: as Redes Booleanas Probabilísticas [Shmulevich et al., 2002a], bem como as Redes Gênicas Probabilísticas, os quais são os alvos de investigação deste trabalho, tendo em vista que eles são capazes de capturar as propriedades globais das GRNs mesmo com uma quantidade limitada de amostras.

As próximas subseções apresentam algumas alternativas para a modelagem e simulação de redes de regulação gênica, nas quais as expressões dos genes são representadas por valores discretos. 


\subsubsection{Modelos Baseados em Grafos}

Inferir redes a partir de dados de expressões gênicas constitui um dos problemas mais desafiadores da bioinformática [Kelemen et al., 2008]. Genes podem ser vistos como nós de uma rede complexa, os quais possuem como entradas proteínas, i.e., fatores de transcrição, e têm como saída a quantidade de transcritos.

O uso de grafos para a representação e modelagem de redes de regulação gênica permite capturar o comportamento coletivo dos genes que constituem esta rede e o relacionamento entre eles de forma direta, e sua topologia exibe estes relacionamentos de forma explícita, os quais se mantém independente da atribuição de algum valor numérico aos genes ou suas ligações. Por essa razão, os grafos são amplamente utilizados para denotar uma relação de dependência [Pearl, 1988].

Há algum tempo, biólogos têm usado grafos para representar informações sobre interações regulatórias [de Jong, 2002, Shmulevich and Dougherty, 2007]. Estas informações podem tratar de vários elementos, como genes, proteínas ou outras moléculas como sendo os vértices de um grafo, os quais são conectados por arestas que representam algum relacionamento entre eles. Por exemplo, uma aresta pode assumir um valor +1 ou -1 , representando que existe uma ativação ou inibição, respectivamente.

Propriedades estruturais dos grafos [Newman, 2003, Narasimhan et al., 2009] podem ser muito úteis para a predição de relacionamentos funcionais em redes biológicas e também para a caracterização dos efeitos de perturbações em elementos desta rede.

Um grafo dirigido (dígrafo) $G$ é definido como uma tupla $(V, E)$, sendo que $V$ representa um conjunto de vértices, e $E \subseteq V \times V$ um conjunto de arestas. Uma aresta dirigida $e_{i, j}$ é um par ordenado de vértices que deixa o vértice $v_{i}$ e chega ao vértice $v_{j}$. Esse relacionamento pode ser representado por uma matriz de adjacências $M=\left(e_{i, j}\right)$ correspondente ao grafo $G=(V, E)$, no qual

$$
e_{i, j}= \begin{cases}1 & \text { se }(i, j) \in E \\ 0 & \text { caso contrário }\end{cases}
$$

e os vértices são numerados consecutivamente $1,2, \ldots,|V|$.

Considerando que um dígrafo represente relacionamentos regulatórios entre genes, então a aresta $e_{i, j}$ pode ser usada para representar um relacionamento entre um "fator de transcrição" $v_{i}$, ativando um gene $v_{j}$. Autorregulação corresponde a um laço no grafo, ou seja, é uma aresta $e_{i, i}$.

Em muitos casos, a direcionalidade das arestas não é importante, como por exemplo, nas interações entre proteínas. Neste caso, ou a interação entre as proteínas acontece ou não [Shmulevich and Dougherty, 2007]. Neste contexto, podem ser usados grafos não dirigidos, ou simplesmente grafos, nos quais o conjunto de arestas $E$ são pares não ordenados de vértices e a matriz de adjacências $M$ é simétrica $\left(e_{i, j}=e_{j, i}\right)$ e antirreflexiva (não possui laços).

Os vértices de um dígrafo possuem algumas propriedades, como o grau de entrada e o grau de saída. O grau de entrada de um vértice $v_{i}$ é o número de arestas incidentes ao vértice $v_{i}$ (arestas recebidas de outros vértices da rede). De forma similar, o grau de saída é o número de arestas que deixam o vértice $v_{i}$ e incidem em outros vértices da rede. Essas medidas representam quantos vértices "influenciam" o vértice $v_{i}$ e quantos vértices são "influenciados" pelo vértice $v_{i}$, respectivamente. 
A Figura 2.2 exibe um exemplo de dígrafo (a) e sua matriz de adjacências (b).

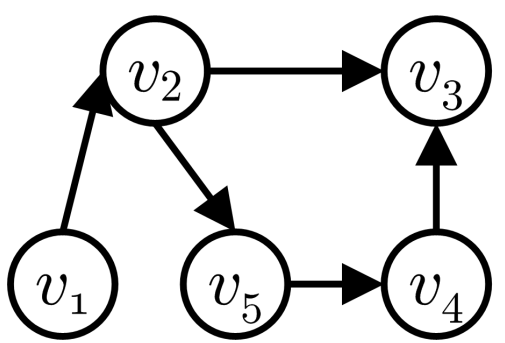

(a)

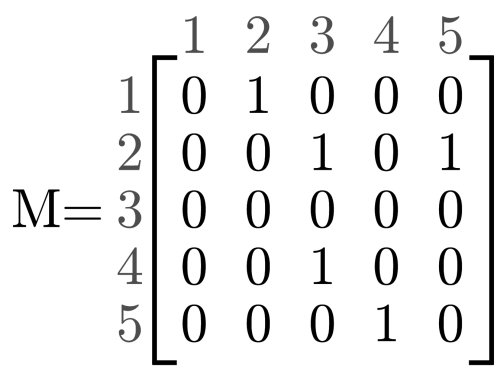

(b)

Figura 2.2: Exemplo de um dígrafo com 5 vértices (a) e sua matriz de adjacências (b). Cada elemento igual a 1 na matriz de adjacências representa um relacionamento regulatório entre dois vértices do dígrafo.

A caracterização de redes biológicas por meio de grafos pode gerar informações relevantes para o conhecimento estrutural e organizacional destas redes, como as apresentadas na Seção 2.8.

\subsubsection{Redes Booleanas}

A representação de GRNs por meio de grafos, embora seja muito útil, não permite especificar um mecanismo de ação (dinâmica) entre os seus vértices. Uma forma bem simples para fornecer esta representação é atribuir valores binários 0 ou 1 (ativo ou inativo) aos vértices "genes" do dígrafo. Desta forma, a dinâmica dos genes ao longo do tempo é determinada pela topologia da rede (ligações entre os genes) e pela aplicação de funções Booleanas.

As redes Booleanas (BNs) foram introduzidas por Kauffman [Kauffman, 1969] para a modelagem de GRNs, e com o objetivo particular de explorar a dinâmica de sistemas complexos, como os representados pelas GRNs. As BNs são definidas por um conjunto de vértices $V=\left\{v_{1}, v_{2}, \ldots, v_{n}\right\}$ e um conjunto de funções Booleanas $\Psi=\left\{\psi_{1}, \psi_{2}, \ldots, \psi_{n}\right\}$, uma para cada gene, também conhecidas como funções de transição Booleanas [D'haeseleer et al., 2000].

Cada gene $v_{i} \in\{0,1\}, i=1,2, \ldots, n$ representa uma variável binária, e seu valor no instante de tempo $t+1$ é completamente determinado pelos valores dos seus $k$ genes preditores $v_{1 i}, v_{2 i}, \ldots, v_{k i}$ no instante de tempo $t$, os quais são aplicados a um circuito lógico de funções Booleanas. Mais formalmente, podemos representar esta dinâmica como $v_{i}(t+1)=f_{i}\left(v_{1 i}(t), v_{2 i}(t), \ldots, v_{k i}(t)\right)$, na qual $v_{1 i}, v_{2 i}, \ldots, v_{k i}$ representam os $k$ genes (preditores ou regulatórios) que possuem arestas incidentes ao gene $v_{i}$ (alvo).

Desta forma, as funções Booleanas $\Psi$ são usadas para atualizar os genes, considerando iterações discretas no tempo, sendo todos os genes atualizados de forma sincronizada de acordo com a função atribuída a ele. Este processo síncrono simplifica a computação e preserva características gerais da dinâmica da rede [Kauffman, 1993].

Nesta rede a dinâmica é determinística, ou seja, a escolha dos $k$ preditores e respectivas funções lógicas para cada gene permanecem inalteradas durante todos os instantes de tempo. Quando as funções Booleanas $\psi_{i}$ são escolhidas de forma aleatória para cada um dos genes, a BN recebe o nome de rede Booleana aleatória (RBN) [Shmulevich and Dougherty, 2007].

$O$ estado de um gene $v_{i}$ em uma BN é definido pelo valor assumido por ele, $v_{i}=1$ representa que o gene está ativo e $v_{i}=0$ inativo. Um estado $\vec{s}$ de uma $\mathrm{BN}$ é definido pelos valores de todos os genes em um dado instante de tempo, $\vec{s}(t)=\left(v_{1}, v_{2}, \ldots, v_{n}\right), v_{i} \in\{0,1\} \forall i=1,2, \ldots, n$. 
O espaço de estados de uma BN pode ser muito grande, mas é finito e definido por $S=$ $\left\{\overrightarrow{s_{1}}, \overrightarrow{s_{2}}, \ldots, \overrightarrow{s_{z}}\right\}, z=2^{n}$, sendo $n$ o número de genes da rede (BN). Dado um estado inicial de uma $\mathrm{BN}$, devido à sua dinâmica, ela irá percorrer um caminho em seu espaço de estados. O caminho de estados percorridos recebe o nome de trajetória. A Figura 2.3 exibe um exemplo de uma BN.

(a)

\begin{tabular}{|c|c|c|c|c|c|}
\hline (c) & \multicolumn{2}{|c|}{ Entrada } & \multicolumn{3}{|c|}{ Saída } \\
\hline & $J_{1}$ & & & 2 & $v_{3}$ \\
\hline & & & ) & & 0 \\
\hline & 0 & & ) & 1 & 0 \\
\hline & 0 & & | & 1 & 1 \\
\hline & 0 & & 1 & 1 & 1 \\
\hline & 1 & & ) & 0 & 1 \\
\hline & 1 & & ) & 0 & 1 \\
\hline & 1 & & 1 & 0 & 1 \\
\hline & 1 & & 1 & 0 & 1 \\
\hline
\end{tabular}

(b)

$$
\begin{aligned}
& v_{1}[\mathrm{t}+1]=v_{2}[\mathrm{t}] \\
& v_{2}[\mathrm{t}+1]=\operatorname{NOT}\left(v_{1}[\mathrm{t}]\right) \\
& v_{3}[\mathrm{t}+1]=v_{1}[\mathrm{t}] \text { OR } v_{2}[\mathrm{t}]
\end{aligned}
$$

Figura 2.3: Exemplo de uma BN contendo 3 genes. (a) representação na forma de um dígrafo, (b) Funções Booleanas, (c) Tabela de transição de estados e (d) Diagrama de transição de estados (adaptada de [Kelemen et al., 2008]).

Na Figura 2.3(a), as arestas direcionais representam uma ativação $\left(v_{2}\right.$ ativa $\left.v_{1}\right)$, e as arestas achatadas representam inibição $\left(v_{1}\right.$ inibe $\left.v_{2}\right)$. O gene $v_{3}$ é ativado se o gene $v_{1}$ ou $(\mathrm{OR})$ o gene $v_{2}$ estiver ativo. Na Figura 2.3(b), este mesmo relacionamento entre os genes é expresso de forma textual. A Figura 2.3(c) exibe a representação de todas as possibilidades de estados da rede (entrada, tempo $t$ ) e os respectivos resultados (saída, tempo $t+1$ ). A Figura 2.3(d) exibe o diagrama de transição de estados desta BN, por exemplo, se a BN estiver no estado $\left(v_{1}=1, v_{2}=0, v_{3}=0\right)$, então o próximo estado desta rede será $\left(v_{1}=0, v_{2}=0, v_{3}=1\right)$.

Pode-se perceber que, pelo determinismo na direcionalidade dos estados de uma BN e como existe um número finito de estados, certos estados serão sempre revisitados. Os estados que serão revisitados em uma BN dependem do estado inicial escolhido. Estes estados são chamados de atratores, e os estados que levam até ele são chamados estados transientes, os quais compõem a bacia de atração do atrator. Por exemplo, na Figura 2.3(d) pode-se perceber que os estados $\left(v_{1}=1, v_{2}=0, v_{3}=0\right),\left(v_{1}=1, v_{2}=1, v_{3}=0\right),\left(v_{1}=0, v_{2}=0, v_{3}=0\right)$ e $\left(v_{1}=0, v_{2}=1\right.$, $\left.v_{3}=1\right)$ são transientes e representam a bacia de atração, enquanto os demais estados (ciclo interno) representam o atrator desta $\mathrm{BN}$. 
Os atratores são estados estacionários de um sistema dinâmico, que capturam o comportamento deste sistema a longo prazo [Shmulevich and Dougherty, 2007]. Os atratores são sempre cíclicos e podem ser formados por um ou mais estados. Iniciando de qualquer estado de um atrator, o número de transições necessárias para retornar ao estado inicial é chamado tamanho do ciclo.

O trabalho de Kauffman [Kauffman, 1993] interpreta que os atratores de uma BN podem ser vistos como diferentes tipos celulares, argumentando que diferentes células são caracterizadas por seu padrão recorrente de expressão gênica, de certa forma correspondente aos atratores de uma BN.

GRNs reais são altamente estáveis na presença de pertubações ocasionadas por fatores externos, seja de algum gene isoladamente ou de vários genes. Considerando o formalismo das BNs, isto representa que, quando um número mínimo de genes são perturbados, estes genes mudam de valores (estados), mas os estados da rede continuam na mesma bacia de atração e acabam por chegar no mesmo atrator [Shmulevich and Dougherty, 2007].

Neste sentido, atratores com grandes bacias de atração conferem uma alta estabilidade para o sistema. Esta estabilidade das redes regulatórias em organismos vivos permite que as células mantenham seu estado funcional no organismo mesmo quando submetidas a perturbações externas.

É amplamente aceito que muitos sistemas complexos e adaptativos tal como o genoma, operam em uma zona entre a ordem e a desordem, conhecido como edge of chaos [Shmulevich and Dougherty, 2007]. Em um regime em ordem, os atratores são pequenos e existem poucos deles, o que implica a existência de grandes bacias de atração e pequenas perturbações nos estados transientes que levam ao mesmo atrator. Sistemas operando na fronteira entre a ordem e o caos são chamados de sistemas complexos ou críticos.

Um exemplo do uso de BNs para modelar o ciclo da divisão celular da levedura pode ser visto em [Li et al., 2004].

\subsubsection{Redes Bayesianas}

Os modelos estocásticos de redes gênicas diferem dos modelos determinísticos por incorporarem aleatoriedade ou incerteza. As BNs assumem uma dependência funcional fixa entre seus elementos, por isso são classificadas como modelos determinísticos de representação de GRNs. Modelos estocásticos diferem de modelos determinísticos por incorporar aleatoriedade ou incerteza. Os valores assumidos pelos genes destes modelos podem ser descritos por distribuições de probabilidade. $\mathrm{O}$ modelo estocástico mais usado para representar GRNs são as redes Bayesianas [Friedman et al., 2000, Kelemen et al., 2008].

A estrutura de uma rede gênica por meio de redes Bayesianas é modelada por um grafo acíclico dirigido (DAG) $G=(V, E)$. Os vértices $v_{i} \in V, 1 \leq i \leq n$, representam genes e correspondem a variáveis aleatórias $X_{i}$. Considerando que $v_{i}$ é um gene, então $X_{i}$ descreve o nível de expressão do gene $v_{i}$. Para cada $X_{i}$, uma distribuição de probabilidade condicional $P\left(X_{i} \mid\right.$ preditores $\left.\left(X_{i}\right)\right)$ é definida, na qual preditores $\left(X_{i}\right)$ representam as variáveis que regulam diretamente o gene $v_{i}$ da rede $G$.

A modelagem de redes Bayesianas consiste de duas partes: a parte qualitativa, na qual influências diretas (causal) entre dois genes são descritas pelas arestas direcionais $E$ em um grafo $G$; e a parte quantitativa, na qual as distribuições condicionais $p\left(X_{i} \mid\right.$ preditores $\left.\left(X_{i}\right)\right)$, representando os níveis de expressão, são anexadas aos genes desta rede. Logo, os níveis de expressão $X_{i}$ de um gene $v_{i}$ são considerados como variáveis aleatórias e as arestas representam dependências condicionais entre as 


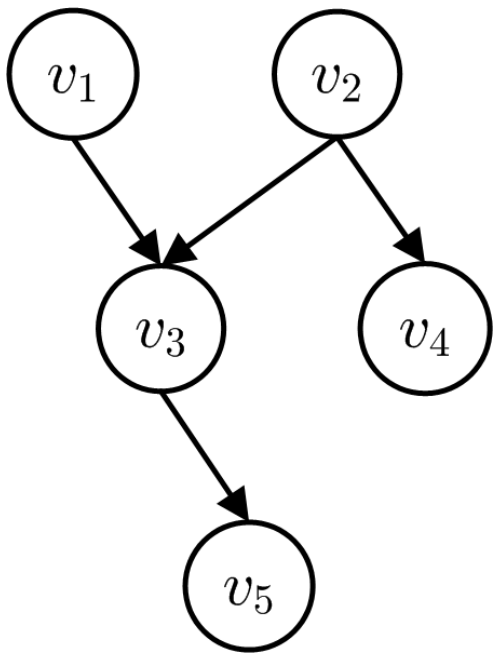

Figura 2.4: Exemplo de rede Bayesiana contendo 5 vértices.

distribuições dessas variáveis aleatórias [Hovatta et al., 2005].

As redes Bayesianas incorporam uma hipótese Markoviana, a qual determina que cada variável $X_{i}$ é independente dos outros genes (não preditores) dados seus preditores em $G$ [Shmulevich and Dougherty, 2007]. Uma distribuição conjunta que satisfaça esta hipótese Markoviana pode ser decomposta em um produto das probabilidades condicionais, dado por:

$$
P\left(X_{1}, \ldots, X_{n}\right)=\prod_{i=1}^{n} P\left(X_{i} \mid \text { preditores }\left(X_{i}\right)\right)
$$

A rede Bayesiana exibida na Figura 2.4 possui 5 vértices. Considerando a hipótese Markoviana, o vértice $v_{3}$ é independente do vértice $v_{4}$ dados os vértices $v_{1}$ e $v_{2}$, ou seja, $P\left(v_{3} \mid v_{1}, v_{2}, v_{4}\right)=P\left(v_{3} \mid\right.$ $\left.v_{1}, v_{2}\right)$. De forma similar, $P\left(v_{4} \mid v_{1}, v_{2}, v_{3}\right)=P\left(v_{4} \mid v_{2}\right)$, dado que $v_{1}$, $v_{3}$ e $v_{5}$ não estão ligados ao vértice $v_{4}$ e o vértice $v_{2}$ é seu único preditor.

A distribuição conjunta deste exemplo pode ser vista como:

$$
P\left(v_{1}, v_{2}, v_{3}, v_{4}, v_{5}\right)=P\left(v_{1}\right) P\left(v_{2}\right) P\left(v_{3} \mid v_{1}, v_{2}\right) P\left(v_{4} \mid v_{2}\right) P\left(v_{5} \mid v_{3}\right) \text {. }
$$

Desta forma, a representação gráfica de uma rede Bayesiana exibe a distribuição de probabilidade conjunta de uma forma compacta e intuitiva [Shmulevich and Dougherty, 2007]. Esta suposição de independência permite a representação mais compacta das dependências condicionais entre os vértices. Considere que o valor possível para cada vértice seja apenas um dos possíveis estados 0 ou 1 (ativo ou inativo). Neste caso, para representar a tabela de probabilidade condicional para o vértice $v_{3}$, seria necessário $2^{5}=32$ entradas. Por outro lado, considerando a Equação (2.3), se torna necessário apenas 4 entradas, como é mostrado na Tabela 2.1 .

\subsubsection{Redes Booleanas Probabilísticas}

Uma consideração muito importante é que uma célula é um sistema aberto e não um sistema fechado. Em outras palavras, elas podem receber estímulos externos. Dependendo das condições externas em um dado instante de tempo, a célula pode alterar sua dinâmica [Shmulevich and Dougherty, 2007]. 
Tabela 2.1: Exemplo de tabela contendo as probabilidades condicionais de um vértice de uma rede Bayesiana. A probabilidade do vértice $v_{3}$ estar inativo dado que $v_{1}$ está ativo e $v_{2}$ está inativo é $P\left(v_{3}=0 \mid v_{1}=1, v_{2}=\right.$ $0)=0.8$.

\begin{tabular}{cc|c|c}
$v_{1}$ & $v_{2}$ & $P\left(v_{3}=0 \mid v_{1}, v_{2}\right)$ & $P\left(v_{3}=1 \mid v_{1}, v_{2}\right)$ \\
\hline 0 & 0 & 0.99 & 0.01 \\
0 & 1 & 0.9 & 0.1 \\
1 & 0 & 0.8 & 0.2 \\
1 & 1 & 0.0 & 1.0
\end{tabular}

Neste sentido, as BNs (Seção 2.3.2) representam um modelo fechado, não considerando tais estímulos. Por outro lado, as Redes Booleanas Probabilísticas (PBNs) [Shmulevich et al., 2002b,Shmulevich et al., 2002a] se apresentam como um modelo generalizado para representar GRNs, permitindo a inclusão de estímulos externos e seus efeitos na dinâmica de um sistema. Conceitualmente, esta é a principal diferença entre as BNs e as PBNs.

A ideia básica das PBNs é usar várias funções Booleanas em conjunto, de forma que, a cada instante de tempo, uma delas possa ser escolhida com uma certa probabilidade para determinar o valor de um gene alvo. As PBNs podem ser interpretadas como um conjunto de BNs que descrevem o funcionamento de uma GRN, sendo que cada uma das BNs pode ser escolhida para definir a dinâmica de um sistema em um dado instante de tempo, as quais representam condições ou estímulos deste sistema.

Desta forma, para cada gene $v_{i}$ de uma PBN, é definido um conjunto de funções Booleanas $\psi_{i}=\left\{\psi_{j}^{(i)}\right\}$, tal que $j=1, \ldots, l(i)$, no qual cada $\psi_{j}^{(i)}$ é uma possível função Booleana que pode ser escolhida para determinar o valor do gene $v_{i}$, e $l(i)$ é o número de possíveis funções atribuídas ao gene $v_{i}$. Se torna claro que se $l(i)=1$ para todo $i=1, \ldots, n$, então a PBN se reduz a uma BN. Nesta notação, cada função $\psi_{j}^{(i)}$ define o circuito lógico e também os preditores associados ao gene $v_{i}$.

A dinâmica de uma PBN em um dado instante de tempo é determinada por um vetor de funções Booleanas, como no caso das BNs. A diferença está na forma como estas funções são escolhidas, antes deterministicamente, agora de forma probabilística. Considerando $u$ possíveis realizações de um vetor de funções Booleanas $\Psi_{1}, \Psi_{2}, \ldots, \Psi_{u}$, sendo definida por:

$$
u=\prod_{i=1}^{n} l(i)
$$

Logo, é necessário definir as probabilidades de escolha entre as funções Booleanas de cada gene $v_{i}$. Desta forma, a probabilidade de $\psi_{j}^{(i)}$ ser escolhida para determinar a dinâmica do gene $v_{i}$, tal que $(1 \leq j \leq l(i))$, em um dado instante de tempo é definida por $c_{j}^{(i)}$. Considerando que $c_{j}^{(i)}$ é uma distribuição de probabilidades, é necessário satisfazer a Equação (2.5)

$$
\sum_{j=1}^{l(i)} c_{j}^{(i)}=1 .
$$

A PBN é dita independente se a escolha das funções Booleanas $\psi^{(1)}, \psi^{(2)}, \ldots, \psi^{(n)}$ forem independentes [Shmulevich and Dougherty, 2007].

A dinâmica das PBNs, como descrita aqui, é essencialmente a mesma das BNs. No entanto, em um dado instante de tempo, o estado de um gene $v_{i}$ é definido por uma das $l(i)$ possíveis funções 
(preditores), de acordo com sua respectiva probabilidade. Isto também pode ser visto como se em cada instante de tempo fosse escolhida uma $\mathrm{BN}$, das $u$ possíveis, para determinar a dinâmica da rede neste instante de tempo.

As PBNs representam uma interface entre o absoluto determinismo das BNs e a natureza probabilística das Redes Bayesianas por incorporar incerteza na escolha das funções de transição Booleanas, as quais determinam a dinâmica do sistema.

\subsubsection{Redes Gênicas Probabilísticas}

As Redes Gênicas Probabilísticas (PGN) foram propostas por Barrera et al [Barrera et al., 2004, Barrera et al., 2007] como um modelo para representar GRNs. As PGNs são baseadas nas PBNs, nas quais a escolha da função de transição não é determinística e os estados dos genes e da rede são representados por valores discretos.

PGNs podem ser representadas como um sistema dinâmico finito, discreto no tempo e com número finito de estados, no qual cada transcrito é representado por uma variável que recebe o valor de expressão deste transcrito. A composição de todas estas variáveis formam um vetor chamado estado do sistema. Cada componente deste vetor possui uma função associada que calcula seu próximo valor a partir do estado anterior de outros genes (preditores), sendo chamada de função de transição, denotada por $\psi$. Estas funções são componentes de um vetor de funções de transição $\Psi$, o qual define a transição de um estado da rede para o próximo e representa o mecanismo de regulação gênica [Barrera et al., 2007].

Com o objetivo de formalizar essas ideias, são introduzidas algumas definições e notações. Seja $R$ o conjunto de valores de todos os componentes, por exemplo $R=\{0,1\}$ como um sistema binário. $\mathrm{O}$ vetor de funções de transição $\Psi=\left\{\psi_{1}, \psi_{2}, \ldots, \psi_{n}\right\}$ para uma rede contendo $n$ genes, é uma função de $R^{n}$ para $R^{n}$. Um sistema dinâmico finito é dado por [Barrera et al., 2007]:

$$
s(t+1)=\Psi(s(t)),
$$

em que $s(t) \in R^{n}, \forall t \geq 0$, representa o estado da rede no instante de tempo $t$. Um componente de $s(t)$ é um valor $x_{i}(t) \in R$. Sistemas definidos dessa forma são invariantes a translação no tempo, i.e., a função de transição é a mesma para todo o tempo discreto $t$. Quando $\Psi$ é uma função estocástica, i.e., para cada estado $s(t)$, o próximo estado $\Psi(s(t))$ é uma realização de um vetor aleatório, o sistema dinâmico é um processo estocástico.

Nas PGNs, as redes de expressão gênica são representadas como um processo estocástico, sendo a função de transição estocástica um caso particular de cadeias de Markov [Kumar and Varaiya, 1986, Cappé et al., 2005, Polanski and Kimmel, 2007]. Considere uma sequência de vetores aleatórios $S_{0}, S_{1}, S_{2}, \ldots$ assumindo valores em $R^{n}$ e suas realizações denotadas respectivamente por $s(0), s(1), s(2), \ldots$. Uma sequência de estados aleatórios $\left(S_{t}\right)_{t=0}^{\infty}$ é chamada de cadeia de Markov se, para todo $t \geq 1, P(S(t)=s(t) \mid S(0)=s(0), \ldots, S(t-1)=s(t-1))=P(S(t)=s(t) \mid S(t-1)=$ $s(t-1))$.

Em outras palavras, assumir este princípio significa que a probabilidade condicional de um evento futuro, dados os eventos anteriores, depende apenas do evento imediatamente anterior. Uma cadeia de Markov é caracterizada por uma matriz de transição $\pi_{Y \mid X}$ de probabilidades condicionais entre os estados, sendo seus elementos denotados por $p_{y \mid x}$, e um vetor de estados iniciais $s_{0}$. Uma 
PGN é uma cadeia de Markov $\left(\pi_{Y \mid X}, s_{0}\right)$, na qual são assumidos alguns axiomas:

- a matriz de transição $\pi_{Y \mid X}$ é homogênea, i.e., $p_{y \mid x}$ não é uma função de $t$. As probabilidades de transição de estados são constantes ao longo do tempo;

- $p_{y \mid x}>0$, i.e., todos os pares de estados $x, y \in R^{n}$ podem ser atingidos (cadeia de Markov ergódica);

- a matriz de transição $\pi_{Y \mid X}$ é condicionalmente independente, i.e., para todo par de estados $x, y \in R^{n}, p_{y \mid x}=\prod_{i=1}^{n} p\left(y_{i} \mid x\right)$.

- $\pi_{Y \mid X}$ é quase determinístico, i.e., para todo estado $x \in R^{n}$, existe um estado $y \in R^{n}$ tal que $p_{y \mid x} \approx 1$.

Estes axiomas que definem as PGNs são motivados por fenômenos biológicos ou simplificações devido à falta de dados para estimação do modelo, como por exemplo nos experimentos de microarrays temporais, nos quais existem poucas observações no tempo e milhares de genes. O primeiro axioma é uma restrição para simplificar o problema de estimação mas poderia ser facilmente generalizado. O segundo impõe que todos os estados são alcançáveis, ou seja, assume que a presença de ruído ou perturbação pode levar o sistema a qualquer estado. O terceiro axioma determina que a expressão de um gene em um dado instante de tempo $t$ independe da expressão de outros genes no mesmo instante $t$. O quarto axioma diz que o sistema tem uma dinâmica estrutural que está sujeita a pequenos ruídos [Barrera et al., 2007].

É importante observar que o terceiro axioma pode não ser verificado dependendo da limitação da resolução temporal dos dados experimentais disponíveis. Entretanto, esse axioma foi adotado neste modelo para permitir alguma tratabilidade estatística. Usando esse axioma, foi possível conseguir resultados biológicos bastante significativos em dados de Plasmodium falciparum, um agente causador da malária [Barrera et al., 2004, Barrera et al., 2007, Martins-Jr., 2008] e também na recuperação de redes a partir de dados simulados [Lopes et al., 2008c, Lopes et al., 2008a, Lopes et al., 2009b].

\subsection{Seleção de Características}

Métodos de reconhecimento de padrões permitem a classificação de objetos (ou padrões) a uma determinada classe [Theodoridis and Koutroumbas, 2008]. No reconhecimento estatístico de padrões [Webb, 2002], dado um conjunto de classes $Y=y_{1}, y_{2}, \ldots, y_{c}$ e um objeto (padrão) desconhecido $X=x_{1}, x_{2}, \ldots, x_{d}$, um sistema de reconhecimento de padrões tenta associar o objeto $x$ a uma das classes $y_{i}$, baseando-se em medidas definidas em seu espaço de características.

Em muitas aplicações, e especificamente na bioinformática, a dimensão do espaço de características tende a ser muito grande, tornando difícil a tarefa de classificação, e consequentemente a inferência de GRNs. Neste contexto, o estudo e desenvolvimento de técnicas para a redução de dimensionalidade é uma tarefa muito importante.

A chamada "maldição da dimensionalidade" [Bishop, 1995, Jain et al., 2000] é um fenômeno no qual o número de amostras de treinamento requeridas para uma classificação satisfatória ou para a inferência de GRNs é dada por uma função exponencial da dimensão do espaço de características. Esse problema consiste na divisão do espaço de características, observando as amostras disponíveis 
no conjunto de treinamento. Se, por exemplo, cada característica $x_{i}$ for dividida em $M$ divisões (classes), cada uma delas associada a uma determinada classe $y_{j}$, então o número total de divisões é $M^{d}$ e passa a crescer exponencialmente com a dimensionalidade do espaço de características. O aumento no número de divisões no espaço de características pode aumentar a precisão com a qual cada objeto é especificado. No entanto, esse é o problema a ser tratado. Considerando que cada divisão deve conter pelo menos uma amostra, então a quantidade de amostras disponíveis para o treinamento também cresce exponencialmente. Esse fenômeno é conhecido na literatura como "maldição da dimensionalidade". Logo, considerando que, na prática, a quantidade de dados é limitada, o aumento da dimensionalidade do espaço de características rapidamente leva ao ponto que os dados se tornam muito esparsos, levando a uma representação muito pobre da classe.

Esta é a maior motivação que torna a tarefa de redução de dimensionalidade tão importante em problemas com grande número de características e pequeno número de amostras de treinamento. Muitas aplicações em bioinformática pertencem a este contexto. Por exemplo, conjuntos de dados contendo perfis de expressões apresentam milhares de genes (características) e um número reduzido de amostras de treinamento, i.e., experimentos biológicos (DNA microarrays).

Existem basicamente duas abordagens para a redução de dimensionalidade: extração de características e seleção de características [Webb, 2002, de Campos, 2001]. Métodos de extração de características criam novas características a partir de transformações ou combinações das características originais. Por outro lado, técnicas de seleção de características procuram por um subconjunto das características que levam a uma boa representação, classificação ou predição das classes dos objetos em análise, de acordo com uma função critério. Este trabalho se concentra nos métodos de seleção de características.

Em se tratando de problemas de bioinformática, em particular os sinais de expressões gênicas, existem dois objetivos principais na aplicação da seleção de características [Shmulevich and Dougherty, 2007]. O primeiro consiste em eliminar genes irrelevantes do processo de classificação (ou predição) com objetivo de melhorar seu desempenho. O segundo é descobrir a estrutura das GRNs ou os mecanismos responsáveis por algum fenômeno biológico de interesse, por exemplo o progresso ou a repressão de uma doença.

Um método de seleção de características é composto por duas partes principais: um algoritmo de busca e uma função critério, a qual atribui um valor de qualidade ao subconjunto de características. Os algoritmos de busca se dividem em duas categorias principais: os algoritmos ótimos e sub-ótimos.

A forma mais simples de implementação de um algoritmo de seleção de características é a busca exaustiva. Este algoritmo busca por todo o espaço de características, retornando o subconjunto ótimo de características de acordo com a função critério usada para guiar o processo de busca. No entanto, o seu custo computacional frequentemente torna essa estratégia inadequada, especialmente para a inferência de GRNs, a qual envolve conjuntos de dados com milhares de características (genes), tornando evidente a existência de um balanceamento (trade-off) entre otimalidade e custo computacional, exigindo, portanto, algoritmos alternativos (não-ótimos).

Os algoritmos ótimos incluem as buscas exaustiva e branch-and-bound, as quais retornam o melhor subconjunto de características. Entretanto, seu custo computacional geralmente é muito alto, especialmente em problemas contendo uma alta dimensionalidade, tal como a inferência de GRNs. Os algoritmos sub-ótimos não garantem que a solução seja ótima, mas algumas abordagens apresentam um custo-benefício razoável entre o custo computacional e a qualidade da solução apresentada. 
Neste trabalho são investigados os algoritmos sub-ótimos: Busca Sequencial para Frente (SFS, do inglês Sequential Forward Selection) e Busca Sequencial Flutuante para Frente (SFFS, do inglês Sequential Forward Floating Selection), com excelente custo benefício [Pudil et al., 1994].

A razão pela qual algoritmos sub-ótimos eficientes de busca, tais como o SFS e o SFFS nem sempre chegam a melhor solução deve-se ao efeito nesting, no qual uma característica não pertencente à solução ótima pode ser incluída na solução parcial do algoritmo e nunca ser descartada, devido a natureza do próprio algoritmo, e.g., SFS, ou a natureza multivariada das características em relação a predição da classe, o que leva a uma solução sub-ótima [Somol et al., 1999].

Esse efeito pode ser explicado pelo fato de que duas características em conjunto podem realizar uma predição ou classificação adequada da classe (ou valor) do objeto alvo, embora as suas predições ou classificações individuais sobre o objeto alvo sejam ruins. Tais pares de características podem ainda ser melhores do que outras características agrupadas que individualmente façam uma boa predição. Este fenômeno é chamado de sinergia ou predição intrinsecamente multivariada [Anastassiou, 2007, Martins-Jr et al., 2008], como discutido na Seção 2.7. Embora dependendo de algumas restrições da função critério adotada, por exemplo ser monotônica ou com forma em U, é possível obter o subconjunto ótimo de características sem a necessidade de percorrer todo o espaço de busca aplicando técnicas branch-and-bound [Somol et al., 2004, Ris et al., 2010].

Em seguida, são apresentados dois algoritmos sub-ótimos clássicos muito utilizados para a seleção de características, o SFS e o SFFS, os quais foram implementados e disponibilizados no software descrito em [Lopes et al., 2008c].

\subsubsection{Busca Sequencial para Frente (SFS)}

O SFS é um algoritmo que apresenta solução única, e segundo [Guyon and Elisseeff, 2003], pertence à classe dos wrappers. A metodologia wrapper consiste em usar o resultado da função critério como uma medida de desempenho da predição de um dado processo de aprendizagem com objetivo de avaliar a utilidade de subconjuntos de variáveis.

Neste contexto, o algoritmo SFS parte de um conjunto resposta vazio e adiciona ao conjunto resposta a melhor característica individual de acordo com a função critério adotada. No próximo passo, o algoritmo adiciona a segunda característica que, em conjunto com a primeira já incluída no conjunto resposta, compõe o melhor par de características. Este processo continua até que uma condição de parada seja encontrada, normalmente baseada em uma dimensão fixa, i.e., o número de características a ser retornado pelo conjunto resposta, ou baseada na variação do valor da função critério, i.e., atinge um valor de limiar ou se não há uma melhoria significativa no valor da função critério de uma etapa para a próxima.

Uma variante do algoritmo SFS é a busca sequencial para trás (SBS, do inglês Sequential Backward Selection), a qual parte do conjunto completo de características e a cada passo remove a característica menos relevante de acordo com a função critério, repetindo este processo sucessivamente até que uma condição de parada seja satisfeita [Pudil et al., 1994]. Considerando o contexto deste trabalho, a implementação adotada foi a abordagem SFS.

\subsubsection{Busca Sequencial Flutuante para Frente (SFFS)}

Os métodos de busca SFS e SBS apresentam um efeito indesejável conhecido como efeito nesting. Esse efeito ocorre porque as características descartadas na abordagem top-down não serão inseridas 
novamente, e as características inseridas na abordagem bottom-up não serão descartadas do conjunto resposta.

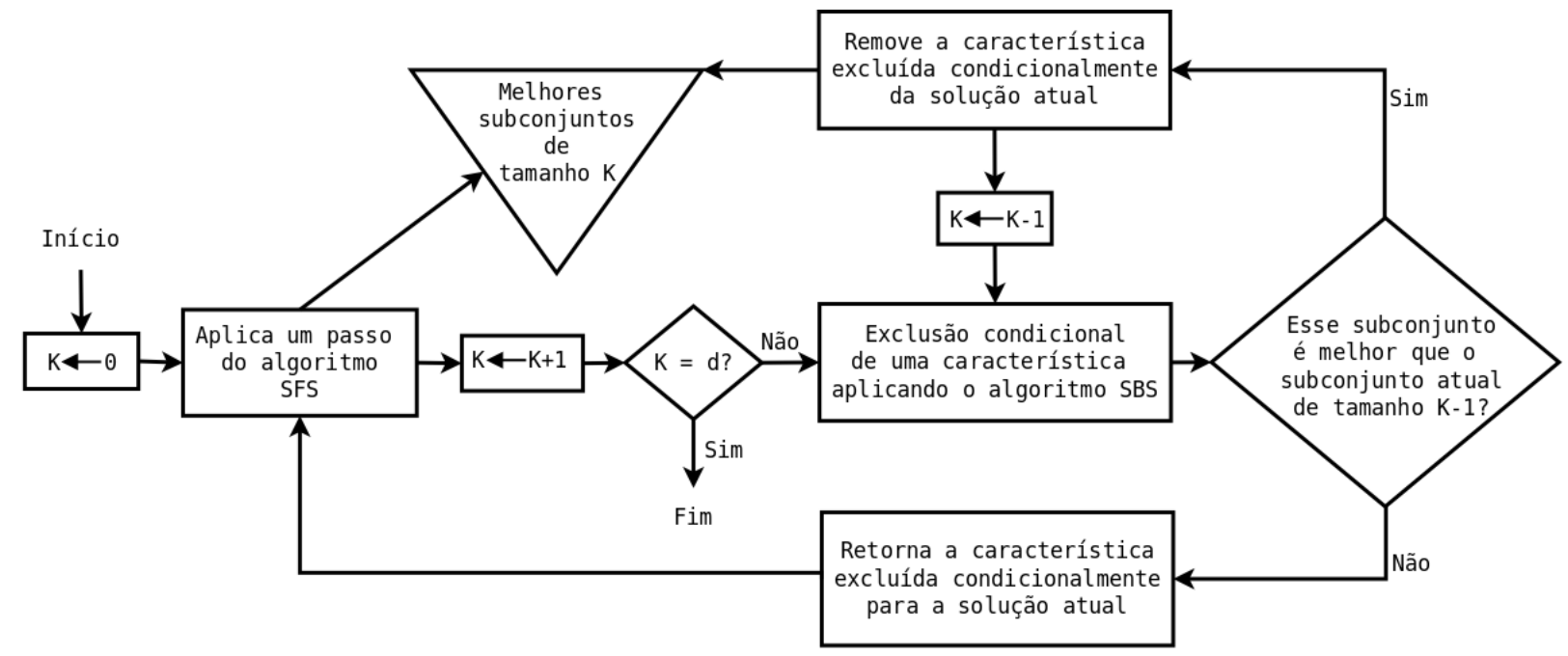

Figura 2.5: Fluxograma simplificado do algoritmo SFFS [Lopes et al., 2008c] (adaptado de [Somol et al., 1999]). K se refere ao tamanho do subconjunto que representa a solução atual e d se refere ao tamanho do subconjunto da solução final desejada (condição de parada do algoritmo).

Com objetivo de evitar esse problema, o algoritmo SFFS também foi adotado neste trabalho. O algoritmo SFFS [Pudil et al., 1994] tenta evitar o efeito nesting permitindo a inclusão e exclusão de características no conjunto resposta de forma flutuante, i.e., sem a necessidade de definir o número de inserções ou exclusões.

O algoritmo SFFS parte de um conjunto resposta vazio e com cardinalidade zero do conjunto resposta, i.e., $k=0$. O algoritmo SFS é aplicado até que o tamanho do subconjunto resposta seja igual a dois, i.e., $k=2$. A partir de conjuntos maiores que duas características $(k>2)$, o algoritmo SBS é aplicado com o objetivo de excluir as características indesejáveis de acordo com a função critério. O SFFS segue aplicando alternadamente os algoritmos SFS e SBS até que uma condição de parada seja atingida. O melhor subconjunto resposta de cada cardinalidade $k$ é armazenado em uma lista. O melhor subconjunto resposta entre eles é selecionado como resposta do algoritmo, e no caso de empates o subconjunto resposta com menor cardinalidade, i.e., menor número de características, é escolhido. Um fluxograma esquemático do algoritmo SFFS é apresentado na Figura 2.5.

Da mesma forma que o SFS, existe a abordagem top-down do algoritmo SFFS, que é conhecido como Busca Sequencial Flutuante para Trás (SBFS, do inglês Sequential Backward Floating Selection), a qual parte do conjunto completo de características e tem seu funcionamento similar ao SFFS, mas de forma invertida.

O algoritmo SFFS é computacionalmente eficiente e normalmente devolve uma solução muito perto do ideal, se apresentando como um excelente custo-benefício. Existem também métodos flutuantes adaptativos e generalizados que tentam melhorar os resultados do SFFS à custa de um aumento significativo no custo computacional. No entanto, eles ainda não conseguem evitar o efeito nesting completamente [Somol et al., 1999]. 


\subsection{Entropia e Informação Mútua}

O conceito de entropia foi introduzido em 1865 por Rudolf Clausius no contexto da termodinâmica considerando apenas demonstrações macroscópicas [Clausius, 1879]. Alguns anos depois em 1877, Ludwig Boltzmann mostrou que a entropia pode ser expressa em termos de probabilidades associadas à configuração microscópica de um sistema [Boltzmann, 1974], a qual passou a ser conhecida na literatura como entropia de Boltzmann-Gibbs (BG). A forma discreta dessa entropia é dada como segue [Tsallis, 2009a]:

$$
H_{B G}(X)=-k \sum_{i=1}^{W} p_{i} \log p_{i},
$$

na qual $k$ é a constante de Boltzmann (e.g., $k=1$ em áreas fora da física, como a teoria da informação, cibernética e outros) [Tsallis, 2009a], e as probabilidades $p_{i}$ correspondem as $W$ configurações microscópicas possíveis, portanto devem satisfazer a equação:

$$
\sum_{i=1}^{W} p_{i}=1
$$

Mais tarde em 1948, a entropia foi aplicada na Teoria da Informação por Claude Shannon [Shannon, 1948]. A entropia é frequentemente utilizada para indicar a quantidade de informação contida em uma determinada fonte, sendo também utilizada para graduar a desordem (incerteza) de um conjunto de dados [Bishop, 1995]. Considere uma variável aleatória $X$ que pode assumir um valor discreto como, por exemplo, o caso Booleano $R=\{0,1\}$. A entropia de Shannon [Shannon and Weaver, 1963], tal como a entropia de Boltzmann-Gibbs, é definida em termos das probabilidades das possíveis ocorrências desta variável aleatória $P(x)$, como segue:

$$
H(X)=-\sum_{x \in X} P(x) \log P(x)
$$

tal que

$$
\sum_{x \in X} P(x)=1
$$

Na Equação 2.9 é realizada a média dos logaritmos das probabilidades das possíveis ocorrências $x(\log (P(x))$ ponderada pelas suas probabilidades $P(x)$, sendo assumido $0 \times \log (0)=0$.

Dessa forma, a entropia representa uma medida de incerteza associada a uma variável, ou seja, quanto maior a entropia de uma variável, maior a incerteza em predizer o valor dessa variável. De forma análoga, a entropia conjunta entre duas variáveis é definida como:

$$
H(X, Y)=-\sum_{x \in X, y \in Y} P(x, y) \log P(x, y),
$$

na qual $P(x, y)$ representa a distribuição de probabilidade conjunta das variáveis aleatórias $X$ e $Y$.

A entropia condicional $H(Y \mid x)$ representa uma medida de incerteza associada a uma variável aleatória $Y$, dado que o valor de uma instância de uma segunda variável aleatória $x$ é conhecida. 
Mais especificamente, quanto menor a entropia condicional de $Y$ dado $x$, melhor será a predição do comportamento de $Y$ observando a variável $x$ [Kelemen et al., 2008]. A entropia condicional é definida como:

$$
H(Y \mid x)=-\sum_{y \in Y} P(y \mid x) \log P(y \mid x) .
$$

A Figura 2.6 exibe dois histogramas, um para baixa entropia condicional e outro para alta entropia condicional de $Y$ dado que $x$ foi observado.

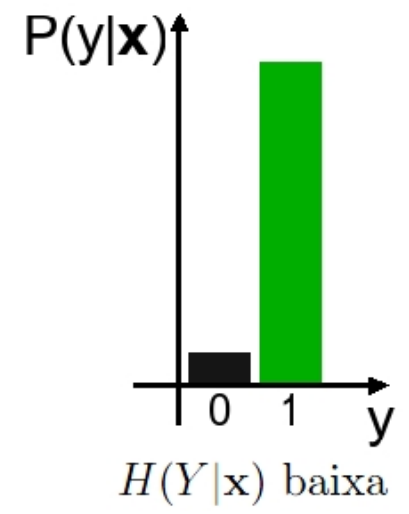

(a)

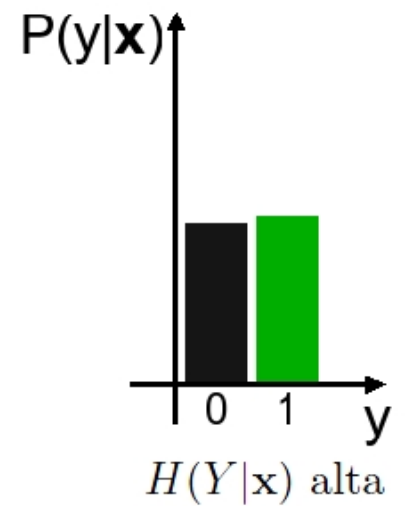

(b)

Figura 2.6: $O$ histograma (a) configura uma situação em que $Y$ é bem predito por $x$ porque a massa de probabilidades condicionais está concentrada em $Y=1$ (entropia condicional baixa). Já para o histograma (b), a massa de probabilidades está espalhada ao longo das classes, o que faz com que o padrão $x$ não seja um bom preditor do comportamento de $Y$ (entropia condicional alta) (figura adaptada de [Martins-Jr., 2008]).

A entropia condicional média [Martins-Jr., 2008] é definida como a média ponderada das entropias condicionais de todas as possíveis instâncias $x \in X$. Sua equação é dada por:

$$
H(Y \mid X)=\sum_{x \in X} P(x) H(Y \mid x)
$$

na qual $H(Y \mid x)$ é a entropia condicional dada pela Equação (2.11). Quanto menor o valor de $H(Y \mid X)$, maior será o ganho de informação sobre $Y$ pela observação de $X$.

A informação mútua pode ser entendida como uma medida de dependência entre duas variáveis [Gray, 1990, Kelemen et al., 2008]. Essa dependência é quantificada por meio do cálculo da quantidade média na incerteza entre uma variável $Y$ dado que a ocorrência de outra variável $X$ é conhecida, e vice-versa. A informação mútua também pode ser interpretada como uma medida da informação compartilhada entre duas variáveis aleatórias. Neste sentido, a informação mútua indica o erro de predição sobre os estados de $Y$ dado que os estados de $X$ foram observados. Dadas duas variáveis aleatórias $Y$ e $X$, sua informação mútua é definida em termos da entropia $H$. Sua equação é dada por:

$$
I(X, Y)=H(X)-H(X \mid Y)=H(Y)-H(Y \mid X) .
$$


A Figura 2.7 exibe as relações entre os conceitos apresentados nesta seção, de forma gráfica.

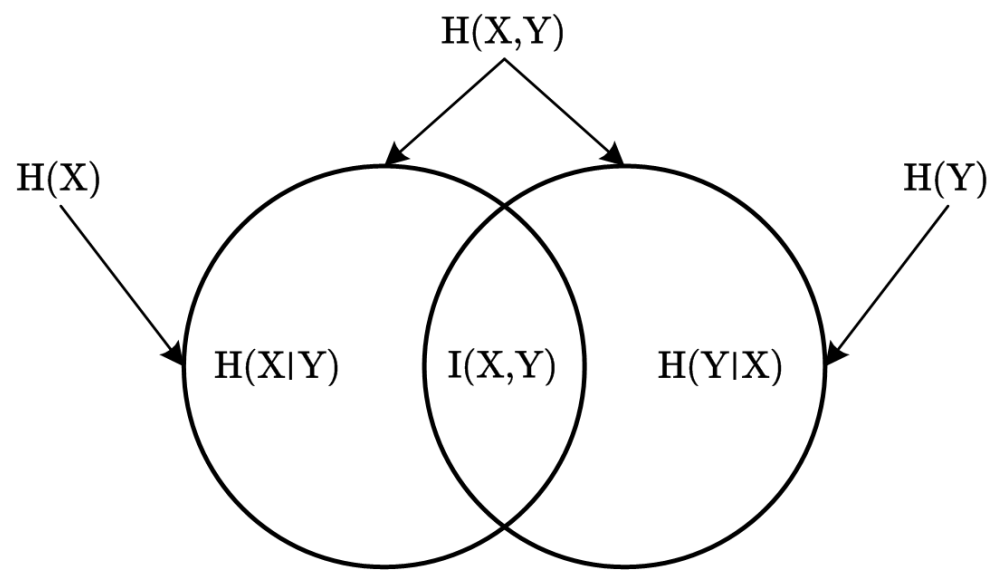

Figura 2.7: Diagrama de Venn com a representação das relações entre entropia, entropia condicional, entropia conjunta e informação mútua, considerando duas variáveis.

\subsubsection{Entropia Generalizada de Tsallis}

O conceito de entropia reflete a informação sobre um determinado sistema. Por muito tempo, acreditou-se que a entropia proposta por Boltzmann-Gibbs, dada pela Equação 2.7, teria que ser universal, i.e., independente do sistema. Porém, esta crença generalizada de universalidade da entropia parece não ter uma base rigorosa, não havendo nenhuma razão fundamental para que a mesma entropia deva ser usada universalmente [Tsallis and Brigatti, 2004].

Uma das propriedades do conceito de entropia proposto por Clausius é a extensividade, a qual pode ser interpretada como a entropia sendo proporcional ao número de elementos do sistema [Tsallis et al., 2005]. Em outras palavras, a entropia de Clausius depende do tamanho e extensão do sistema. A forma da entropia de Boltzmann-Gibbs (Equação 2.7), que constitui a base de sua mecânica estatística, é aditiva [Tsallis, 2009a], ou seja, em um sistema contendo dois elementos ou subsistemas $A$ e $B$, o valor de entropia para o sistema inteiro é igual a soma dos valores de entropia das partes deste sistema, i.e., $H(A+B)=H(A)+H(B)$. Essa aditividade na equação da entropia de Boltzman garante a sua extensividade.

No entanto, a entropia de Boltzman satisfaz a extensividade proposta por Clausius apenas sob certas condições. Uma condição conhecida é que seus elementos sejam probabilisticamente independentes ou apenas localmente correlacionados (semi-independentes), i.e., sistemas nos quais os elementos interagem por meio de interações de curto alcance [Abe, 2004, Tsallis et al., 2005]. Por outro lado, se as correlações entre os elementos são fortes ou globais, i.e., sistemas com interações de longo alcance, então a extensividade da entropia de Boltzman é perdida, se tornando incompatível com a termodinâmica clássica [Tsallis, 2009a, Tsallis, 2009b]. Assim, apesar da grande importância da entropia de Boltzmann, existem sistemas naturais, artificiais e sociais para os quais os conceitos estatísticos da entropia tradicional não parecem ser aplicáveis [Wilk and Wlodarczyk, 2008, Tsallis, 2009b].

Neste contexto, tentando superar essa dificuldade, foi proposta em 1988 por Constantino Tsallis uma forma de entropia que permite a generalização da mecânica estatística de Boltzman, se tornando conhecida como entropia generalizada de Tsallis ou apenas entropia de Tsallis [Tsallis, 1988], a qual ao longo de duas décadas, tem sido bem sucedida em apresentar propriedades desejadas da teoria da 
física estatística [Abe, 2004, Tsallis, 2004]. A mecânica estatística proposta por Tsallis é formalizada como segue:

$$
H_{q}=k \frac{\left(1-\sum_{i}^{w} p_{i}^{q}\right)}{q-1} \quad\left(q \in \mathbb{R}, H_{1}(X)=H(X)\right),
$$

na qual $k$ é uma constante positiva (que define a dimensão e a escala), $w$ é o número de configurações (valores) distintas do sistema, $p_{i}$ é a probabilidade da configuração $i$ e $q \in \mathbb{R}$ é o parâmetro entrópico.

Aplicando a notação apresentada na Seção 2.5, a equação pode ser reescrita como segue:

$$
H_{q}(X)=k \frac{\left(1-\sum_{x \in X} P(x)^{q}\right)}{q-1} \quad\left(q \in \mathbb{R}, H_{1}(X)=H(X)\right),
$$

na qual $x$ é um valor possível da variável aleatória $X, P(x)$ é a probabilidade de $x$ e $q \in \mathbb{R}$ é o parâmetro entrópico.

O parâmetro entrópico $q$ caracteriza o grau de não extensividade do sistema, o qual no limite $q \rightarrow 1$, recupera a entropia de Shannon. Logo, a forma entrópica de $H_{q}$ não é aditiva para qualquer $q \neq 1$, e a conexão entre o parâmetro entrópico $q$ e a não extensividade da entropia é dada pela regra [Tsallis, 2001]:

$$
H_{q}(A+B)=H_{q}(A)+H_{q}(B)+(1-q) \times H_{q}(A) \times H_{q}(B),
$$

na qual A e B são dois sistemas independentes, i.e., $P(A, B)=P(A) \times P(B)$. A partir da Equação 2.16 foi gerada a expressão "entropia não extensiva", na qual é possível observar algumas propriedades como a não negatividade $\left(H_{q} \geq 0\right)$, super aditividade (super-extensividade) para $q<1$, aditividade (extensividade) para $q=1$ e sub aditividade (sub-extensividade) para $q>1$.

A entropia de Tsallis (Equação 2.15) tem sido largamente aplicada em diferentes problemas ${ }^{1}$, apresentando uma boa concordância entre sua teoria e os dados experimentais. Alguns artigos têm sido publicados para verificar a fundamentação matemática da entropia de Tsallis, bem como investigar suas propriedades não extensivas e suas interpretações [Abe, 2004, Furuichi, 2006].

Ao definir $\ln _{q}(x) \equiv\left(x^{1-q}-1\right) /(1-q)$, a Equação 2.15 pode ser escrita de uma forma similar à entropia de Boltzmann, tal que $H_{q}=-k \sum_{i}^{w} p_{i}^{q} \ln _{q} p_{i}$. Desta forma, a informação mútua generalizada entre $X$ e $Y$ pode ser definida como [Borland et al., 1998]:

$$
I_{q}(X, Y)=\sum_{x \in X} \sum_{y \in Y} P(x, y) \ln _{q}\left(\frac{P(x, y)}{P(x) P(y)}\right) .
$$

A informação mútua generalizada possui as características necessárias para ser usada como uma função critério de forma consistente [Tsallis, 1998].

Para genes binários, $X \in\{0,1\}$, tem-se $H_{q}(X)=\left(1-\left[P(x=1)^{q}+(1-P(x=1))^{q}\right]\right) /(q-1)$. Nesta equação, a influência do parâmetro entrópico $q$ pode ser facilmente observada. Na Figura 2.8, o valor máximo da entropia para o gene aumenta à medida que o valor do parâmetro $q$ diminui, tomando o limite $H_{q}^{\max }=1$ quando $q \rightarrow 0$. De fato, quando $q \approx 0, H_{q}(X)$ será significativamente diferente de $H_{q}^{\max }$, o que significa um critério muito rígido, no sentido de que os candidatos a preditor devem cumprir todas as restrições impostas pelos dados ou eles não serão selecionadas como preditores. Por outro lado, quando $H_{q}^{\max } \rightarrow 0$ e $q \gg 1$, podendo ser interpretado como

\footnotetext{
${ }^{1}$ Veja http://www.cbpf.br/GrupPesq/StatisticalPhys/biblio.htm para uma ampla bibliografia.
} 
uma função critério muito flexível, no sentido de que qualquer gene ou grupo de genes pode ser selecionado como bons preditores.

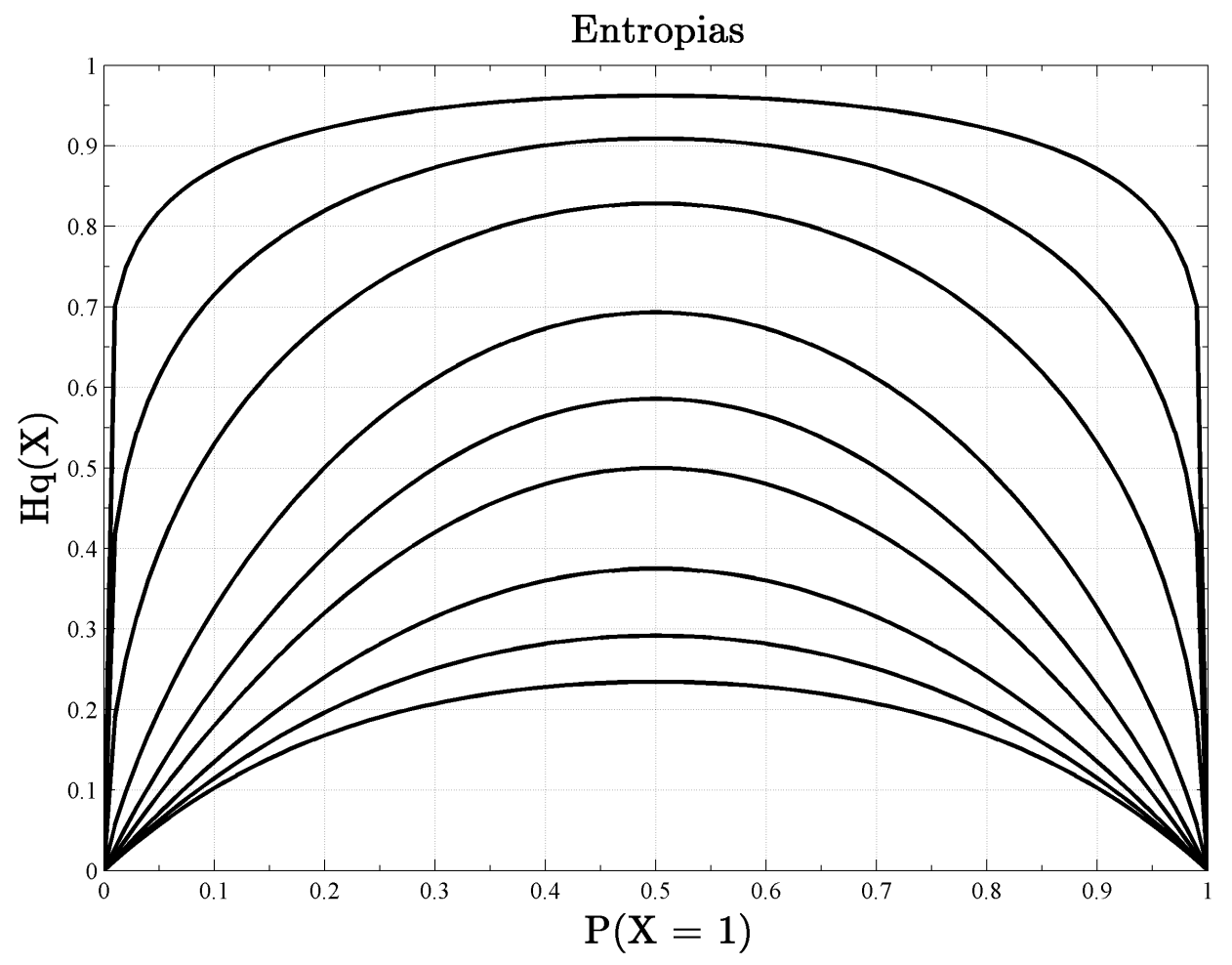

Figura 2.8: Entropia generalizada de Tsallis $H_{q}$ como uma função da probabilidade $P(x=1)$, considerando genes binários, $X \in\{0,1\}$. De cima para baixo, as curvas de entropia foram obtidas com o parâmetro entrópico q definido como: 0.1, 0.25, 0.5, 1.0, 1.5, 2.0, 3.0, 4.0, 5.0.

Outro ponto importante é a ordenação da entropia em relação à $P(x=1)$. Se a entropia de $P(x=1)=a$ é maior que a entropia de $P(x=1)=b$ para um dado $q^{*}$, então a entropia de $a$ será sempre maior que a entropia de $b$ para qualquer valor de $q$ - veja a Figura 2.8. No entanto, esta ordenação não é preservada na entropia condicional média. Para $H_{q}(Y \mid X)$, a entropia de $Y$ dado $X$ é ponderada pela probabilidade de $X$,

$$
H_{q}(Y \mid X)=\sum_{x \in X} P(x) \frac{\left(1-\sum_{y \in Y} P(y \mid x)^{q}\right)}{(q-1)},
$$

de tal forma que é possível ter $H_{q^{\prime}}^{a}(Y \mid X)>H_{q^{\prime}}^{b}(Y \mid X)$ e $H_{q^{\prime \prime}}^{a}(Y \mid X)<H_{q^{\prime \prime}}^{b}(Y \mid X)$ para algum $q^{\prime} \neq q^{\prime \prime}$. Esse resultado representa um trade-off entre a relevância da entropia condicional e a distribuição de probabilidade dos genes preditores.

No contexto de seleção de características ou testes de dependências entre variáveis, nos quais a entropia é usada como função critério, a não preservação da ordem entre os valores de entropias representa a existência de um $q^{*}$ ótimo, pelo qual um sistema pode ser melhor reproduzido. Como em problemas da física, a ocorrência de $q^{*}$ está relacionada com as propriedades do sistema [Tsallis et al., 2005]. Descobrir as leis, princípios ou características que conduzem à escolha de $q^{*}$ de acordo com as propriedades do sistema, pode contribuir para a descrição desse sistema e, em particular, pode levar a melhoria dos métodos de inferência de GRNs. 


\subsection{Inferência de Redes}

A combinação de análise de expressão, perturbações, tratamentos e mutações de genes podem indicar informações de efeitos moleculares ou funções específicas dos genes. Inferir redes de regulação gênica a partir de dados de expressão, processo também conhecido como engenharia reversa, não é uma tarefa computacional fácil devido ao enorme volume de dados (genes), e ao pequeno número de amostras (medidas) disponível, incluindo a alta complexidade das redes biológicas, representando um importante desafio na pesquisa em bioinformática e biologia computacional [Hovatta et al., 2005].

A inferência de GRNs a partir de dados temporais de expressão busca identificar a variação dos níveis de expressão ao longo do tempo, sendo possível indicar informações como: diferentes vias regulatórias, ciclo celular e mapeamento de alterações provocadas por estímulos, servindo como modelo para a representação funcional das interações gênicas.

É importante destacar que a inferência de GRNs tem o objetivo de encontrar redes de interação entre genes que sejam potencialmente interessantes sob o ponto de vista biológico a partir da observação de suas expressões. Desta forma, ela sugere os relacionamentos entre os genes de acordo com algum estimador para delimitar o número de interações, as quais podem ser examinadas em bancada. Como estes experimentos possuem um alto custo financeiro, humano e de tempo, a ideia é oferecer ao biólogo especialista a visualização de um conjunto reduzido de interligações entre os genes, na forma de uma GRN, na qual ele terá a oportunidade de gerar hipóteses de forma integrada sobre um determinado fenômeno de interesse [Martins-Jr., 2008].

Quanto à função critério, existem essencialmente três tipos frequentemente utilizados para a inferência de GRNs. O primeiro é a correlação de Pearson entre duas características, i.e., os genes, recebem uma ligação entre si caso a correlação entre seus perfis de expressão seja maior que um limiar [Stuart et al., 2003]. Métodos baseados em correlação consideram apenas relacionamentos 1-para-1, sendo adequados para identificar co-regulação ou co-expressão, módulos funcionais e agrupamentos entre os genes. Porém, é ignorado o fato de que a expressão de um determinado gene pode ser regulada por um grupo de genes de forma multivariada.

Outra classe de funções critério baseia-se na estimação do erro Bayesiano dos preditores ao classificar o perfil de expressão do gene alvo. Nesse contexto, um critério amplamente utilizado para inferir GRNs é o coeficiente de determinação (CoD, do inglês Coefficient of Determination) [Hashimoto et al., 2004, Dougherty et al., 2009, Ghaffari et al., 2010], no qual é possível estimar relacionamentos multivariados entre um grupo de preditores e o gene alvo, i.e., N-para-1.

As funções critério baseadas na teoria da informação (entropia e informação mútua, veja Seção 2.5) também são frequentemente aplicadas em métodos de inferência de GRNs. No entanto, as funções critério baseadas na teoria da informação são usadas na detecção tanto de relacionamentos 1-para-1, em substituição a correlação de Pearson, quanto em relacionamentos N-para-1 [Liang et al., 1998, Butte and Kohane, 2000,Steuer et al., 2002, Margolin et al., 2006, Faith et al., 2007, Rao et al., 2007, Barrera et al., 2007, Zhao et al., 2008], nos quais são consideradas a uniformidade das distribuições de probabilidade condicional de um gene alvo, dados os candidatos a preditores como um todo.

A diferença entre as medidas baseadas em entropia e as baseadas no erro de estimação Bayesiano é que a entropia tem por base a maximização das distribuições entre as classes de probabilidade condicional do gene alvo dado o subconjunto de preditores, i.e., distribuição mais concentrada 
condicionada a observação dos preditores. O que é equivalente à minimização do erro Bayesiano de classificação do gene alvo com base na observação de um subconjunto de preditores. Logo, a entropia depende da uniformidade dessas distribuições de probabilidade condicional como um todo (maior uniformidade leva a uma maior entropia, que por sua vez leva a uma menor informação mútua). Um trabalho recente mostra que o uso de funções critério baseadas na teoria da informação pode ser mais adequado que o CoD na inferência de GRNs [Martins-Jr et al., 2010].

A literatura relacionada à modelagem e inferência de GRNs é vasta e continua a crescer rapidamente, o que reflete a importância desta área de pesquisa. Algumas revisões sobre este tema podem ser encontradas nos trabalhos [D'haeseleer et al., 2000, de Jong, 2002, Styczynski and Stephanopoulos, 2005,Schllit and Brazma, 2007, Markowetz and Spang, 2007,Karlebach and Shamir, 2008, Hecker et al., 2009, Xiao, 2009, de Smet and Marchal, 2010, Marbach et al., 2010, Lu and Zhou, 2010], os quais apresentam as ideias centrais de métodos de inferência de GRNs e respectivas modelagens matemáticas adotadas.

A seguir são apresentados, de forma resumida, alguns métodos de inferência de redes, os quais utilizam medidas baseadas na teoria de informação (entropia ou informação mútua) para inferir interações regulatórias entre os genes de uma GRN a partir de dados de expressão gênica.

\subsubsection{REVEAL}

A estratégia adotada pelo algoritmo REVEAL(REVerse Engineering ALgorithm) [Liang et al., 1998, Kelemen et al., 2008] é inferir interações regulatórias entre genes a partir de medidas de informação mútua (Seção 2.5) de uma tabela de transição de estados como a apresentada na Figura 2.3(c) da Seção 2.3.2.

A tabela de transição de estados pode ser vista como dados temporais, na qual a entrada representa o instante de tempo $t$ e a saída o instante de tempo $t+1$. Desta forma, o algoritmo REVEAL estima o relacionamento entre os genes a partir da informação mútua das medidas temporais de expressão gênica, como por exemplo, microarrays temporais.

Dado um conjunto de expressões temporais, considere um gene alvo $Y$. A ideia do algoritmo REVEAL é fazer uma busca por outro gene ou subconjunto de genes $X$, tal que $I(X, Y)=H(Y)$, representando que $X$ determina completamente o comportamento de $Y$. Neste caso, uma aresta é adicionada na rede estimada. $\mathrm{O}$ tamanho máximo $k$ do subconjunto $X$ é um parâmetro deste método, representando que a busca por preditores será limitada a no máximo $k$ preditores por gene.

É possível observar que se $H(X)=H(Y, X)$, então $I(X, Y)=H(Y)$, não sendo necessário o cálculo da informação mútua $I(X, Y)$ de forma explícita, tornando a computação mais rápida [Liang et al., 1998]. Uma vantagem deste algoritmo é que redes pequenas podem ser rapidamente inferidas, apenas pela comparação das transições de estados entre os genes (alvo e preditores).

\subsubsection{ARACNE}

As abordagens baseadas em redes de relevância [Butte and Kohane, 2000] procuram por similaridade ou dissimilaridade entre pares de genes. São necessárias duas etapas para a inferência de redes: (1) todos os pares de genes são comparados usando alguma medida de similaridade ou dissimilaridade (em geral são adotadas medidas como coeficiente de correlação e informação mútua [Kelemen et al., 2008]); (2) o conjunto completo de comparações entre pares é filtrado para determinar as 
conexões relevantes, feito tipicamente pelo uso de um limiar. A seleção destas conexões relevantes representa a descoberta das arestas entre os genes na rede inferida.

ARACNE (Algorithm for the Reconstruction of Accurate Cellular NEtworks) [Margolin et al., 2006] é um algoritmo baseado nas redes de relevância, que utiliza a informação mútua para identificar as relações regulatórias entre os genes.

Após estimar os relacionamentos usando a informação mútua, o algoritmo ARACNE realiza um filtro para eliminar arestas da rede que representam relacionamentos indiretos entre os genes. Isto é realizado usando a desigualdade de tratamento de dados (data processing inequality), a qual determina que se três variáveis aleatórias $X, Y, Z$ dependem umas das outras de forma linear $X \rightarrow Y \rightarrow Z$, então a informação mútua $I(X, Z) \leq \min [I(X, Y), I(Y, Z)]$ [Kelemen et al., 2008].

Desta forma, cada tripla de genes é analisada com o objetivo de eliminar relacionamentos indiretos $X \rightarrow Z$. Os autores do algoritmo ARACNE argumentam que, ao final do processo de reconstrução da rede, os relacionamentos identificados tem alta probabilidade de representarem interações regulatórias diretas [Margolin et al., 2006].

\subsubsection{CLR}

O algoritmo CLR (Context Likelihood of Relatedness) [Faith et al., 2007] é baseado na abordagem de redes de relevância, associando as arestas entre dois genes $X_{i}$ e $X_{j}$ se alguma medida de similaridade for maior que um dado limiar.

Ao invés de considerar a informação mútua $I\left(X_{i}, X_{j}\right)$ diretamente, como no caso do ARACNE, este método calcula uma medida baseada na distribuição do valores de informação mútua. Esta medida é dada por $z_{i j}=\sqrt{z_{i}^{2}+z_{j}^{2}}$, na qual

$$
z_{i}=\max \left(0, \frac{I\left(X_{i}, X_{j}\right)-\mu_{i}}{\sigma_{i}}\right),
$$

sendo que $\mu_{i}$ é a média e $\sigma_{i}$ o desvio padrão da distribuição empírica dos valores de informação mútua $I\left(X_{i}, X_{j}\right), j=1,2, \ldots, n$.

O algoritmo CLR foi aplicado com sucesso na inferência da rede regulatória da E. coli [Faith et al., 2007].

\subsubsection{MRNET}

O método MRNET [Meyer et al., 2007] utiliza o método de seleção de características por máxima relevância / mínima redundância [Peng et al., 2005] para inferência de GRNs.

Para cada gene escolhido como alvo $Y$, é realizada uma busca para determinar a variável $X_{i}$ que tenha o maior valor de informação mútua com relação ao gene alvo $I\left(X_{i}, Y\right)$. O segundo gene escolhido $X_{j}$ será o que apresentar a maior informação mútua com relação ao gene alvo $I\left(X_{j}, Y\right)$ e ao mesmo tempo, a menor informação mútua com o gene já escolhido como preditor $I\left(X_{i}, X_{j}\right)$, gerando um conjunto de preditores $Z$. Nas etapas seguintes, este conjunto é atualizado pela inclusão de novos genes $X_{i}$ que maximizem a diferença $u_{i}-r_{i}$, sendo que $u_{i}$ representa a relevância, dada pela informação mútua $I\left(X_{i}, Y\right)$ e $r_{i}$ representa a redundância, dada por:

$$
r_{i}=\frac{1}{|Z|} \sum_{X_{j} \in Z} I\left(X_{i}, X_{j}\right),
$$


a qual estima uma medida de redundância entre $X_{i}$ e cada um dos elementos $X_{j} \in Z$ do conjunto de preditores já escolhidos para $Y$.

\subsubsection{SFFS-MCE}

No método SFFS-MCE (do inglês Sequential Forward Floating Selection - Mean Conditional Entropy) [Barrera et al., 2007,Lopes et al., 2008a] a inferência de redes é realizada considerando as interações regulatórias entre os genes representados por uma PGN, como descrito na Seção 2.3.5.

O processo de inferência é iniciado escolhendo um gene de interesse (alvo) $Y$. Uma busca é realizada com o objetivo de encontrar um subconjunto de genes preditores $\mathbf{X}$ que façam a melhor predição de $Y$ no próximo instante de tempo. Em outras palavras, os perfis temporais de expressão são usados para construir uma tabela de probabilidades condicionais das classes $Y$ dados os padrões $\mathbf{X}$ que minimizem a entropia condicional média $H(Y \mid \mathbf{X})$. As classes são definidas pelos valores assumidos pelo gene alvo $Y$ no instante de tempo $t+1$, enquanto os padrões são definidos pelos valores assumidos pelos preditores no tempo $t$.

Em geral, experimentos envolvendo expressões temporais possuem milhares de genes e apenas poucas observações ao longo do tempo. Em face desta grande limitação de dados, é adotada uma forma de penalização de instâncias não observadas no cálculo da entropia condicional média [Martins-Jr et al., 2006, Martins-Jr., 2008, Lopes et al., 2008c]. Instâncias não observadas correspondem a padrões gerados pelas combinações dos valores dos preditores que não aparecem no conjunto de dados de expressões.

A estas instâncias não observadas são atribuídos valores de entropia iguais a $H(Y)$. A penalização para as instâncias não observadas é parametrizada por $\alpha$, sendo este parâmetro somado com a frequência absoluta (número de ocorrências) de todas as instâncias. A entropia condicional média com este tipo de penalização é dada pela seguinte equação:

$$
H(Y \mid \mathbf{X})=\frac{1}{\alpha M+d}\left[\alpha(M-N) H(Y)+\sum_{i=1}^{N}\left(f_{i}+\alpha\right) H\left(Y \mid \mathbf{X}=\mathbf{x}_{\mathbf{i}}\right)\right]
$$

em que $M$ representa o número de possíveis padrões gerados pela combinação dos valores dos preditores no conjunto $\mathbf{X}, N$ é o número de padrões observados nos dados (o número de instâncias não observadas é dado por $M-N), f_{i}$ é a frequência absoluta de padrões observados $\mathbf{x}_{\mathbf{i}}$, e $d$ é o número de amostras temporais.

O espaço de busca em geral é muito grande e, desta forma, uma busca exaustiva pelos preditores de um gene alvo é impraticável. Neste método, é adotado o algoritmo de busca sequencial flutuante para frente (SFFS, veja Seção 2.4.2) [Pudil et al., 1994], aplicado para cada gene alvo, com o objetivo de encontrar o subconjunto de preditores $\mathbf{X}$ que minimize a entropia condicional média penalizada dada pela Equação (2.21). Os genes contidos nos subconjuntos são considerados como preditores do gene alvo, criando uma aresta direcional, saindo de cada preditor e chegando ao gene alvo, e desta forma recuperando a topologia da rede a partir dos dados temporais de expressão gênica.

\subsection{Genes de Predição Intrinsecamente Multivariada}

Devido ao efeito nesting (veja Seção 2.4), a busca pelo melhor subconjunto de preditores de um gene geralmente requer a investigação de todo o espaço possível de subconjuntos, i.e., uma busca 
exaustiva.

Um conjunto de características de um preditor é considerado de predição intrinsecamente multivariada em relação a um gene alvo, se o gene alvo tem seu comportamento predito fortemente por todo o conjunto de preditores, mas é mal predito por qualquer de seus subconjuntos próprios de preditores. Esse conceito foi introduzido em [Martins-Jr., 2008, Martins-Jr et al., 2008].

Formalmente, um conjunto de características $\mathbf{X}$ é de predição intrinsecamente multivariada para o gene alvo $Y$ com relação a $\lambda$ e $\delta$, para $0 \leq \lambda, \delta \leq 1$ e $\lambda<\delta$, se

$$
\max _{\mathbf{Z} \varsubsetneqq \mathbf{X}} \mathcal{F}_{Y}(\mathbf{Z}) \leq \lambda \wedge \mathcal{F}_{Y}(\mathbf{X}) \geq \delta
$$

na qual $\mathcal{F}$ é uma função critério que varia de 0 a 1 ( 0 significa a ausência de predição e 1 significa uma predição total) [Martins-Jr et al., 2008].

Geralmente, $\lambda$ tem um valor pequeno (geralmente menor que 0,2 ) e $\delta$ tem um valor alto (geralmente maior que 0,6$)$.

Para um par de preditores-alvo $(\mathbf{X}, Y)$, o maior $\delta$ para o qual a predição é intrinsecamente multivariada é $\delta=\mathcal{F}_{Y}(\mathbf{X})$. Neste sentido, é possível definir uma taxa ou pontuação de predição intrinsecamente multivariada, (IMP score, do inglês intrinsically multivariate prediction score) [Martins-Jr., 2008], por meio do valor máximo de $\delta-\lambda$. Assim, o IMP score é definido como segue:

$$
I_{Y}(\mathbf{X})=\mathcal{F}_{Y}(\mathbf{X})-\max _{\mathbf{Z} \varsubsetneqq \mathbf{X}} \mathcal{F}_{Y}(\mathbf{Z})
$$

O conceito de predição intrinsecamente multivariada está relacionado ao efeito nesting que ocorre quando um algoritmo guloso de seleção de características como o SFS ou outras heurísticas subótimas são aplicadas. Em seguida, é apresentado um exemplo que esclarece este conceito. Suponha duas variáveis Booleanas $X_{1}=x_{1} \in\{0,1\}, X_{2}=x_{2} \in\{0,1\}$, consideradas como preditores e uma outra variável Booleana $Y=y \in\{0,1\}$ considerada como alvo. Também suponha a distribuição de probabilidade conjunta entre os preditores $P\left(x_{1}, x_{2}, y\right) \forall\left\{x_{1}, x_{2}, y\right\} \in\{0,1\}^{3}$ apresentados na Tabela 2.2. Considere o coeficiente de determinação não-linear $(\mathrm{CoD})$ como função critério, o qual é definido como $C o D_{Y}(\mathbf{X})=\frac{\varepsilon_{Y}-\varepsilon_{Y}(\mathbf{X})}{\varepsilon_{Y}}$, sendo que $\varepsilon_{Y}$ é o erro obtido pela classificação de $Y$ na ausência de outras observações (erro a priori) e $\varepsilon_{Y}(\mathbf{X})$ é o erro obtido pela classificação de $Y$ baseado na observação do conjunto de características $\mathbf{X}$ [Dougherty et al., 2000].

Este par de preditores-alvo possui $\operatorname{CoD}_{Y}\left(X_{1}, X_{2}\right)=\frac{0.5-0.2}{0.5}=0.6$. Por outro lado, se forem considerados $X_{1}$ e $X_{2}$ individualmente, ambos $C o D_{Y}\left(X_{1}\right)$ e $C o D_{Y}\left(X_{2}\right)$ recebem zero, considerando que $P\left(X_{1}=x_{1}, Y=y\right)=P\left(X_{2}=x_{2}, Y=y\right)=0.25, \quad \forall x_{1} \in\{0,1\}, x_{2} \in\{0,1\}, y \in\{0,1\}$, o que implica $C o D_{Y}\left(X_{1}\right)=C o D_{Y}\left(X_{2}\right)=\frac{0.5-0.5}{0.5}=0$. Logo, o IMP score neste caso é $I_{Y}\left(X_{1}, X_{2}\right)=$ $0.6-0=0.6$, que é considerado alto $\left(X_{1}, X_{2}\right.$ e $Y$ formam um conjunto IMP).

É importante observar que neste exemplo, o gene alvo $Y$ é o resultado de uma função estocástica ou-exclusivo (XOR), i.e., $\operatorname{argmax}_{y \in Y} P\left(y \mid x_{1}, x_{2}\right)=0$ se $x_{1}=x_{2}$ ou $\operatorname{argmax}_{y \in Y} P\left(y \mid x_{1}, x_{2}\right)=1$ se $x_{1} \neq x_{2}$.

De acordo com [Martins-Jr et al., 2008], no caso de dois preditores binários, existem oito lógicas que podem produzir altos valores de IMP score: XOR, NXOR (XOR negado), AND, OR, NOR, NAND, $x_{1} \wedge \overline{x_{2}}$ e $x_{1} \vee \overline{x_{2}}$. No entanto, existem outras propriedades, além da lógica de predição, que podem gerar conjuntamente os conjuntos IMP: poder preditivo (definido como $1-\varepsilon_{Y}(\mathbf{X})$ ), covari- 
Tabela 2.2: Exemplo de uma distribuição de probabilidade conjunta entre o gene alvo $Y$ e os dois preditores $X_{1}$ e $X_{2}$ que formam um conjunto de predição intrinsecamente multivariada $\left(I_{Y}(\mathbf{X})=0.6\right.$, usando o CoD como função critério).

\begin{tabular}{|c|cccc|}
\hline$X_{1}=x_{1}$ & 0 & 0 & 1 & 1 \\
$X_{2}=x_{2}$ & 0 & 1 & 0 & 1 \\
\hline$P\left(X_{1}=x_{1}, X_{2}=x_{2}, Y=0\right)$ & 0.2 & 0.05 & 0.05 & 0.2 \\
$P\left(X_{1}=x_{1}, X_{2}=x_{2}, Y=1\right)$ & 0.05 & 0.2 & 0.2 & 0.05 \\
\hline
\end{tabular}

ância entre os preditores e distribuição de probabilidade de cada preditor isolado (probabilidades marginais).

Neste contexto, a natureza multivariada da relação entre as variáveis preditoras e as variáveis preditas, faz com que algoritmos computacionalmente eficientes de seleção de características, tais como o SFS e o SFFS, descartem características que realizam uma predição individual ruim sobre o alvo na composição de suas soluções iniciais. Dessa forma, pode ocorrer o efeito nesting, dado que uma característica inserida no subconjunto resposta pode não pertencer ao subconjunto ótimo inicial, e não removida. O fenômeno de predição intrinsecamente multivariada é uma das principais causas desse efeito [Martins-Jr., 2008], o que torna ainda mais desafiadora a inferência de GRNs. O conceito IMP é usado nas Seções 3.2.2 e 3.2.3.

\subsection{Redes Complexas}

O início da teoria dos grafos [Diestel, 2005] é atribuída a Leonard Euler que, em 1736, provou a inexistência de um caminho que passasse por todas as sete pontes de Königsberg apenas uma única vez. Este problema foi resolvido utilizando um grafo, no qual cada ponte foi representada por uma aresta e os vértices representavam as regiões de terra ligadas pelas pontes.

A teoria de redes complexas estende o formalismo da teoria dos grafos por acrescentar medidas e métodos fundamentados em propriedades reais de um sistema [Costa et al., 2007]. Esta extensão se concentra principalmente na interpretação de que o objetivo das redes é a representação de sistemas reais, por meio da análise de dados experimentais, considerando que as redes são dinâmicas, podendo modificar sua estrutura ao longo do tempo.

O primeiro modelo de redes complexas foi o de redes aleatórias, proposto por Paul Erdös e Alfréd Rényi em 1959 [Erdös and Rényi, 1959]. Desde então, outros modelos de redes complexas foram propostos para a representação de sistemas reais, com destaque para os modelos: mundo pequeno (small-world) [Watts and Strogatz, 1998], livre de escala (scale-free) [Barabási and Albert, 1999] e geográfico [Gastner and Newman, 2006].

Os modelos de redes complexas apresentam topologias distintas e propriedades bem definidas, as quais podem ser usadas para representar GRNs, bem como caracterizá-las em termos de medidas de redes complexas [Costa et al., 2007]. Desta forma, a teoria de redes complexas permite a caracterização, análise e representação dos mais variados sistemas complexos, como por exemplo sistemas biológicos [Kauffman, 1971,Kauffman, 1993, Jeong et al., 2000, Hartemink et al., 2001, Guelzim et al., 2002, Shen-Orr et al., 2002, Farkas et al., 2003, Albert, 2005, Costa et al., 2008, Narasimhan et al., 2009]. 
Uma rede complexa é representada por um grafo $G=(V, E)$ composto por um conjunto $V=\left\{v_{1}, v_{2}, \ldots, v_{n}\right\}$ de vértices (genes), conectados por um conjunto $E=\left\{e_{1}, e_{2}, \ldots, e_{m}\right\}$ de arestas [Costa et al., 2008]. Uma rede complexa possui um tamanho definido pelo número de vértices $n$ da rede e um grau médio $\langle k\rangle$ de arestas conectadas aos vértices.

A seguir, são apresentados os principais modelos de redes complexas e suas propriedades.

\subsubsection{Redes Aleatórias}

As redes aleatórias propostas por Erdös e Rényi em seu primeiro artigo [Erdös and Rényi, 1959] podem ser consideradas o modelo mais elementar de redes complexas. A arquitetura (topologia) ER baseia-se na ligação aleatória dos vértices considerando uma distribuição uniforme de probabilidade entre eles. Este modelo de geração de redes se inicia com $n$ vértices desconectados, e sua topologia é definida pela inclusão aleatória de $m$ arestas entre os vértices, evitando auto-relacionamentos e conexões múltiplas. O nome de rede aleatória se refere à natureza desordenada da organização das arestas entre os vértices.

Outro modelo similar de redes complexas aleatórias, conhecido como modelo de Erdös-Rényi (ER), define $n$ vértices e uma probabilidade $0<p<1$ de conectar cada par de vértices da rede.

No modelo ER, em redes grandes com tamanho $n \rightarrow \infty$, o número médio de conexões $\langle k\rangle$ (grau médio) para cada vértice é dado por $\langle k\rangle=p(n-1)$. Se for considerado o modelo anterior, o número médio de conexões passa a ser definido por $\langle k\rangle=\frac{2 m}{n}$ [Boccaletti et al., 2006].

A fim de construir redes ER e garantir graus médios $\langle k\rangle$ semelhantes entre os seus vértices, pode ser adotado uma probabilidade fixa $P$ de uma aresta ocorrer entre dois vértices $v_{i}$ e $v_{j}$, tal que:

$$
P\left(v_{i} \leftrightarrow v_{j}\right)=\frac{\langle k\rangle}{n-1}
$$

A distribuição do número de conexões por vértice $P(k)$ é bem aproximada por uma distribuição de Poisson [Costa et al., 2007], dada por:

$$
P(k)=\mathrm{e}^{-\langle k\rangle} \frac{\langle k\rangle^{k}}{k !}
$$

Neste sentido, as redes ER também são chamadas de Poisson random graphs [Boccaletti et al., 2006].

\subsubsection{Redes Small-World}

As redes small-world foram propostas por Watts e Strogatz em 1988 [Watts and Strogatz, 1998], tendo, por isso, recebido o nome de modelos de redes small-world de Watts-Strogatz (WS). Este modelo representa uma alternativa ao modelo aleatório, assumindo como hipótese que as redes biológicas, tecnológicas e sociais podem apresentar uma topologia que não é totalmente aleatória.

Este modelo foi chamado de small-world por analogia ao fenômeno small-world (mundo pequeno) [Milgram, 1967], no qual o pesquisador Stanley Milgram em 1967 descobriu que a distância média (medida em termos de conexões de conhecimento) entre duas pessoas nos Estados Unidos era próxima de seis. Esta descoberta ficou conhecida como seis graus de separação.

Com o objetivo de gerar um modelo que não fosse totalmente aleatório, foi considerada uma rede em forma de anel contendo $n$ vértices e $k$ arestas por vértice, ligadas aos seus vizinhos mais 
próximos. Após esta construção, cada aresta pode ser reconectada aleatoriamente entre os vértices com probabilidade $p$, permitindo que a rede seja ajustada entre uma rede regular $(p \approx 0)$ ou aleatória $(p \approx 1)$, e desta forma permitir a geração de uma topologia intermediária $0<p<1$.

As redes WS são caracterizadas a partir de duas medidas principais: o tamanho do caminho $L(p)$ e o coeficiente de agrupamento $C(p)$. $L(p)$ é definido como o número de arestas percorridas pelo caminho mais curto entre dois vértices, sendo calculada a média sobre todos os pares de vértices (propriedade global). $C(p)$ mede a conectividade de um vértice (propriedade local).

Em geral, as redes WS apresentam a propriedade small-world, sendo que a maioria dos vértices podem ser alcançados pelos demais vértices percorrendo um pequeno número de arestas. Outra propriedade das redes WS é a presença de um grande número de laços (loops) de tamanho três, ou seja, se um vértice $v_{i}$ esta conectado aos vértices $v_{j}$ e $v_{l}$, então a probabilidade dos vértices $v_{j}$ e $v_{l}$ estarem conectados é alta (o coeficiente de agrupamento é alto) [Costa et al., 2007]. As redes ER têm a propriedade de mundo pequeno, mas um baixo coeficiente de agrupamento.

Foi observado no trabalho de Watts-Strogatz que a rede de neurônios da Caenorhabditis elegans e a rede de distribuição de energia dos Estados Unidos podem ser caracterizadas como redes smallworld [Watts and Strogatz, 1998].

\subsubsection{Redes Scale-Free}

Os modelos ER e WS apresentam um padrão de conexões aleatórias contendo um número de conexões $k$ similar entre seus vértices. Barabási e Albert [Barabási and Albert, 1999], procurando entender a dinâmica e a estabilidade topológica de grandes redes reais, perceberam que independentemente do sistema analisado, a probabilidade $P(k)$ de um vértice da rede interagir com $k$ outros vértices decai como uma lei de potência, na forma:

$$
P(k) \sim k^{-\gamma}
$$

na qual o parâmetro $\gamma$ é uma constante que determina o decaimento exponencial, o qual pode ser observado na Figura 2.9.

As redes scale-free (livres de escala) não apresentam uma distribuição homogênea de conexões $k$ entre seus vértices, apresentando poucos vértices altamente conectados a outros vértices da rede, e um grande número de vértices com poucas conexões [Costa et al., 2007]. Estes vértices altamente conectados são chamados de hubs.

O modelo de redes proposto por Barabási e Albert [Barabási and Albert, 1999] (BA), é baseado em duas regras: crescimento e preferência linear de ligação. A geração de redes BA é iniciada com a inclusão de $n_{0}<n$ vértices conectados aleatoriamente, em geral usando o modelo ER.

$\mathrm{Na}$ etapa de crescimento da rede, a cada instante de tempo $t=1,2,3, \ldots, n-n_{0}$ um novo vértice $v_{i}$ contendo $\langle k\rangle \leq n_{0}$ arestas é adicionado na rede, seguindo uma preferência linear de ligação. Ou seja, a probabilidade de um vértice $v_{j}$ já existente na rede ser conectado ao novo vértice $v_{i}$, é linearmente proporcional ao grau $k_{j}$ do vértice $v_{j}$, tal que:

$$
P\left(v_{i} \leftrightarrow v_{j}\right)=\frac{k_{j}}{\sum_{u} k_{u}}, \forall v_{u} \in V
$$

Dado que todo novo vértice possui $\langle k\rangle$ arestas, a rede no tempo $t$ terá $n=n_{0}+t$ vértices e 


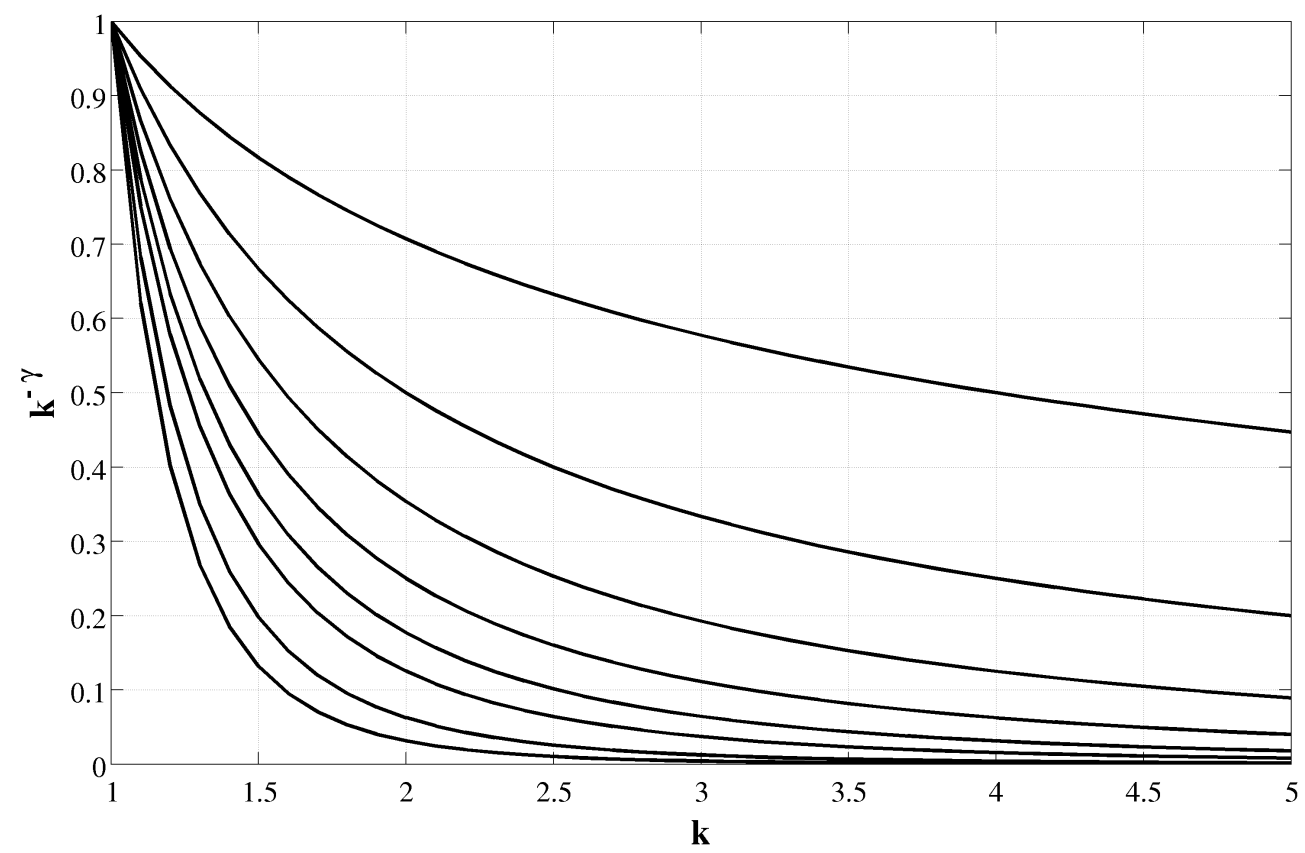

Figura 2.9: Lei de potência em função do número de conexões $k$. De cima para baixo, as curvas de lei de potência foram obtidas com o parâmetro $\gamma$ definido como: $0,5,1,1,5,2,2,5,3,4,5$.

$m=k t$ arestas, correspondendo a uma conexão média $\langle k\rangle=2 k$, considerando um grafo com arestas não direcionais. A preferência de ligação pelos vértices mais conectados também é conhecida como paradigma o rico fica mais rico [Costa et al., 2007].

O modelo de redes scale-free e suas propriedades têm sido utilizado para simular e descrever o comportamento das GRNs [Jeong et al., 2000, Guelzim et al., 2002, Farkas et al., 2003, Barabási and Oltvai, 2004, Albert, 2005, Costa et al., 2008, Barabási, 2009]. Em geral, muitas redes, tais como a Internet, redes de colaboração humana e redes metabólicas, seguem uma estrutura scalefree [Albert, 2005]. Em particular, muitas das redes biológicas conhecidas apresentam uma estrutura scale-free [Costa et al., 2008], implicando que a distribuição das relações entre os genes ( $k$, grau) é irregular. Por exemplo, o trabalho de Stuart et al [Stuart et al., 2003] mostra que redes gênicas de co-expressão de seres humanos, moscas, vermes e levedura possuem propriedades scale-free. Redes biológicas como a rede metabólica, redes de transcrição gênica de eucariotos e procariotos e redes de interação entre proteínas em leveduras exibem uma distribuição dos graus dos vértices próxima a scale-free [Albert, 2005].

\subsubsection{Redes Geográficas}

A posição espacial dos vértices em uma rede complexa em geral não é considerada por não ter um significado específico. No entanto, existem muitas redes reais em que a posição dos vértices é particularmente importante na rede a que pertencem. Este tipo de redes são chamadas geográficas ou redes espaciais [Gastner and Newman, 2006, Costa et al., 2007].

O modelo de redes geográficas pode ser criado a partir da distribuição aleatória de seus $n$ vértices em um espaço bi-dimensional. Cada par de vértices $v_{i}, v_{j}$ que tenham uma distância geográfica $a_{i j}<A$ entre si, recebem uma aresta, i.e., $v_{i} \leftrightarrow v_{j}$. O valor do parâmetro $A$ é escolhido com objetivo de produzir um grau médio $\langle k\rangle$, que pode ser conseguido da seguinte forma: considerando um espaço bi-dimensional com uma determinada largura e altura, o número de vértices $n$, a densidade espacial 
de pontos é dada por $a=\frac{n}{\text { largura } \times \text { altura }}$. Dentro de um círculo de raio $r$, centrado no vértice $v_{i}$, existem $\pi \times r^{2}$ pontos. Logo, o número médio de vértices dentro deste círculo é dado por $\langle k\rangle=\pi \times r^{2} \times a$. Considerando a distância Euclidiana [Webb, 2002], adotada neste trabalho, a distância é igual ao raio do círculo, tal que:

$$
A=r=\sqrt{\frac{\langle k\rangle}{(\pi \times a)}} .
$$

Este modelo gera uma distribuição de Poisson para o grau dos vértices, como observado nas redes aleatórias [Costa et al., 2007].

As redes geográficas podem ser usadas para representar muitos sistemas reais, tais como aeroportos, rodovias, redes de transmissão elétrica, internet, entre outras. Em particular, também podem ser usadas para representar sistemas biológicos que precisam de uma organização espacial em sua estrutura para seu correto desenvolvimento e função biológica, como por exemplo a distribuição de fotorreceptores na retina, estrutura do rim, comunicação celular, redes neurais, entre outros [Carroll et al., 2004]. 


\section{Capítulo 3}

\section{Materiais e Métodos}

Métodos computacionais têm sido extensivamente utilizados para análise e interpretação do enorme volume de dados biológicos gerados por técnicas como os DNA microarrays. Em particular, identificar redes de regulação gênica (GRNs), a partir de dados de expressão, representa um grande desafio na pesquisa em bioinformática. Vários métodos computacionais já foram propostos para esta tarefa [Liang et al., 1998, Weaver et al., 1999, D'haeseleer et al., 2000, Soinov et al., 2003, Zhou et al., 2004, Margolin et al., 2006, Barrera et al., 2007, Meyer et al., 2007, Faith et al., 2007, Lopes et al., 2008a, Meyer et al., 2008, Zhao et al., 2008]. No entanto, a análise das GRNs identificadas por métodos computacionais geram várias questões como: a estrutura (topologia) global está correta? Todas as dependências entre os genes foram encontradas? Existem falsos positivos? As estruturas locais foram encontradas?

Neste sentido, um problema crítico é a validação de tais métodos com relação à sua capacidade de recuperar a estrutura original, bem como a sua robustez em relação ao ruído, perturbações e falta de dados, os quais representam situações comuns em se tratando de dados reais.

Este trabalho aborda estas questões propondo o desenvolvimento de uma nova abordagem que envolve essencialmente três etapas: (1) geração de redes gênicas artificiais (AGNs), baseadas em modelos teóricos de redes complexas, as quais são usadas para gerar dados temporais de expressão simulados; (2) aplicação de métodos de inferência de redes; e (3) validação das redes inferidas observando a estrutura original (AGN). O modelo proposto, gerado por estas etapas, é descrito na Seção 3.1, na qual também são apresentadas as etapas e como elas estão integradas para atingir os objetivos apresentados.

Outro objetivo deste trabalho foi o desenvolvimento de novas abordagens para a inferência de GRNs, as quais são apresentadas na Seção 3.2. As metodologias desenvolvidas para a inferência de GRNs estão no contexto de seleção de características (veja Seção 2.4), envolvendo uma função critério, baseada na entropia generalizada de Tsallis (veja Seção 2.5.1) e dois novos algoritmos de busca, os quais são baseados no algoritmo SFFS (veja Seção 2.4.2) com a inclusão de informações a priori para guiar o processo de busca, de forma que ela ocorra de forma mais eficiente.

Este capítulo é finalizado pela Seção $3.4 \mathrm{com}$ a aplicação das metodologias desenvolvidas em dados biológicos, usando a Arabidopsis thaliana como planta modelo. 


\subsection{Síntese: Modelo Conceitual de Redes Gênicas Artificiais (AGNs)}

Esta seção define o modelo conceitual proposto para gerar redes gênicas artificiais (AGNs) [Lopes et al., 2011a]. No contexto deste trabalho, uma rede gênica artificial (AGN) é um grafo dirigido, no qual os vértices representam genes e suas arestas são relações de dependência entre os genes ligados, ou seja, uma ligação direcional de dependência. Essas dependências podem ser representadas de forma determinística ou probabilística. Dessa forma, as arestas de uma AGN permitem expressar as relações de dependência de forma direta, de modo que a topologia resultante represente essas relações de forma explícita. Por esta razão, os grafos tornaram-se a metáfora mais comum para representar dependências conceituais [Pearl, 1988].

Mais formalmente, uma AGN é uma tupla $G=(V, E, S, \Psi)$, na qual $V=\left\{v_{1}, v_{2}, \ldots, v_{n}\right\}$ representa um conjunto de $n$ vértices ou "genes", conectados por um conjunto $E=\left\{e_{1}, e_{2}, \ldots, e_{m}\right\}$ de $m$ arestas, no qual cada aresta $e_{l}=(i, j)$ é um par ordenado de vértices em $G$ do $v_{i}$ ao vértice $v_{j}$, ou seja, $v_{i} \rightarrow v_{j}$. Cada um dos vértices (genes) de uma AGN pode assumir um valor numérico de um conjunto discreto $D \subset \mathbb{Z}$, tal que $v_{i} \in D, \forall i=1,2, \ldots, n$, o qual representa o nível de expressão (estado) desses genes. Os dois componentes (vértices e arestas) definem a topologia da rede, sendo que as arestas incidentes a um gene alvo definem quais genes (preditores ou regulatórios) influenciam diretamente o seu comportamento.

O conjunto de estados de uma AGN é definido por $S=\left\{\overrightarrow{s_{1}}, \overrightarrow{s_{2}}, \ldots, \overrightarrow{s_{z}}\right\}$, no qual o número de estados possíveis é definido por $z=|D|^{n}$. Cada elemento $v_{i}$ representa o estado (nível de expressão) do gene $i$, e o estado da rede $\overrightarrow{s_{j}}$ é determinado pela configuração dos valores (estados) de todos os genes. O conjunto $\Psi=\left\{\psi_{1}, \psi_{2}, \ldots, \psi_{n}\right\}$ define as $n$ funções de transição, uma para cada gene, as quais são aplicadas a um dado estado inicial $\overrightarrow{s_{j}}$ com o objetivo de gerar a dinâmica de uma AGN. Em outras palavras, dado um estado inicial arbitrário para uma rede $\overrightarrow{s_{j}}$ em um instante de tempo $t$, as funções de transição são aplicadas para gerar o estado da rede $\overrightarrow{s_{u}}$ no tempo $t+1$, tal que $\overrightarrow{s_{u}}(t+1)=\Psi\left(\overrightarrow{s_{j}}(t)\right), \overrightarrow{s_{u}}, \overrightarrow{s_{j}} \in S, \forall t=1,2, \ldots, T$, sendo $T$ o número de instantes de tempo, i.e., o tamanho do sinal de expressão.

As próximas subseções apresentam detalhes de implementação deste modelo conceitual.

\subsubsection{Topologias das AGNs}

Os modelos teóricos de redes complexas apresentam topologias distintas, cada qual com propriedades bem definidas. Os modelos de redes podem ser efetivamente usados para simular o comportamento das GRNs, como sugerido nos trabalhos [Guelzim et al., 2002, Farkas et al., 2003, Albert, 2005, Costa et al., 2008, Narasimhan et al., 2009], bem como caracterizá-las em termos de medidas da teoria de redes complexas [Boccaletti et al., 2006, Costa et al., 2007].

Alguns dos mais importantes modelos teóricos de redes complexas (veja Seção 2.8), a saber: redes aleatórias (uniformly-random) de Erdös-Rényi (ER) [Erdös and Rényi, 1959], mundo pequeno (small-world) de Watts-Strogatz (WS) [Watts and Strogatz, 1998], livre de escala (scale-free) de Barabási-Albert (BA) [Barabási and Albert, 1999] e geográfico (geographical networks) de GastnerNewman (GN) [Gastner and Newman, 2006], foram adotadas neste trabalho com objetivo de especificar as topologias das AGNs.

Neste trabalho, uma rede complexa é um grafo representado por um par ordenado $G=(V, E)$ formado por um conjunto de $n$ vértices $V=\left\{v_{1}, v_{2}, \ldots, v_{n}\right\}$ (genes), conectados por um conjunto 
de arestas $E=\left\{e_{1}, e_{2}, \ldots, e_{m}\right\}$ [Costa et al., 2008]. Foi adotado o modelo de grafos dirigidos (dígrafo), no qual cada aresta $e_{l}=\left(v_{i}, v_{j}\right)$ sai do vértice $v_{i}$, chamado origem, e chega ao vértice $v_{j}$, chamado destino [Shmulevich and Dougherty, 2007]. Redes complexas podem ser representadas por sua matriz de adjacência $M$, tal que cada aresta $e_{l}=\left(v_{i}, v_{j}\right)$ implica $M(i, j)=1, \operatorname{com} M(i, j)=0$ caso contrário, como apresentado na Seção 2.3.1.

Os modelos de redes complexas ER, WS, BA e GN adotados neste trabalho são grafos dirigidos (dígrafos) construídos considerando-se dois parâmetros: o tamanho da rede $n$ (o número de vértices ou "genes") e um grau médio $\langle k\rangle$ de arestas por vértice. É importante manter estes parâmetros fixos durante uma análise comparativa, de forma que seus resultados possam ser comparados.

Em geral, os modelos de redes complexas são definidos como redes não direcionais, como os apresentados na Seção 2.8, nos quais a matriz de adjacências é simétrica. Em outras palavras, para cada vértice $v_{i}$ com uma aresta até $v_{j}$, existe também uma aresta $v_{j} \rightarrow v_{i}$. Como resultado, o grau médio de conexões entre seus elementos é $2 k$. A fim de quebrar a simetria entre os vértices da rede, foi adotada a seguinte estratégia: após gerar uma rede usando um dos modelos de redes complexas ER, WS, BA ou GN, como apresentado na Seção 2.8 , cada posição $(i, j)$ de sua matriz de adjacências $M$ é visitada. Para cada posição contendo uma aresta $M(i, j)=1$, a aresta correspondente é removida com uma probabilidade de 50\%. Esse procedimento representa uma forma simples de produzir redes com arestas dirigidas mantendo seu tamanho $n$ e grau médio $\langle k\rangle$ de arestas por vértice (gene), no qual o grau médio representa tanto o grau de entrada quanto o grau de saída dos genes dessa rede.

O uso de modelos de redes complexas, além de permitir a validação dos métodos de inferência de redes, também torna possível investigar como diferentes tipos de dados, amostragem, ruído ou pré-processamento afetam o processo de inferência.

A seção seguinte apresenta como a topologia, obtida a partir dos modelos de redes complexas (ER, WS, BA e GN), pode ser usada para gerar a dinâmica de uma AGN.

\subsubsection{Funções de Transição}

Nesta proposta, uma AGN é uma rede complexa com $n$ genes, os quais assumem um valor de um conjunto de valores discretos $D=\{0,1\}$, ou seja, ligado/desligado (on/off), que representam seus estados. As funções de transição são definidas por um conjunto de funções Booleanas ou circuitos lógicos, um para cada gene, também conhecidas como função de transição Booleana [D'haeseleer et al., 2000], como definido na Seção 2.3.2.

Cada circuito lógico define a dinâmica de um gene da rede, representado como $v_{i}(t+1)=$ $\psi_{i}\left(v_{1 i}(t), v_{2 i}(t), \ldots, v_{k i}(t)\right)$, no qual $v_{1 i}, v_{2 i}, \ldots, v_{k i}$ correspondem aos $k$ genes (preditores ou regulatórios) que enviam arestas ao gene $v_{i}$ (alvo). As arestas de entrada são consequência da topologia de rede escolhida. A dinâmica é definida considerando o modelo de redes Booleanas probabilísticas (PBN) [Shmulevich et al., 2002a, Shmulevich et al., 2002b], no qual cada gene $v_{i}$ pode possuir mais de uma função Booleana, tal que $\psi_{i}=\left\{f_{j}^{(i)}\right\}, j=1, \ldots, l(i)$, sendo que $f_{j}^{(i)}$ é uma possível função que determina o valor do gene $v_{i}$ e $l(i)$ é o número total de funções possíveis para o gene $v_{i}$. Logo, há uma probabilidade $c_{j}^{(i)}$ de que a função $f_{j}^{(i)}$ seja usada para predizer o gene $v_{i},(1 \leq j \leq l(i))$. As redes permanecem fixas na escolha dos $k$ vértices de entrada (preditores). A função de transição Booleana $\psi_{i}$ que define a dinâmica de cada gene alvo $v_{i}$, i.e., uma possível função Booleana $f_{j}^{(i)}$, é escolhida aleatoriamente em cada instante de tempo $t$, de acordo com sua probabilidade $c_{j}^{(i)}$.

Logo, nesta proposta, a dinâmica é definida de forma probabilística, na qual as redes permanecem 
fixas na escolha dos $v_{1 i}, v_{2 i}, \ldots, v_{k i}$ vértices incidentes a um gene $v_{i}$ e a escolha das suas funções de transição $\psi_{i}$ é realizada de forma probabilística, ou seja, o circuito lógico escolhido pode ser alterado a cada instante de tempo. No entanto, assume-se que uma rede deve apresentar uma maior massa de probabilidades em uma de suas funções, como proposto em [Barrera et al., 2007] (Seção 2.3.5). Dessa forma, a regulação gênica é tratada como um sistema aberto, o qual pode receber estímulos externos. Dependendo das condições externas em um dado instante de tempo, a regulação gênica pode alterar sua dinâmica [Shmulevich and Dougherty, 2007].

A Figura 3.1 exibe um exemplo de um circuito Booleano representado como um circuito lógico (a) e como uma tabela de regras (b). A tabela de regras mostra todas as combinações dos valores (estados) dos preditores no tempo $t$ (entrada), e o respectivo estado assumido pelo gene alvo no tempo $t+1$ (saída).

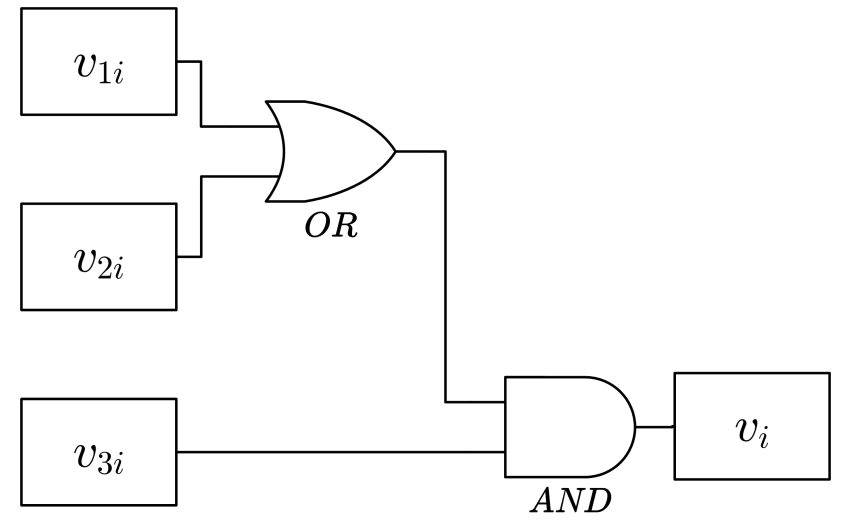

(a)

\begin{tabular}{ccc|c} 
& $\mathrm{t}$ & $\mathrm{t}+1$ \\
$v_{1 i}$ & $v_{2 i}$ & $v_{3 i}$ & $v_{i}$ \\
\hline 0 & 0 & 0 & 0 \\
0 & 0 & 1 & 0 \\
0 & 1 & 0 & 0 \\
0 & 1 & 1 & 1 \\
1 & 0 & 0 & 0 \\
1 & 0 & 1 & 1 \\
1 & 1 & 0 & 0 \\
1 & 1 & 1 & 1
\end{tabular}

(b)

Figura 3.1: Exemplo de uma função de transição Booleana representada como um circuito lógico (a) e como uma tabela de regras (b), as quais definem a dinâmica dos sinais de expressão de um gene alvo $v_{i}$ no instante de tempo $t+1$ baseando-se nos valores de seus preditores $v_{1 i}(t), v_{2 i}(t), \ldots, v_{k i}(t),(k=3)$ no instante de tempo $t$.

Cada função de transição Booleana $\psi_{i}, i=1, \ldots, n$ é criada a partir de funções Booleanas escolhidas aleatoriamente de um conjunto discreto $F$. Existem $2^{2^{k}}$ funções Booleanas possíveis, i.e., se um gene alvo possui dois preditores, existem $2^{2^{2}}=16$ funções Booleanas possíveis que podem ser usadas para representar sua dependência funcional com os genes preditores. Por outro lado, existem funções Booleanas que não dependem de um ou mais preditores, tais como a contradição (sempre falsa) e a tautologia (sempre verdadeira), para citar apenas duas.

O circuito lógico $\psi_{i}\left(v_{1 i}(t), v_{2 i}(t), \ldots, v_{k i}(t)\right)$ é aleatoriamente escolhido de um conjunto discreto $F$. São propostos dois conjuntos: (1) usando apenas seis funções Booleanas $F=\{N O T, A N D$, OR, NAND, NOR, XOR\}; (2) usando todas as funções Booleanas possíveis $2^{2^{k}}$. Esta divisão tem por objetivo disponibilizar esta opção para a análise da influência desta escolha na recuperação de redes por métodos computacionais, uma vez que os métodos computacionais só podem detectar preditores que realmente participam da geração do sinal [Liang et al., 1998]. Em particular, todos os resultados apresentados no Capítulo 4 foram gerados a partir do uso do grupo reduzido de funções Booleanas (1). 


\subsubsection{Simulação de Perfis Temporais de Expressão Gênica}

Uma vez definida a topologia da rede e as funções de transição para uma AGN, é possível simular sinais temporais de expressão aplicando as funções de transição. Neste trabalho, a dinâmica de uma AGN é dada por um sistema dinâmico finito (Seção 2.3.5), discreto no tempo e finito nos seus estados, dado por:

$$
\vec{s}(t+1)=\Psi(\vec{s}(t))
$$

na qual $s(t) \in D^{n}, \forall t \geq 0$.

A dinâmica é determinada por três elementos:

(a) um estado inicial arbitrário $\vec{s}(t)=\left(v_{1}, v_{2}, \ldots, v_{n}\right), v_{i} \in\{0,1\} \forall i=1,2, \ldots, n$, no instante de tempo $t$;

(b) as funções de transição $\Psi$;

(c) o número de instantes de tempo $T$ (tamanho do sinal), tal que $\overrightarrow{s_{u}}(t+1)=\Psi\left(\overrightarrow{s_{j}}(t)\right), \overrightarrow{s_{u}}, \overrightarrow{s_{j}} \in$ $S, \forall t=1,2, \ldots, T$.

Esta estrutura e os parâmetros definem a geração dos dados temporais de expressão simulados de uma AGN, e consequentemente a trajetória percorrida em seu espaço de estados. A Figura 3.2 exibe um exemplo de diagrama de estados de uma AGN.

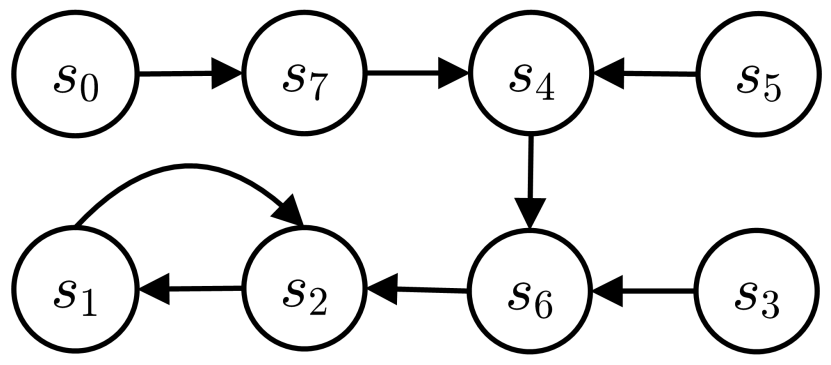

Figura 3.2: Exemplo de diagrama de estados de uma AGN. Cada vértice representa um estado da rede.

Como apresentado na Seção 2.3.2, uma trajetória é o caminho percorrido por uma rede em seu espaço de estados, dado um estado de inicialização. O espaço de estados de uma AGN pode ser muito grande, mas ele é finito e definido por $S=\left\{\overrightarrow{s_{1}}, \overrightarrow{s_{2}}, \ldots, \overrightarrow{s_{z}}\right\}, z=2^{n}$. A Figura 3.2 exibe um exemplo de um grafo de transições de estado para uma AGN com três genes, i.e., $n=3$. Um exemplo de trajetória é o caminho formado pelos estados $S_{5}, S_{4}, S_{6}, S_{2}, S_{1}$.

Em resumo, a dinâmica de uma AGN é modelada pela aplicação das funções de transição Booleanas de forma probabilística, considerando um dado estado inicial no instante de tempo $t_{0}$ e o número de instantes de tempo $T$ (número de expressões temporais desejado). O estado do gene alvo no instante de tempo $t_{i+1}, i=0,1, \ldots, T-1$ é obtido observando os valores de seus preditores no instante de tempo $t_{i}$ e aplicando-se as respectivas funções de transição Booleanas, tal que $v_{i}(t+1)=\psi_{i}\left(v_{1 i}(t), v_{2 i}(t), \ldots, v_{k i}(t)\right)$, a qual é escolhida aleatoriamente dentre suas possíveis funções booleanas, observando sua respectiva probabilidade.

Como resultado, tem-se os dados temporais simulados ao longo de $T$ instantes de tempo (tamanho do sinal), que pode ser usado no processo de identificação da rede, apresentado na seção seguinte. 


\subsection{Identificação: Inferência de Redes}

O método de identificação de redes adotado neste trabalho é baseado nos níveis de expressão apresentados pelos genes, os quais são observados ao longo do tempo, gerando uma série temporal. Essa série temporal é submetida ao método de inferência (reconhecimento estatístico de padrões) para identificação das atividades gênicas que apresentem padrões similares em termos de alguma medida. Neste trabalho, a entropia é explorada para esta finalidade.

Em geral, não é possível recuperar as redes gênicas com muita precisão. As principais razões para isso são a falta de informação sobre o organismo biológico, a alta complexidade das redes, o ruído intrínseco das medidas de expressão gênica e também a típica falta de dados: alta dimensionalidade de variáveis (genes) com pequeno número de amostras (experimentos). Dessa forma, não é objetivo deste trabalho analisar e construir um modelo bioquímico detalhado de cada gene envolvido, determinando todas as suas ligações e reações. O objetivo consiste em desenvolver uma metodologia para análise das ligações dos genes de uma forma global e simplificada, identificando as ligações e reações mais marcantes.

Neste contexto, existem várias iniciativas recentes para tentar superar essas limitações, por meio da inclusão de outras informações, além dos dados de expressão nas metodologias de inferência. Um tipo de iniciativa é a utilização de informações biológicas conhecidas, e.g., a partir de bancos de dados públicos como Gene Ontology [Ashburner et al., 2000], GenBank [Benson et al., 2008], KEGG [Kanehisa and Goto, 2000], entre outros. Em geral, estas informações biológicas são usadas em métodos de agrupamentos (clustering), o que resulta em agrupamentos mais significativos do ponto de vista biológico [Macintyre et al., 2010, Cui et al., 2010, De Haan et al., 2010]. Outra iniciativa é utilizar a informação biológica para a descoberta de relações na regulação da transcrição, i.e., inferir GRNs [Werhli and Husmeier, 2008, Ernst et al., 2008, Seok et al., 2010]. Uma variedade de técnicas de integração de dados biológicos para a inferência GRNs são descritos nos trabalhos [Troyanskaya, 2005, Karlebach and Shamir, 2008, Baumbach et al., 2009, Hecker et al., 2009].

Apesar da integração entre informações biológicas e modelos matemáticos ser extremamente importante na descoberta de novos conhecimentos biológicos, ela é limitada pela informação biológica prévia de cada gene ou entidade biológica envolvida. Uma maneira para continuar usando informações a priori nos métodos de inferência e torná-los menos restritivos é aplicar uma classe de informação, em vez de uma única informação, i.e., o uso de informações locais ou globais como conhecimento a priori sobre um organismo, em vez de uma informação sobre um único gene, e.g., utilizar a estrutura de rede (topologia) como uma informação a priori.

Neste sentido, o uso integrado de vários tipos de dados, juntamente com propriedades topológicas locais e globais, pode ser decisivo para a identificação efetiva das GRNs e suas funções, em face das limitações conhecidas [Troyanskaya, 2005, Vidal, 2005, Aittokallio and Schwikowski, 2006, Ray et al., 2009, Kuchaiev et al., 2010]. A análise das propriedades locais e globais das redes biológicas e suas aplicações no processo de inferência é muito recente e tem sido muito promissora [Klamt et al., 2007, Lacroix et al., 2008, Karlebach and Shamir, 2008, Lenas et al., 2009, Przytycka and Kim, 2010]. Por exemplo, a aplicação de características locais e globais sobre os organismos biológicos pode ocorrer na forma da similaridades entre os módulos conectados das redes [Ulitsky and Shamir, 2007], interpretação estrutural baseada na teoria dos grafos para os componentes de rede [Narasimhan et al., 2009, Kuchaiev et al., 2010], levando em conta o conhecimento de que a rede é esparsa [Andrecut et al., 2008, Andrecut and Kauffman, 2008, Christley et al., 2009], moti- 
vos (motifs) de rede (subgrafos) [Ott et al., 2005] e busca por cliques nas redes [Yu et al., 2006]. E mais importante, as redes biológicas, especialmente as GRNs, são conhecidas não só por serem esparsas, mas também organizadas, assim como seus elementos pertencem a diferentes classes de conectividade [Charbonnier et al., 2010].

As informações sobre a topologia da rede podem ajudar na investigação dos processos biológicos, inclusive na descrição desses processos a partir da teoria de redes complexas e suas propriedades [Strogatz, 2001, Albert and Barabási, 2002, Newman, 2003, Costa et al., 2008]. Sabe-se que muitos relacionamentos podem ser descritos com sucesso utilizando a teoria de redes complexas. Em particular, a teoria de redes complexas descreve vários tipos de topologias de redes, as quais apresentam propriedades bem definidas e podem ser usadas na caracterização de processos biológicos e inter-relações entre os genes. Algumas redes biológicas apresentam a propriedade scale-free, na qual muitos vértices da rede (genes) são fracamente conectados e alguns poucos vértices são altamente conectados (hubs) (veja Seção 2.8.3). Em geral, o uso de padrões topológicos e sua análise estrutural é um dos tópicos mais promissores em pesquisa na análise de redes complexas [Alon, 2007, Goemann et al., 2009]. Em particular, a aplicação das propriedades estruturais das redes pode ser uma valiosa informação a priori a ser considerada pelos métodos de inferência de GRNs.

Em face às limitações e às informações biológicas já conhecidas, se torna evidente a necessidade do desenvolvimento de métodos alternativos para recuperar as redes gênicas de forma mais adequada e com mais precisão. Logo, em se tratando dos métodos de seleção de características (veja Seção 2.4), escopo deste trabalho, existem dois tópicos a serem abordados: algoritmo de busca e função critério. Considerando a função critério, o uso da entropia para inferir GRNs a partir de séries temporais de expressão gênica tem se mostrado uma ferramenta promissora [Barrera et al., 2007, Lopes et al., 2009b]. O processo de inferência é conduzido observando a dependência condicional de um gene alvo dados seus potenciais preditores e seus perfis de expressão temporal, e aplicando a entropia condicional média como função critério [Liang et al., 1998, Martins-Jr et al., 2006, Barrera et al., 2007, Lopes et al., 2008c]. Este processo tem sido reconhecido como um instrumento estatístico adequado para modelar interações diretas entre genes [Charbonnier et al., 2010] e, naturalmente, a precisão da inferência depende das informações disponíveis e da adequação de seu uso.

Além disso, a entropia generalizada de Tsallis tem se destacado nos últimos anos como uma generalização da entropia de Shannon (veja Seção 2.5), não apenas devido às suas aplicações [Issue, 2005], mas também devido à sua fundamentação teórica [Abe, 2004]. Seu uso se torna importante em sistemas com interações de longo alcance, as quais causam correlações de longo alcance, uma característica particular dos sistemas não extensivos. Com objetivo de investigar a possibilidade de não extensividade das GRNs, e consequentemente sua interpretação neste contexto, é proposta uma nova função critério para a inferência de GRNs,baseada na entropia generalizada de Tsallis, a qual é apresentada na Seção 3.2.1.

Considerando o algoritmo de busca, as propriedades locais e globais das informações biológicas conhecidas podem ser usadas para orientar o processo de busca com objetivo de tornar o processo de inferência mais adequado para uma classe de problemas e, com isso, obter resultados com maior precisão. Neste sentido, são propostos neste trabalho dois novos algoritmos de busca para a inferência de GRNs: SFFS-MR e SFFS-BA. O algoritmo SFFS-MR explora uma característica biológica local, os genes que possuem relacionamentos de predição intrinsecamente multivariada (veja Seção 2.7), o qual é apresentado na Seção 3.2.2. O algoritmo SFFS-BA, por sua vez, explora uma característica 
global de várias redes biológicas conhecidas, nas quais suas topologias podem ser bem aproximadas pelo modelo de redes scale-free (veja Seção 2.8.3). Assim, é proposto que o algoritmo considere como informação a priori a topologia scale-free em seu processo de busca, o qual é apresentado na Seção 3.2.3.

\subsubsection{Função Critério Baseada na Entropia de Tsallis}

Neste trabalho, o objetivo é a inferência das topologias de redes a partir de perfis de expressão temporal, minimizando a entropia condicional entre os genes, i.e., a entropia do gene alvo condicionada ao estado de outros genes (preditores ou regulatórios). Dado um gene alvo, a ideia é definir como preditores os genes que minimizam sua entropia condicional. Portanto, a entropia condicional funciona como uma função critério que deve ser minimizada. Como em um problema típico de aprendizagem de máquina, a qualidade da inferência depende dos dados e da função critério. Se os dados não são representativos, provavelmente a solução obtida não será um mínimo global, mas um mínimo local. Da mesma forma, se a função critério não for adequada, a solução poderá satisfazer parcialmente a restrição imposta pelos dados ou até mesmo representar uma solução errada. Considerando que a função critério segue as propriedades da entropia, não é esperada uma solução completamente errada, mas pode não ser a melhor solução ou a ótima, o que traz a questão: Qual é a melhor função de entropia para a inferência de GRNs?

Para investigar a sensibilidade da entropia condicional quanto à sua forma funcional e a possibilidade de não extensividade das GRNs, é proposto neste trabalho uma nova função critério baseada na entropia generalizada de Tsallis (veja Seção 2.5.1). O método de inferência utilizado para a realização desta investigação foi proposto por [Barrera et al., 2007], o qual é apresentado na Seção 2.6.5.

Neste contexto, a inferência da rede é modelada como uma série de problemas de seleção de características, um para cada gene. Dado o perfil temporal de expressão de todos os genes, o método de inferência é iniciado fixando um gene alvo $Y$, e verifica o grupo de genes $\mathbf{X}$ que minimize a entropia condicional generalizada $H_{q}(Y(t+1) \mid \mathbf{X}(t))$ para um $q$ fixo. Dado que geralmente as redes possuem muitos genes, o espaço de busca torna-se imenso, de forma que uma busca exaustiva por todas as combinações de preditores não é apropriada. Então, para contornar esta explosão combinatória, normalmente são usados algoritmos como os apresentados nas Seções 2.4, 3.2.2 e 3.2.3.

Para o cálculo da entropia condicional (Equação 2.18 da Seção 2.5.1), é necessário estimar as probabilidades condicionais do gene alvo, dado seus candidatos a preditores, bem como as probabilidades desses preditores. Na ausência de informação a priori, essas probabilidades são estimadas a partir das frequências relativas, considerando-se seus respectivos perfis temporais de expressão. Logo, a precisão depende da representatividade dos dados contidos nos perfis de expressão. Considerando que busca-se pela menor entropia, não é recomendado definir a probabilidade das instâncias não observadas como nula. É possível que algumas das instâncias não estejam presentes no perfil de expressão temporal devido ao número reduzido de observações (tamanho do sinal) ou pela própria dinâmica do sistema. Portanto, com o objetivo de definir uma função critério que considere a penalização dos casos não observados, foi adotada a estratégia de penalização das instâncias não observadas proposta em [Martins-Jr et al., 2006, Martins-Jr., 2008, Lopes et al., 2008c]. 
A função critério penalizada adotando a entropia generalizada de Tsallis é definida como segue:

$$
\begin{aligned}
H_{q}(Y \mid \mathbf{X}) & =\sum_{i=1}^{M} P(\mathbf{X}) \frac{1-\sum_{y \in Y} P\left(y \mid \mathbf{X}=\mathbf{x}_{\mathbf{i}}\right)^{q}}{q-1} \\
& =\sum_{i=1}^{M} \frac{\left(f_{i}+\alpha\right)}{\alpha M+d} \frac{1-\sum_{y \in Y} P\left(y \mid \mathbf{X}=\mathbf{x}_{\mathbf{i}}\right)^{q}}{q-1} \\
& =\frac{\alpha(M-N)}{\alpha M+d} H_{q}(Y)+\sum_{i=1}^{N} \frac{\left(f_{i}+\alpha\right)}{\alpha M+d} \frac{1-\sum_{y \in Y} P\left(y \mid \mathbf{X}=\mathbf{x}_{\mathbf{i}}\right)^{q}}{q-1}
\end{aligned}
$$

na qual $\alpha \geqslant 0$ é o peso da penalização, $M$ é o número de configurações possíveis do conjunto de genes preditores $\mathbf{X}, N$ é o número de configurações observadas nos dados de expressão (o número de instâncias ou configurações não observadas é dado por $M-N), f_{i}$ é a frequência observada da configuração $\mathbf{x}_{\mathbf{i}}$ no perfil de expressão temporal, e $d$ é o número total de amostras temporais disponíveis (tamanho do sinal).

No contexto da entropia condicional média, apresentada na Seção 2.5, quando o parâmetro $\alpha$ é definido como zero, a penalização passa a não existir e $P(\mathbf{X})$ é estimado por sua frequência relativa, aplicando-se os termos $f_{i} / d$ da equação, considerando-se os dados de expressão, $\operatorname{logo} \sum_{i=1}^{N} f_{i}=d$. No caso de $N=M$, a penalização, primeiro termo da Equação 3.2, é cancelada, e $P(\mathbf{X})$ passa a ser estimado pela frequência relativa dos preditores, mas agora modulada por $\alpha^{1}$, i.e.,

$$
P(\mathbf{X})=\frac{\left(f_{i}+\alpha\right)}{\alpha M+d}
$$

e finalmente quando $N<M$, o parâmetro $\alpha$ será considerado $M-N$ vezes para as instâncias não observadas e, $N$ vezes para as instâncias observadas. Dessa forma, na Equação 3.2 é atribuída uma massa positiva de probabilidades para as configurações de $\mathbf{X}$ não observadas nos dados de expressão, a qual é parametrizada por $\alpha$. Além disso, a penalização das instâncias não observadas é ponderada pela entropia do gene alvo, i.e., $H_{q}(Y)$. Isto é importante considerando que a função torna-se sensível a uma boa predição mesmo quando as instâncias observadas para o gene alvo sejam suficientes para descrever sua dinâmica, i.e., quando o gene alvo tenha um baixo valor de entropia. Neste contexto, neste trabalho foi adotado $\alpha=1$.

Assim, é proposto um método de inferência de GRNs que consiste em determinar a entropia condicional média generalizada, dada pela Equação 3.2 e um algoritmo de busca para selecionar um subgrupo de genes que a minimize. Esta busca pode ser realizada pelos algoritmos SFS, SFFS, SFFS-MR, SFFS-BA ou ainda outros algoritmos de busca disponíveis na literatura.

\subsubsection{SFFS-MR}

Atualmente, a inferência de GRNs é um dos problemas mais desafiadores da biologia sistêmica. Um dos fatores que tornam este problema tão desafiador é a existência de genes dessa rede que apresentam uma predição intrinsecamente multivariada (veja Seção 2.7).

Neste contexto, é proposta uma estratégia alternativa de busca para a inferência de GRNs, chamada busca sequencial flutuante para frente com múltiplas raízes (SFFS-MR, do inglês Sequential

\footnotetext{
${ }^{1}$ Adicionando uma massa $(\alpha)$ a cada uma das instâncias $\mathbf{x}_{\mathbf{i}}$.
} 
Forward Floating Selection - Multiple Roots) [Lopes et al., 2010], a qual apresenta-se como uma estratégia de seleção de características que estende o algoritmo SFFS considerando não apenas as boas características, mas também as características indesejáveis (ruins) ${ }^{2}$ do ponto de vista individual, que podem formar conjuntos com predição intrinsecamente multivariada.

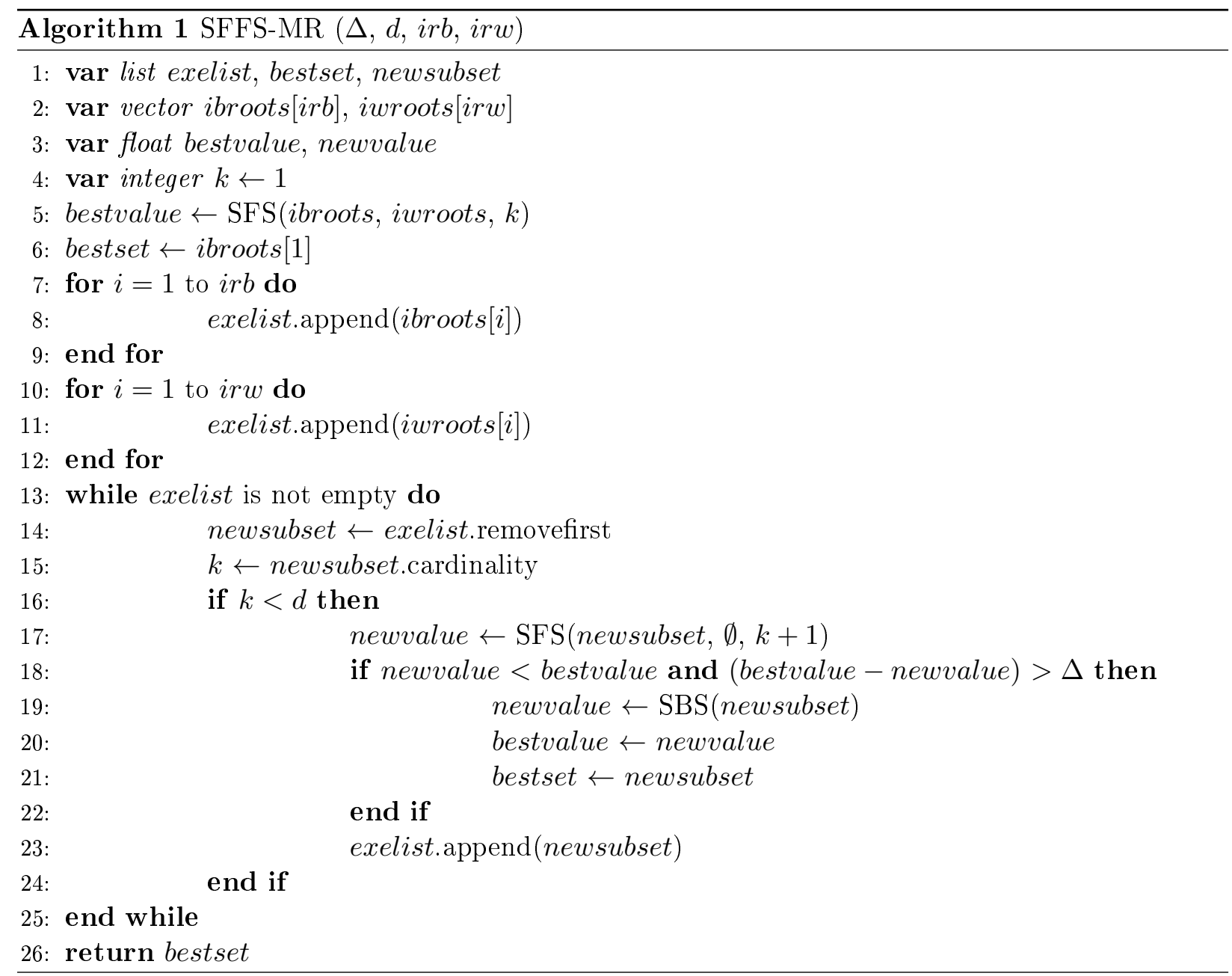

O Algoritmo 1 apresenta a especificação do algoritmo SFFS-MR. Este algoritmo é iniciado aplicando a estratégia de busca SFS (veja Seção 2.4.1) com objetivo de descobrir as irb melhores e as irw piores características individuais, i.e., $k=1$, as quais recebem um valor quanto a sua qualidade de predição, de acordo com a função de critério adotada. A variável bestvalue representa o melhor valor obtido pela função critério, o qual é alcançado pela a melhor característica bestset[1]. Os subconjuntos individuais, $i r b$ e $i r w$, são adicionados a uma lista de execução (exelist). Na estrutura de repetição while, o primeiro subconjunto na lista de execução é removido e sua cardinalidade é testada. Caso sua cardinalidade não tenha atingido o limite, o SFS irá incrementá-la, i.e., incluir uma nova característica que, em conjunto com as características já presentes em newsubset, compõe o melhor subconjunto de características com cardinalidade $k+1$.

A variável newvalue representa o valor da função critério ao avaliar o subconjunto newsubset. Caso o subconjunto newsubset possua um valor de função critério melhor (maior ou menor, dependendo da função critério adotada), e o ganho (melhoria) é maior do que $\Delta$, então a exclusão condicional é realizada, a qual é representada pela chamada da função SBS. Neste contexto, a fun-

\footnotetext{
${ }^{2}$ De acordo com a função critério adotada.
} 
ção SBS realiza uma exclusão condicional de cada uma de suas características. Caso o subconjunto que apresente o melhor valor de função critério seja o obtido com a exclusão condicional da última característica que foi inserida, esta característica é mantida no subconjunto e o algoritmo SBS é finalizado. Caso contrário, a característica excluída condicionalmente é removida em definitivo, e um novo processo de exclusão condicional é realizado. Este processo é repetido até que a exclusão condicional de cada uma das características do subconjunto produza um valor de função critério pior do que o valor da função critério obtido considerando todo o conjunto.

Após o processo de exclusão condicional, as variáveis bestvalue e bestset são atualizadas pelos valores retornados do método SBS: newvalue e newsubset, respectivamente. No final, o subconjunto newsubset será armazenado na lista de execução para uma nova tentativa de estendê-lo.

Em resumo, o algoritmo SFFS-MR difere do SFFS (Seção 2.4.2) devido à exploração de múltiplas raízes, com objetivo de ampliar o número de possíveis candidatos a preditores e, com isso, ser mais adequado na identificação de genes que tenham predição intrinsecamente multivariada. Considerando que irb e irw (número de raízes iniciais) são constantes com valores muito pequenos comparados ao número total de variáveis, que é na ordem de milhares no problema de inferência de GRNs, seu custo computacional assintótico não é pior do que o do SFFS.

O parâmetro $d$ representa a cardinalidade máxima do subconjunto de preditores. Um $\Delta$ que considera a variação de valor da função critério foi adotado com objetivo de impedir que pequenas variações da função de critério $(\leq \Delta)$ provoquem o aumento de características no subconjunto de preditores. Neste trabalho foi adotado os seguintes valores para os parâmetros: $d=5, \Delta=0.05$, $i r b=1$ e $i r w=5$.

\subsubsection{SFFS-BA}

Nesta seção é proposto um novo algoritmo de seleção de características orientado por uma função critério de dependência condicional aplicado à inferência de GRNs a partir de dados de expressão, o qual assume que a estrutura das GRNs segue uma topologia scale-free (veja Seção 2.8.3). Assim, é proposto um algoritmo iterativo de busca sequencial flutuante para frente guiada pela topologia de redes scale-free, (SFFS-BA, do inglês Sequential Forward Floating Selection - Barabási-Albert), no qual a topologia scale-free é uma informação a priori incluída no algoritmo de busca, e o mesmo é aplicado ao problema de inferência de GRNs.

Considerando as limitações de dados, de conhecimento sobre os organismos biológicos, presença de ruído nas medidas de expressão e a complexidade das redes biológicas, o objetivo principal deste método é mostrar a importância de considerar informações a priori, a fim de melhorar o processo de inferência e torná-lo mais adequado para uma classe de problemas (neste trabalho, as redes scale-free).

O método proposto baseia-se nas redes gênicas probabilísticas (PGNs, veja Seção 2.3.5), na qual são estabelecidos alguns axiomas. No algoritmo de busca proposto, são assumidas as propriedades descritas para as PGNs e considerados dois novos pressupostos:

i Para cada gene alvo, adicionando-se um novo preditor em seu subconjunto de preditores, o qual passa a contar com uma cardinalidade maior do que 1, deve haver um ganho de informação na predição do gene alvo, no caso do preditor escolhido ser parte do subconjunto de preditores verdadeiro para o gene alvo. Se o ganho de informação com a inclusão de um novo preditor em seu subconjunto de preditores for muito pobre, o preditor pode não fazer parte do subconjunto 
de preditores verdadeiro ou não há dados suficientes para executar a predição. Em ambos os casos, a inclusão do preditor no subconjunto de preditores deve ser evitada.

ii A topologia da rede segue uma lei de potência em sua distribuição de conexões, i.e., trata-se de uma rede scale-free tal como a descrita na Seção 2.8.3.

Ao assumir o modelo PGN e estes dois novos pressupostos, a principal contribuição deste método é incluir a informação estrutural como um conhecimento a priori, e, com isso, realizar uma pesquisa em um espaço de busca reduzido e alcançar melhores resultados. A ideia é baseada na heurística de que os genes sem preditores (fontes) tendem a um comportamento aleatório, enquanto os genes com preditores tendem a um comportamento mais ordenado. Desta forma, é possível esperar que um gene sem preditores de uma GRN tenha seu comportamento aproximadamente constante, quando da tentativa de identificar um possível preditor para ele. Em outras palavras, considerando-se um gene alvo sem preditores reais, espera-se pequenas variações de valores da função critério ao incluir novos preditores em seu subconjunto de preditores, como exibido pela Figura 3.3 (Fonte).

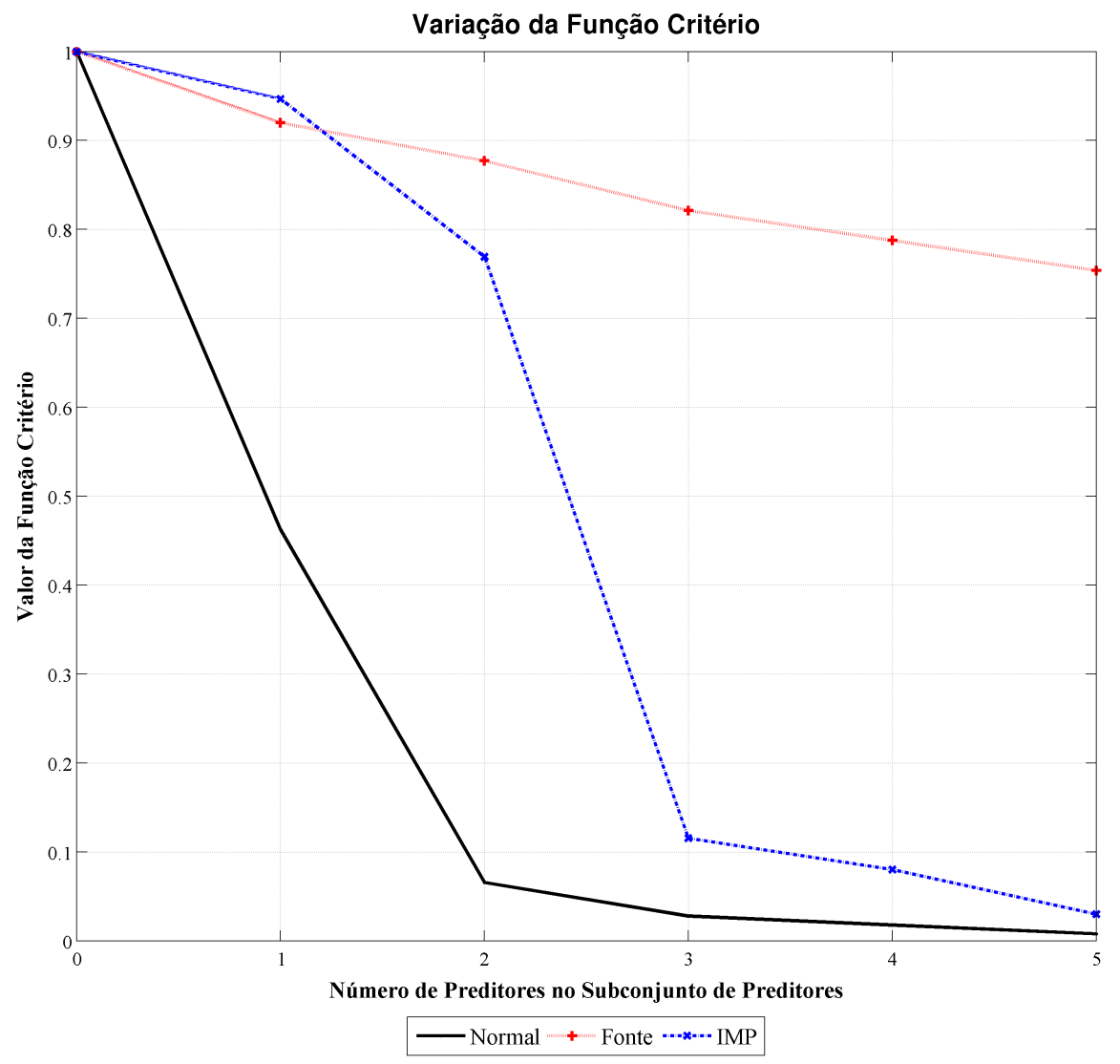

Figura 3.3: Comportamento da função critério considerando-se a inclusão de novos preditores no subconjunto de preditores. Na figura assume-se a minimização do valor da função critério, i.e., seu valor ótimo é zero.

Por outro lado, quando um gene alvo possui preditores, é esperado um comportamento distinto, principalmente ao incluir um possível preditor que faz parte de seu subconjunto de preditores (verdadeiros positivos). Desta forma, espera-se algumas variações do valor da função critério ao realizar a busca por seus possíveis preditores, como mostra a Figura 3.3 (Normal e IMP). 
Dado o pressuposto (i), o algoritmo proposto realiza uma busca por todos os preditores individuais (melhores e piores), baseado no algoritmo SFFS-MR [Lopes et al., 2010] (Seção 3.2.2), considerando-se todos os genes da rede. Na segunda etapa, a busca é realizada novamente para todos os genes, mas o algoritmo escolhe por genes alvo que apresentam um ganho maior de predição (i.e., o valor da função critério se aproxima do ótimo), quando o seu subconjunto de preditores é incrementado. Logo, os genes alvo com um ganho de predição ao adicionar um novo preditor em seu subconjunto de preditores têm seus subconjuntos de preditores preservados para a próxima iteração. Os genes alvo com pequena melhoria em sua função critério, i.e., predições pobres quando aumentado seu subconjunto de preditores, não são considerados nas próximas iterações do algoritmo, bem como os genes alvo que apresentarem um subconjunto de preditores que atingem o valor ótimo da função critério ou chegam muito perto, ou seja, assume a presença de ruído na entrada de dados que pode causar pequenos erros na função critério.

Dessa forma, a cada iteração, o algoritmo descarta a expansão dos subconjuntos de preditores para os genes alvo que atingirem o valor ótimo da função critério ou chegarem muito próximo, e atribui uma fila de prioridade aos genes alvo, de acordo com o ganho obtido na função critério ao adicionar um novo preditor em seu subconjunto resposta (preditores). Logo, os genes alvo com maior ganho têm maior chance de serem escolhidos pelo algoritmo para expandirem seus subconjuntos de preditores na próxima iteração do algoritmo.

Neste contexto, a topologia de redes scale-free e a suposição do ganho na função critério ao adicionar novos preditores são consideradas pelo algoritmo proposto com objetivo de integrar estes conhecimentos a priori e guiar o processo de busca, aplicado à inferência de GRNs a partir de perfis de expressão temporal.

A topologia scale-free, pressuposto (ii), a qual é caracterizada por uma lei de potência $P(k) \approx$ $k^{-\gamma}$ na distribuição de suas conexões (Seção 2.8), é considerada pelo algoritmo como um limitador ou "poda" do número de genes alvo que serão escolhidos para a expansão de seus subconjuntos de preditores a cada iteração. Logo, o número de genes alvo considerados a cada iteração do algoritmo é dado por uma lei de potência. Os Algoritmos 2 e 3 em conjunto, apresentam a formalização do método proposto.

O Algoritmo 2 é iniciado considerando todos os genes alvo e amostras temporais de expressão disponibilizadas ao algoritmo. A iteração inicial tem objetivo de selecionar os preditores individuais para todos os genes alvo, i.e., $k=1$. Para isto, o algoritmo SFFS-BA (Algoritmo 3) é aplicado com objetivo de identificar os melhores preditores individuais para cada um dos genes alvo, que são classificados de acordo com a função critério adotada.

Uma diferença importante no método proposto de seleção de características é que o algoritmo irá explorar o espaço de busca em etapas, i.e., os preditores são escolhidos de forma iterativa considerando o parâmetro de cardinalidade $k$. Outra diferença é que, para $k=1$, o algoritmo SFFS-BA retorna todos os subconjuntos de preditores e os respectivos valores obtidos pela função critério com objetivo de explorar todos os preditores individuais na próxima iteração do algoritmo e recuperar com maior precisão os preditores dos genes IMP. Naturalmente, outra metodologia como a apresentada pelo algoritmo SFFS-MR, pode ser facilmente aplicada neste contexto, limitando-se o número de melhores e piores preditores individuais para cada gene alvo.

Considerando-se os subconjuntos de preditores com cardinalidade $k>1$, o algoritmo SFFS-BA 

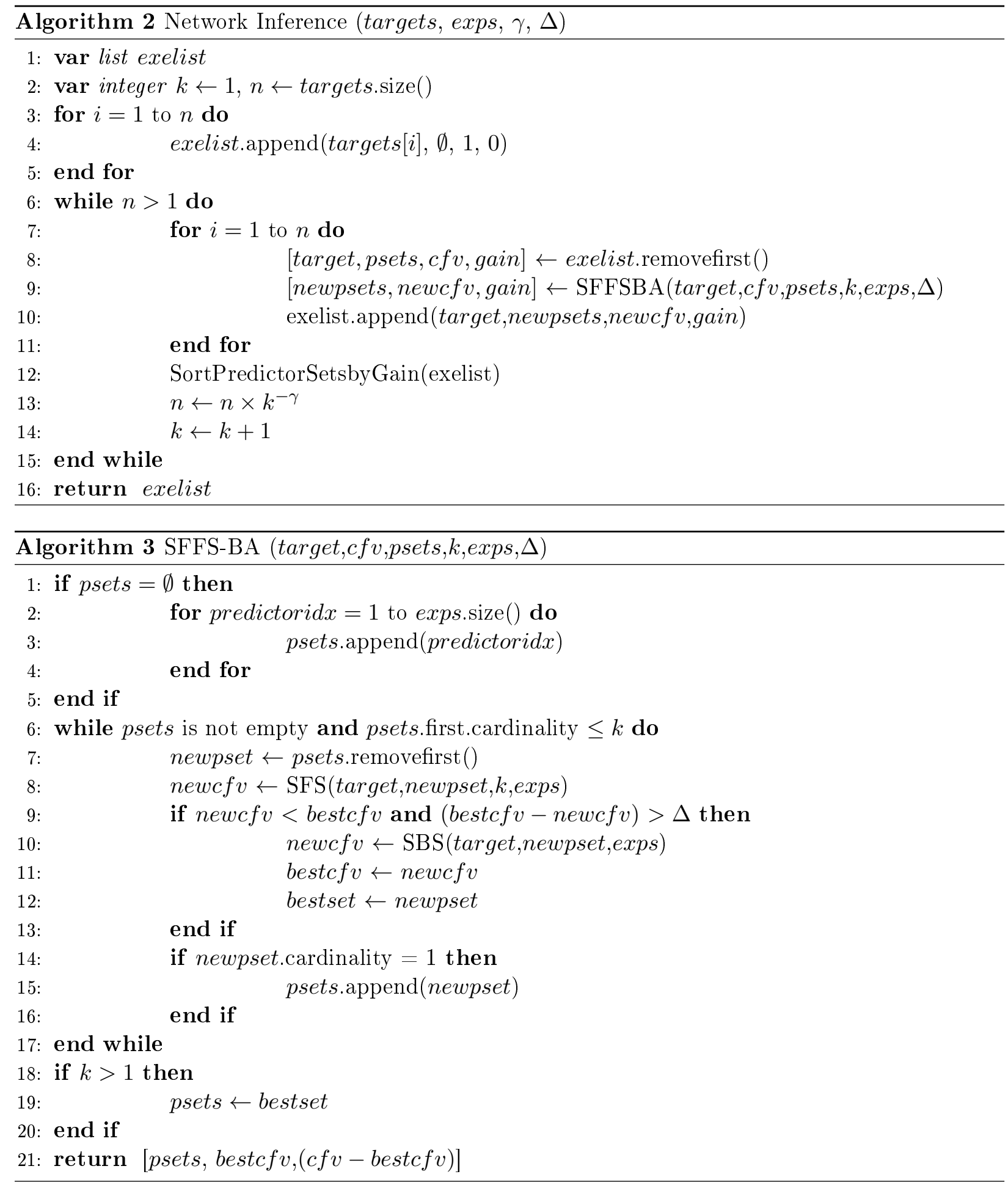

passa a tratar, e a retornar, apenas o melhor subconjunto de preditores de cada gene alvo, assumindo que alguns dos preditores verdadeiros podem já estar no subconjunto de preditores selecionados. Ao final de cada iteração do Algoritmo 2, os genes alvo são ordenados pelo ganho de predição obtido ao receberem um novo preditor em seu subconjunto de preditores. $\mathrm{O}$ número de genes alvo que serão considerados na próxima iteração do algoritmo é atualizado seguindo uma lei de potência, dada por $n=n \times k^{-\gamma}$, e a cardinalidade dos subconjuntos de preditores é incrementada $(k+1)$. Logo, nas próximas iterações, i.e., $k \geq 2$, o algoritmo irá considerar apenas os $n$ genes alvo com maiores ganhos na função critério ao receberem um novo preditor, e, com isso, incrementarem 
a cardinalidade $k$ de seu subconjunto de preditores. É importante notar que os genes alvo que atingem o valor ótimo da função de critério, ou se aproximam o suficiente, não são considerados para o aumento da cardinalidade em seus subconjuntos de preditores. A busca é realizada enquanto houver genes alvo para serem expandidos, i.e., $n \geq 1$ (condição de parada).

Em resumo, o algoritmo SFFS-BA difere do algoritmo SFFS (Seção 2.4.2) pela exploração das combinações dos subconjuntos com cardinalidade $k \leq 2$ e a inclusão de um fator que reduz o espaço de busca, baseando-se na suposição que os dados de expressão (entrada de dados) foram gerados a partir dos inter-relacionamentos gênicos que compõem uma topologia de rede scale-free. O parâmetro exps representa os perfis de expressão temporal, nos quais geralmente os genes estão dispostos nas linhas e os experimentos nas colunas, formando uma matriz de dados. O parâmetro $\gamma$ é uma constante que determina o decaimento exponencial do número de genes alvo que serão considerados na próxima iteração do algoritmo, como descrito na Seção 2.8.3. Da mesma forma que o algoritmo SFFS-MR, o algoritmo SFFS-BA também considera um $\Delta$ na variação de valores da função critério, com objetivo de impedir que pequenas variações $(\leq \Delta)$ provoquem o aumento da cardinalidade no subconjunto de preditores.

Neste trabalho, foi considerada a constante $\gamma=2.5$ e $\Delta=0.05$. O valor adotado para a constante $\gamma$ está relacionado com o valor médio encontrado na literatura para esta constante. No trabalho apresentado em [Jeong et al., 2000] é descrito que a topologia scale-free é adequada para representar a rede metabólica de Escherichia coli, a qual possui uma distribuição de probabilidade em suas conexões bem aproximada a uma lei de potência com constante $\gamma=2.2$. Os trabalhos [Jeong et al., 2001, Boccaletti et al., 2006] descrevem que a distribuição de probabilidades de uma dada proteína de levedura interagir com $k$ outras proteínas segue uma lei de potência, $\operatorname{com} \gamma=2.4$. Em geral, verifica-se na literatura que as distribuições das conexões em diversas redes, como a Internet, redes de colaboração humana e redes metabólicas seguem uma lei de potência no decaimento do número de elementos, quando aumentado o número de conexões, geralmente encontrando-se o valor da constante (expoente de decaimento) no intervalo $2<\gamma<3$ [Albert and Barabási, 2002, Albert, 2005].

A aplicação do algoritmo proposto para predizer um único gene ou um conjunto de genes de interesse, em vez de toda a rede, é direto, bastando selecionar os genes alvo no parâmetro targets.

Com relação aos genes com predição intrinsecamente multivariada (IMP) de tamanho maior ou igual a 3, é importante notar que o SFFS-BA tende a considerá-los desde que, a cada passo, um preditor individual acrescido ao subconjunto tenha um ganho de predição maior do que os candidatos a preditores dos genes considerados fontes. Ou seja, a tendência é que um conjunto moderadamente IMP seja detectado, desde que o número de amostras contidas na matriz de expressões gênicas seja suficiente para estimar sua distribuição de probabilidades conjuntas. Entretanto, existem duas situações nas quais há o risco do SFFS-BA considerar um gene alvo IMP com relação a seus preditores como gene fonte. A primeira situação é o caso em que a dimensão do conjunto é excessiva em relação ao tamanho de amostras, fazendo com que o erro de estimação da tabela de probabilidades conjuntas seja um fator determinante (lembrando que o número de parâmetros a serem estimados crescem exponencialmente em relação à cardinalidade $k$ ). O segundo caso, refere-se aos conjuntos fortemente IMP onde todos os seus subconjuntos próprios oferecem um ganho de informação muito pobre em relação ao alvo. Esse problema é inerente aos métodos de seleção de características que exploram apenas um subespaço entre todas as possíveis soluções, como é o caso do SFFS-BA. A única 
maneira de garantir que características IMP sejam devolvidas é através de uma busca exaustiva por todo espaço de soluções.

Na próxima seção são apresentadas as medidas utilizadas para comparar as redes inferidas com base nas AGNs, as quais têm por objetivo definir a similaridade entre elas. Estas medidas permitem analisar o desempenho do método de identificação de redes, bem como seu comportamento em relação a outros fatores como tamanho do sinal de entrada, presença de ruído ou perturbações, entre outras.

\subsection{Análise: Medidas de Similaridade Topológicas}

Considerando-se os modelos de redes complexas que podem ser usados na definição da topologia de uma AGN, se torna claro que tais modelos podem ser representados em termos de sua matriz de adjacências $M$, tal que cada aresta saindo do vértice $v_{i}$ e chegando ao vértice $v_{j}$ implica que $M(i, j)=1, \operatorname{com} M(i, j)=0$ caso contrário.

Com o objetivo de medir a similaridade entre duas redes $A$ (modelo AGN) e $B$ (rede identificada), é proposto o uso das medidas de similaridade topológica apresentadas em [Dougherty, 2007], as quais são baseadas na matriz de confusão [ml1, 1998, Webb, 2002]. Cada elemento desta matriz de confusão é uma medida de como o método de identificação de redes fica "confuso" entre identificar ou não identificar as arestas de uma rede.

A matriz de confusão, apresentada na Tabela 3.1, contém informações sobre as arestas (conexões) de uma AGN e sobre as arestas inferidas pelo método de identificação. No contexto deste trabalho, as entradas desta matriz de confusão possuem os seguintes significados: TN (verdadeiro negativo, do inglês True Negative) é o número de arestas não identificadas, e que não existem na respectiva rede original (AGN), FP (falso positivo, do inglês False Positive) é o número de arestas identificadas, e que não existem na respectiva rede original (AGN), FN (falso negativo, do inglês False Negative) é o número de arestas não identificadas, e que existem na respectiva rede original (AGN), e TP (verdadeiro positivo, do inglês True Positive) é o número de arestas identificadas, e que existem na respectiva rede original (AGN).

Tabela 3.1: Matriz de confusão exibindo as medidas usadas para quantificar a similaridade entre a matriz de adjacências de uma $A G N(A)$ e a matriz de adjacências de uma rede identificada $(B),(T P=$ verdadeiro positivo, $F N=$ falso negativo, $F P=$ falso positivo, $T N=$ verdadeiro negativo).

\begin{tabular}{|c|c|c|}
\hline Aresta / Conexão & Inferida em B & Não Inferida em B \\
\hline Presente em A & TP & FN \\
Ausente em A & FP & TN \\
\hline
\end{tabular}

As medidas consideradas neste trabalho são amplamente utilizadas por métodos de inferência e calculadas da seguinte forma [Dougherty, 2007]:

$$
\begin{gathered}
P P V=\frac{T P}{(T P+F P)}, \\
\text { Especificidade }=\frac{T N}{(T N+F P)}, \\
\text { Sensibilidade }=\frac{T P}{(T P+F N)} .
\end{gathered}
$$


A medida PPV (do inglês Positive Predictive Value) também conhecida como precisão (do inglês, precision) e a medida de Especificidade, definidas pela Equação 3.3 quantificam as arestas inferidas corretamente e incorretamente, observando os valores apresentados na Tabela 3.1 [ml1, 1998]. A Sensibilidade, também conhecida como recuperação (do inglês, recall), quantifica as arestas da rede original que não foram inferidas.

Considerando que as medidas PPV, Especificidade e Sensibilidade não são independentes entre elas, quando utilizadas em conjunto é adequado utilizar sua média geométrica, também conhecida como média proporcional, para representar o valor médio entre as medidas. A média geométrica é dada por:

$$
M_{G}(X)=\sqrt[n]{x_{1}, x_{2}, \ldots, x_{n}}
$$

dessa forma, quando estas medidas são utilizadas em conjunto, a fim de produzir uma medida de similaridade entre duas redes Similaridade $(A, B)$, é adotada neste trabalho uma média geométrica entre as medidas envolvidas, como por exemplo, nos casos definidos pela Equação 3.5, como segue:

$$
\begin{gathered}
\text { Similaridade }(A, B)=\sqrt[3]{P P V \times \text { Especificidade } \times \text { Sensibilidade }}, \\
\text { Similaridade }(A, B)=\sqrt{P P V \times \text { Sensibilidade }}, \\
\text { Similaridade }(A, B)=\sqrt{\text { Especificidade } \times \text { Sensibilidade }} \\
\text { Similaridade }(A, B)=\sqrt{P P V \times \text { Especificidade }}
\end{gathered}
$$

É importante observar que ambas as taxas de arestas corretas e incorretas são consideradas pelas medidas na Equação 3.5, implicando que a similaridade máxima é obtida por valores destas medidas próximos a 1 .

\subsection{Aplicações: Investigação Biológica}

Em geral, organismos biológicos respondem rapidamente a mudanças no ambiente externo ou interno, ajustando o perfil de expressão gênica e consequentemente das proteínas. Em decorrência deste fato, as redes regulatórias e metabólicas se ajustarão. No entanto, pouco se sabe sobre como estas mudanças na produção de transcritos e proteínas estão interligadas e reguladas ao longo do tempo [Mahalingam et al., 2005]. Com o objetivo de entender melhor este processo, é proposto o estudo investigativo da evolução temporal da resposta gênica a estímulos externos, usando os dados temporais de expressões da Arabidopsis thaliana como modelo a ser analisado.

A aplicação da metodologia apresentada nas seções anteriores em dados biológicos é muito importante para o aperfeiçoamento dos métodos e contribuição deste trabalho. Neste sentido, em se tratando da Arabidopsis thaliana, o gene thi1 está envolvido na biossíntese de tiamina (vitamina B1), assim como seu ortólogo thi4, em Saccharomyces cerevisiae [Gomes and Van Sluys, 2010].

A vitamina B1 (tiamina) é necessária como cofator de diversas enzimas de vias metabólicas produtoras de energia armazenada na forma de adenosina trifosfato (ATP). Estas vias são respiração, glicólise e fotossíntese. A síntese de tiamina ocorre em bactérias, arqueas e alguns eucariotos como a levedura e plantas. Os seres humanos e os animais devem ingerir alimentos que contenham a tiamina pois não a produzem. Bactérias e leveduras utilizam-se de rotas metabólicas distintas 
para a síntese de tiamina enquanto que em plantas pouco se sabe até o presente [Momoli, 2008]. O estudo do gene thi1 de Arabidopsis thaliana deve contribuir ao entendimento da via de síntese. Do mesmo modo, associar o padrão de expressão de thi1 e de genes chave das rotas metabólicas dependentes da presença de tiamina e, poderá contribuir na elucidação do papel da proteína THI1.

Neste contexto, é proposta a aplicação dos métodos desenvolvidos neste trabalho na identificação de redes gênicas envolvidas na biossíntese de tiamina e, em particular com o gene thi1, considerando quatro vias metabólicas de interesse: respiração, fotossíntese, glicólise e síntese de tiamina, usando a Arabidopsis thaliana como planta modelo. O objetivo é verificar a existência de uma rede potencial entre a síntese de um cofator essencial (tiamina) ao funcionamento das quatro vias citadas.

No trabalho desenvolvido em [Momoli, 2008], foi realizada a caracterização funcional do gene thi1 em linhagens mutantes e selvagens de Arabidopsis thaliana, no qual foi identificado um pico de expressão no período da tarde, sugerindo um ritmo circadiano em potencial. Além disso, o acúmulo da proteína produzida pelo gene nos tecidos acompanha seu perfil de expressão de mRNA, apontando que o modo de regulação do gene ocorre em nível transcricional [Momoli, 2008].

Neste sentido, foram definidos como materiais deste trabalho, os dados temporais de expressão de dois tipos: normal e sob condição de estresse a frio, os quais foram obtidos do banco de dados público TAIR [D’Angelo et al., 2010] com número de submissão ME00325 http://www.arabidopsis. org/servlets/TairObject?type=expression_set\&id=1007966553. Estes dados de expressão foram extraídos de Arabidopsis thaliana com 18 dias. O material foi colhido nos instantes de tempo: 30min, 1h, 3h, $6 \mathrm{~h}, 12 \mathrm{~h}$ e $24 \mathrm{~h}$ após exposição da planta ao frio, com temperatura de $4^{\circ} \mathrm{C}$.

Para cada amostra temporal foram geradas amostras de duas partes da planta: folha e raiz, e para cada parte, foram geradas duas réplicas biológicas. O material das raízes e folhas foram separados e tratados individualmente. Amostras de controle (não expostas ao frio) também foram colhidas nos respectivos instantes de tempo, incluindo o tempo 0h, a uma temperatura média de $25^{\circ} \mathrm{C}$. Os dados de expressão foram gerados utilizando o chip ATH1 da Affymetrix, o qual é do tipo one-color microarray, como descrito na Seção 2.1.

Os dados de expressão temporal foram submetidos aos métodos apresentados nas seções anteriores com objetivo de identificar os inter-relacionamentos entre alguns genes de interesse. Para isto, foram selecionados grupos de genes, um de cada via metabólica: síntese de tiamina, respiração, fotossíntese, glicólise e controle, os quais são apresentados na Tabela 3.2.

O locus, apresentado na Tabela 3.2, é um identificador de uma parte do cromossomo onde está localizado o gene, e a identificação de cada gene no array é dado pelo chip ATH1 da Affymetrix.

Após a geração das redes, foi desenvolvido um software para a integração de dados biológicos e visualização das redes inferidas. Neste sentido, a primeira etapa da integração de dados foi relacionar cada spot do array com sua identificação de locus. Para esta tarefa, foi desenvolvido um algoritmo para relacionar os identificadores de cada gene do array, i.e., o Probe set, com seu identificador de locus. Nesta etapa foi utilizado o arquivo affy ATH1 array_elements-2009-7-29.txt copiado do banco de dados público TAIR (ftp://ftp.arabidopsis.org/home/tair/Microarrays/Affymetrix/), no qual é disponibilizada uma tabela de identificadores AGI (do inglês Arabidopsis Genome Initiative) correspondente a cada elemento do array da Affymetrix. Um AGI consiste basicamente em um nome de locus padrão para cada um dos genes e proteínas de Arabidopsis thaliana.

Após identificar o mapeamento entre locus e Probe set, o segundo passo foi integrar informações vindas de diferentes fontes de dados a respeito de cada gene do array. Nesta etapa, considerando 
Tabela 3.2: Descrição dos grupos de genes alvo considerados para a geração das GRNs a partir de dados de expressão temporal de Arabidopsis thaliana.

\begin{tabular}{|c|c|c|c|}
\hline Nome do Gene & Locus & Identificação no Array (Probe set) & Via Metabólica \\
\hline XPB2 & AT5G41360 & 249307 s at & controle \\
\hline GTF2H2 & AT1G05055 & 265218 at & controle \\
\hline ERCC1 & AT3G05210 & 259304_at & controle \\
\hline UVH6 & AT1G03190 & 264356_at & controle \\
\hline AT1G14030 & AT1G14030 & 262648 at & fotossíntese \\
\hline AT1G67090 & AT1G67090 & 264474_s_at & fotossíntese \\
\hline CPN60A & AT2G28000 & 264069 & fotossíntese \\
\hline AT2G34590 & AT2G34590 & 266904_at & fotossíntese \\
\hline AT3G55410 & AT3G55410 & 251787 at & fotossíntese \\
\hline PGI1 & AT4G24620 & 254141_at & respiração \\
\hline PFK5 & $\mathrm{AT} 2 \mathrm{G} 22480$ & 264044_at & respiração \\
\hline AT2G01140 & AT2G01140 & 265735 at & respiração \\
\hline AT1G74030 & AT1G74030 & 260392_at & respiração \\
\hline PCK1 & AT4G37870 & 253041_at & respiração \\
\hline ACLA-3 & AT1G09430 & 264504_at & glicólise \\
\hline FUM1 & AT2G47510 & 248461 s__at & glicólise \\
\hline PDH-E1_ALPHA & AT1G01090 & 261583 at & glicólise \\
\hline ATAPY1 & AT3G04080 & 258567 at & síntese de tiamina \\
\hline TH1 & AT1G22940 & 264771_at & síntese de tiamina \\
\hline AT3G24030 & AT3G24030 & 256907_at & síntese de tiamina \\
\hline NFS1 & AT5G65720 & 247164_at & síntese de tiamina \\
\hline THI1 & AT5G54770 & 248128_at & síntese de tiamina \\
\hline LOS2 & AT2G36530 & 263924_at & sem classe definida \\
\hline EDA9 & AT4G34200 & 253274_at & sem classe definida \\
\hline
\end{tabular}

a Arabidopsis thaliana, foram obtidas informações sobre anotação, proteínas e vias metabólicas, a partir dos seguintes bancos de dados públicos: Gene Ontology [Ashburner et al., 2000], GenBank [Benson et al., 2008], KEGG [Kanehisa and Goto, 2000] e TAIR [D'Angelo et al., 2010]. Em seguida, utilizando-se o identificador AGI, foi desenvolvido outro algoritmo para integrar as informações vindas destes bancos de dados, por meio de busca e identificação textual de cada AGI nas diferentes bases de dados. Uma vez localizado o identificador AGI, as informações biológicas contidas em cada um dos arquivos de dados foram identificadas e estruturadas na forma de classes de dados da linguagem de programação orientada a objetos Java [Deitel and Deitel, 2003].

Considerando-se uma rede inferida a partir do programa [Lopes et al., 2008c], no qual está disponível o método de inferência apresentado na Seção 2.6.5 e também os métodos apresentados neste capítulo, foi possível armazenar a estrutura da rede inferida na forma de arquivo em disco, e então fazer a integração entre os dados da rede inferida e os dados biológicos estruturados, gerando um único arquivo (classe) no qual todas as informações passam a estar integradas na forma de um objeto Java serializado em arquivo [Deitel and Deitel, 2003]. O uso da serialização de objetos Java em arquivo dispensa a configuração e instalação de bancos de dados na máquina do cliente, reunindo todas as informações em um único arquivo que pode ser recuperado a qualquer momento pelo software proposto. A Figura 3.4 exibe uma captura da tela principal do software de integração de dados e visualização das redes inferidas. 


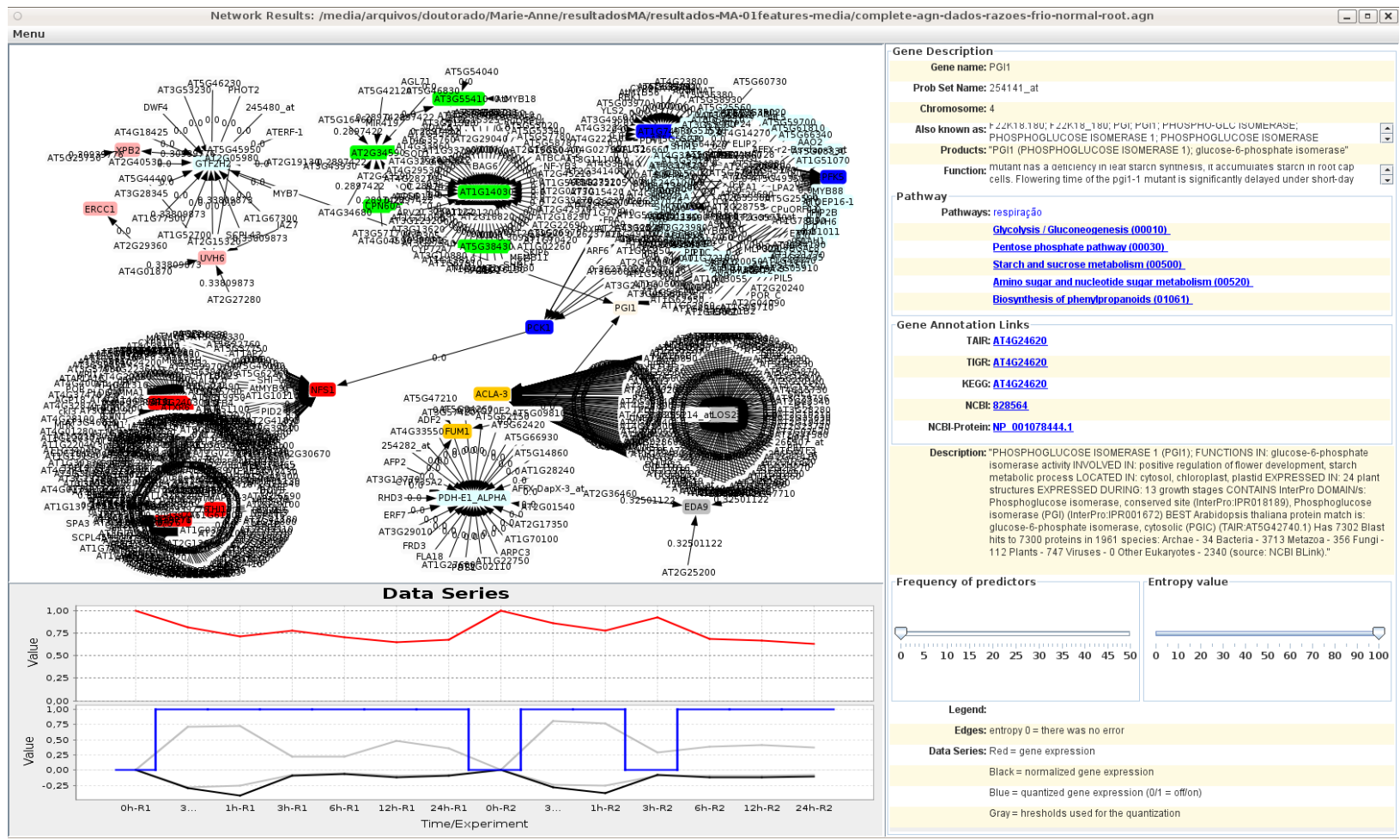

Figura 3.4: Captura da tela inicial do programa de integração de dados e visualização das redes inferidas.

Neste programa também foram implementadas facilidades para a visualização do usuário como diferentes escalas de visualização (zoom), adequação da visualização de toda a rede usando um clique direito, salvar imagem da rede, visualização dos perfis de expressão, links diretos ao bancos de dados públicos e filtro da visualização da rede por meio da frequência de ocorrência dos preditores para um mesmo gene alvo e pelo valor da função critério, entre outras. As funcionalidades relacionadas à visualização da rede foram implementadas adotando a tecnologia de visualização de informação Prefuse [Heer et al., 2005]. A tecnologia Prefuse é escrita na linguagem de programação Java usando a biblioteca de gráficos Java2D, a qual é disponibilizada na forma de uma biblioteca que inclui algoritmos para desenho de grafos, diferentes formas de navegação e interação, pesquisa entre seus elementos, uso de formas, cores e diversas formas para representação de conectividade entre seus elementos, entre outras.

A qualquer momento durante a visualização e análise da rede, as alterações realizadas podem ser salvas, bastando o usuário usar o menu e selecionar o arquivo de destino, no qual é armazenado um objeto atualizado, contendo toda a rede e suas respectivas informações, por meio do recurso de serialização de objetos da linguagem Java.

Tanto o trabalho de investigação biológica quanto o respectivo software, continuam em desenvolvimento em colaboração com a Profa. Dra. Marie-Anne Van Sluys, co-orientadora deste trabalho, e com Kleber Alves Gomes, doutorando do programa interunidades de pós-graduação em Biotecnologia. Alguns resultados obtidos a partir da análise das GRNs inferidas são apresentados no próximo capítulo deste trabalho. 


\section{Capítulo 4}

\section{Resultados}

Este capítulo está organizado de forma a apresentar os resultados experimentais obtidos durante o desenvolvimento deste trabalho. Inicialmente, na Seção 4.1, são apresentados os resultados obtidos pela aplicação do modelo AGN, o qual foi apresentado na Seção 3.1. Em seguida, o modelo AGN foi utilizado em um estudo comparativo entre quatro métodos de inferência de GRNs, os quais são apresentados na Seção 2.6. Os resultados dessa investigação são apresentados na Seção 4.2.

A análise dos resultados, incluindo o comportamento dos métodos de inferência, levaram ao desenvolvimento de novas metodologias para a inferência de GRNs. A primeira metodologia trata de uma função critério que atribui um valor de predição entre um gene alvo e um subconjunto de preditores, a partir da observação dos seus perfis de expressão, utilizando a entropia generalizada de Tsallis, como apresentado na Seção 3.2.1. Os resultados obtidos pela aplicação desta função critério são apresentados na Seção 4.3.

As outras duas metodologias desenvolvidas estão relacionadas com o método de busca entre os possíveis subconjuntos de preditores para um gene alvo. Neste sentido, foram propostos dois novos algoritmos: SFFS-MR (veja Seção 3.2.2) e SFFS-BA (veja Seção 3.2.3). Os resultados da aplicação desses dois algoritmos no processo de inferência de GRNs são apresentados nas Seções 4.4 e 4.5, respectivamente.

Finalmente, as metodologias desenvolvidas foram aplicadas para a inferência de GRNs a partir de dados de expressão da Arabidopsis thaliana, com objetivo de investigar a existência de uma rede potencial entre a síntese de tiamina e o funcionamento de outras vias metabólicas, como apresentado na Seção 3.4. Os resultados da metodologia em dados biológicos são apresentados na Seção 4.6.

\subsection{Redes Gênicas Artificiais (AGNs)}

Nesta seção, são apresentados os resultados experimentais obtidos pela aplicação do modelo AGN [Lopes et al., 2008a, Lopes et al., 2011a] (veja Seção 3.1), considerando quatro topologias de redes complexas, a fim de investigar algumas propriedades das redes, incluindo sua topologia, e o impacto dessas propriedades sobre a metodologia de inferência. Os aspectos considerados na realização desses experimentos foram: (1) diferentes topologias de redes complexas (ER), (WS), (BA) e (GN); (2) complexidade das redes em termos do número médio de conexões $\langle k\rangle$; (3) número de instantes de tempo, i.e., tamanho do sinal de expressão; e (4) desempenho do método ao recuperar todos os genes da rede e aplicado na recuperação das conexões considerando apenas os genes mais conectados da rede (primeiros $10 \%$ em conectividade), i.e., hubs. 


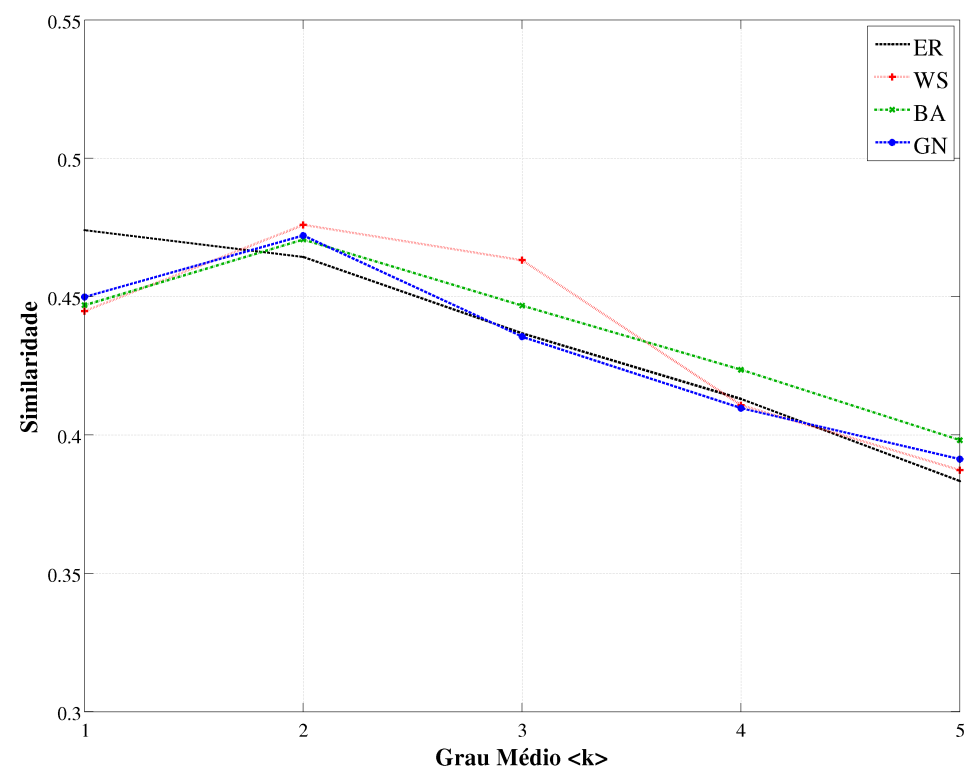

(a) todos os genes

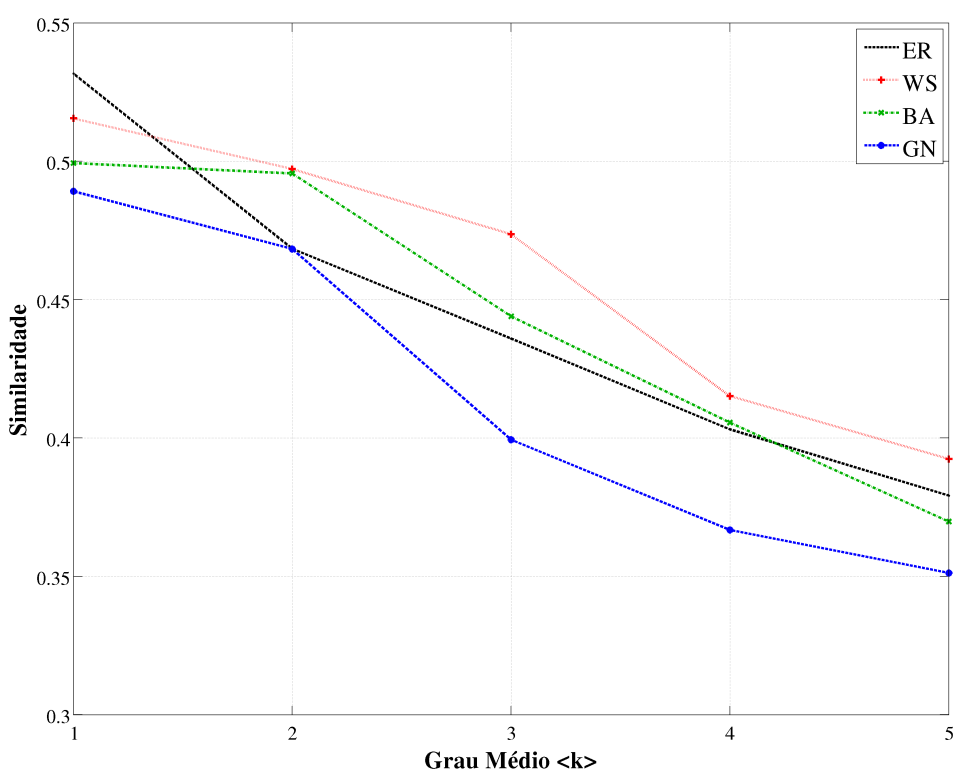

(b) apenas os hubs

Figura 4.1: Medida de similaridade obtida pelo aumento do grau médio de conexões (arestas) por gene (vértice), i.e., $\langle k\rangle,($ a) considerando todos os genes de cada rede e (b) considerando apenas $10 \%$ dos genes mais conectados de cada rede, i.e., hubs.

Em todos experimentos foram consideradas redes contendo 100 vértices (genes). O grau médio de conexões $\langle k\rangle$ variou de $1,2, \ldots, 5$, e o número de instantes de tempo considerados (tamanho do sinal) variou de 5, 10, 15, 20 até 100 em incrementos de tamanho 20. Para cada gene $v_{i}$ foram consideradas 3 funções Booleanas possíveis para gerar sua dinâmica (veja Seção 3.1.2), as quais foram definidas aleatoriamente, tal que $\psi_{i}=\left\{f_{j}^{(i)}\right\}, j=1, \ldots, l(i)=3$ e as probabilidades de ocorrência adotadas foram $c_{1}^{(i)}=0,95, c_{2}^{(i)}=0,025, c_{3}^{(i)}=0,025, i=1, \ldots, 100$. Essas probabilidades foram especificadas com objetivo de não só definir uma dinâmica estrutural principal para as redes, mas também adicionar pequenas pertubações, como sugerido em [Barrera et al., 2007]. Os resultados experimentais foram obtidos a partir de 50 simulações de cada topologia de rede, variação do grau 


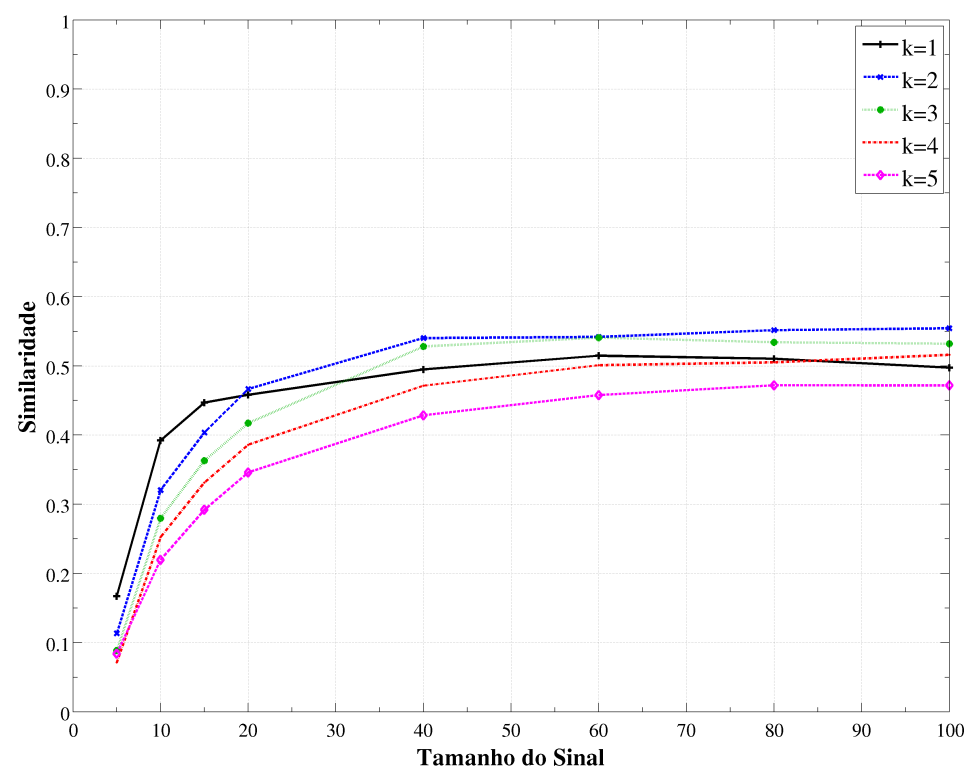

(a) ER - todos os genes

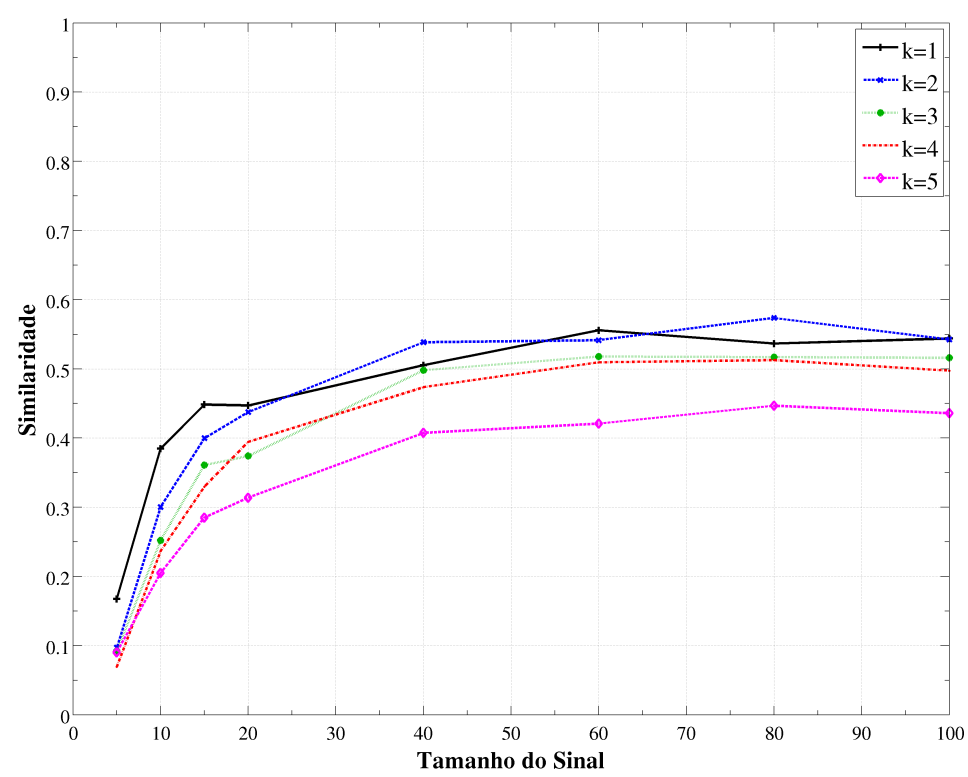

(b) ER - hubs

Figura 4.2: Medida de similaridade obtida pelo aumento do número de instantes de tempo da expressão temporal (tamanho do sinal), (a) considerando todos os genes da rede ER e (b) considerando apenas 10\% dos genes mais conectados da rede ER, i.e., hubs.

médio $\langle k\rangle$ e tamanho do sinal.

Com objetivo de inferir as redes, os sinais de expressão simulados por cada AGN foram submetidos ao software descrito em [Lopes et al., 2008c] que implementa o método de identificação de redes apresentado na Seção 2.6.5, o qual é uma das contribuições deste trabalho. Foram adotados os parâmetros padrão (default) do software em todos os experimentos apresentados nesta seção, na qual as figuras apresentadas têm a medida de Similaridade $=\sqrt[3]{P P V \times \text { Especificidade } \times \text { Sensibilidade }}$ (descrita na Seção 3.3) entre cada rede AGN e a respectiva rede inferida a partir das expressões simuladas. A Similaridade é exibida no eixo das ordenadas (y). No eixo das abscissas (x), estão algumas variações paramétricas da geração do sinal de expressão simulado, tais como o tamanho do sinal e o número médio de conexões entre os genes da rede. 


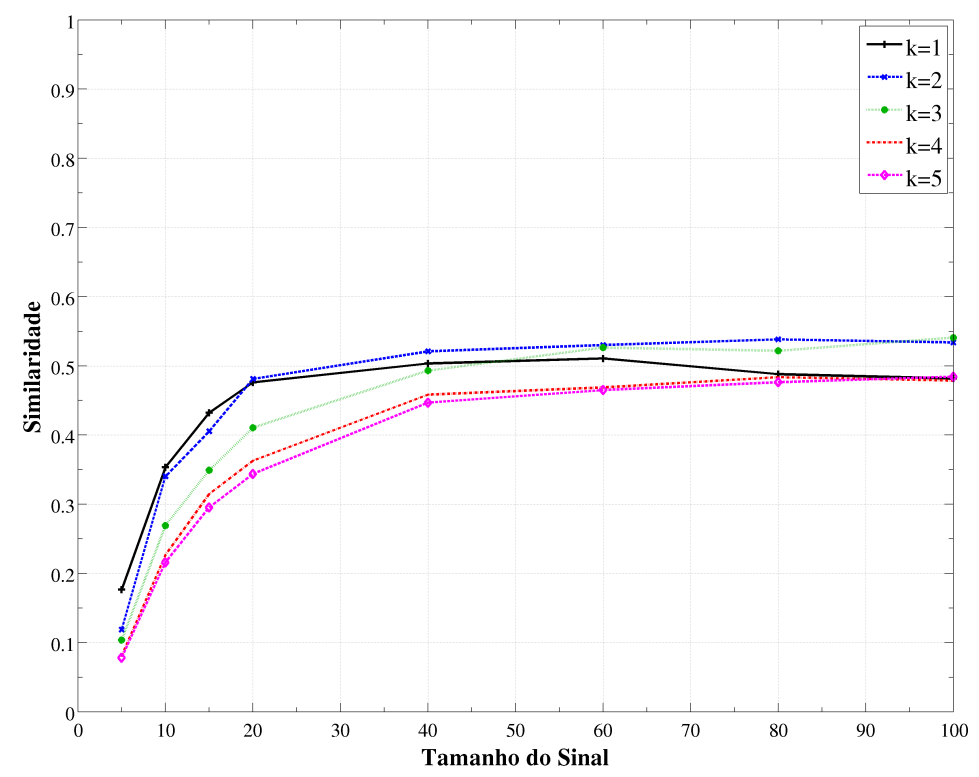

(a) WS - todos os genes

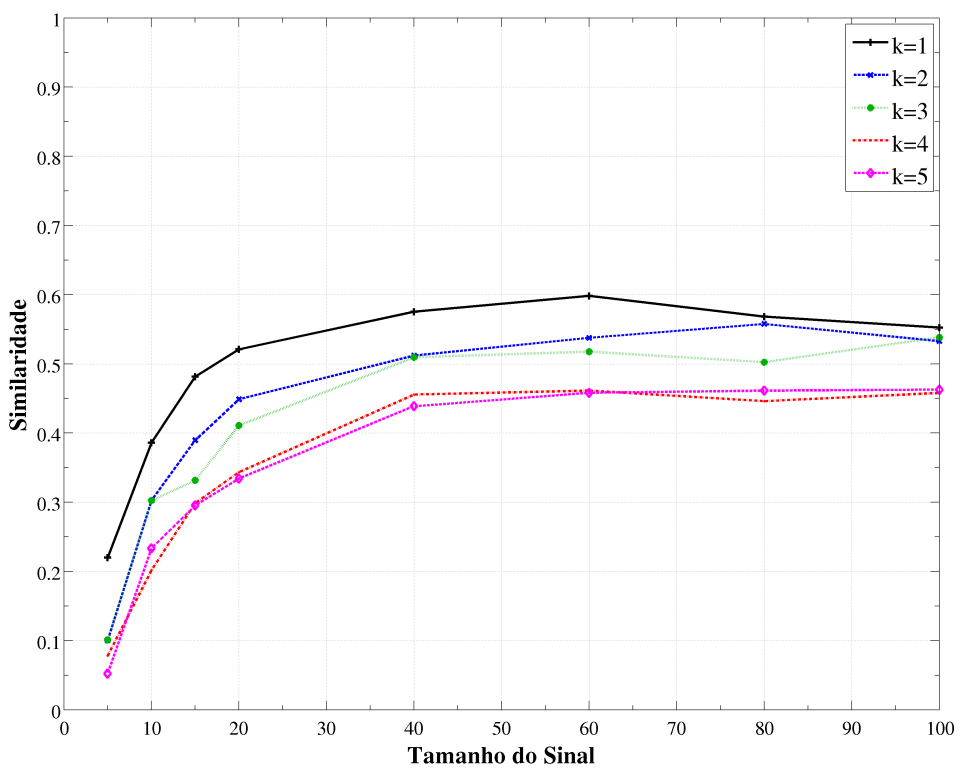

(b) WS - hubs

Figura 4.3: Medida de similaridade obtida pelo aumento do número de instantes de tempo da expressão temporal (tamanho do sinal), (a) considerando todos os genes da rede WS e (b) considerando apenas $10 \%$ dos genes mais conectados da rede WS, i.e., hubs.

O primeiro experimento foi realizado para analisar o impacto do aumento da complexidade, em termos de grau médio $\langle k\rangle$, ao inferir as GRNs. A Figura 4.1 apresenta esses resultados considerandose as topologias ER, WS, BA e GN, para as quais a medida de Similaridade foi calculada, para cada grau médio $\langle k\rangle$, tomando em conta os resultados médios entre todas as variações de tamanho do sinal.

É possível perceber que, como esperado, o grau médio de conexões $\langle k\rangle$ é um componente importante de complexidade da rede no que diz respeito a geração de sua dinâmica, como apontado por Kauffman em seus trabalhos [Kauffman, 1969,Kauffman, 1993], sendo que as inferências de todas as topologias de redes sofreram uma diminuição da taxa de Similaridade com o aumento do número médio de conexões por gene. No entanto, houve uma melhoria nos resultados considerando-se o 


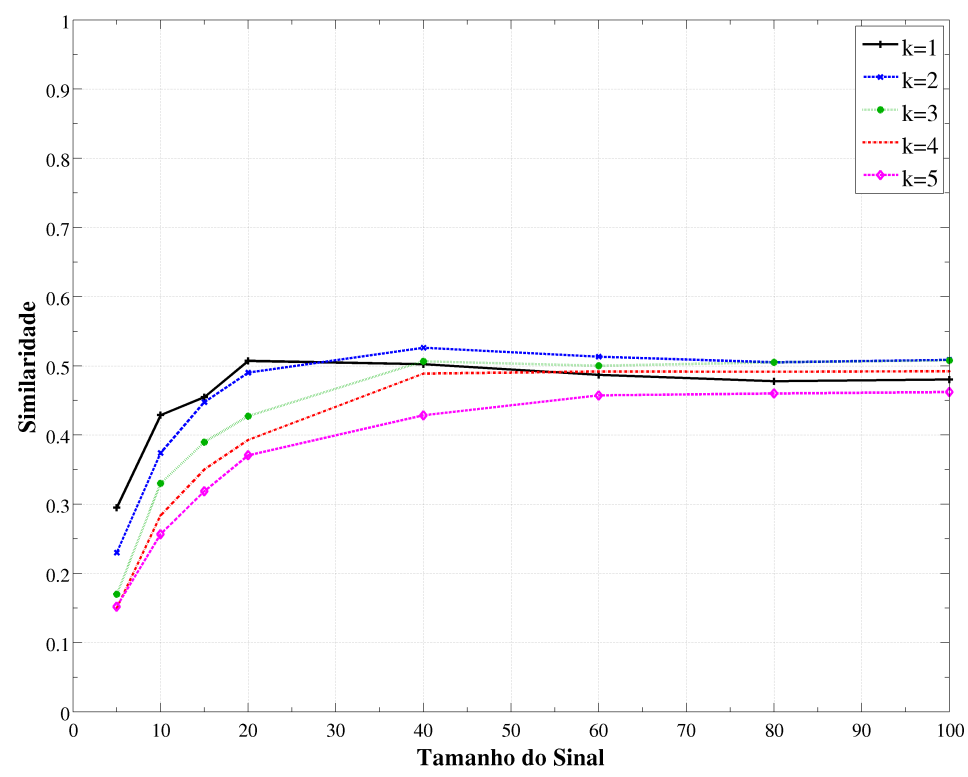

(a) BA - todos os genes

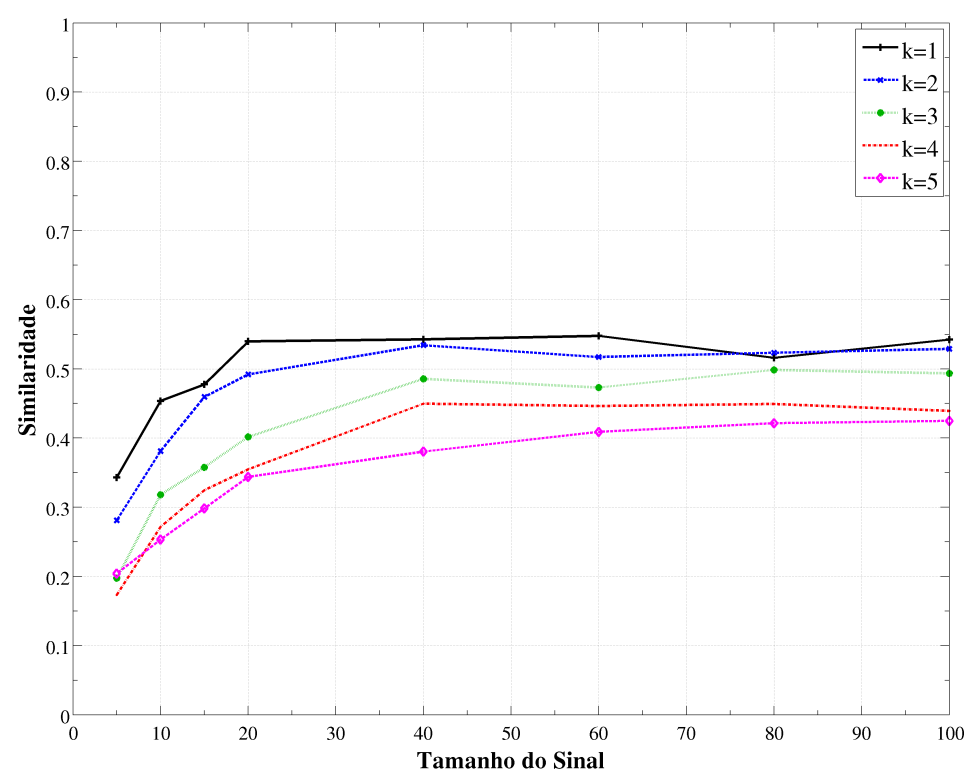

(b) BA - hubs

Figura 4.4: Medida de similaridade obtida pelo aumento do número de instantes de tempo da expressão temporal (tamanho do sinal), (a) considerando todos os genes da rede BA e (b) considerando apenas 10\% dos genes mais conectados da rede BA, i.e., hubs.

grau médio de $\langle k\rangle=1$ até $\langle k\rangle=2$ para as topologias WS, BA e GN quando observada a recuperação de todas as conexões dessas redes, como pode ser observado na Figura 4.1(a). Embora essas redes sejam menos complexas para $\langle k\rangle=1$, vários genes podem não ter nenhum preditor, mas o método de inferência encontra um falso positivo, reduzindo assim a sua medida de Similaridade. O mesmo comportamento não ocorre com os hubs, quando observada a Figura 4.1(b), que se manteve monotonicamente decrescente.

O segundo experimento foi realizado com objetivo de analisar o impacto do número de instantes de tempo contidos no perfil de expressão temporal, na inferência das redes. As Figuras 4.2, 4.3, $4.4 \mathrm{e}$ 4.5 apresentam esses resultados considerando-se, respectivamente, as topologias de redes complexas ER, WS, BA e GN, nas quais o grau médio de conexões $\langle k\rangle$ foi observado individualmente a fim de 


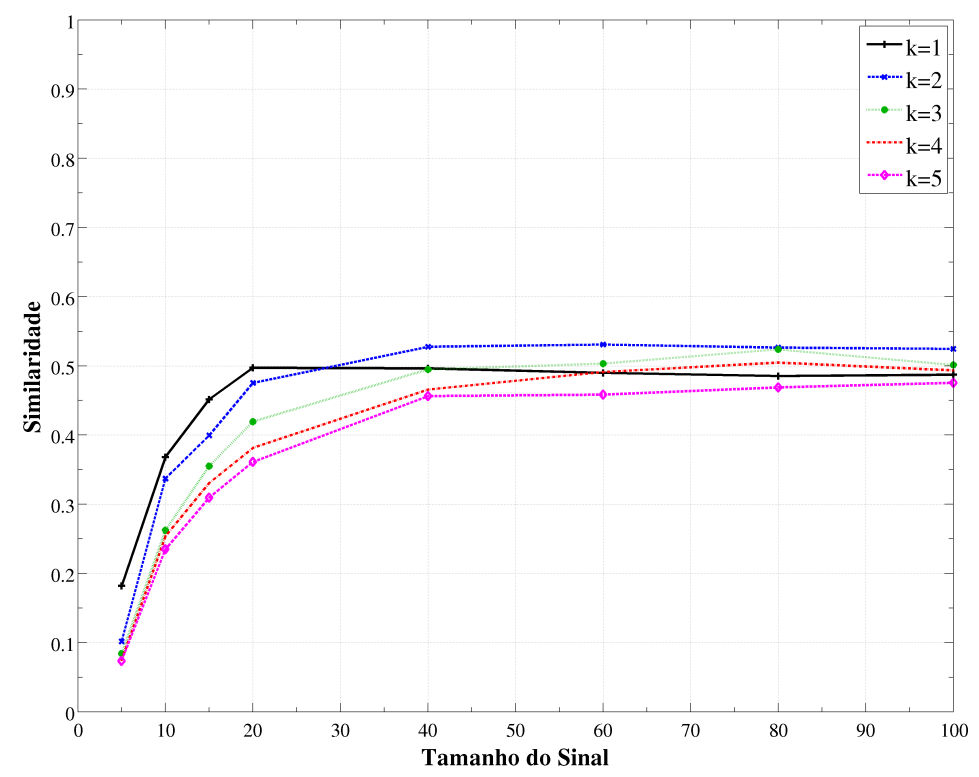

(a) GN - todos os genes

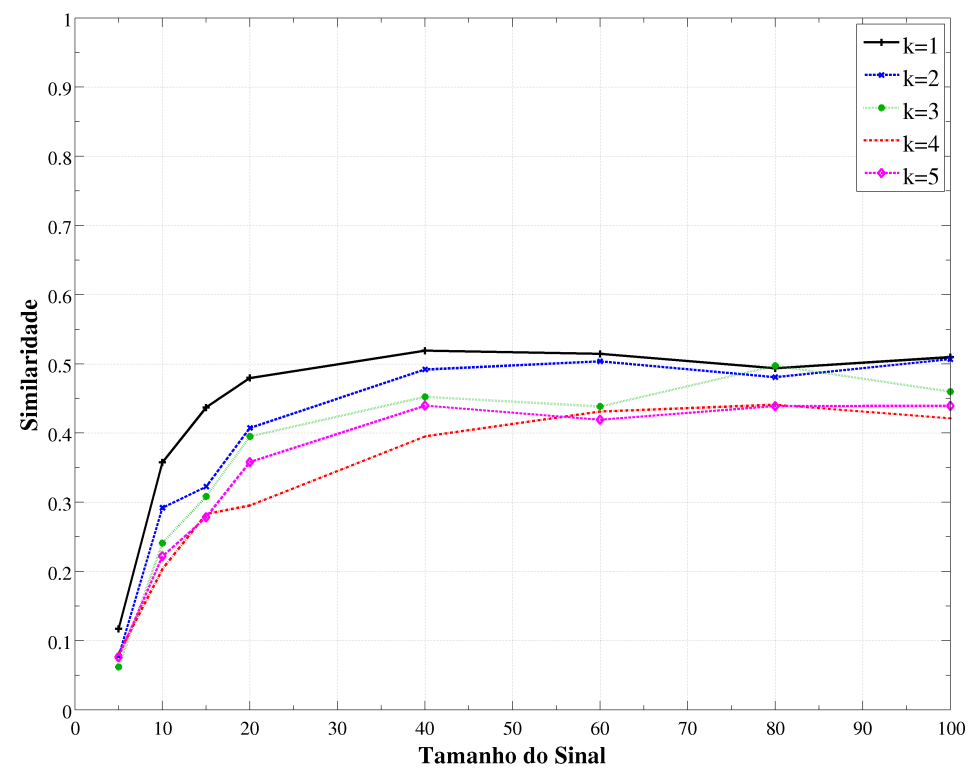

(b) GN - hubs

Figura 4.5: Medida de similaridade obtida pelo aumento do número de instantes de tempo da expressão temporal (tamanho do sinal), (a) considerando todos os genes da rede GN e (b) considerando apenas $10 \%$ dos genes mais conectados da rede GN, i.e., hubs.

identificar a Similaridade obtida em diferentes escalas de complexidade da rede.

É possível observar uma melhoria significativa na Similaridade até aproximadamente 20 instantes de tempo para os quatro modelos de redes, indicando, como esperado, que o tamanho do sinal é um fator importante para a correta recuperação da rede. No entanto, é importante observar que para essas redes, que envolvem $2^{100}$ estados possíveis, foi possível obter em média mais de $50 \%$ de Similaridade da rede depois de considerar apenas 40 instantes de tempo. O mesmo comportamento ocorreu para os hubs. Esses resultados mostram uma propriedade importante do método de inferência, que foi capaz de obter uma boa taxa de Similaridade, observando poucos instantes de tempo. Outra propriedade importante foi a recuperação dos hubs, que ocorreu em uma taxa semelhante à de outros genes menos conectadas da rede. 


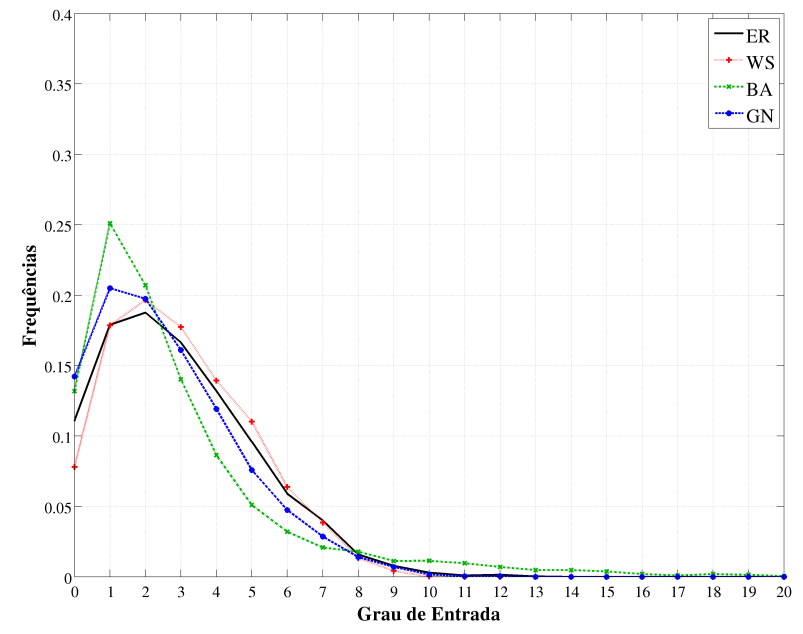

(a) Distribuição dos graus de entrada das AGNs

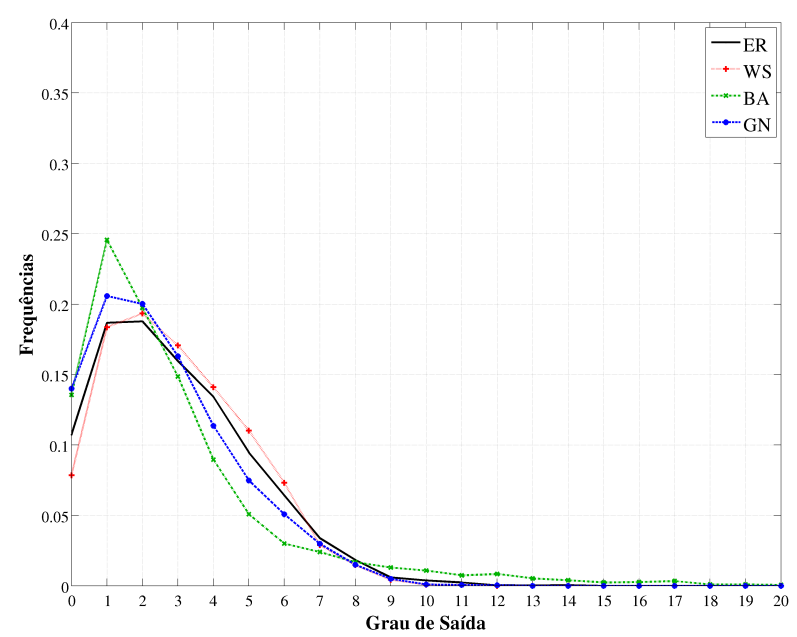

(c) Distribuição dos graus de saída das AGNs

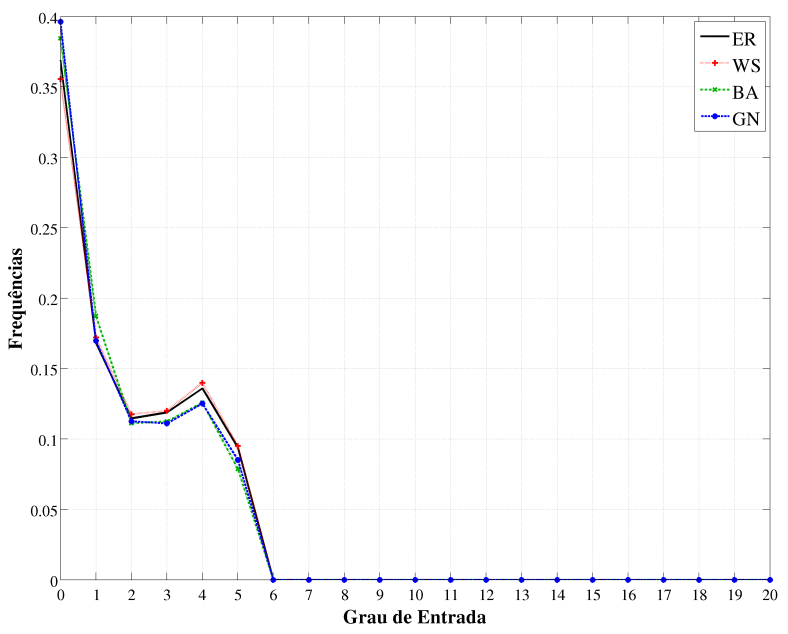

(b) Distribuição dos graus de entrada das redes inferidas

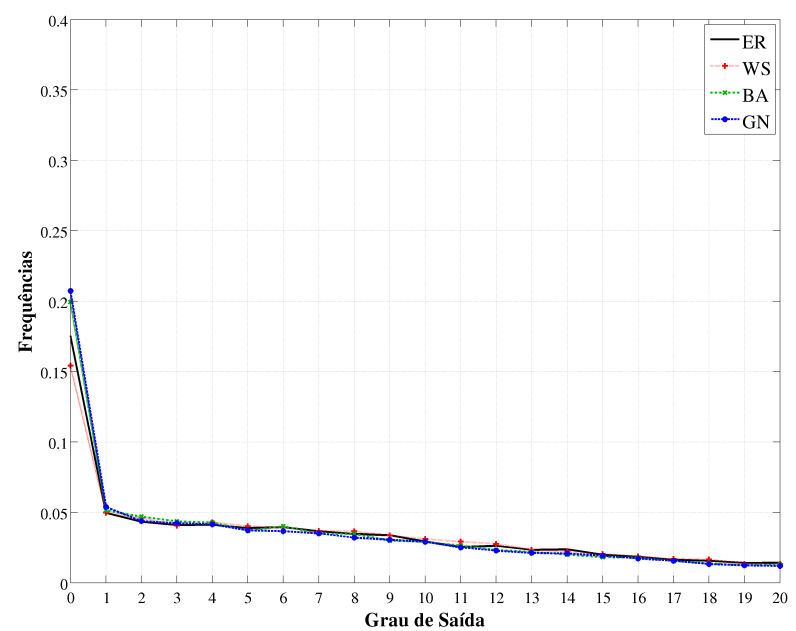

(d) Distribuição dos graus de saída das redes inferidas

Figura 4.6: Distribuições dos graus de entrada e saída, obtidos a partir das AGNs e das redes inferidas, considerando-se a distribuição média das conexões das redes sobre todas as variações de tamanho de sinal e grau médio $\langle k\rangle$.

Surpreendentemente, o método de inferência não foi sensível à variação da topologia da rede, apresentando respostas semelhantes para diferentes topologias. Para investigar este comportamento, foram gerados os histogramas das distribuições, de entrada e de saída, das conexões dos genes das redes, considerando-se a média (entrada e saída das arestas) dos genes sobre todas as variações do tamanho do sinal e do grau médio $\langle k\rangle$.

Os resultados experimentais, apresentados na Figura 4.6, mostram que a metodologia AGN, adotada para a construção das topologias das redes, produz uma quantidade equilibrada entre as conexões de entrada e saída. Por outro lado, esses resultados confirmam que o método de inferência produz respostas muito semelhantes para todas as topologias, i.e., não mostrou-se sensível ao identificar as diferentes estruturas de relacionamentos entre os genes, as quais foram geradas por diferentes topologias de rede. Além disso, a distribuição dos graus de saída das redes inferidas indicam que vários genes não são selecionadas como preditores, enquanto outros participam da predição de muitos genes. 


\subsection{Estudo Comparativo entre Métodos de Inferência de GRNs}

Nesta seção, são apresentados os resultados obtidos a partir de um estudo comparativo [Lopes et al., 2009a], no qual dois modelos distintos de redes complexas são confrontados, com objetivo de analisar a importância da topologia de rede para os métodos de inferência apresentados na Seção 2.6. As redes aleatórias (ER), que possuem uma distribuição de Poisson nas conexões dos genes e, as redes scale-free (BA), que possuem uma distribuição na forma de lei de potência nas conexões dos genes, foram testadas. Essas redes e, seus respectivos perfis de expressão, foram obtidas considerando-se o modelo AGN [Lopes et al., 2008a] determinístico, i.e., aplicando-se uma única função de transição entre os genes alvos e seus preditores. Outro objetivo aqui é investigar o impacto da variação do grau médio em ambos os modelos de redes.

Em todos os experimentos desta seção, foram considerados os modelos de redes (ER e BA) contendo 100 genes. O grau médio de conexões $\langle k\rangle$ variou entre $1,2, \ldots, 5$ e as observações temporais foram geradas com tamanho fixo, com 300 instantes de tempo. Os resultados experimentais apresentam os resultados médios obtidos de 50 simulações para cada topologia de rede (ER e BA) e grau médio $\langle k\rangle$. Os métodos de inferência de redes, aplicados neste experimento, foram obtidos a partir dos softwares disponíveis em [Meyer et al., 2008, Lopes et al., 2008c], apresentados na Seção 2.6, que foram aplicados na inferência de GRNs utilizando-se seus parâmetros padrões.

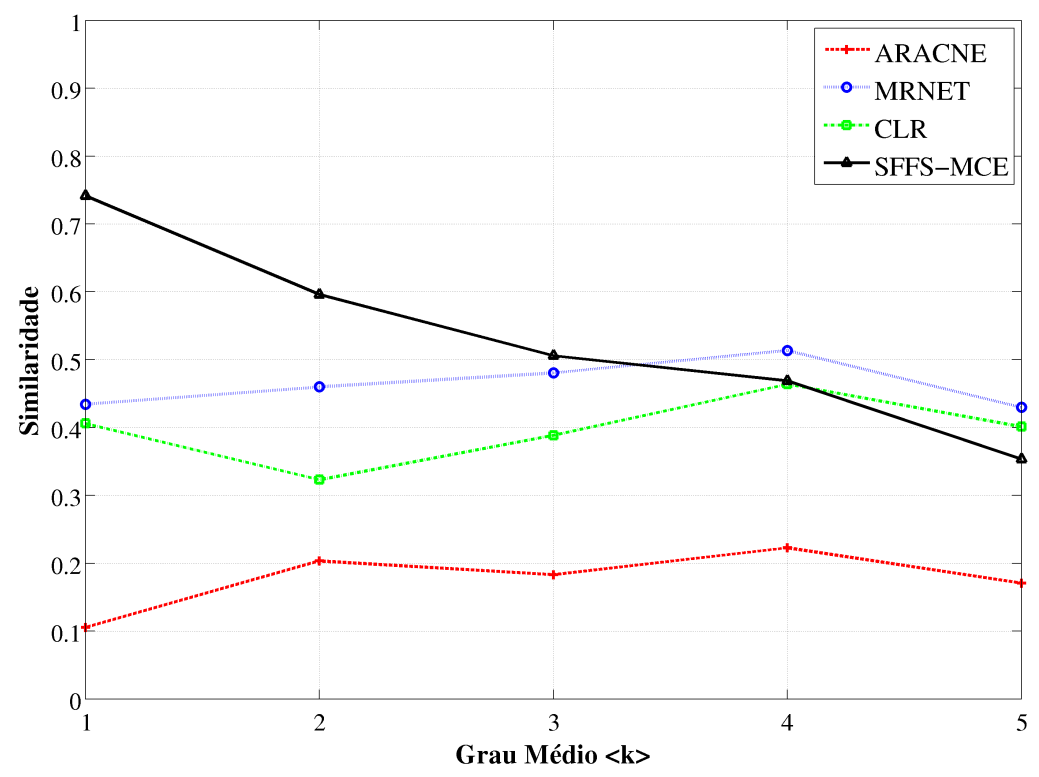

Figura 4.7: Medida de similaridade obtida pelo aumento do grau médio de conexões (arestas) por gene (vértice), i.e., $\langle k\rangle$, considerando-se os métodos de inferência ARACNE, MRNET, CLR e SFFS-MCE, aplicados ao modelo de redes aleatórias de Erdös-Rényi (ER). A medida de similaridade aplicada neste resultado é dada por Similaridade $=\sqrt{\text { Sensibilidade } \times \text { Especificidade }}$, entre as AGNs e as redes inferidas pelos respectivos métodos.

As Figuras 4.7 e 4.8 exibem a Similaridade (descrita na Seção 3.3) entre as AGNs e as redes inferidas, em termos do grau médio de conexões, considerando, respectivamente, as topologias ER e BA. A medida de Similaridade adotada aqui considera a média geométrica entre a Sensibilidade (razão entre verdadeiros positivos e falsos negativos) e Especificidade (razão entre verdadeiros negativos e falsos positivos).

Nas Figuras 4.7 e 4.8, observa-se claramente que apenas o método SFFS-MCE exibe uma importante queda de Similaridade ao aumentar a complexidade da rede em termos de seu número médio 


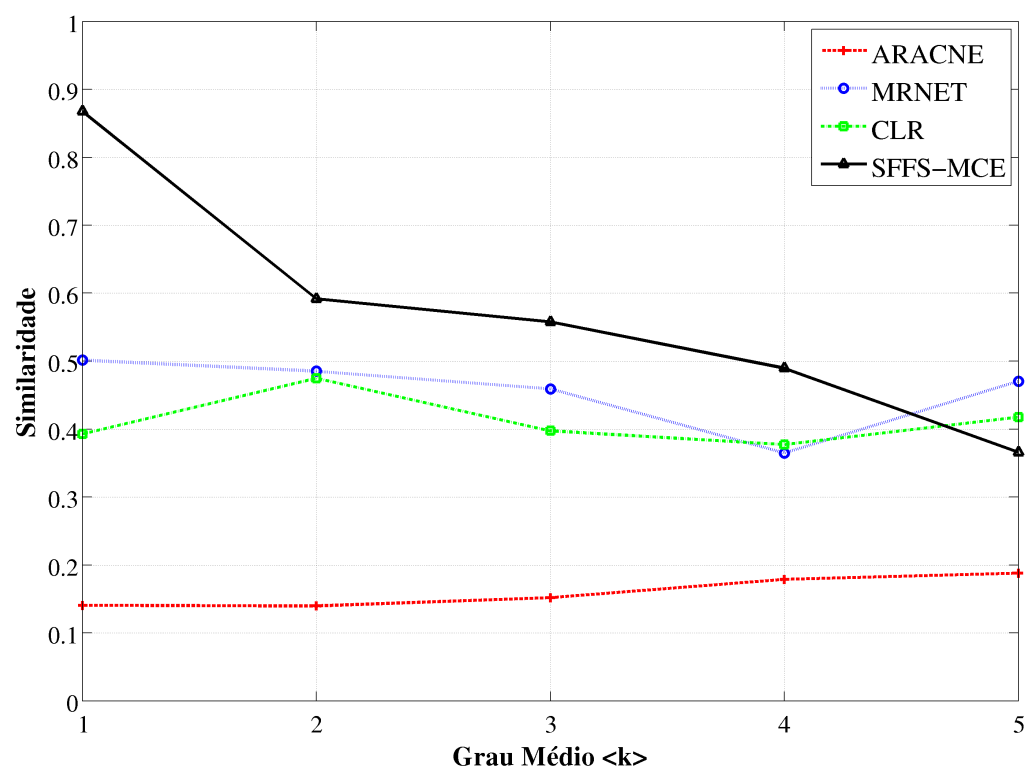

Figura 4.8: Medida de similaridade obtida pelo aumento do grau médio de conexões (arestas) por gene (vértice), i.e., $\langle k\rangle$, considerando-se os métodos de inferência ARACNE, MRNET, CLR e SFFS-MCE, aplicados ao modelo de redes scale-free de Barabási-Albert (BA). A medida de similaridade aplicada neste resultado é dada por Similaridade $=\sqrt{\text { Sensibilidade } \times \text { Especificidade }}$, entre as AGNs e as redes inferidas pelos respectivos métodos.

de conexões $\langle k\rangle$. Esse comportamento era esperado devido ao fato das redes geradas (AGNs) terem mais conexões para valores maiores de $\langle k\rangle$, i.e., o perfil de expressão do gene alvo é determinado pela composição de funções Booleanas de um número maior de preditores, gerando funções Booleanas sofisticadas, as quais são mais difíceis de identificar pelos métodos de inferência. Curiosamente, o método MRNET apresenta uma ligeira melhoria dos resultados para os graus médios de $\langle k\rangle=1$ até $\langle k\rangle=4$, considerando a topologia ER (Figura 4.7). Considerando-se a topologia BA, na Figura 4.8, o desempenho do método MRNET é invertido, i.e., ele apresenta uma ligeira diminuição da taxa de Similaridade a partir de $\langle k\rangle=1$ até $\langle k\rangle=4$.

Para ambas as topologias de redes, o método SFFS-MCE apresentou os melhores resultados, considerando-se as redes contendo um número médio de conexões $\langle k\rangle \leq 3$ para a topologia ER e $\langle k\rangle \leq 4$ para a topologia BA, atingindo $86 \%$ de Similaridade para as redes BA e $74 \%$ para as redes ER, quando $\langle k\rangle=1$. O método de inferência MRNET, teve melhor desempenho para redes mais complexas, i.e., $\langle k\rangle \geq 4$ para a topologia ER e $\langle k\rangle=5$ para a topologia BA. O método CLR apresentou um comportamento muito próximo do método MRNET, mas apresentando taxas de Similaridade um pouco menor. A melhor taxa de recuperação de redes exibida pelo método MRNET quando comparado ao método CLR, pode ser explicada pela inclusão do termo de redundância ao método MRNET, como apresentado na Seção 2.6.4. O método ARACNE apresentou as menores taxas de Similaridade em todos os experimentos.

Uma propriedade importante a ser considerada ao analisar esses resultados é que os sistemas dinâmicos, como os sistemas biológicos, estão na fronteira entre exibirem um comportamento caótico e não-caótico. Os componentes (genes) de tais sistemas apresentam um grau de conexões, em média, entre 2 e 3 [Kauffman, 1993], indicando que o método SFFS-MCE, entre os métodos testados e considerando a metodologia aplicada, se mostrou mais eficiente na inferência de GRNs para essa faixa de valores de conectividade média. 


\subsection{Função Critério Baseada na Entropia de Tsallis}

O uso da teoria da informação (entropia e informação mútua) como função critério para o problema de inferência de redes não é novo e, tem sido largamente aplicada para a inferência de GRNs nos últimos anos [Cheng et al., 1997, Liang et al., 1998, Margolin et al., 2006, Barrera et al., 2007, Meyer et al., 2007, Bansal et al., 2007, Zhao et al., 2008, Kim et al., 2010]. Seu uso é explicado pela possibilidade de que alguns genes podem ser bem preditos, observando os estados de outros genes em uma GRN, o que torna o uso da entropia condicional apropriada. Se a relação entre esses genes são lineares, uma simples análise de correlação de Pearson seria suficiente para obter uma boa descrição da GRN. No entanto, quando a relação entre os genes não é linear e descrita por funções de mais de um gene preditor, espera-se que a inferência por meio de métodos baseados no conceito de entropia produzam melhores resultados do que aqueles baseados em correlação de Pearson. Naturalmente, isso leva à necessidade de investigar a sensibilidade ou rigidez desses métodos em relação à extensividade da entropia aplicada nesta tarefa.

Neste contexto, é explorada neste trabalho uma função critério baseada na entropia generalizada de Tsallis [Lopes et al., 2009a, Lopes et al., 2011b] (veja Seção 3.2.1). Os experimentos foram conduzidos com objetivo de não apenas investigar a adequação da entropia generalizada de Tsallis à inferência de GRNs, mas também investigar a possibilidade da não extensividade das redes, levando a uma possível dependência da inferência sobre a forma funcional de entropia. Outro objetivo foi o de caracterizar como essa dependência ocorre em termos do parâmetro entrópico $q$. Assim, foram desenvolvidos alguns experimentos e seus resultados são apresentados nesta seção.

Com objetivo de verificar o efeito do parâmetro entrópico $q$, foram realizados alguns experimentos de inferência, considerando dois tipos de topologias de rede: redes aleatórias de Erdös-Rényi (ER) e redes scale-free de Barabási-Albert (BA). No modelo ER, cada ligação (aresta) está presente com igual probabilidade, de tal forma que a distribuição de probabilidade da conectividade dos genes segue uma distribuição de Poisson, com média em $\langle k\rangle$. Por outro lado, no modelo BA, a probabilidade de um novo gene $v_{j}$ ser conectado a um gene $v_{i}$ é proporcional à conectividade de $v_{i}$, o que produz uma lei de potência na distribuição da conectividade entre os genes dessa rede.

O conjunto de dados de expressão foi gerado a partir de redes (ER e BA) contendo 100 genes, i.e., $n=100$. Para cada modelo de rede, foram gerados perfis de expressão contendo 300 instantes de tempo. Essas redes e seus respectivos perfis de expressão foram obtidos considerando-se o modelo AGN [Lopes et al., 2011a], de acordo como apresentado na Seção 3.1, no qual o grau médio de conexões por gene $\langle k\rangle$ foi variado de 1 até 5 , Para cada gene $v_{i}$, sua dinâmica foi gerada a partir da seleção aleatória entre 3 possíveis funções de transição Booleanas $\left\{f_{1}^{(i)}, f_{2}^{(i)}, f_{3}^{(i)}\right\}$, com as respectivas probabilidades de serem selecionadas $c_{1}^{(i)}=0.95, c_{2}^{(i)}=0.025, c_{3}^{(i)}=0.025, i=1, \ldots, n$.

A inferência das redes foi obtida a partir da metodologia proposta por [Barrera et al., 2007], apresentada na Seção 2.3.5, aplicando o algoritmo SFFS e a função critério baseada na entropia de Tsallis, apresentada na Seção 3.2.1 (Equação 3.2). Durante o processo de inferência, o valor do parâmetro entrópico $q$ sofreu uma variação, a partir de 0,1 até 3,1 em incrementos de 0,1 e de 3,1 até 10,1 em incrementos de 0,5, i.e., a Similaridade entre as AGNs e a redes inferidas foi obtida para cada valor de $q$ nesses intervalos.

As curvas de Similaridade exibidas na Figura 4.9 foram obtidas a partir da média sobre 50 execuções (50 AGNs diferentes) para cada um dos modelos de rede (ER e BA) e conectividade $\langle k\rangle$. Em ambos os modelos de rede, foram observadas melhorias na similaridade variando o parâmetro 


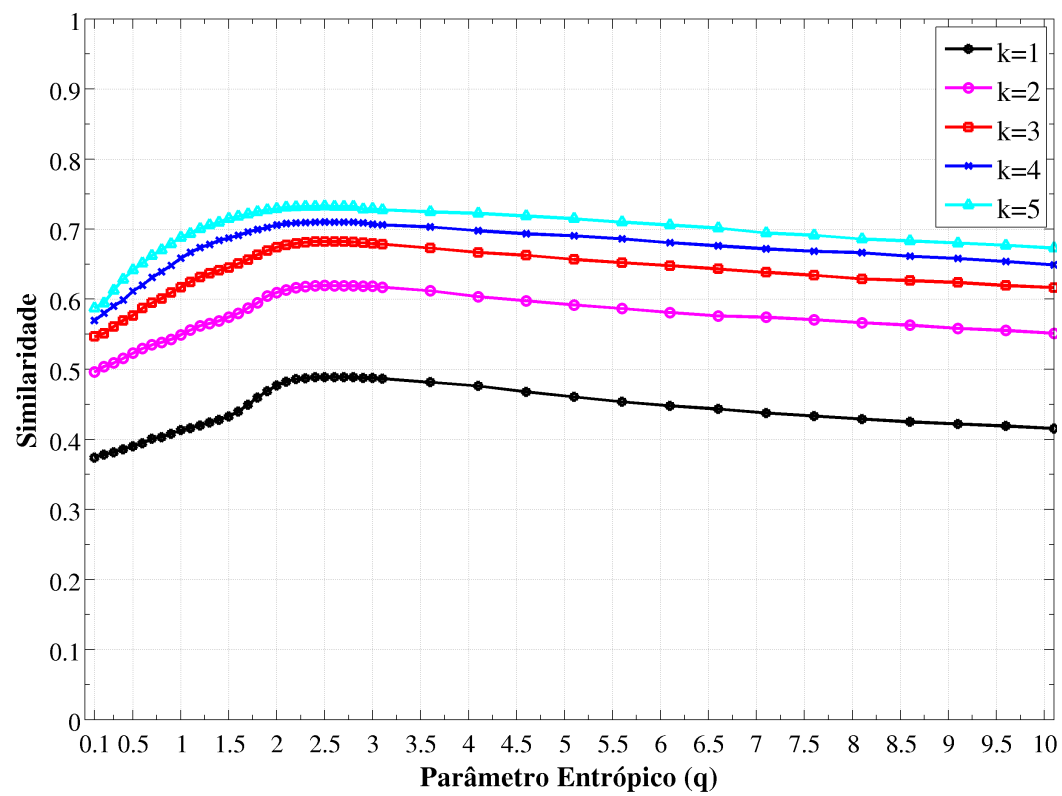

(a) modelo de rede ER

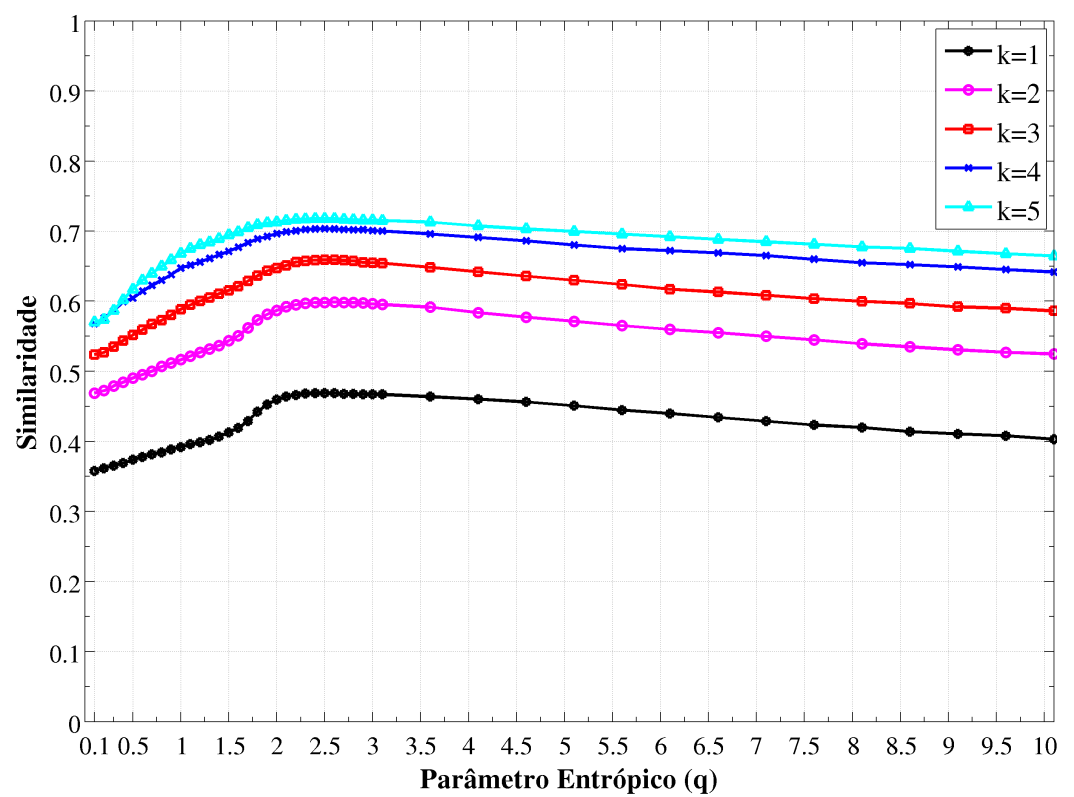

(b) modelo de rede BA

Figura 4.9: Medida de similaridade entre as AGNs e as redes inferidas obtida em função da variação do parâmetro entrópico $q$, considerando-se os graus médios de conectividade $1 \leqslant\langle k\rangle \leqslant 5:(a)$ redes aleatórias de Erdös-Rényi (ER) e (b) redes scale-free de Barabási-Albert (BA). A similaridade aplicada neste resul-

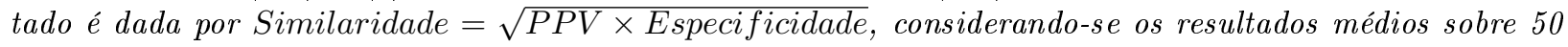
execuções e redes contendo 100 genes.

entrópico $q$, atingindo o máximo de Similaridade quando $q \neq 1$, entre todos os valores de conexões médias $\langle k\rangle$. Além disso, também pode ser notado que o $q^{*}$ que maximiza a Similaridade parece ser quase independente do modelo de rede e da conectividade média.

Com objetivo de melhor investigar esse comportamento, a Figura 4.10 mostra as curvas de frequência normalizada dos melhores valores do parâmetro entrópico $q$, no sentido de terem obtido a melhor taxa de Similaridade para cada gene da rede. Pode ser claramente observado que as frequências mais elevadas estão concentradas na faixa de valores entre $2 \leqslant q \leqslant 3$ para ambos os 


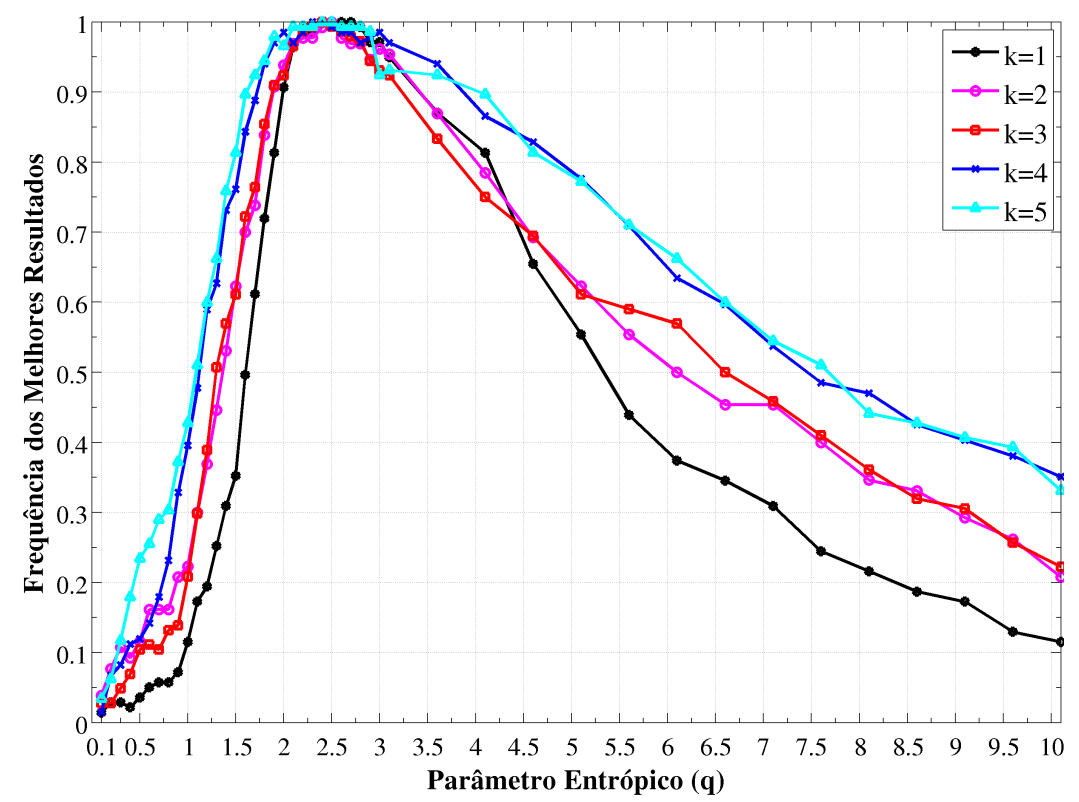

(a) modelo de rede ER

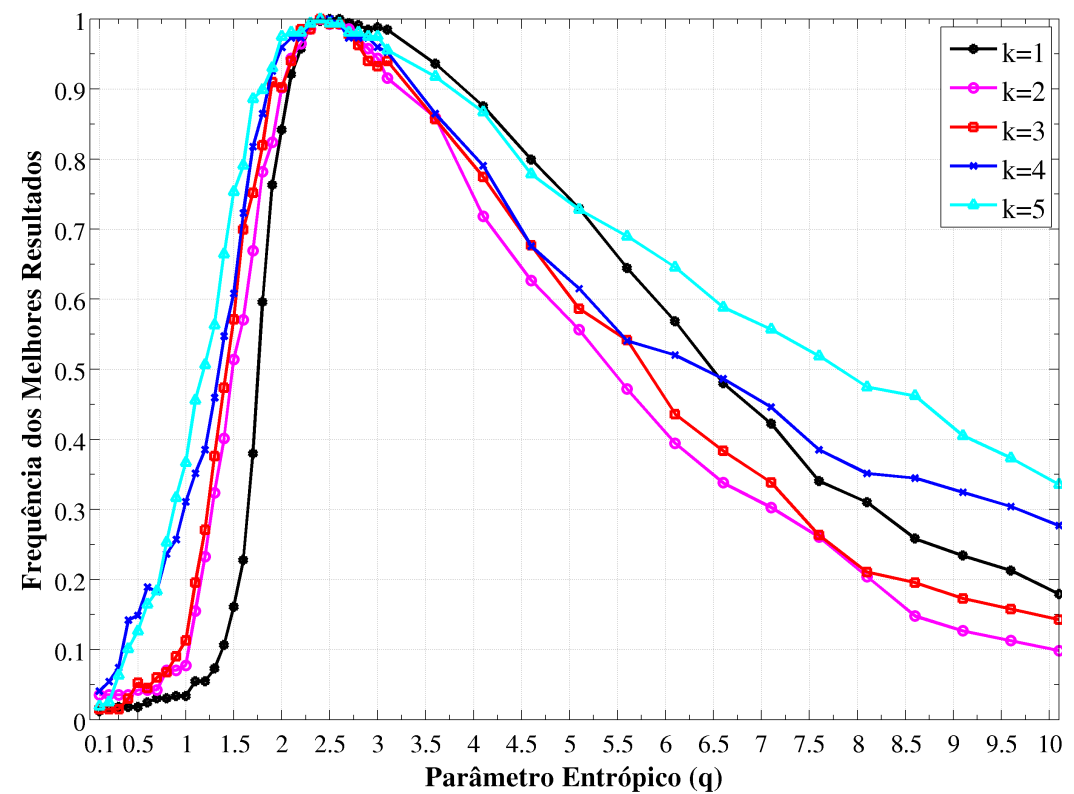

(b) modelo de rede BA

Figura 4.10: Curvas das frequências normalizadas das melhores taxas de similaridade obtidas em função do parâmetro $q$, para cada gene alvo e grau médio de conexões $(1 \leqslant\langle k\rangle \leqslant 5)$ : (a) redes aleatórias de ErdösRényi (ER) e (b) redes scale-free de Barabási-Albert (BA). A similaridade aplicada neste resultado é dada por Similaridade $=\sqrt{P P V \times E s p e c i f i c i d a d e}$, considerando-se os resultados médios sobre 50 execuções e redes contendo 100 genes.

modelos de rede e valores médios de conectividade $\langle k\rangle$. Esses resultados indicam e reforçam os resultados anteriores (Figura 4.9) quanto à independência da topologia de rede para a melhoria da inferência, quando aplicada a metodologia de inferência baseada na entropia generalizada de Tsallis, i.e., $q \neq 1$.

Em particular, considerando as curvas de frequências, exibidas na Figura 4.10, o valor médio do parâmetro $q^{*}$ foi calculado para cada modelo de rede e conectividade média. Os valores médios são apresentados na Tabela 4.1. Essas médias parecem ser quase constantes, ficando próximas de 3,20 
para o modelo ER e 3, 23 para o modelo BA, bem como as frequências mais altas das curvas obtidas pela variação do parâmetro $q$, i.e., a amplitude máxima nas curvas de frequências. Esses resultados experimentais reforçam a evidência de que a melhoria nas curvas de Similaridade, exibidas na Figura 4.9, é independente da topologia de rede escolhida e conectividade média, considerando-se os modelos de redes e intervalos de valores testados.

Tabela 4.1: Médias das curvas de frequências da Figura 4.10.

\begin{tabular}{|c|c|c|}
\hline$\langle k\rangle$ & modelo de rede ER & modelo de rede BA \\
\hline 1 & $\langle q\rangle=3,12$ & $\langle q\rangle=3,52$ \\
2 & $\langle q\rangle=3,18$ & $\langle q\rangle=3,05$ \\
3 & $\langle q\rangle=3,23$ & $\langle q\rangle=3,10$ \\
4 & $\langle q\rangle=3,28$ & $\langle q\rangle=3,18$ \\
5 & $\langle q\rangle=3,21$ & $\langle q\rangle=3,32$ \\
\hline
\end{tabular}

Com o objetivo de confirmar os resultados obtidos, também foi investigado o comportamento da metodologia de inferência proposta, utilizando-se os dados fornecidos pelo DREAM4, quarta edição do diálogo para avaliações de métodos de engenharia reversa (do inglês, Dialogue for Reverse Engineering Assessments and Methods) [DREAM, 2009]. Nesse desafio, foram considerados os dados temporais, para os quais foram disponibilizadas 5 redes contendo 10 genes e outras 5 redes contendo 100 genes, cada uma delas contendo diferentes conexões. Para as redes de tamanho 10, foram disponibilizados 5 perfis de expressão, enquanto para as redes contendo 100 genes, foram disponibilizados 10 perfis de expressão. Cada perfil de expressão, para ambos os tamanhos de redes, possuem 21 instantes de tempo gerados a partir de um modelo de equações diferenciais com a presença de ruído.

A mesma metodologia foi aplicada, incluindo os parâmetros utilizados. Apenas uma etapa adicional foi incluída para a quantização dos dados disponibilizados pelo desafio DREAM4, uma vez que o uso da entropia condicional média exige a quantização dos dados para valores discretos. Para a quantização desses dados foi aplicado o método descrito em [Lopes et al., 2008c], no qual foram considerados dois níveis para redes de tamanho 10 e três níveis para redes de tamanho 100, com objetivo de capturar as variações de expressão dos genes pelos valores discretos, i.e., 0,1 e $-1,0,1$ respectivamente. Todos os instantes de tempo disponíveis para cada rede foram concatenados formando um único sinal. Em seguida, o sinal quantizado, de cada uma das 5 redes e tamanhos diferentes, foi submetido à mesma metodologia de inferência aplicada anteriormente. A Figura 4.11 exibe os resultados médios para cada tamanho de rede DREAM: 10 e 100. É possível notar uma melhoria na medida de Similaridade, variando o parâmetro $q$, em que os melhores resultados foram obtidos por $q \neq 1$ para os dois tamanhos de rede.

A Figura 4.12 apresenta as frequências normalizadas, nas quais o valor de $q$ foi capaz de inferir o melhor subconjunto de preditores (maior Similaridade observando a rede original) para cada gene. As frequências mais altas estão concentradas na faixa $2,2 \leqslant q \leqslant 4,1$ para as redes DREAM de tamanho 10 e na faixa $3,2 \leqslant q \leqslant 5,5$ para as redes DREAM de tamanho 100 .

Em relação à curva de frequência da Figura 4.12, as médias do parâmetro entrópico $q^{*}$ foram calculadas para cada tamanho de rede: 3,30 para as redes de tamanho 10 e 3,92 para as redes de tamanho 100. Esses valores são semelhantes aos apresentados para as redes de ER e BA, mas com valor um pouco maior para a rede DREAM contendo 100 genes. Neste contexto, é importante destacar a existência de um intervalo de valores de $q$ que produzem melhores resultados na inferência 


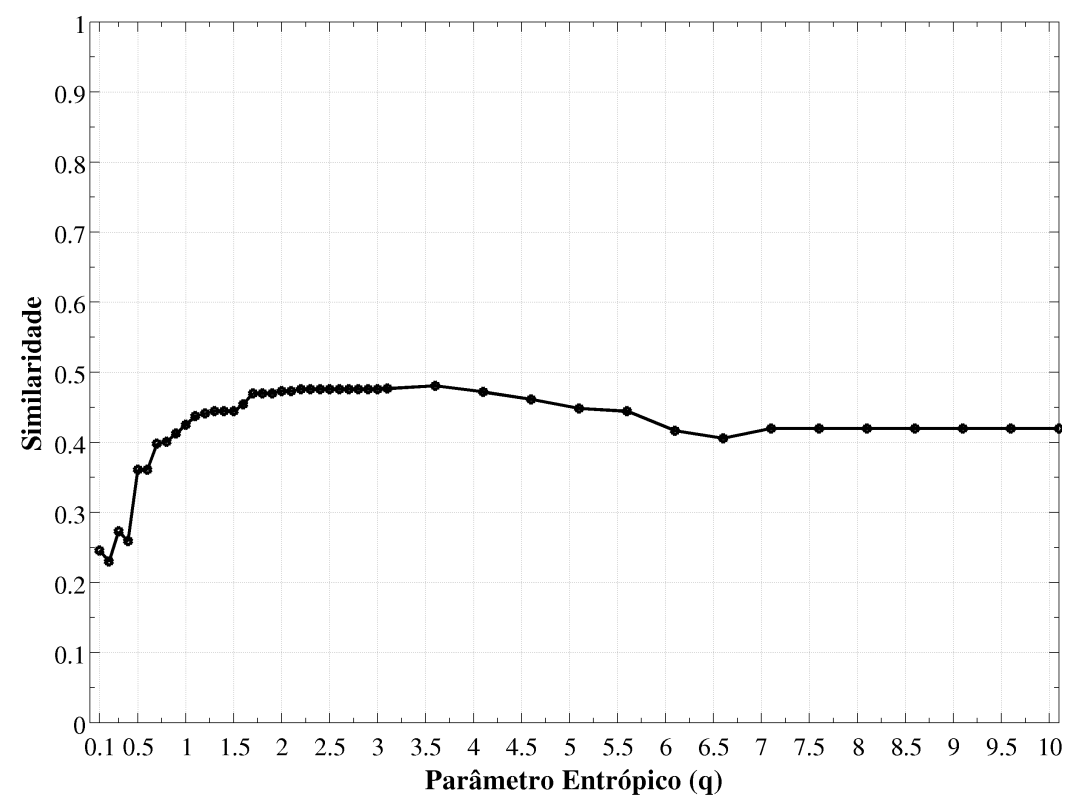

(a) DREAM contendo 10 genes

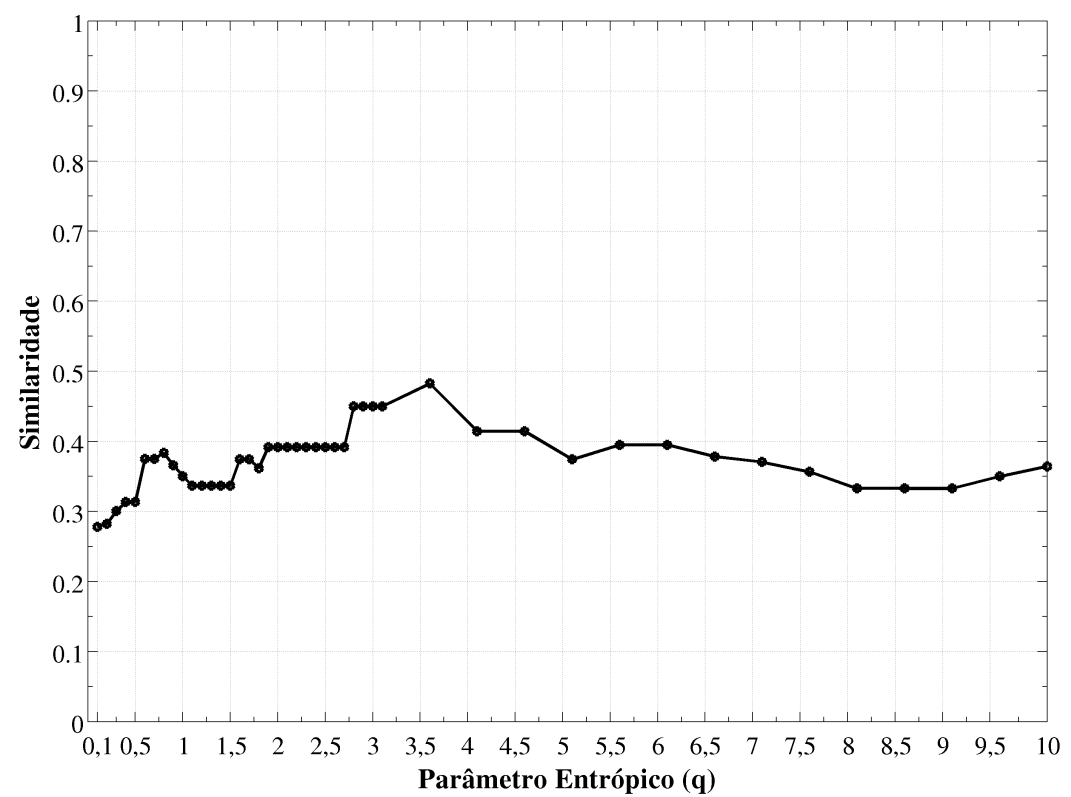

(b) DREAM contendo 100 genes

Figura 4.11: Medida de similaridade entre as redes DREAM e as redes inferidas obtida em função da variação do parâmetro entrópico q, considerando-se os resultados médios de cada rede DREAM: (a) contendo 10 genes e (b) contendo 100 genes. A similaridade aplicada neste resultado é dada por Similaridade $=$ $\sqrt{P P V} \times$ Especificidade, considerando-se os resultados médios sobre as redes DREAM.

das redes, que em média ficou entre $2,5 \leqslant q \leqslant 3,5$, indicando que a entropia sub extensiva produz melhores resultados, e, consequentemente, se mostrou mais adequada para a inferência das redes.

Em geral, pode-se observar nos resultados uma diferença de Similaridade quando aplicados diferentes valores para o parâmetro entrópico $q$, mantendo-se fixos todos os demais parâmetros e metodologia adotada. A medida de Similaridade máxima obtida para todos os modelos de rede testados foi alcançada pelo parâmetro entrópico $q \neq 1$, com uma melhoria de $20 \%$ na medida de Similaridade quando comparados os resultados com os obtidos a partir de $q=1$ (veja Figuras 4.9 e 4.11). Com objetivo de oferecer uma melhor visualização dessa melhoria, a Tabela 4.2 exibe o 


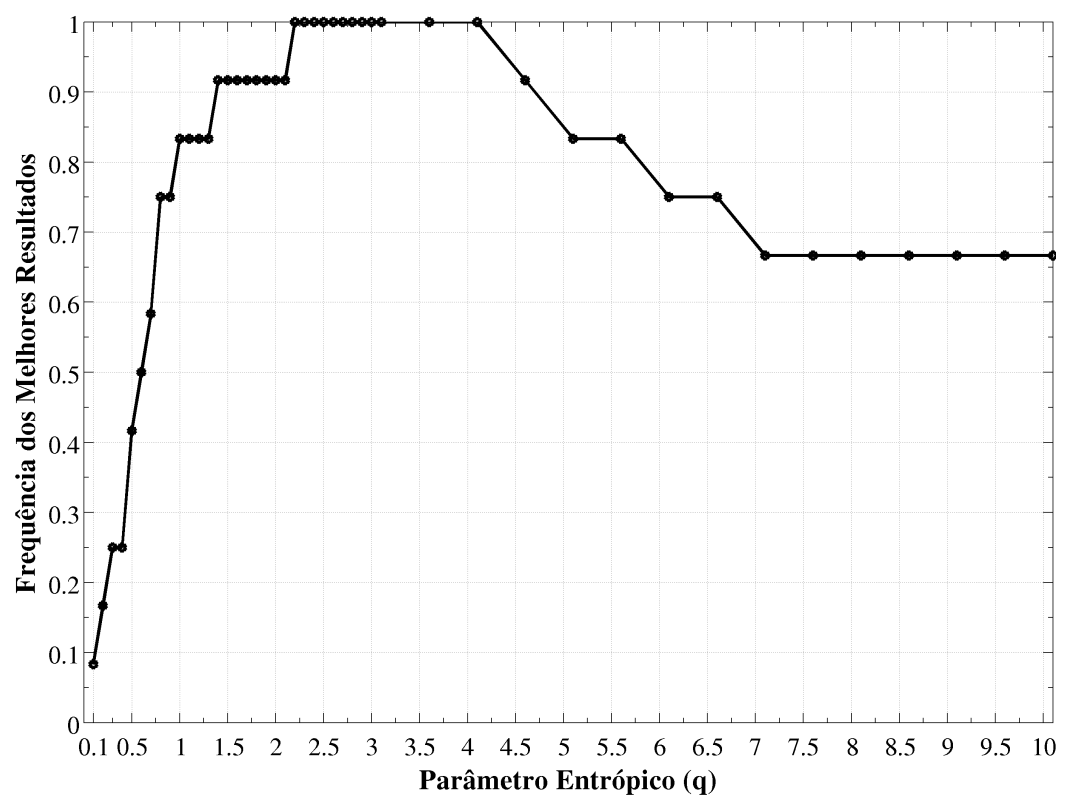

(a) DREAM contendo 10 genes

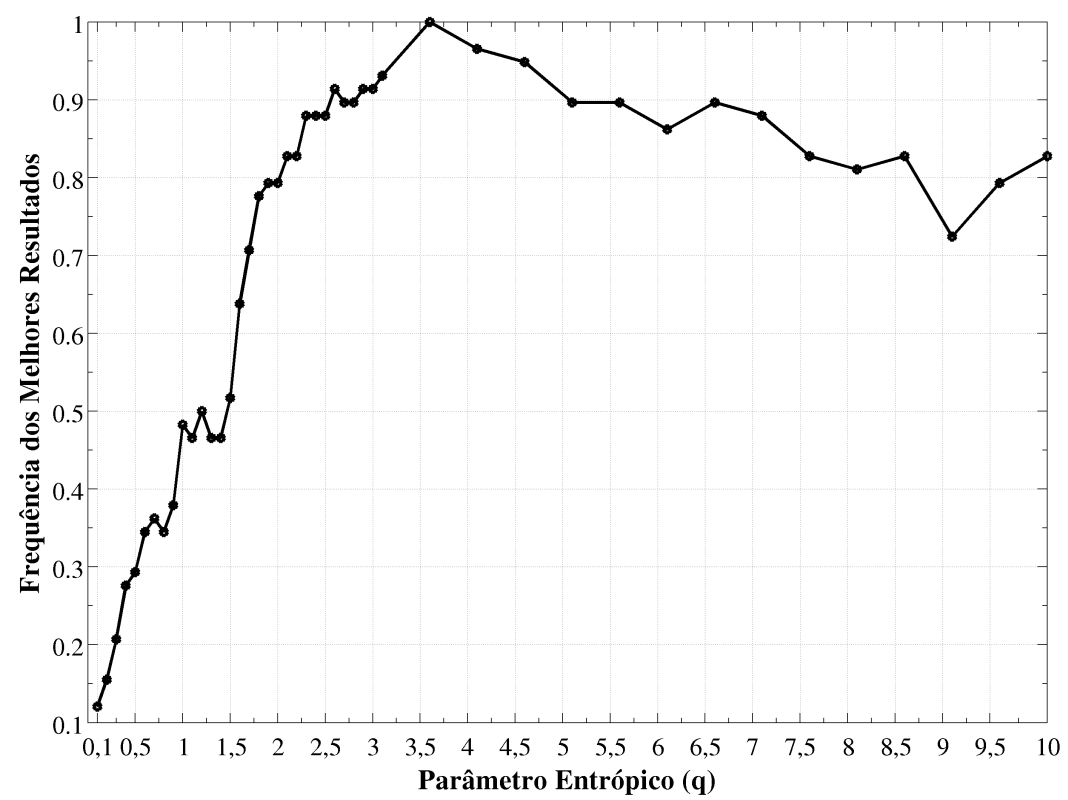

(b) DREAM contendo 100 genes

Figura 4.12: Curvas das frequências normalizadas das melhores taxas de similaridade obtidas em função do parâmetro q, considerando-se os resultados médios de cada rede DREAM: (a) contendo 10 genes e (b) contendo 100 genes. A similaridade aplicada neste resultado é dada por Similaridade = $\sqrt{P P V \times E s p e c i f i c i d a d e}$, considerando-se os resultados médios sobre das redes DREAM.

número médio de arestas corretamente e incorretamente inferidas para os modelos de redes ER e BA.

A Tabela 4.2 apresenta o número de conexões, corretamente e incorretamente inferidas considerando-se cada gene individualmente. É possível notar uma precisão muito boa de recuperação das conexões (TP e FP), para os modelos de redes ER e BA quando adotado o parâmetro entrópico $q=2,5$ (entropia sub extensiva). Neste contexto, a inferência das conexões falsas $(F P)$ parece ser dependente da forma funcional da entropia. No entanto, os modelos de rede ER e BA não parecem ser dependentes. Além disso, a redução do número de falsos positivos $(F P)$ inferidos não 
parece depender do modelo de rede, i.e., em ambos os resultados (ER e BA), houve uma redução significativa da inferência de conexão que não existem entre um par de genes $(F P)$. Isso indica uma inferência mais conservadora quando é aplicado um $q \approx 2,5$, mesmo para redes com alta conectividade. O número de falsos positivos obtidos pela entropia de Shannon, quando $\langle k\rangle=5$, foi mais de seis vezes maior que os obtidos pela entropia generalizada de Tsallis com o parâmetro entrópico $q=2,5$ para as redes BA, e mais de oito vezes maior para as redes ER.

Tabela 4.2: Resultados obtidos pela inferência de redes, aplicando o parâmetro entrópico $q=2,5$ (sub extensivo) comparado com a entropia de Shannon (extensiva, com $q=1$ ): (a) redes aleatórias de ErdösRényi (ER) e (b) redes scale-free de Barabási-Albert (BA).

(a) modelo de rede ER

\begin{tabular}{|c|c|c|c|c|c|}
\hline$q$ & $k$ & TP & FP & FN & TN \\
\hline 1 & \multirow{2}{*}{1} & 223 & 229 & 21 & 9735 \\
2,5 & & 229 & 105 & 15 & 9741 \\
\hline 1 & \multirow{2}{*}{2} & 311 & 162 & 27 & 9635 \\
2,5 & & 320 & 50 & 18 & 9644 \\
\hline 1 & \multirow{2}{*}{3} & 344 & 131 & 36 & 9584 \\
2,5 & & 362 & 17 & 18 & 9602 \\
\hline 1 & \multirow{2}{*}{4} & 381 & 96 & 46 & 9527 \\
2,5 & & 397 & 15 & 30 & 9543 \\
\hline 1 & \multirow{2}{*}{5} & 383 & 96 & 91 & 9435 \\
2,5 & & 401 & 11 & 73 & 9453 \\
\hline
\end{tabular}

(b) modelo de rede BA

\begin{tabular}{|c|c|c|c|c|c|}
\hline$q$ & $k$ & $\mathbf{T P}$ & $\mathbf{F P}$ & $\mathbf{F N}$ & $\mathbf{T N}$ \\
\hline 1 & \multirow{2}{*}{1} & 168 & 285 & 47 & 9738 \\
2,5 & & 175 & 149 & 40 & 9745 \\
\hline 1 & \multirow{2}{*}{2} & 251 & 212 & 30 & 9689 \\
2,5 & & 259 & 83 & 22 & 9697 \\
\hline 1 & \multirow{2}{*}{3} & 304 & 156 & 55 & 9586 \\
2,5 & & 314 & 37 & 45 & 9596 \\
\hline 1 & \multirow{2}{*}{4} & 348 & 125 & 102 & 9448 \\
2,5 & & 356 & 21 & 94 & 9456 \\
\hline 1 & \multirow{2}{*}{5} & 360 & 110 & 117 & 9406 \\
2,5 & & 383 & 16 & 94 & 9429 \\
\hline
\end{tabular}

Os resultados experimentais forneceram evidências sobre a sensibilidade do processo de inferência para as entropias extensivas / não extensivas. Além disso, todos os resultados experimentais confirmam que a função critério proposta, baseada na entropia generalizada de Tsallis, pode melhorar a precisão do processo de inferência quando comparada com a entropia de Shannon, a qual é usualmente adotada nesta tarefa. Em particular, o uso da entropia não extensiva se mostrou um fator importante a ser investigado e explorado no processo de inferência de GRNs a fim de melhorar sua precisão. Sua aplicação abre novas perspectivas para os métodos de inferência baseados no princípio de minimização da entropia, com objetivo de obter uma melhor precisão na inferência de GRNs a partir de seus padrões de expressão gênica.

Dado os resultados experimentais, uma outra questão a ser explorada diz respeito a como ocorre 
essa melhoria, ou seja, qual característica está associada ao processo de inferência que torna a forma funcional da entropia de Tsallis, em particular a forma sub extensiva, mais adequada à inferência de GRNs. Neste sentido, foi observado que as distribuições de probabilidade entre as classes, com massa concentrada em uma das classes, são menos penalizadas quando aplicados valores para o parâmetro entrópico $q$ próximos a 2,5. Ao considerar que as GRNs (organismos) têm um comportamento estocástico e podem receber perturbações externas, espera-se que as distribuições de probabilidade entre as classes possíveis ${ }^{1}$ não sejam determinísticas, mas sim concentradas em uma das classes e apresentando pequenas perturbações. Em outras palavras, dada a natureza do sistema, é mais adequado que o método de inferência identifique conexões a partir de distribuições de probabilidades entre as classes que apresentem pequenos erros entre todas as instâncias, ao invés de conterem pequenos erros na distribuições para uma das instâncias e apresentar uma distribuição balanceada para a outra instância. Um aspecto importante que foi observado é que as entropias sub extensivas, e.g., valores de $q$ próximos a 2,5 , promovem essa adequação ao método de inferência utilizado. A Tabela 4.3 mostra um exemplo de distribuição de probabilidades entre as classes, que ilustra essa situação.

Tabela 4.3: Exemplo das mudanças nos preditores inferidos a partir da aplicação de diferentes valores para o parâmetro entrópico q: (a) distribuiçôes de probabilidade que, em geral, levam a um preditor errado e (b) distribuições de probabilidade que, em geral, levam a um preditor correto.

(a)

\begin{tabular}{|c|c|c|c|c|c|}
\hline & \multicolumn{2}{|c|}{ gene alvo } & \multicolumn{3}{c|}{ resultados da função critério } \\
\hline Preditor $A$ & $\mathbf{0}$ & $\mathbf{1}$ & $\mathbf{q}=\mathbf{0 , 5}$ & $\mathbf{q}=\mathbf{1}$ & $\mathbf{q}=\mathbf{2 , 5}$ \\
\hline 0 & 18 & 23 & 0,108 & 0,090 & 0,056 \\
1 & 278 & 0 & 0 & 0 & 0 \\
\hline \multicolumn{2}{|c|}{ entropia condicional média } & $0,108^{*}$ & $0,090^{*}$ & 0,056 \\
\hline
\end{tabular}

(b)

\begin{tabular}{|c|c|c|c|c|c|}
\hline & \multicolumn{2}{|c|}{ gene alvo } & \multicolumn{3}{c|}{ resultados da função critério } \\
\hline Preditor $B$ & $\mathbf{0}$ & $\mathbf{1}$ & $\mathbf{q}=\mathbf{0 , 5}$ & $\mathbf{q}=\mathbf{1}$ & $\mathbf{q}=\mathbf{2 , 5}$ \\
\hline 0 & 1 & 16 & 0,024 & 0,013 & 0,005 \\
1 & 295 & 7 & 0,265 & 0,104 & 0,036 \\
\hline \multicolumn{2}{|c|}{ entropia condicional média } & 0,289 & 0,117 & $0,041^{*}$ \\
\hline
\end{tabular}

A Tabela 4.3 mostra os estados dos preditores na primeira coluna e as respectivas frequências dos estados observados para o gene alvo em cada uma das classes ( 0 e 1 ) nas colunas dois e três. Essas distribuições de frequências entre as classes do preditor e o alvo são usadas para estimar as distribuições de probabilidades condicionais para um gene alvo dado a observação dos estados dos candidatos a preditor. As distribuições de probabilidades condicionais, por sua vez, são aplicadas no cálculo da entropia condicional média generalizada, adotada como função critério neste trabalho (veja Seção 3.2.1). Nas colunas quatro, cinco e seis, são dispostos os resultados da função critério para cada uma das distribuições de frequências, aplicando diferentes valores de $q$. Os resultados de entropia condicional média generalizada marcadas com * representam o mínimo alcançado pelo método e, portanto, selecionado como preditor para o alvo pelo método de inferência.

\footnotetext{
${ }^{1}$ No caso binário as classes são 0 ou 1.
} 
Como pode ser observado, o valor mínimo da função critério é alterado de acordo com a variação do parâmetro $q$, e assim também é alterado o gene selecionado como preditor. Para $q=0,5$ (entropia super extensiva) e 1 (entropia extensiva), o método seleciona o gene $A$ como melhor preditor, enquanto que o gene $B$ é selecionado como preditor para $q=2,5$ (entropia sub extensiva). Esse caso simples exemplifica o trade-off mencionado na Seção 2.5.1, entre a relevância da entropia condicional e a distribuição de probabilidade dos genes preditores.

Para os estados equiprováveis, a derivada da entropia generalizada aumenta a medida que o parâmetro $q$ diminui, como mostrado na Figura 2.8 da Seção 2.5.1. Esse comportamento torna possível $H_{q}($ alvo $\mid B=1)$ ser significativamente maior que $H_{q}($ alvo $\mid A=1)$ dependendo do valor de $q$. Nesse contexto, as distribuições concentradas em uma das classes (pequenos erros) podem produzir altos valores de entropia, os quais podem ser amplificados pela distribuição de massa dos preditores. Portanto, para os valores $q=0,5$ ou 1 o método seleciona o gene preditor $A$, uma vez que ele induz a uma entropia nula para o gene alvo, quando o preditor $A$ está ativo, i.e., classe 1 e, quando o preditor $A$ está inativo (0), o valor de entropia é maior, mas ele é reduzido pela menor massa de observações do preditor nesse estado, levando a uma entropia condicional média generalizada menor. No entanto, quando $q$ é definido como 2,5 , o equilíbrio entre a entropia condicional e a distribuição de massa do gene preditor é ajustada, de forma que o valor de entropia recebido é menor e, consequentemente, será menos penalizada pela massa de observações do preditor, i.e., probabilidade do preditor ocorrer em cada estado. Esse ajuste, como mostrado nos resultados experimentais, produz uma melhor precisão no processo de inferência.

Em geral, os algoritmos de inferência a partir de dados temporais de expressão gênica precisam ser melhorados [Bansal et al., 2007]. Assim, este trabalho abre novas perspectivas para os métodos de inferência de GRNs baseados na teoria da informação, tendo em vista que todos os resultados discutidos mostram uma melhoria significativa na precisão da inferência por meio da adoção de entropias não extensivas, propostas por Tsallis. Em particular, as entropias não extensivas proporcionaram uma melhoria significativa na precisão, reduzindo significativamente o número de falsos positivos detectados pelo método.

\subsection{Algoritmo de busca SFFS-MR}

Nesta seção, são apresentados os resultados obtidos a partir da aplicação do algoritmo SFFSMR [Lopes et al., 2010], o qual é apresentado na Seção 3.2.2, com objetivo de investigar sua eficiência na inferência de GRNs. Os resultados experimentais foram obtidos considerando-se a abordagem AGN [Lopes et al., 2011a]. As AGNs foram geradas contendo 20 genes, a partir da topologia de redes aleatórias de Erdös-Rényi (ER). O grau médio de conexões por gene $\langle k\rangle$ variou entre $1,2, \ldots, 5$, e o número de instantes de tempo observados (tamanho do sinal) variou de 5, 10, 15, 20 até $100 \mathrm{em}$ incrementos de 20 instantes de tempo. Para cada gene $g_{i}$ das redes, sua dinâmica foi definida por meio da escolha aleatória entre 3 funções de transição Booleanas $\left\{f_{1}^{(i)}, f_{2}^{(i)}, f_{3}^{(i)}\right\}$, com as respectivas probabilidades delas serem selecionadas a cada instante de tempo $c_{1}^{(i)}=0,95, c_{2}^{(i)}=0,025, c_{3}^{(i)}=$ $0,025, i=1, \ldots, 20$.

Com o objetivo de identificar as redes, os perfis de expressão simulados foram submetidos ao software apresentado em [Lopes et al., 2008c], o qual implementa a metodologia proposta por [Barrera et al., 2007], apresentada na Seção 2.3.5, por meio de métodos de seleção de características 
para a inferência da redes, aplicando os algoritmos SFS e SFFS como estratégias de busca. Logo, a inferência das redes foi obtida a partir desse software com a aplicação dos algoritmos SFS (Seção 2.4.1), SFFS (Seção 2.4.2) e SFFS-MR (Seção 3.2.2), mantendo-se fixa a função critério, a qual é baseada na entropia condicional média penalizada, apresentada na Seção 2.6.5, sendo que os demais parâmetros (default) foram mantidos fixos durante a análise comparativa entre os algoritmos.

As medidas de similaridade topológica aplicadas na comparação entre as AGNs e as redes inferidas por cada algoritmo são apresentadas na Seção 3.3. Os resultados experimentais foram obtidos a partir de 50 simulações para cada tamanho de sinal e número médio de conexões $\langle k\rangle$.

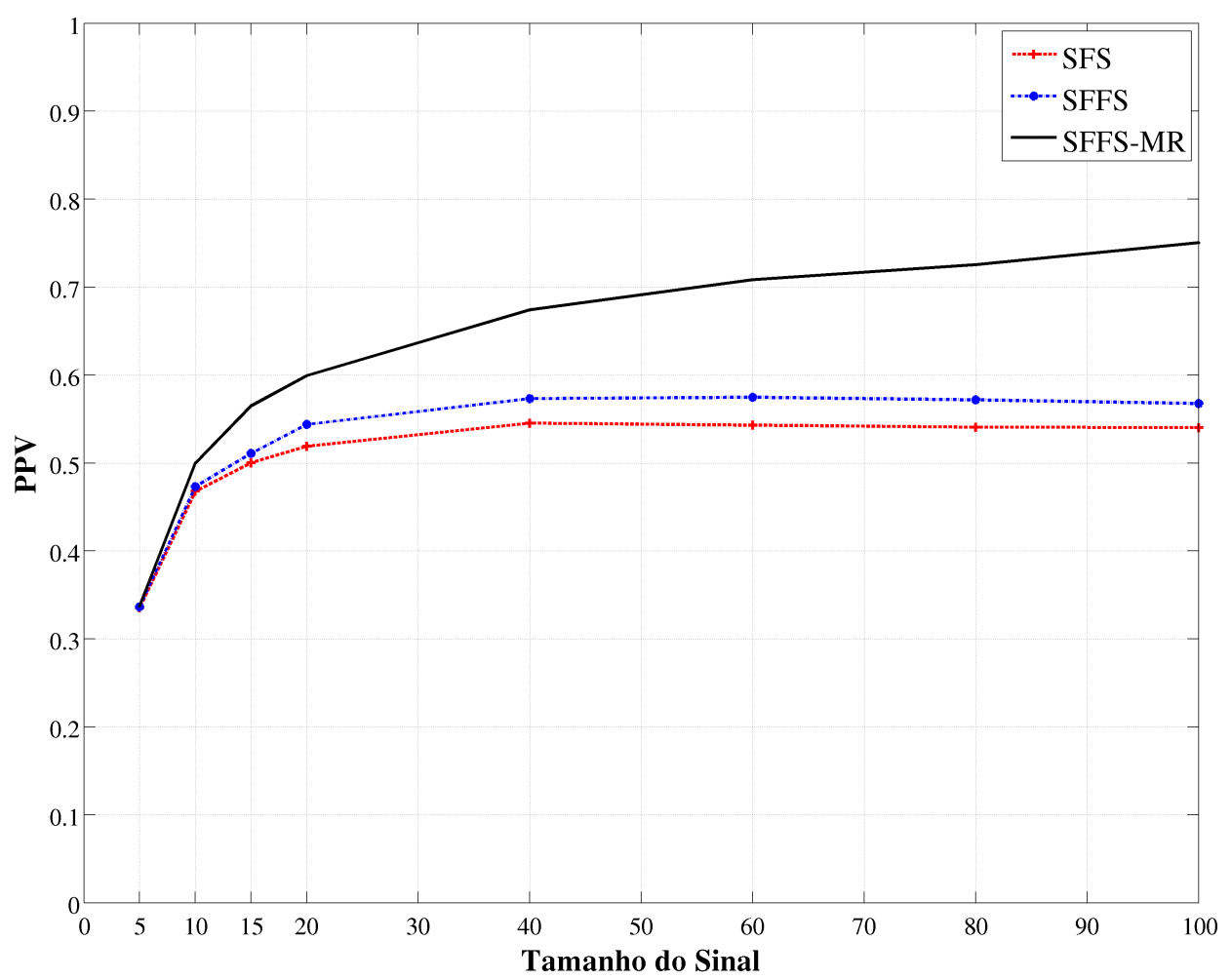

Figura 4.13: Medida PPV obtida pela inferência das redes considerando-se os algoritmos SFS, SFFS e SFFS-MR, aplicados sobre diferentes tamanhos de perfis de expressão temporal. Os valores de PPV representam os valores médios sobre 50 execuções, i.e., 50 AGNs e suas respectivas inferências.

O primeiro experimento foi realizado para comparar os três algoritmos: SFS, SFFS e SFFS-MR em relação ao tamanho dos perfis de expressões temporais. A Figura 4.13 apresenta os resultados, nos quais a medida $P P V$ foi calculada considerando-se os resultados médios para todas as variações do grau médio de conexões $\langle k\rangle$ sobre as 50 simulações.

É possível perceber que todos os algoritmos mostram um aumento em seu desempenho em função do aumento do tamanho do sinal de entrada. No entanto, a melhoria observada para o algoritmo SFFS-MR foi mais consistente, e.g., atingindo $60 \%$ na medida PPV contra $55 \%$ (SFFS) e $51 \%$ (SFS) depois de apenas 20 observações temporais e atingindo $75 \%$ contra $57 \%$ (SFFS) e $54 \%$ (SFS) depois de 100 observações temporais, mesmo com a presença de algumas perturbações no sinal temporal, ocasionadas pela estocasticidade na aplicação das funções de transição Booleanas.

O segundo experimento foi realizado para comparar a robustez dos algoritmos por meio do aumento da complexidade das redes, em termos do grau médio de conexões $\langle k\rangle$. A média geométrica entre o PPV e Sensibilidade, apresentada na Figura 4.14, foi calculada considerando-se os resultados médios entre todas as variações do tamanho do sinal. A Figura 4.14 mostra que os três métodos 


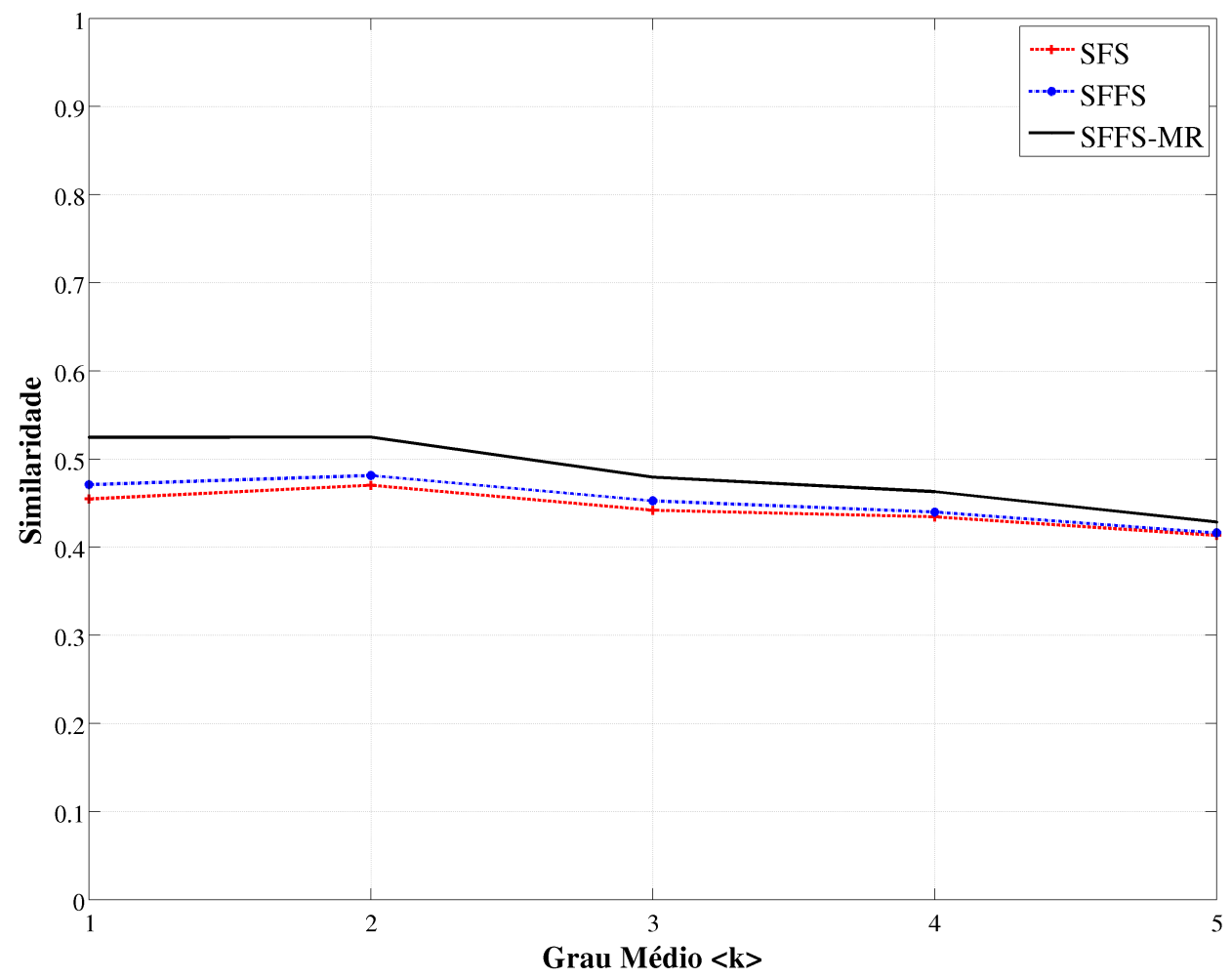

Figura 4.14: Medida de similaridade obtida pela inferência das redes considerando-se os algoritmos SFS, SFFS e SFFS-MR, aplicados sobre diferentes complexidades de redes, em termos do número médio de conexões por gene $\langle k\rangle$. A similaridade aplicada neste resultado é dada por Similaridade = $\sqrt{P P V \times \text { Sensibilidade, }}$ considerando-se os resultados médios sobre 50 execuções e redes contendo 20 genes.

foram muito robustos ao aumentar a complexidade das redes, apresentando uma diminuição suave na medida de Similaridade em função do aumento do grau médio de conexões $\langle k\rangle$. Além disso, o algoritmo SFFS-MR apresentou resultados ligeiramente melhores do que o SFS e SFFS, indicando uma boa eficiência e robustez quando aplicado à inferência de GRNs.

\subsection{Algoritmo de busca SFFS-BA}

Nesta seção, são apresentados os resultados experimentais obtidos, os quais foram desenvolvidos com o objetivo de aferir a eficiência do algoritmo SFFS-BA [Lopes et al., 2011c], apresentado na Seção 3.2.3, aplicado à inferência de GRNs.

Os resultados foram gerados a partir das redes artificiais (AGNs), descritas em [Lopes et al., 2011a], e apresentadas na Seção 3.1. Como forma de avaliar o desempenho do algoritmo aplicado a diferentes topologias de redes, e não só à topologia livre de escala (scale-free) de Barabási-Albert (BA), as AGNs foram construídas considerando-se também as topologias de redes aleatórias de Erdös-Rényi (ER) e mundo pequeno (small-world) de Watts-Strogatz (WS).

Em todos os experimentos, as redes de todas as topologias (ER, WS e BA) foram construídas contendo $n=100$ vértices (genes). O grau médio de conexões por gene $\langle k\rangle$ variou entre $1,2, \ldots, 5$, e o número de instantes de tempo observados (tamanho do sinal) variou de 5, 10, 15, 20 até 100, em incrementos de 20. Cada gene $g_{i}$ dessas redes teve sua dinâmica determinada a partir da escolha aleatória entre três possíveis funções de transição Booleanas, i.e., $\psi_{i}=\left\{f_{j}^{(i)}\right\}, j=$ $1, \ldots, l(i)=3$, cada qual com a respectiva probabilidade de ser escolhida a cada instante de tempo 
$c_{1}^{(i)}=0,95, c_{2}^{(i)}=0,025, c_{3}^{(i)}=0,025, i=1, \ldots, 100$. Como mencionado anteriormente, essas probabilidades foram definidas com objetivo de não só definir uma dinâmica estrutural principal para as redes, mas também adicionar pequenas pertubações, como sugerido em [Barrera et al., 2007].

Para a identificação das redes, foi utilizado o software descrito em [Lopes et al., 2008c], o qual implementa a metodologia proposta por [Barrera et al., 2007], apresentada na Seção 2.3.5, por meio de métodos de seleção de características para a inferência da redes, aplicando os algoritmos SFS e SFFS como estratégias de busca. Logo, a inferência das redes foi obtida a partir desse software com a aplicação dos algoritmos SFS (Seção 2.4.1), SFFS (Seção 2.4.2) e SFFS-BA (Seção 3.2.3), mantendose fixa a função critério, baseada na entropia condicional média penalizada (veja Seção 2.6.5), sendo aplicados os valores padrão do software, os quais foram mantidos fixos durante a análise comparativa entre os algoritmos.

Para medir a semelhança entre uma rede sintética $A$ e uma rede inferida $B$, foi adotada uma medida de Similaridade mais restritiva do que apenas o $P P V$, como apresentado na seção anterior. Foi adotada a média geométrica entre o $P P V$ e a $\operatorname{Sensibilidade,~dado~por~} \operatorname{Similaridade}(A, B)=$ $\sqrt{P P V \times \text { Sensibilidade }}$, i.e., $\sqrt{\text { Precision } \times \text { Recall }}$ (veja Seção 3.3 ), os quais são amplamente utilizados para comparar os resultados dos métodos de inferência de GRNs [Dougherty, 2007]. Os resultados experimentais foram obtidos a partir de 50 simulações para cada modelo de rede, tamanho de sinal e variação do número médio de conexões $\langle k\rangle$.

O primeiro experimento foi realizado a fim de comparar os três métodos: SFS, SFFS e SFFS-BA em relação ao número de observações contidas nas expressões temporais. A Figura 4.15 apresenta esses resultados, na qual a medida de Similaridade foi calculada considerando-se os resultados médios para todas as variações de $\langle k\rangle$. É possível perceber que todos os algoritmos têm um aumento em seu desempenho em função do aumento do número de observações, considerando-se as três topologias de redes observadas (ER, WS e BA). No entanto, a melhoria observada para o algoritmo SFFS-BA ocorre mais rapidamente, quando observados apenas 20 instantes de tempo, superando os outros dois algoritmos de forma consistente deste ponto em diante. Enquanto isso, o algoritmo SFFS supera o SFS apenas a partir de sinais de expressão contendo 80 instantes de tempo e de uma forma mais suave, ou seja, a diferença da taxa de Similaridade entre o SFFS e o SFS, é menor que a diferença alcançada pelo algoritmo SFFS-BA se comparado aos outros dois. Essa melhoria e variações se repetem para todas as topologias de rede observadas.

Além disso, conforme o esperado, a curva de Similaridade do algoritmo SFFS-BA, exibida na Figura 4.15, mostra uma melhoria mais significativa se comparada com os outros dois algoritmos (SFS e SFFS) em função do aumento do tamanho do sinal, considerando-se a topologia da rede BA. No entanto, considerando-se as topologias ER e WS, também pode ser observado uma melhoria significativa na qual o algoritmo SFFS-BA não apenas supera os outros dois algoritmos, mas também o faz de forma consistente, mesmo na presença de algumas perturbações contidas no sinal temporal, causadas pela estocasticidade na aplicação das funções de transição Booleanas. Esse comportamento de melhoria nos resultados, sobretudo considerando-se as topologias ER e WS, deve-se à natureza mais restritiva de inferência adotada pelo algoritmo SFFS-BA, por meio da restrição do número de genes alvo que podem atingir uma quantidade maior de candidatos a predição, i.e., aumentando a cardinalidade do seu subconjunto de preditores $k$.

O segundo experimento foi realizado para comparar a robustez dos algoritmos por meio do 


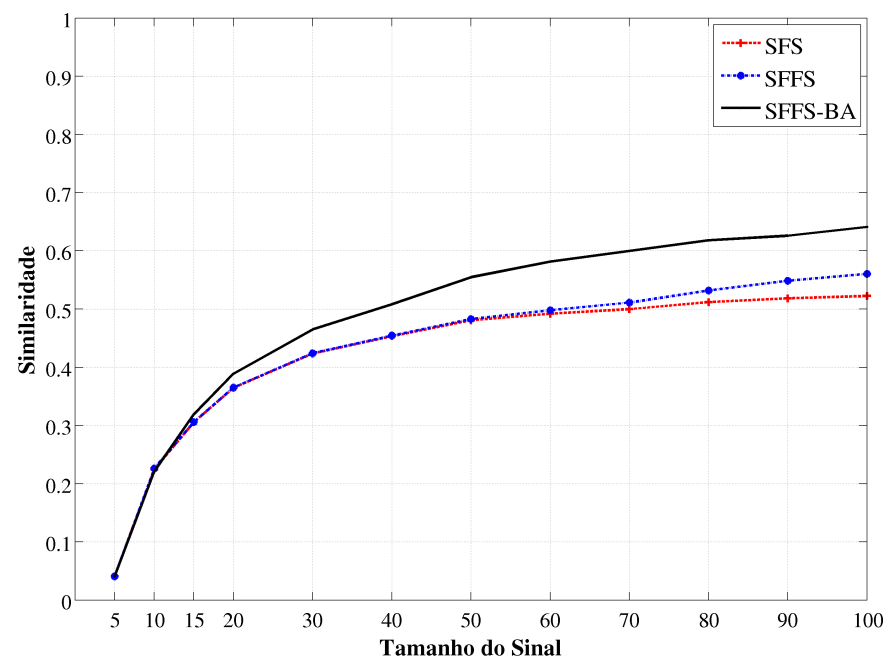

(a) ER

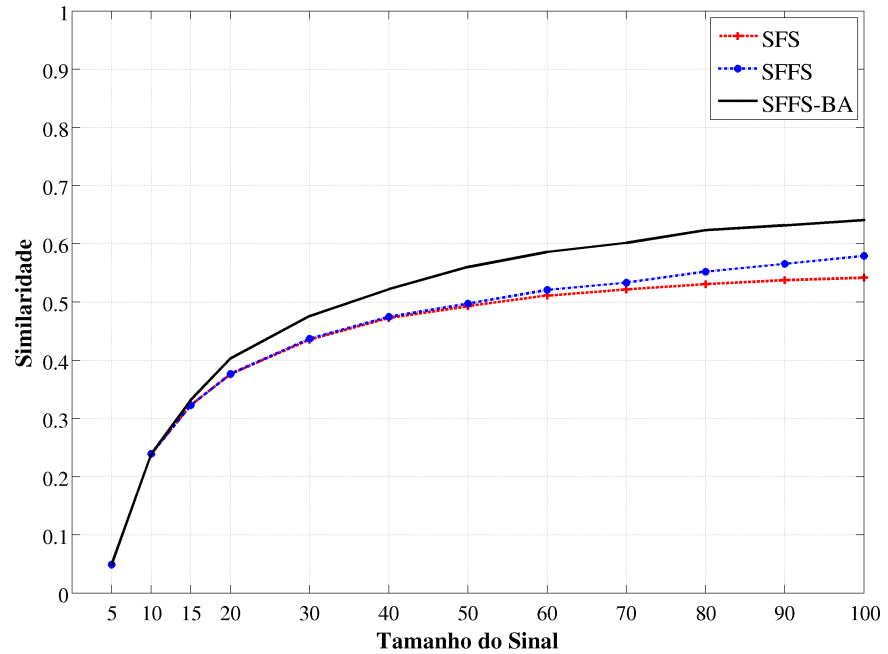

(b) WS

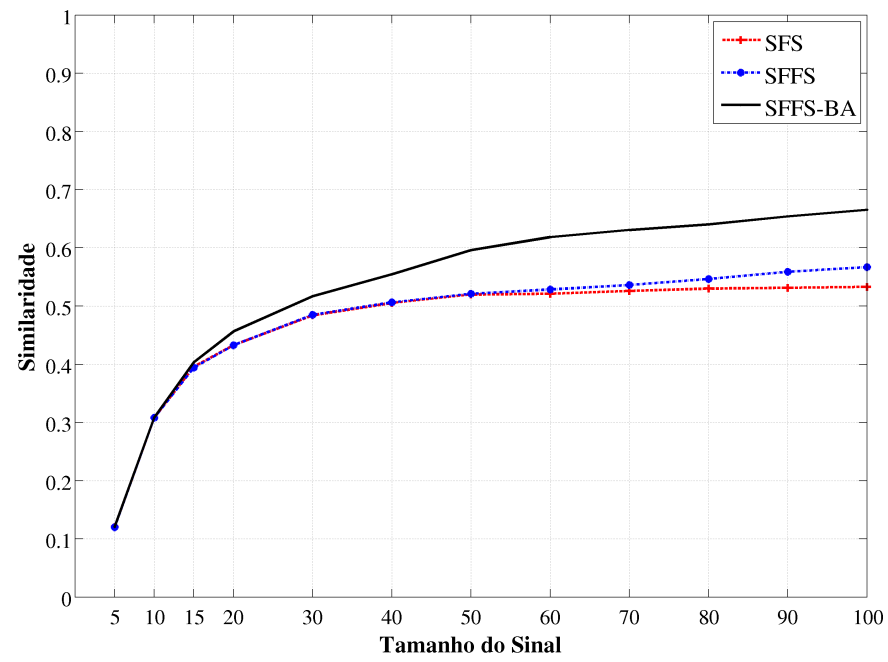

(c) BA

Figura 4.15: Medida de similaridade obtida pela inferência das redes considerando-se os algoritmos SFS, SFFS e SFFS-BA, aplicados sobre diferentes tamanhos de perfis de expressão temporal. Os valores de PPV representam os valores médios sobre 50 execuções, i.e., 50 AGNs e suas respectivas inferências. A similaridade aplicada neste resultado é dada por Similaridade $=\sqrt{P P V \times \text { Sensibilidade }}$, considerando-se os resultados médios sobre 50 execuções e redes contendo 100 genes. 


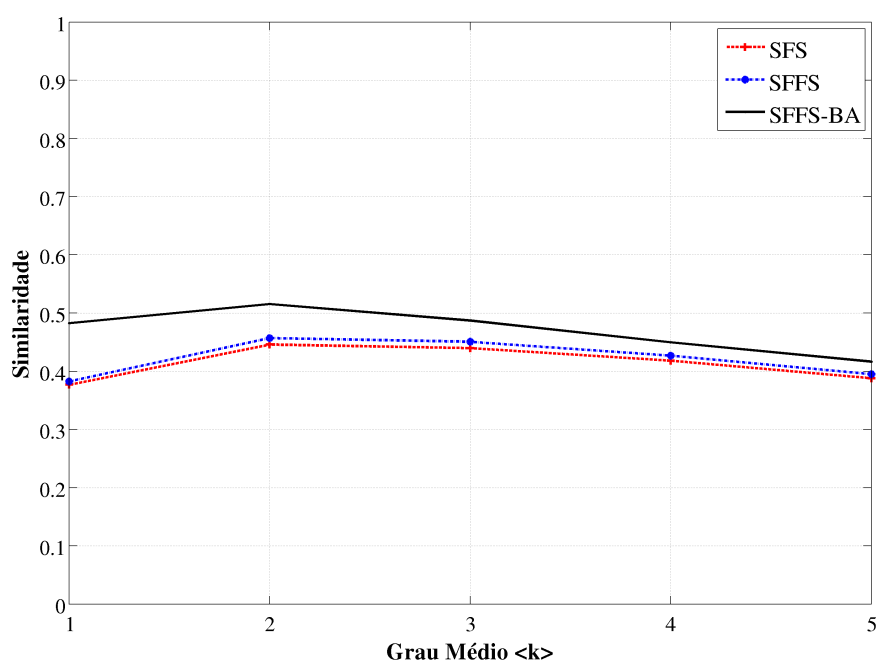

(a) ER

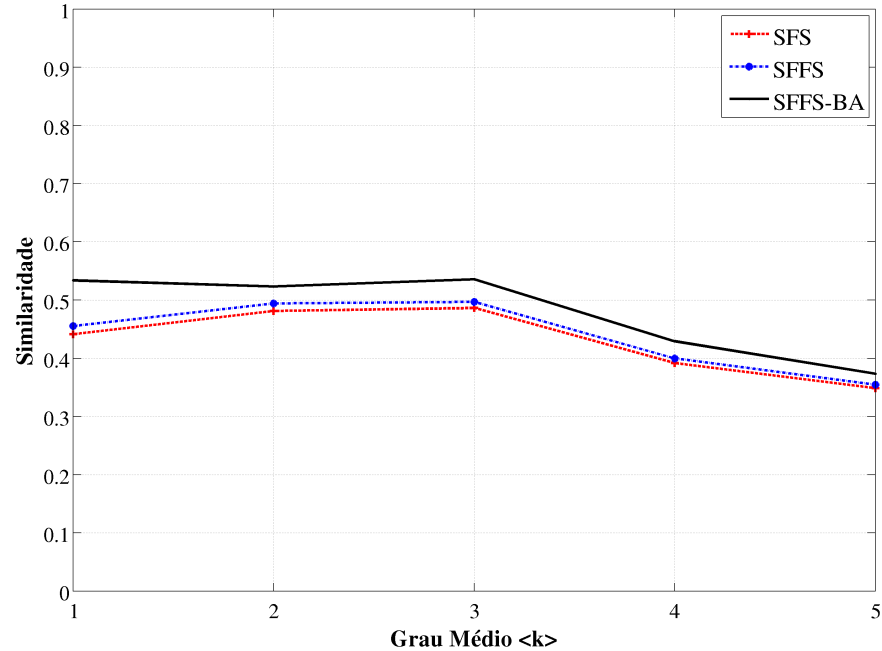

(b) WS

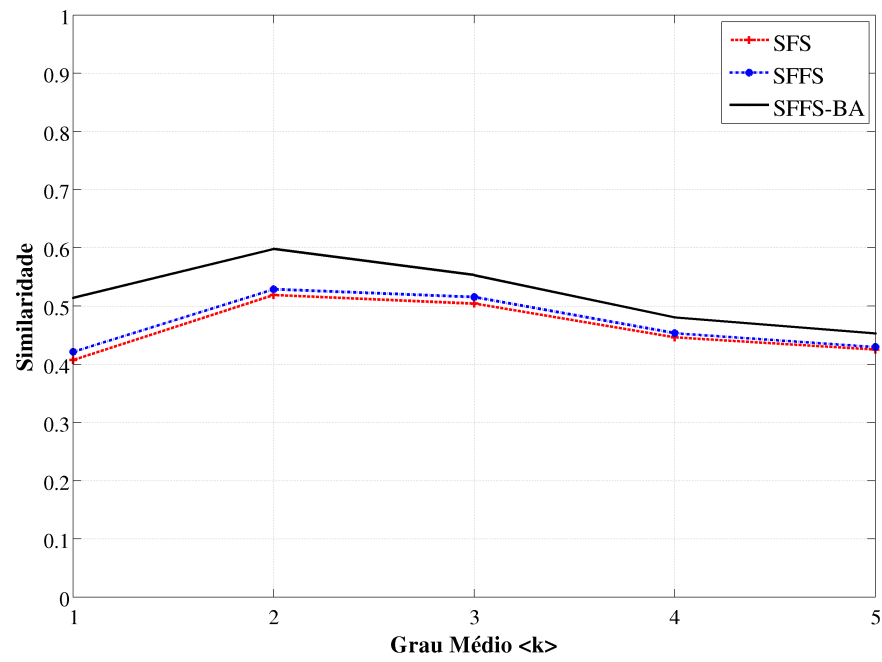

(c) BA

Figura 4.16: Medida de similaridade obtida pela inferência das redes considerando-se os algoritmos SFS, SFFS e SFFS-BA, aplicados sobre diferentes complexidades de redes, em termos do número médio de conexões por gene $\langle k\rangle$. A similaridade aplicada neste resultado é dada por Similaridade = $\sqrt{P P V \times \text { Sensibilidade, }}$ considerando-se os resultados médios sobre 50 execuções e redes contendo 20 genes. 
aumento da complexidade das redes, em termos do número médio de conexões $\langle k\rangle$. A Figura 4.16 apresenta os resultados médios para todas as variações de tamanho do sinal (número de instantes de tempo). É possível notar que a medida de Similaridade apresenta um decremento em função do aumento do número médio de conexões da rede para os três algoritmos. No entanto, houve uma melhoria nos resultados para $\langle k\rangle=1$ até $\langle k\rangle=2$ quando observadas as topologias ER e BA. Esse comportamento pode ser explicado pela natureza estocástica da aplicação das funções de transição Booleanas e a presença de um número menor de conexões nas redes, i.e., redes menos complexas $\langle k\rangle=1$, as quais podem ter vários genes alvo que não possuem preditores, mas o método de inferência encontrada um falso positivo para eles, reduzindo as respectivas medidas de Similaridade.

Neste contexto, o algoritmo SFFS-BA também superou os algoritmos SFS e SFFS, apresentando uma diminuição mais suave de Similaridade com o aumento do grau médio $\langle k\rangle$, considerando-se a topologia de ER. Na presença de uma estrutura de rede que não a aleatória, como é o caso das topologias WS e BA, a redução da medida de Similaridade foi menos suave, mas mesmo nesses casos, o SFFS-BA apresentou melhores resultados que os algoritmos SFS e SFFS. Dessa forma, os resultados experimentais indicam que o algoritmo SFFS-BA teve uma boa eficiência e robustez quando aplicado à inferência de GRNs.

\subsection{Investigação Biológica}

Nesta seção, são apresentados os resultados obtidos a partir da aplicação do algoritmo SFFSMR [Lopes et al., 2010], o qual é apresentado na Seção 3.2.2, em conjunto com a entropia condicional média penalizada, apresentada na Seção 2.6.5, com objetivo de inferir e investigar as redes gênicas envolvidas na biossíntese de tiamina e, em particular o gene thi1, conforme descrito na Seção 3.4.

Inicialmente, os dados de expressão obtidos das partes da planta, folha e raiz, e suas respectivas réplicas biológicas, foram separadas e tratadas individualmente. Os perfis temporais obtidos nos instantes de tempo: 0h, 30min, 1h, 3h, 6h, 12h e 24h, após a exposição da planta ao frio (caso) e não expostos ao frio (controle), foram normalizados e discretizados aplicando-se as duas formas de quantização descritas na Seção 2.2, as quais utilizam-se dos valores máximos e médias das expressões dos experimentos. O mesmo processo de quantização foi repetido para as réplicas biológicas.

Com o objetivo de aumentar o tamanho do sinal, i.e., instantes de tempo observados, os perfis de expressão foram concatenados às suas réplicas e, como resultado, os sinais temporais passaram a ter 14 instantes de tempo para cada um dos experimentos: folha e raiz. Para não inserir um ruído desnecessário ao método de inferência, foi incluída uma separação entre os dados da última amostra de expressão temporal e a primeira amostra da réplica biológica, de forma que essa descontinuidade seja detectada e desconsiderada pelo método computacional.

Um dos objetivos aqui é investigar alguns processos metabólicos (grupos de genes escolhidos) que utilizam a tiamina (vitamina B1). Mais especificamente, verificar se entre grupos metabólicos das GRNs inferidas afetam de algum modo a síntese dessa vitamina. Sabe-se que a tiamina na sua forma pirofosfato (TPP, do inglês thiamine pyrophosphate) é cofator de enzima da glicólise, mais especificamente o piruvato desidrogenase, descrita no enzyme commission (EC) número 1.2.4.1 http://www.genome.jp/dbget-bin/www_bget?ec:1.2.4.1. A TPP também está presente como cofator da enzima 2-oxoglutarato desidrogenase, a qual está envolvida na respiração 
e, mais especificamente, no ciclo do citrato, a qual é descrita no enzyme commission (EC) número 1.2.4.2 http://www.genome.jp/dbget-bin/www_bget?ec:1.2.4.2. No ciclo de Calvin, também conhecido como ciclo de redução fotossintética do carbono [Nelson and Cox, 2004], associado à fotossíntese, está a enzima transcetolase, descrita no enzyme commission (EC) número 2.2.1.1 http://www.genome.jp/dbget-bin/www_bget?ec:2.2.1.1, a qual também utiliza TPP como cofator. A avaliação da formação da rede de preditores foi realizada selecionando genes que codificam proteínas associadas a cada uma das três vias citadas a pouco e um grupo externo de genes (controles) associados ao processo de transcrição nuclear, i.e., genes cujos processos de transcrição ocorrem no núcleo celular.

As Figuras 4.17 e 4.18 exibem os diferentes grupos de genes selecionados como alvos e as redes resultantes dos dois tratamentos de quantização dos dados de expressão, média e máximo, considerando-se os dados temporais de expressão obtidos a partir de tecido radicular e foliar, respectivamente. Nota-se claramente, a partir da rede inferida utilizando-se a forma máxima de quantização, um número maior de preditores em cada tecido (folha e raiz). É interessante notar que há forte conexão nas folhas entre síntese de tiamina (vermelho) e as três redes metabólicas glicólise (laranja), fotossíntese (verde) e respiração (azul). Esta observação sustenta que as redes estão conectadas não só através de seus metabólitos, como por exemplo o piruvato, mas também entre os preditores. Esse fato não é observado na raiz onde o metabolismo energético é dependente basicamente da respiração.

Nas GRNs geradas a partir de valores médios, verifica-se um número menor de preditores e menor número de conexões, sugerindo que as relações são mais fracamente sustentadas ou que as diferenças observadas são achatadas diminuindo a capacidade de identificação de um sinal significante. Vale ressaltar que o grupo externo (controle, em rosa) se comportou de modo esperado, praticamente não apresentando arestas entre os conjuntos de genes testados. Outro ponto importante a ser observado é que não há ligações entre todos os genes de um dado conjunto e seus preditores.

Os dois genes em cinza, LOS2 e EDA9, estão associados com proteínas identificadas no estudo realizado em [Momoli, 2008] como apresentando um perfil de expressão modificado em linhagem mutante de Arabidopsis thaliana. A inclusão destes genes no conjunto aqui analisado pretendeu avaliar sua relação com as vias em estudo e a síntese de tiamina. Não havia relação previamente estabelecida entre o metabolismo e ambos. A partir dos resultados aqui apresentados, nota-se que há um conjunto de preditores associando-os com o metabolismo na raiz.

Em geral, pode ser observado nas Figuras 4.17 e 4.18 que as relações inferidas entre os genes e os grupos metabólicos envolvidos em um mesmo processo celular ou em processos dependentes foram mais inter-conectados entre si do que os genes envolvidos em processos diferentes [Chiquet et al., 2009]. Logo, é intuitivo que genes pertencentes a processos distintos não sejam fortemente conectados entre si e, como esperado, a inferência dos preditores dos genes alvos pertencentes a diferentes vias metabólicas apresentaram essa característica, indicando a coerência biológica da estrutura da rede inferida.

Um aspecto bastante interessante da abordagem de GRNs apresentada aqui é a possibilidade de visualizar as ligações não previstas/preditas entre genes a partir de seus transcritos. Se considerarmos o mapa metabólico como um plano no qual a enzima A se utiliza de um substrato X para gerar um produto Y que por sua vez é substrato para enzima B que gera um produto Z, as redes de preditores permitem visualizar a relação entre a síntese de um cofator (portanto nem enzima, nem 


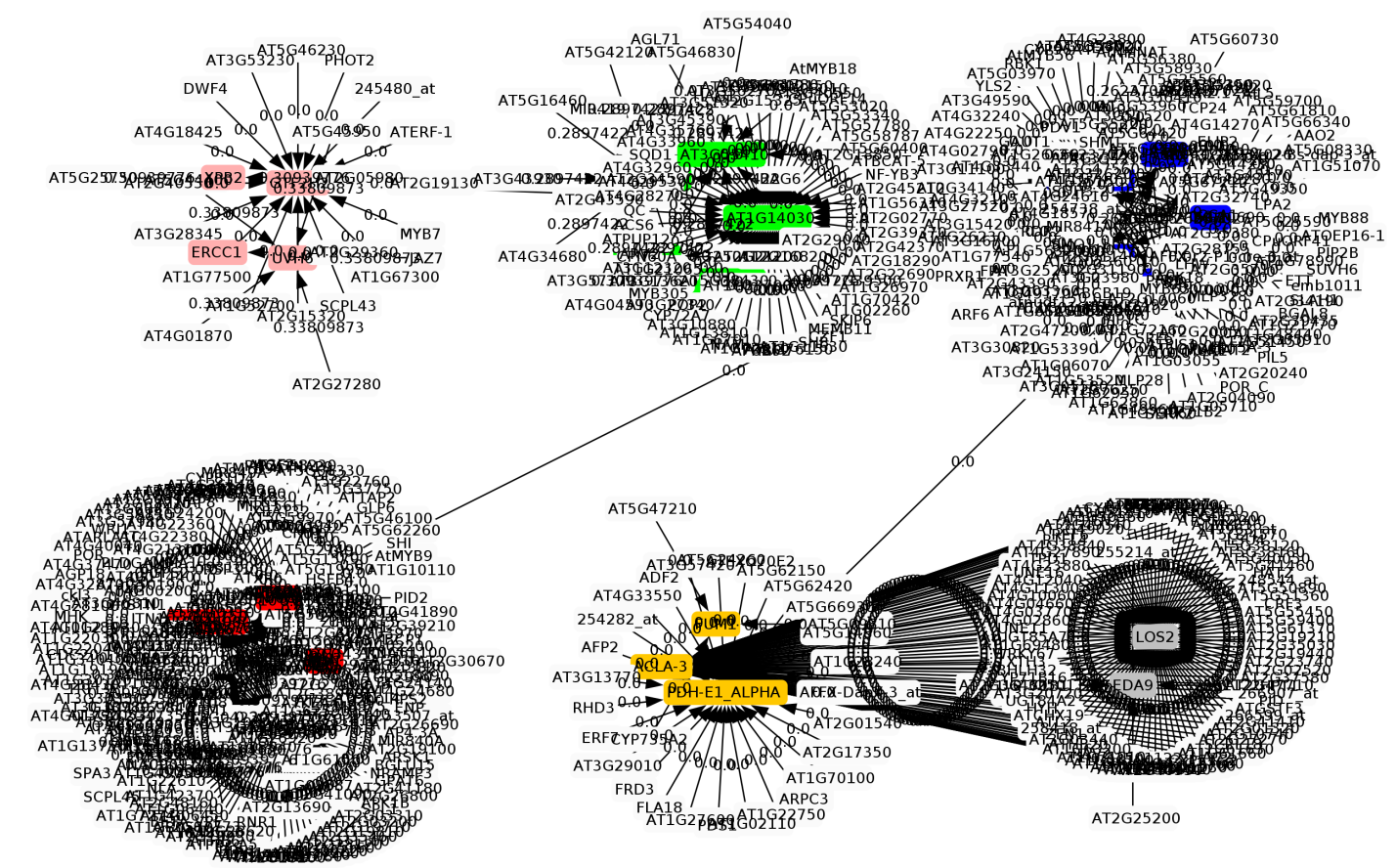

(a) quantização utilizando-se as médias - raiz

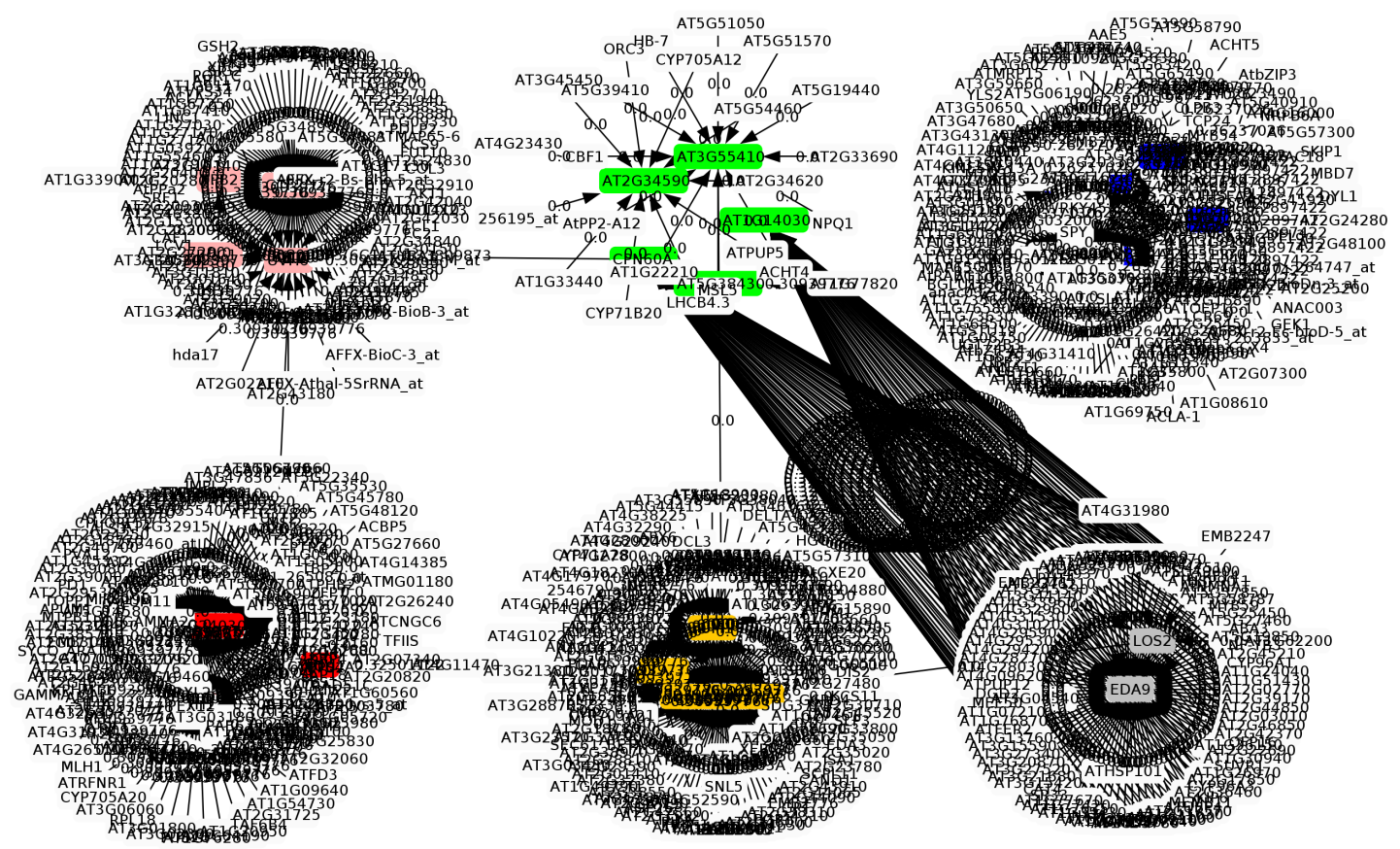

(b) quantização utilizando-se valores máximos e mínimos - raiz

Figura 4.17: Redes inferidas a partir de dados temporais de expressão da raiz de Arabidopsis thaliana a partir do método SFFS-MR, considerando duas formas de quantização dos dados: (a) utilizando-se os niveis máximos positivos e mínimos negativos e (b) considerando-se os valores positivos e negativos médios. 

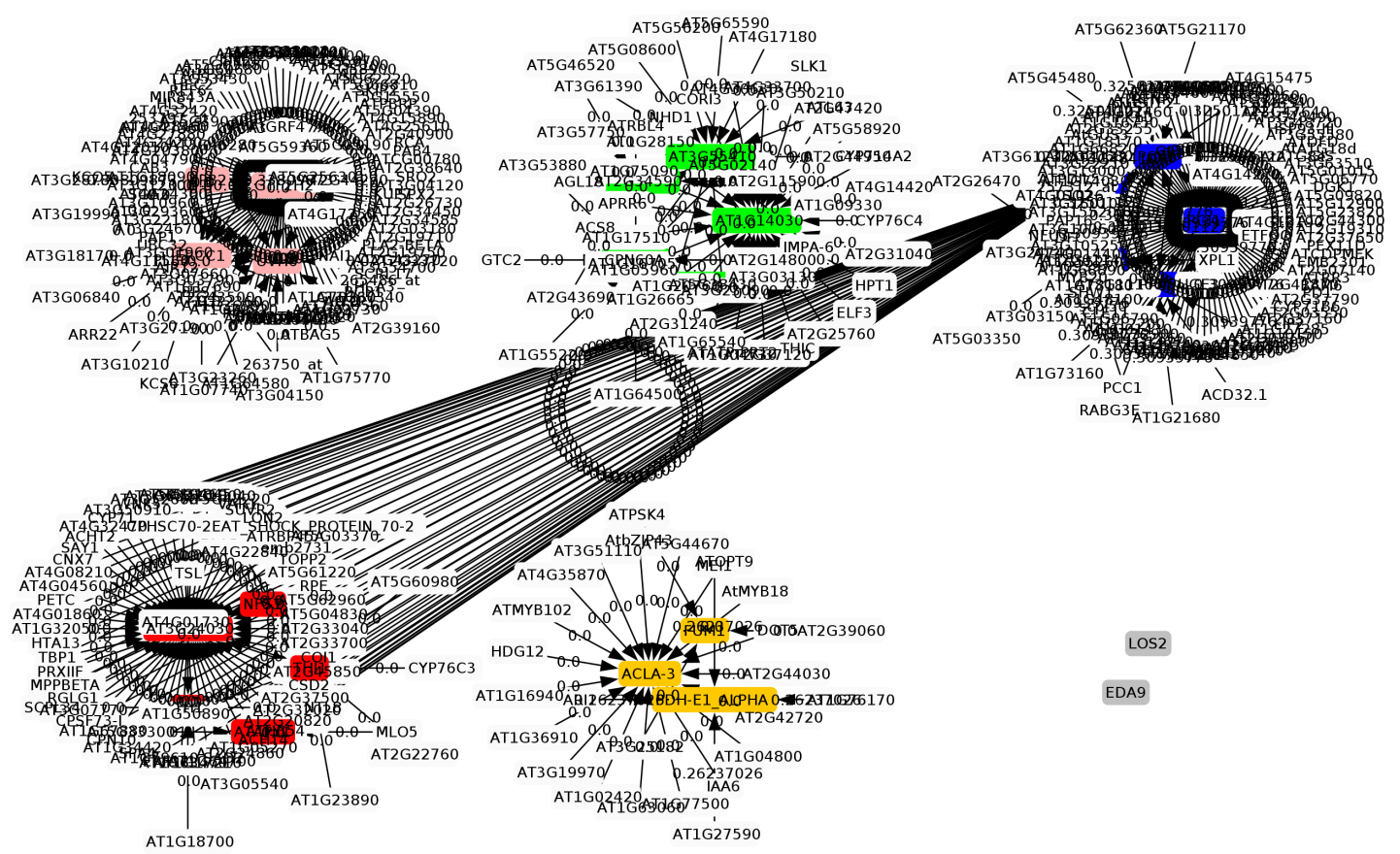

LOS2

EDA9

(a) quantização utilizando-se as médias - folha

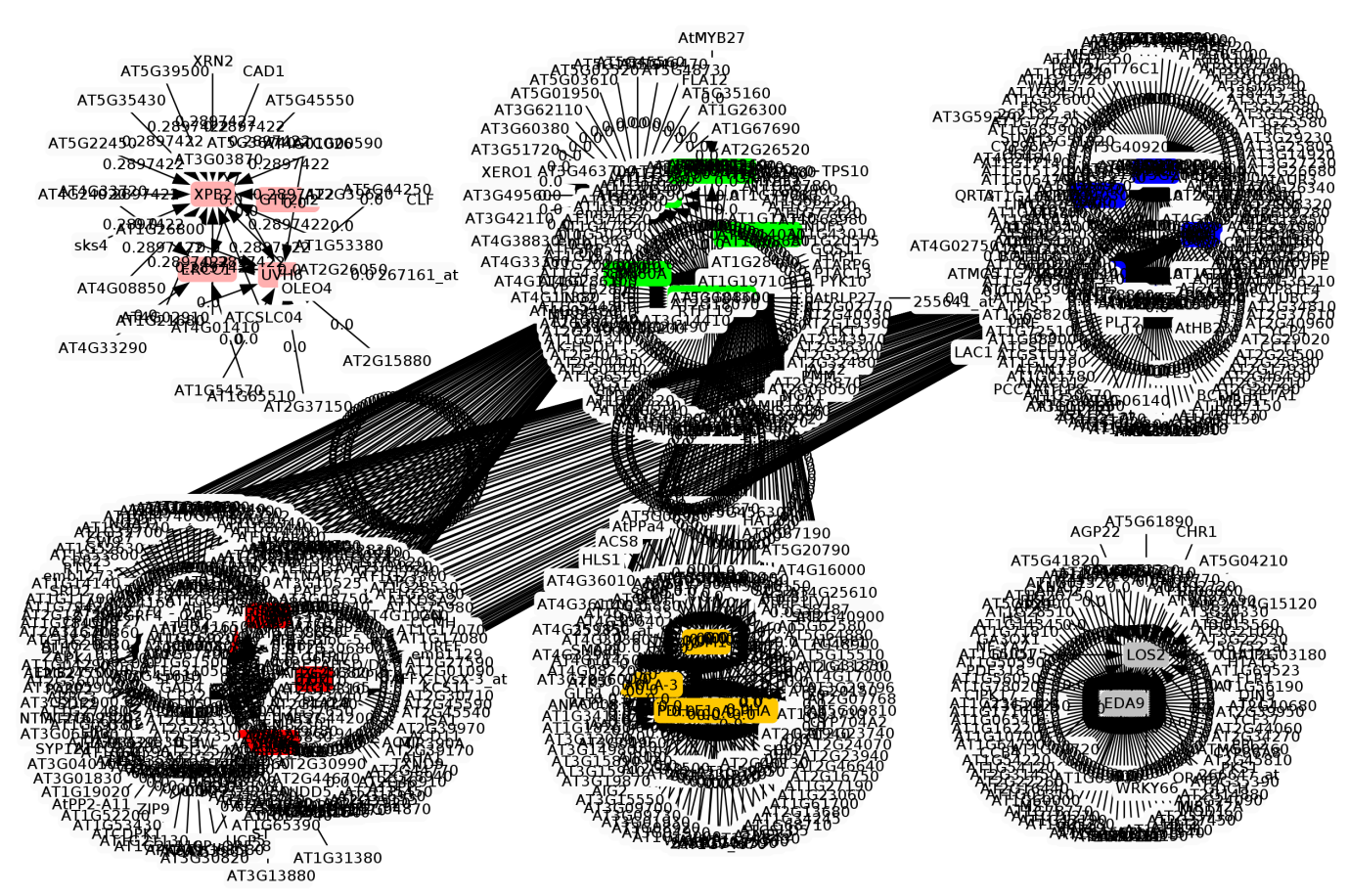

(b) quantização utilizando-se valores máximos e mínimos - folha

Figura 4.18: Redes inferidas a partir de dados temporais de expressão da folha de Arabidopsis thaliana a partir do método SFFS-MR, considerando duas formas de quantização dos dados: (a) utilizando-se os niveis máximos positivos e mínimos negativos e (b) considerando-se os valores positivos e negativos médios. 
substrato/produto) e as vias metabólicas em que a TPP atua.

Como perspectiva, é relevante a identificação dos preditores comuns às vias metabólicas energéticas e de síntese de tiamina. É possível também averiguar a existência de outros produtos proteicos envolvidos na sinalização entre os compartimentos celulares e a transdução de sinal entre o ambiente e a célula, como por exemplo no tecido foliar, no qual pode incidir a luz e produzir fotossíntese e a raiz que não faz fotossíntese.

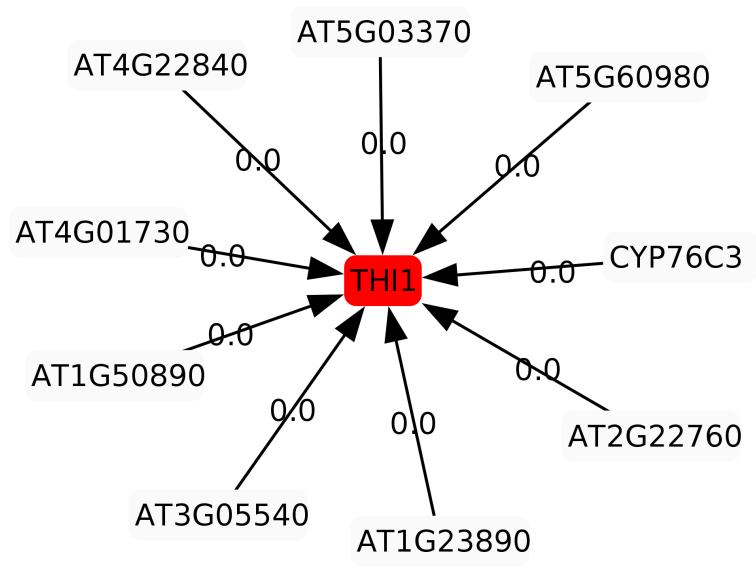

(a) Preditores de thi1 utilizando-se a quantização por médias - folha

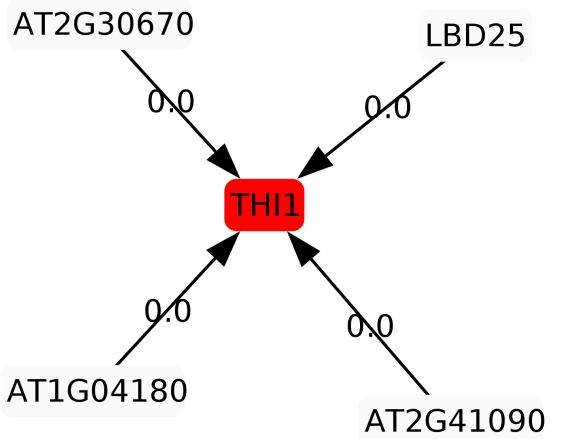

(a) Preditores de thi1 utilizando-se a quantização por médias - raiz

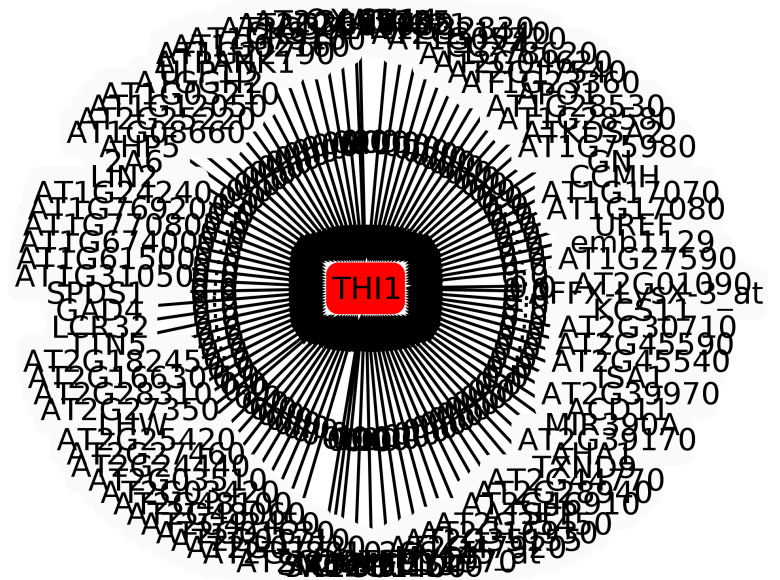

(b) Preditores de thi1 utilizando-se a quantização por máximos - folha

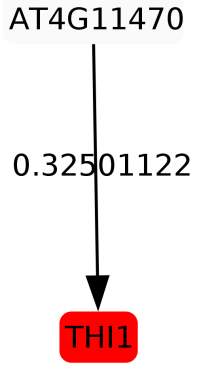

(b) Preditores de thi1 utilizando-se a quantização por máximos - raiz

Figura 4.19: Preditores do gene thi1 a partir de dados temporais de expressão de Arabidopsis thaliana a partir do método SFFS-MR, considerando: (a) utilizando-se os niveis médios das expressões da folha, (b) utilizando-se os niveis máximos das expressões da folha, (c) utilizando-se os niveis médios das expressões da raiz, (d) utilizando-se os niveis máximos das expressões da raiz.

Algumas observações importantes a respeito dos preditores inferidos para o gene thi1 podem ser identificadas na Figura 4.19. O primeiro ponto a ser ressaltado é que o tecido foliar apresenta maior número de preditores que o tecido radicular em qualquer das formas de quantização de dados (máximo e médio). O tecido foliar é mais ativo metabolicamente e, portanto, demanda maior aporte de tiamina, no qual deve haver um balanço entre os diferentes compartimentos celulares e suas especificidades metabólicas, tal como a fotossíntese que ocorre no cloroplasto, a respiração que ocorre na mitocôndria e a glicólise que ocorre no citoplasma, as quais fazem uso de tiamina, 
indicando uma concordância biológica à rede inferida.

Em se tratando da raiz, pode ser destacada a identificação da enzima flavina monoxigenase, preditor AT1G04180, a qual é descrita no enzyme commission (EC) número 1.14.13.8 http:// www.genome.jp/dbget-bin/www_bget?ec:1.14.13.8. A ontologia gênica (GO, do inglês Gene Ontology) [Ashburner et al., 2000] do preditor AT1G04180 mostra que ele está envolvido no processo de oxidação-redução e também na ligação aos transportadores de elétrons por meio da coenzima nicotinamida adenina dinucleotídeo fosfato (NADP, do inglês nicotinamide adenine dinucleotide phosphate). Sabe-se que na via de biossíntese de tiamina são necessários carregadores de hidrogênio por meio da coenzima nicotinamida adenina dinucleotídeo (NAD, do inglês nicotinamide adenine dinucleotide) [Godoi et al., 2006]. Dessa forma, há uma relação biológica, mesmo que indireta, entre a expressão do gene thi1 com a flavina monoxigenase (AT1G04180).

No caso da folha, a enzima acilfosfatase, AT5G03370, também pode ser destacada como preditor relevante visto que a enzima faz parte do metabolismo global de piruvato. Essa enzima participa da conversão entre piruvato e acetil-coA, mais especificamente entre acetil fosfato e acetato como descrito no enzyme commission (EC) número 3.6.1.7 http://www.genome.jp/dbget-bin/www_bget?ec: 3.6.1.7. A identificação deste preditor e a análise do mapa metabólico do piruvato (ATH00620) http://www.genome.jp/dbget-bin/www_bget?ath00620, chama a atenção que mais de uma rota enzimática produz acetil-coA a partir de piruvato. Uma é dependente de tiamina e a outra independente. Tendo em mente que piruvato e acetil-coA, estão diretamente ligadas, o preditor inferido possui significado biológico podendo ser um sensor global da via, i.e., em particular da presença de tiamina.

Tabela 4.4: Preditores inferidos para o gene thi1 que possuem função organelar.

\begin{tabular}{|c|c|c|c|}
\hline Nome do Gene & Locus & Identificação no Array (Probe set) & Organela \\
\hline AT1G28530 & AT1G28530 & 262738 at & cloroplasto \\
\hline AT1G78620 & AT1G78620 & 263129 at & cloroplasto \\
\hline AT2G17540 & AT2G17540 & 263066 at & cloroplasto \\
\hline AT2G04700 & AT2G04700 & 263624 at & cloroplasto \\
\hline AT2G27350 & AT2G27350 & 265630 at & cloroplasto \\
\hline AT2G39970 & AT2G39970 & 267363_at & mitocôndria \\
\hline AT2G42450 & AT2G42450 & 265879_at & mitocôndria \\
\hline AT2G46910 & AT2G46910 & 266767 at & cloroplasto \\
\hline $\mathrm{CCMH}$ & AT1G15220 & 262591_at & mitocôndria \\
\hline ISA1 & AT2G39930 & 267356 at & cloroplasto \\
\hline LIN2 & AT1G03475 & $264820 \_$at & cloroplasto \\
\hline MIR390A & AT2G38330 & 267027_at & cloroplasto \\
\hline OXA1L & AT2G46470 & 263778_at & mitocôndria \\
\hline TIC21 & AT2G15290 & 263298_at & cloroplasto \\
\hline TIC55 & AT2G24820 & 263533 at & cloroplasto \\
\hline
\end{tabular}

Outro ponto importante que pode ser observado na Tabela 4.4 foi que considerando as informações conhecidas no TAIR [D'Angelo et al., 2010], vários dos preditores inferidos são de função organelar: cloroplasto, onde se realiza a fotossíntese e mitocôndria, onde é realizada a respiração celular. Essas organelas estão envolvidas na produção de ATP, justamente onde a proteína THI1 atua [Chabregas et al., 2001] ${ }^{2}$, o que se apresenta como um indicativo biológico positivo das cone-

\footnotetext{
${ }^{2}$ A proteína THI1 é direcionada para as duas organelas, mitocôndrias e cloroplastos.
} 
xões inferidas pelo método proposto.

Assim, mesmo tendo em mente que ainda há muitos outros genes preditores a serem analisados e confirmados (ou não) como alvo de uma análise biológica mais aprofundada, foi possível perceber que as conexões inferidas mostram relações biológicas coerentes entre os preditores cujos mapas estão caracterizados e os genes alvo no que diz respeito a sua função e relação biológica conhecida.

Por fim, as redes inferidas a partir dos dados de expressão quantizados considerando-se seus valores máximos apresentam maior interação entre as vias metabólicas em estudo, se mostrando mais adequado nesta tarefa. 


\section{Capítulo 5}

\section{Considerações Finais e Direcionamentos}

Os organismos biológicos respondem rapidamente às mudanças no ambiente interno ou externo, ajustando o seu perfil de expressão gênica, i.e., sua regulação gênica. Como resultado, as redes de regulação gênica serão ajustadas a essas mudanças. Os sistemas regulatórios podem ser vistos como uma rede complexa de sinais codificados no material genético, que controlam as trajetórias das expressões gênicas, as quais podem explicar alguns fenômenos como a diferenciação celular e o desenvolvimento de um organismo. No entanto, ainda há muito para ser descoberto sobre a forma como estas alterações na produção de transcritos e proteínas estão ligadas e reguladas ao longo do tempo. Compreender este sistema regulatório pode ser crucial para o entendimento da individualidade física e psicológica dos seres humanos, bem como as variações nas características de plantas e animais.

Nessa direção, o início deste trabalho se deu a partir do desenvolvimento de um software de seleção de características, com código livre, que permite a análise de dados utilizando alguns algoritmos, funções critério e ferramentas de visualização gráfica [Lopes et al., 2008c,Lopes et al., 2008b], o qual está disponível em http://code.google.com/p/dimreduction/. Embora este software seja de uso geral para problemas de reconhecimento de padrões, envolvendo seleção de características, tem seu foco em tarefas de bioinformática, especialmente aquelas que envolvem dados contendo alta dimensionalidade, e.g., grande número de genes, com pequeno número de amostras (experimentos). Neste software estão disponíveis funcionalidades como selecionar os arquivos de entrada, quantização, algoritmos de busca (Seção 2.4 .1 e 2.4.2), funções critério (Seção 2.5), métodos de estimação de erros e visualização dos resultados. Também está disponível um sistema de ajuda intuitiva que apresenta rapidamente as instruções das funcionalidades presentes ao usuário. Em particular, o software implementa o método de inferência de GRNs apresentado na Seção 2.6.5. Além disso, a disponibilidade do software em código aberto permite aos programadores explorarem os métodos implementados como bibliotecas em seus próprios programas.

Embora vários métodos tenham sido propostos na literatura para a modelagem e identificação de GRNs a partir de perfis de expressão, em geral, a informação necessária para validar as redes inferidas é incompleta ou desconhecida. Neste sentido, a segunda etapa deste trabalho se concentrou no desenvolvimento de uma abordagem objetiva para gerar redes gênicas artificiais (AGNs) [Lopes et al., 2008a, Lopes et al., 2011a].

As AGNs possuem topologias definidas por modelos teóricos de redes complexas. Neste trabalho foram aplicados quatro modelos distintos: redes aleatórias (uniformly-random) de Erdös-Rényi (ER) (Seção 2.8.1), mundo pequeno (small-world) de Watts-Strogatz (WS) (Seção 2.8.2), livre de 
escala (scale-free) de Barabási-Albert (BA) (Seção 2.8.3) e geográfico (geographical networks) de Gastner-Newman (GN) (Seção 2.8.4). Essas topologias de redes complexas, constituídas por arestas direcionais, são usadas para gerar a dinâmica das redes a partir de um estímulo inicial. A dinâmica das redes é gerada a partir de funções Booleanas, aplicadas como funções de transição probabilísticas. Essa dinâmica é traduzida em um sinal temporal de expressão simulado, o qual pode ser submetido a um método de inferência de redes, como o descrito na Seção 2.6.5, com objetivo de analisar as redes inferidas em termos da AGN que gerou o sinal. Uma vez recuperada a topologia da rede a partir de seu perfil de expressão temporal, ela pode ser comparada com a AGN geradora por meio de medidas topológicas (Seção 3.3), que envolvem as ligações corretas e incorretas inferidas a fim de validar a rede identificada.

O modelo AGN é baseado principalmente em dois parâmetros: número de vértices ou genes $n$ e o número médio de conexões por gene (grau médio) $\langle k\rangle$. Há outros dois parâmetros que norteiam a estocasticidade do modelo: o número de funções booleanas por gene $l(i)$ e suas respectivas probabilidades de serem aplicadas, a cada instante de tempo, para descrever a dinâmica deste gene. Isso é feito de forma a considerar um estímulo externo sobre a dinâmica da rede, que pode mudar o comportamento (função de transição) dos genes. Apesar de simples, é baseado no formalismo Booleano que possui um suporte teórico sólido, o qual se mostrou adequado para a validação das redes inferidas, identificando algumas propriedades importantes do método avaliado. É importante notar que, devido ao formalismo Booleano, não foi necessária a etapa de pré-processamento dos dados, que é particularmente importante para os métodos de inferência baseados na teoria da informação.

O modelo AGN foi aplicado na investigação do comportamento do método de inferência de redes em relação a: (1) diferentes topologias de redes complexas (ER), (WS), (BA) e (GN); (2) complexidade das redes em termos do número médio de conexões $\langle k\rangle$; (3) número de instantes de tempo, i.e., tamanho do sinal de expressão; e (4) desempenho do método ao recuperar todos os genes da rede e aplicado na recuperação de apenas $10 \%$ dos genes mais conectados da rede, i.e., hubs.

Os resultados experimentais confirmaram que o número médio de conexões $\langle k\rangle$ é um componente importante de complexidade das redes. O método de inferência exibiu uma queda na taxa de Similaridade com o incremento de $\langle k\rangle$. Os resultados também mostraram que o método de inferência foi sensível à topologia de rede apenas quando houve uma variação de sua complexidade, i.e., $\langle k\rangle$. A melhoria de desempenho observada para $\langle k\rangle=1$ até $\langle k\rangle=2$ ocorreu apenas para as topologias WS, BA e GN, as quais apresentam um nível de organização entre suas conexões.

O tamanho do sinal também foi um fator importante para a inferência correta das ligações entre os genes da rede. Este resultado era esperado como consequência do aumento do tamanho do sinal, disponibilizando ao método mais observações temporais. No entanto, o método de inferência foi capaz de recuperar mais de $50 \%$ de Similaridade da rede depois de apenas 40 observações temporais, de um espaço de estados de tamanho $2^{100}$, apresentando resultados muito bons. A taxa de Similaridade considerando-se todos os genes da rede foi muito parecida quando comparada à recuperação de apenas $10 \%$ dos genes mais conectados da rede. Estes resultados indicam uma boa propriedade para o método de inferência, através da identificação de genes que são determinados pela composição de funções Booleanas contendo mais preditores, gerando combinações Booleanas mais sofisticadas, as quais são mais difíceis de recuperar.

Surpreendentemente, o método de inferência adotado mostrou resultados semelhantes para to- 
das as topologias de redes complexas testadas, o que chamou a atenção para as topologias que têm sido aplicadas para caracterizar redes biológicas [Watts and Strogatz, 1998, Stuart et al., 2003, Barabási and Oltvai, 2004, Carroll et al., 2004, Albert, 2005]. Os resultados indicaram que a topologia da rede pode ser um aspecto importante a ser explorado como informação a priori pelos métodos de inferência, com objetivo de melhorar sua precisão. O método de identificação de rede se mostrou robusto mesmo na presença de algumas perturbações no sinal temporal, implicadas pela estocasticidade na aplicação das funções de transição.

Uma possível extensão desta etapa do trabalho é a implementação de medidas de redes complexas e, em seguida, analisar não só medidas globais, mas também medidas locais das redes [Costa et al., 2007], ou seja, medidas baseadas em genes individuais ou subconjuntos de genes. Além disso, é possível considerar medidas de similaridade que exploram outras propriedades da rede, como por exemplo, medidas baseadas na identificação das transições das redes, probabilidades das transições, trajetórias, entre outras [Dougherty, 2007]. A aplicação do modelo AGN a fim de avaliar redes de grande escala ou outros métodos de inferência é direto. Finalmente, o software de código livre que implementa o modelo AGN está disponível em http://code.google.com/p/jagn/, que pode ser usado para replicar os experimentos apresentados neste trabalho, bem como para gerar novos experimentos.

A terceira etapa do desenvolvimento deste trabalho foi concentrada na avaliação de métodos de inferência e desenvolvimento de novas metodologias para essa tarefa. Inicialmente, foi desenvolvido um estudo comparativo [Lopes et al., 2009b] entre quatro métodos de inferência de GRNs (Seção 2.6). Os resultados experimentais foram obtidos pela aplicação dos métodos de inferência a partir de dados simulados de expressão temporal gerados pelas AGNs, de forma determinística, i.e., usando apenas uma função de transição para cada gene da rede.

Os resultados indicam que a topologia da rede foi importante para o método SFFS-MCE, em termos de taxa de Similaridade adotada. A importância da topologia também foi observada em outros métodos, especialmente o MRNET que apresentou um comportamento completamente oposto em sua taxa de Similaridade de uma topologia de rede para outra. Considerando o número médio de conexões, o método SFFS-MCE apresentou melhores resultados para ambas as topologias de redes (ER e BA) quando o número médio de conexões $\langle k\rangle \leq 3$ para a topologia ER e $\langle k\rangle \leq 4$ para a topologia BA, enquanto que o método MRNET apresentou melhor desempenho para as conectividades acima desses valores. O método CLR apresenta um comportamento estreitamente relacionado com MRNET, mas apresentando taxas de similaridade um pouco menor. O método ARACNE apresentou as menores taxas de Similaridade em todos os experimentos. Os resultados indicam que o método SFFS-MCE é mais apropriado para inferência de redes do que os outros três métodos comparados.

O desenvolvimento da primeira etapa, em conjunto com a investigação dos métodos desse estudo comparativo, foram importantes para entender seus mecanismos de funcionamento e as respectivas adequações desses métodos ao processo de inferência de redes a partir dos perfis de expressão. Essa análise investigativa serviu como base para o desenvolvimento de novas metodologias de inferência de GRNs.

A primeira trata de uma função critério baseada na entropia de Tsallis [Lopes et al., 2009a,Lopes et al., 2011b], a qual foi aplicada utilizando-se o algoritmo de busca SFFS, considerado-se três aspectos principais: (1) variação do parâmetro entrópico $q$ (grau de não extensividade) da entropia 
de Tsallis; (2) topologias distintas de redes complexas (ER e BA); (3) complexidade das redes em termos do número médio de conexões $(k)$.

Os resultados indicaram uma melhoria significativa na precisão da inferência de GRNs usando a entropia de Tsallis. Essa melhoria foi observada em ambas as topologias de redes (ER e BA) e também para diferentes graus de complexidade $k$ (grau médio). As melhores redes inferidas, em termos da medida de Similaridade, foram obtidas a partir do intervalo do parâmetro entrópico $2,5 \leqslant q \leqslant 3,5$, indicando que a entropia sub-extensiva produz melhores resultados, sendo mais adequada para a inferência de redes. De fato, os resultados mostraram que as redes tendem a ser um pouco sub-extensivas $(q>1)$.

Os resultados podem ser vistos como uma primeira etapa para compreender melhor a inferência de topologias de rede por métodos baseados na teoria da informação. O ponto principal é a possibilidade da não extensividade das GRNs e, portanto, a dependência dos métodos baseados na entropia nesse processo. Uma possível extensão deste trabalho é a investigação da dependência da forma funcional da entropia ou informação mútua em outros métodos que aplicam a teoria da informação para inferência GRNs. Outro ponto interessante é sobre os circuitos lógicos criados por funções Booleanas e sua dinâmica. O método de inferência encontra alguns deles independente do valor de $q$, enquanto outros são encontrados apenas ajustando o valor de $q$. Nesse sentido, um trabalho futuro seria investigar as funções booleanas ou circuitos lógicos que são sensíveis ao parâmetro entrópico $q$ e as respectivas estruturas locais formadas pelos genes.

A segunda metodologia trata de uma estratégia de busca flutuante para a inferência de GRNs, chamada SFFS-MR [Lopes et al., 2010], a qual é apresentada na Seção 3.2.2. Dadas as limitações conhecidas, o objetivo foi adicionar uma informação a priori no método de busca, de forma que ele ocorra de maneira mais eficiente. A estratégia proposta é baseada na suposição de que alguns genes nos organismos biológicos têm uma predição intrinsecamente multivariada (veja Seção 2.7). Logo, o método explora esta propriedade com a inclusão de múltiplas raízes no início da pesquisa, que são definidas pelos melhores e piores resultados individuais do algoritmo SFS (veja Seção 2.4.1). Neste contexto, o espaço de busca percorrido pelo método SFFS-MR é um pouco maior do que pelos algoritmos SFS e SFFS, mas não agrava o custo computacional assintótico do SFFS.

Os resultados experimentais obtidos utilizando-se a topologia ER, mostram que o SFFS-MR proporciona uma melhor precisão no processo de inferência ( $P P V$, veja Seção 3.3) do que os algoritmos SFS e SFFS, não só ao considerar sinais de expressão com tamanhos pequenos, entre 15 e 20 instantes de tempo, mas também os sinais maiores contendo 100 instantes de tempo. Além disso, o SFFS-MR foi capaz de alcançar $60 \%$ de precisão na recuperação da rede, após considerar apenas 20 observações temporais de um espaço de estados do tamanho $2^{20}$, apresentando resultados muito bons.

O SFFS-MR também provou ser robusto, característica compartilhada pelos algoritmos SFS e SFFS, quando submetidos ao aumento da complexidade das redes, em termos de grau médio $\langle k\rangle$. A robustez é uma propriedade importante para os métodos de inferência, mesmo na presença de algumas perturbações no sinal temporal, implicadas pela estocasticidade na aplicação das funções de transição. Além disso, o SFFS-MR apresentou resultados melhores do que o SFS e SFFS.

Uma possível extensão deste trabalho é aplicar o SFFS-MR a fim de avaliar as redes de grande escala e outras topologias de redes, bem como comparar esse método com outros métodos de inferência de redes baseados em seleção de características. Uma extensão importante seria a inclusão 
da informação a priori de uma classe de problemas, nos métodos de busca para a inferência de GRNs. Como exemplo, pode ser mencionada a inclusão da topologia livre de escala (scale-free) de Barabási-Albert (BA) para guiar o processo de busca. Além disso, obter as raízes por uma heurística baseada na matriz de convariância também poderia ser uma alternativa para essa tarefa.

Neste sentido, foi desenvolvida a terceira metodologia aplicada à inferência de GRNs, a qual trata de uma estratégia de busca, interativa e flutuante, incluindo a hipótese de que as GRNs possuem uma topologia livre de escala, como uma informação a priori, no processo de inferência. Dadas as limitações conhecidas, o foco foi a inclusão de um conhecimento prévio no método de busca. Em particular, o objetivo foi o desenvolvimento de um algoritmo mais adequado e eficiente para a inferência de GRNs a partir de perfis de expressão temporal, que apresentam um número pequeno de amostras e uma dimensionalidade enorme (genes).

O algoritmo proposto, chamado SFFS-BA [Lopes et al., 2011c], é baseado no pressuposto de que várias redes biológicas podem ser bem aproximadas por uma topologia livre de escala. O método explora esta propriedade podando o espaço de busca ao aplicar uma lei de potência como um peso para a redução do espaço de busca. Neste contexto, o espaço de busca percorrido pelo método SFFSBA combina uma busca mais permissiva, quando o número de combinações é pequeno $(\langle k\rangle \leq 2)$, com uma busca mais restritiva quando o número de combinações torna-se muito grande $(\langle k\rangle \geq 3)$.

Os resultados experimentais mostraram que o algoritmo SFFS-BA oferece uma melhor precisão na inferência do que os algoritmos SFS e SFFS, ao considerar os sinais de expressão de tamanhos pequenos, contendo entre 20 e 30 instantes de tempo e também com perfis de expressão maiores, contendo 100 instantes de tempo. Além disso, mesmo adotando redes maiores e uma medida de Similaridade mais restritiva se comparada com a usada no caso anterior (SFFS-MR), o SFFS-BA foi capaz de atingir $60 \%$ na recuperação da rede depois de observados apenas 50 instantes de tempo, de um espaço de estados de tamanho $2^{100}$, apresentando resultados muito bons.

Outra qualidade muito importante para os métodos de inferência e, em particular, para os métodos de busca, é a robustez em identificar bons subconjuntos de preditores. O SFFS-BA manteve essa característica, quando comparado aos algoritmos SFS e SFFS, mesmo quando foi submetido ao aumento de complexidade das redes, em termos de grau médio $\langle k\rangle$, e a presença de algumas perturbações no sinal temporal, geradas pela estocasticidade na aplicação das funções de transição. Além disso, o SFFS-BA apresentou resultados melhores, em termos da medida de Similaridade, quando comparados aos resultados dos algoritmos SFS e SFFS.

Uma extensão importante deste trabalho é a inclusão, a priori, do modelo de redes mundo pequeno (WS) [Watts and Strogatz, 1998] a fim de orientar o processo de busca, de forma que a inferência dessa topologia de rede aconteça de forma mais adequada. Outra extensão é aplicar essa técnica para inferir GRNs a partir de dados reais.

Em se tratando da aplicação da metodologia proposta em dados reais, o algoritmo SFFS-MR foi aplicado, em conjunto com a entropia condicional média penalizada, com objetivo de inferir GRNs a partir de dados de expressão da Arabidopsis thaliana, como apresentado na Seção 3.4. Os resultados obtidos foram apresentados na Seção 4.6.

Foi possível verificar, com participação essencial da Profa. Dra. Marie-Anne Van Sluys, coorientadora deste trabalho e Kleber Alves Gomes, doutorando do programa interunidades de pósgraduação em Biotecnologia, algumas relações que se mostraram importantes. Inicialmente, foi observada uma maior quantidade de conexões entre a síntese de tiamina e as vias metabólicas de 
respiração e fotossíntese nas folhas, o que se mostrou como um fator positivo e coerente com a biologia conhecida do organismo, uma vez que essas duas vias metabólicas utilizam a tiamina como cofator. Como esperado, o mesmo não ocorreu considerando-se o tecido radicular.

Outro fator importante detectado foi que vários dos preditores inferidos da rede possuem uma função organelar: cloroplasto (fotossíntese) e mitocôndria (respiração celular), as quais estão envolvidas na produção de ATP, na qual a proteína THI1 atua. Indicando uma coerência biológica das conexões inferidas pelo método proposto e, ainda mais importante porque os relacionamentos inferidos foram obtidos apenas a partir dos transcritos (mRNAs) e não das proteínas.

Os genes investigados: LOS2 e EDA9, estão associados com proteínas identificadas no estudo realizado em [Momoli, 2008], os quais não apresentam relação previamente conhecida. A partir da inferência das GRNs, foi possível identificar potenciais candidatos de regulação desses genes, associando-os com o metabolismo na raiz.

Considerando-se o grupo controle, com transcrição nuclear, os preditores identificados para esse conjunto de genes se comportou de modo esperado, praticamente não apresentando arestas entre o conjunto controle e os demais conjuntos de genes. Outro ponto a ser destacado foi que a aplicação da metodologia proposta para a inferência das redes de Arabidopsis thaliana identificou preditores entre vias metabólicas e a síntese de tiamina não identificados anteriormente.

As conexões inferidas entre as vias metabólicas, em geral, se mostraram adequadas, indicando uma coerência biológica na estrutura das GRNs inferidas pelo método SFFS-MR. A aplicação biológica se mostrou potencialmente importante, sendo que uma possível extensão desse trabalho consiste na validação dos preditores do gene thi1 e dos relacionamentos encontrados entre os genes envolvidos na síntese de tiamina e nas demais vias metabólicas consideradas nesse estudo, incluindo os relacionamentos inferidos para os genes LOS2 e EDA9, os quais indicaram uma possível associação ao metabolismo da raiz. Outra possível extensão é com relação ao software desenvolvido para integração dos dados biológicos e visualização da rede, com objetivo de integrar essa visualização com as vias e processos metabólicos nos quais os genes dessa rede participam. 


\title{
Apêndice A
}

\section{Trabalhos produzidos}

\begin{abstract}
"AGN Simulation and Validation Model" Fabrício M. Lopes, Roberto M. Cesar-Jr e Luciano da Fontoura Costa. Advances in Bioinformatics and Computational Biology, Third Brazilian Symposium on Bioinformatics (BSB 2008), vol. 5167 of Lecture Notes in Computer Science, SpringerVerlag, Berlin, pp. 169-173, 2008. Disponível em http://dx.doi.org/10.1007/978-3-540-85557-6_17.
\end{abstract}

"Feature selection environment for genomic applications" Fabrício M. Lopes, David C. Martins-Jr e Roberto M. Cesar-Jr. BMC Bioinformatics (9):451, 2008. Disponível em http://dx. doi.org/10.1186/1471-2105-9-451.

"Comparative study of GRNs inference methods based on feature selection by mutual information" Fabrício M. Lopes, David C. Martins-Jr e Roberto M. Cesar-Jr. 7th IEEE International Workshop on Genomic Signal Processing and Statistics (GENSIPS 2009), IEEE Signal Proc Soc, New York, pp. 110-113, 2009. Disponível em http://dx.doi.org/10.1109/GENSIPS.2009. 5174334.

"Analysis of the GRNs inference by using Tsallis entropy and a feature selection approach" Fabrício M. Lopes, Evaldo A. de Oliveira e Roberto M. Cesar-Jr. 14th Iberoamerican Congress on Pattern Recognition (CIARP 2009), vol. 5856 of Lecture Notes in Computer Science, Springer-Verlag, Berlin, pp. 473-480, 2009. Disponível em http://dx.doi.org/10.1007/ 978-3-642-10268-4_55.

"SFFS-MR: a floating search strategy for GRNs inference" Fabrício M. Lopes, David C. Martins-Jr, Junior Barrera e Roberto M. Cesar-Jr. 5th IAPR International Conference on Pattern Recognition in Bioinformatics (PRIB 2010), vol. 6282 of Lecture Notes in Computer Science, Springer-Verlag, Berlin, pp. 407-418, 2010. Disponível em http://dx.doi.org/10.1007/978-3-642-16001-1_ 35. 
"Inference of gene regulatory networks from time series by Tsallis entropies" Fabrício M. Lopes, Evaldo A. de Oliveira e Roberto M. Cesar-Jr. BMC Systems Biology (5):61, 2011. Disponível em http://dx.doi.org/10.1186/1752-0509-5-61.

"Gene expression complex networks: synthesis, identification and analysis" Fabrício M. Lopes, Roberto M. Cesar-Jr. e Luciano da Fontoura Costa. Journal of Computational Biology, (aceito para publicação), 2011. Disponível em http://dx.doi.org/10.1089/cmb.2010.0118.

"An iterative feature selection method for GRNs inference by exploring its topology properties" Fabrício M. Lopes, David C. Martins-Jr, Junior Barrera e Roberto M. Cesar-Jr. (em preparação). Pré-impressão disponível em http://arxiv.org/abs/1107.5000. 


\section{Referências Bibliográficas}

[ml1, 1998] (1998). Glossary of terms. Machine Learning, 30:271-274. 54, 55

[Abe, 2004] Abe, S. (2004). Tsallis entropy: how unique? Continuum Mechanics and Thermodynamics, 16(3):237-244. 25, 26, 45

[Aittokallio and Schwikowski, 2006] Aittokallio, T. and Schwikowski, B. (2006). Graph-based methods for analysing networks in cell biology. Brief Bioinform, 7(3):243-255. 44

[Albert, 2005] Albert, R. (2005). Scale-free networks in cell biology. J Cell Sci, 118(21):4947-4957. $33,36,40,53,91$

[Albert and Barabási, 2002] Albert, R. and Barabási, A.-L. (2002). Statistical mechanics of complex networks. Rev. Mod. Phys., 74(1):47-97. 3, 45, 53

[Albert and Othmer, 2003] Albert, R. and Othmer, H. G. (2003). The topology of the regulatory interactions predicts the expression pattern of the segment polarity genes in Drosophila melanogaster. Journal of Theoretical Biology, 223(1):1-18. 3

[Alon, 2007] Alon, U. (2007). Network motifs: theory and experimental approaches. Nat Rev Genet, 8(6):450-461. 45

[Anastassiou, 2007] Anastassiou, D. (2007). Computational analysis of the synergy among multiple interacting genes. Molecular Systems Biology, 3(1):83. 21

[Andrecut et al., 2008] Andrecut, M., Huang, S., and Kauffman, S. (2008). Heuristic approach to sparse approximation of gene regulatory networks. Journal of Computational Biology, 15(9):11731186. 2,44

[Andrecut and Kauffman, 2008] Andrecut, M. and Kauffman, S. (2008). On the sparse reconstruction of gene networks. Journal of Computational Biology, 15(1):21-30. 2, 44

[Ashburner et al., 2000] Ashburner, M., Ball, C. A., Blake, J. A., Botstein, D., Butler, H., Cherry, J. M., Davis, A. P., Dolinski, K., Dwight, S. S., Eppig, J. T., Harris, M. A., Hill, D. P., IsselTarver, L., Kasarskis, A., Lewis, S., Matese, J. C., Richardson, J. E., Ringwald, M., Rubin, G. M., and Sherlock, G. (2000). Gene ontology: tool for the unification of biology. Nat Genet, $25(1): 25-29.44,57,87$

[Bansal et al., 2007] Bansal, M., Belcastro, V., Ambesi-Impiombato, A., and di Bernardo, D. (2007). How to infer gene networks from expression profiles. Mol Syst Biol, 3(1):78. 3, 68, 76

[Barabási, 2009] Barabási, A.-L. (2009). Scale-Free Networks: A Decade and Beyond. Science, 325(5939):412-413. 36

[Barabási and Albert, 1999] Barabási, A.-L. and Albert, R. (1999). Emergence of scaling in random networks. Science, 286(5439):509-512. 33, 35, 40 
[Barabási and Oltvai, 2004] Barabási, A.-L. and Oltvai, Z. (2004). Network biology: Understanding the cell's functional organization. Nature Reviews Genetics, 5:101-113. 36, 91

[Barrera et al., 2004] Barrera, J., Cesar-Jr, R. M., Martins-Jr, D. C., Vencio, R. Z. N., Merino, E. F., Yamamoto, M. M., Leonardi, F. G., Pereira, C. A. B., and Portillo, H. A. (2004). A new annotation tool for malaria based on inference of probabilistic genetic networks. In Proc. Fifth International Conference for the Critical Assessment of Microarray Data Analysis (CAMDA 2004), Durham. 18, 19

[Barrera et al., 2007] Barrera, J., Cesar-Jr, R. M., Martins-Jr, D. C., Vencio, R. Z. N., Merino, E. F., Yamamoto, M. M., Leonardi, F. G., Pereira, C. A. B., and Portillo, H. A. (2007). Constructing probabilistic genetic networks of Plasmodium falciparum, from dynamical expression signals of the intraerythrocytic development cycle. In McConnell, P., Lin, S. M., and Hurban, P., editors, Methods of Microarray Data Analysis V, pages 11-26. Springer US. 2, 4, 18, 19, 28, 31, 39, 42, $45,46,60,68,76,79$

[Baumbach et al., 2009] Baumbach, J., Tauch, A., and Rahmann, S. (2009). Towards the integrated analysis, visualization and reconstruction of microbial gene regulatory networks. Brief Bioinform, 10(1):75-83. 44

[Benson et al., 2008] Benson, D. A., Karsch-Mizrachi, I., Lipman, D. J., Ostell, J., and Wheeler, D. L. (2008). GenBank. Nucleic Acids Research, 36(suppl 1):D25-D30. 44, 57

[Bishop, 1995] Bishop, C. M. (1995). Neural networks for pattern recognition. Oxford University Press. 19, 23

[Boccaletti et al., 2006] Boccaletti, S., Latora, V., Moreno, Y., Chavez, M., and Hwang, D. U. (2006). Complex networks: Structure and dynamics. Physics Reports, 424(4-5):175-308. 34, 40, 53

[Boltzmann, 1974] Boltzmann, L. (1974). Theoretical physics and philosophical problems: selected writings. Springer. 23

[Borland et al., 1998] Borland, L., Plastino, A. R., and Tsallis, C. (1998). Information gain within nonextensive thermostatistics. Journal of Mathematical Physics, 39(12):6490-6501. 26

[Butte and Kohane, 2000] Butte, A. and Kohane, I. (2000). Mutual information relevance networks: functional genomic clustering using pairwise entropy measurements. In Proceedings of the Pacific Symposium on Biocomputing, pages 418-429. 2, 4, 28, 29

[Cappé et al., 2005] Cappé, O., Moulines, E., and Ryden, T. (2005). Inference in Hidden Markov Models (Springer Series in Statistics). Springer-Verlag New York, Inc., Secaucus, NJ, USA. 18

[Carroll et al., 2004] Carroll, S. B., Grenier, J. K., and Weatherbee, S. D. (2004). From DNA to diversity: molecular genetics and the evolution of animal design. Wiley-Blackwell, 2nd edition. 37,91

[Chabregas et al., 2001] Chabregas, S. M., Luche, D. D., Farias, L. P., Ribeiro, A. F., Van Sluys, M.-A., Menck, C. F., and Silva-Filho, M. C. (2001). Dual targeting properties of the n-terminal signal sequence of arabidopsis thaliana thi1 protein to mitochondria and chloroplasts. Plant Molecular Biology, 46:639-650. 10.1023/A:1011628510711. 87

[Charbonnier et al., 2010] Charbonnier, C., Chiquet, J., and Ambroise, C. (2010). Weighted-lasso for structured network inference from time course data. Statistical Applications in Genetics and Molecular Biology, 9(1):15. 45

[Chen et al., 1999] Chen, T., He, H. L., and Church, G. M. (1999). Modeling gene expression with differential equations. In Pacific Symposium on Biocomputing, pages 29-40. 3, 11 
[Cheng et al., 1997] Cheng, J., Bell, D. A., and Liu, W. (1997). Learning belief networks from data: an information theory based approach. In CIKM '97: Proceedings of the sixth international conference on Information and knowledge management, pages 325-331, New York, NY, USA. ACM. 68

[Chiquet et al., 2009] Chiquet, J., Smith, A., Grasseau, G., Matias, C., and Ambroise, C. (2009). SIMoNe: Statistical Inference for MOdular NEtworks. Bioinformatics, 25(3):417-418. 83

[Christley et al., 2009] Christley, S., Nie, Q., and Xie, X. (2009). Incorporating existing network information into gene network inference. PLoS ONE, 4(8):e6799. 44

[Clausius, 1879] Clausius, R. (1879). The mechanical theory of heat. Macmillan, London. 23

[Costa et al., 2008] Costa, L. d. F., Rodrigues, F. A., and Cristino, A. S. (2008). Complex networks: the key to systems biology. Genetics and Molecular Biology, 31(3):591-601. 33, 34, 36, 40, 41, 45

[Costa et al., 2007] Costa, L. d. F., Rodrigues, F. A., Travieso, G., and Villas-Boas, P. R. (2007). Characterization of complex networks: a survey of measurements. Advances in Physics, 56(1):167242. $3,33,34,35,36,37,40,91$

[Cui et al., 2010] Cui, X., Wang, T., Chen, H.-S., Busov, V., and Wei, H. (2010). Tf-finder: A software package for identifying transcription factors involved in biological processes using microarray data and existing knowledge base. BMC Bioinformatics, 11(1):425. 44

[D’Angelo et al., 2010] D’Angelo, C., Kilian, J., Kudla, J., Batistic, O., and Weinl, S. (2010). The Arabidopsis Information Resource (TAIR). 56, 57, 87

[Davidich and Bornholdt, 2008] Davidich, M. I. and Bornholdt, S. (2008). Boolean network model predicts cell cycle sequence of fission yeast. PLoS ONE, 3(2):e1672. 3

[de Campos, 2001] de Campos, T. (2001). Técnicas de seleção de características com aplicações em reconhecimento de faces. Master's thesis, University of Sao Paulo. Awarded as the Best Computer Science MSc. Thesis in the CTD/SBC 2002. 20

[De Haan et al., 2010] De Haan, J., Piek, E., van Schaik, R., de Vlieg, J., Bauerschmidt, S., Buydens, L., and Wehrens, R. (2010). Integrating gene expression and go classification for pca by preclustering. BMC Bioinformatics, 11(1):158. 44

[de Jong, 2002] de Jong, H. (2002). Modeling and simulation of genetic regulatory systems: A literature review. Journal of Computational Biology, 9(1):67-103. 2, 11, 12, 29

[de Jong et al., 2003] de Jong, H., Geiselmann, J., Hernandez, C., and Page, M. (2003). Genetic Network Analyzer: qualitative simulation of genetic regulatory networks. Bioinformatics, 19(3):336-344. 3

[de la Fuente et al., 2004] de la Fuente, A., Bing, N., Hoeschele, I., and Mendes, P. (2004). Discovery of meaningful associations in genomic data using partial correlation coefficients. Bioinformatics, 20(18):3565-3574. 3

[de Smet and Marchal, 2010] de Smet, R. and Marchal, K. (2010). Advantages and limitations of current network inference methods. Nat Rev Micro, 8(10):717-729. 2, 29

[Deitel and Deitel, 2003] Deitel, H. M. and Deitel, P. J. (2003). Java Como Programar. Bookman, Porto Alegre, 4th edition. 57

[D’Haeseleer et al., 1999] D'Haeseleer, P., Liang, S., and Somogyi, R. (1999). Gene expression data analysis and modeling. In Proceedings of the Pacific Symposium on Biocomputing, pages 1-34. 2 
[D'haeseleer et al., 2000] D'haeseleer, P., Liang, S., and Somogyi, R. (2000). Genetic network inference: from co-expression clustering to reverse engineering. Bioinformatics, 16(8):707-726. 2, $13,29,39,41$

[Diestel, 2005] Diestel, R. (2005). Graph Theory. Springer-Verlag, Heidelberg, 3rd edition. 33

[dos Santos and Liu, 2007] dos Santos, C. C. and Liu, M. (2007). Chapter 5: Gene expression profiling by microarray. In Ye, S. Q., editor, Bioinformatics: A Practical Approach. Chapman \& HallCRC Mathematical \& Computational Biology, 1st edition. 9, 10

[Dougherty, 2007] Dougherty, E. R. (2007). Validation of inference procedures for gene regulatory networks. Current Genomics, 8(6):351-359. 2, 4, 54, 79, 91

[Dougherty et al., 2009] Dougherty, E. R., Brun, M., Trent, J. M., and Bittner, M. L. (2009). Conditioning-based modeling of contextual genomic regulation. IEEE/ACM TCBB, 6:310-320. 28

[Dougherty et al., 2000] Dougherty, E. R., Kim, S., and Chen, Y. (2000). Coefficient of determination in nonlinear signal processing. Signal Processing, 80:2219-2235. 32

[Dougherty et al., 2008] Dougherty, J., Tabus, I., and Astola, J. (2008). Inference of gene regulatory networks based on a universal minimum description length. EURASIP Journal on Bioinformatics and Systems Biology, 2008:1-11. 4

[DREAM, 2009] DREAM (2009). Dream: Dialogue for reverse engineering assessments and methods. project website: http://wiki.c2b2.columbia.edu/dream/. 2, 71

[Erdös and Rényi, 1959] Erdös, P. and Rényi, A. (1959). On random graphs. Publ. Math. Debrecen, 6:290-297. 33, 34, 40

[Ernst et al., 2008] Ernst, J., Beg, Q. K., Kay, K. A., Balázsi, G., Oltvai, Z. N., and Bar-Joseph, Z. (2008). A semi-supervised method for predicting transcription factor-gene interactions in Escherichia coli. PLoS Comput Biol, 4(3):e1000044. 44

[Espinosa-Soto et al., 2004] Espinosa-Soto, C., Padilla-Longoria, P., and Alvarez-Buylla, E. R. (2004). A Gene Regulatory Network Model for Cell-Fate Determination during Arabidopsis thaliana Flower Development That Is Robust and Recovers Experimental Gene Expression Profiles. Plant Cell, 16(11):2923-2939. 3

[Faith et al., 2007] Faith, J., Hayete, B., Thaden, J., Mogno, I., Wierzbowski, J., Cottarel, G., Kasif, S., Collins, J., and Gardner, T. (2007). Large-scale mapping and validation of escherichia coli transcriptional regulation from a compendium of expression profiles. PLoS Biology, 5(1):259-265. $2,4,28,30,39$

[Fall et al., 2002] Fall, C., Marland, E., Wagner, J., and Tyson, J. (2002). 978-0-387-95369-4. Springer Verlag, 3rd edition. 11

[Farkas et al., 2003] Farkas, I. J., Jeong, H., Vicsek, T., Barabási, A.-L., , and Oltvai, Z. N. (2003). The topology of the transcription regulatory network in the yeast, saccharomyces cerevisiae. Physica A: Statistical Mechanics and its Applications, 318(3-4):601-612. 33, 36, 40

[Faure et al., 2006] Faure, A., Naldi, A., Chaouiya, C., and Thieffry, D. (2006). Dynamical analysis of a generic Boolean model for the control of the mammalian cell cycle. Bioinformatics, 22(14):e124-131. 3

[Friedman et al., 2000] Friedman, N., Linial, M., Nachman, I., and Pe'er, D. (2000). Using bayesian networks to analyze expression data. Journal of Computational Biology, 7(3-4):601-620. 11, 15 
[Fujita, 2007] Fujita, A. (2007). Análise de dados de expressão gênica: normalização de microarrays e modelagem de redes regulatórias. PhD thesis, Instituto de Matemática e Estatística da Universidade de São Paulo, Rua do Matão, 1010. 10

[Furuichi, 2006] Furuichi, S. (2006). Information theoretical properties of Tsallis entropies. Journal of Mathematical Physics, 47(2):023302. 26

[Gastner and Newman, 2006] Gastner, M. T. and Newman, M. E. J. (2006). The spatial structure of networks. The European Physical Journal B - Condensed Matter and Complex Systems, 49:247252. $33,36,40$

[Ghaffari et al., 2010] Ghaffari, N., Ivanov, I., Qian, X., and Dougherty, E. R. (2010). A CoD-based reduction algorithm for designing stationary control policies on Boolean networks. Bioinformatics, 26(12):1556-1563. 28

[Gibson et al., 2010] Gibson, D. G., Glass, J. I., Lartigue, C., Noskov, V. N., Chuang, R.-Y., Algire, M. A., Benders, G. A., Montague, M. G., Ma, L., Moodie, M. M., Merryman, C., Vashee, S., Krishnakumar, R., Assad-Garcia, N., Andrews-Pfannkoch, C., Denisova, E. A., Young, L., Qi, Z.-Q., Segall-Shapiro, T. H., Calvey, C. H., Parmar, P. P., Hutchison, Clyde A., I., Smith, H. O., and Venter, J. C. (2010). Creation of a Bacterial Cell Controlled by a Chemically Synthesized Genome. Science, 329(5987):52-56. 2

[Godoi et al., 2006] Godoi, P. H. C., Galhardo, R. S., Luche, D. D., Van Sluys, M.-A., Menck, C. F. M., and Oliva, G. (2006). Structure of the Thiazole Biosynthetic Enzyme THI1 from Arabidopsis thaliana. Journal of Biological Chemistry, 281(41):30957-30966. 87

[Goemann et al., 2009] Goemann, B., Wingender, E., and Potapov, A. (2009). An approach to evaluate the topological significance of motifs and other patterns in regulatory networks. $B M C$ Systems Biology, 3(1):53. 45

[Gomes and Van Sluys, 2010] Gomes, K. A. and Van Sluys, M.-A. (2010). Estudo do papel do gene THI1 e sua relação com redes metabólicas em cana de açúcar. Technical report, Departamento de Botânica do Instituto de Biociências da Universidade de São Paulo. 55

[Gray, 1990] Gray, R. M. (1990). Entropy and Information Theory. Springer-Verlag, 1st edition. 24

[Guelzim et al., 2002] Guelzim, N., Bottani, S., Bourgine, P., and Képès, F. (2002). Topological and causal structure of the yeast transcriptional regulatory network. Nature genetics, 31:60-63. $33,36,40$

[Guyon and Elisseeff, 2003] Guyon, I. and Elisseeff, A. (2003). An introduction to variable and feature selection. J. Mach. Learn. Res., 3:1157-1182. 21

[Hartemink et al., 2001] Hartemink, A. J., Gifford, D. K., Jaakkola, T. S., and Young, R. (2001). Using graphical models and genomic expression data to statistically validate models of genetic regulatory networks. In Pac. Symp. Biocomput, volume 6, pages 422-433. 33

[Hashimoto et al., 2004] Hashimoto, R. F., Kim, S., Shmulevich, I., Zhang, W., Bittner, M. L., and Dougherty, E. R. (2004). Growing genetic regulatory networks from seed genes. Bioinformatics, 20(8):1241-1247. 4, 28

[Haynes and Brent, 2009] Haynes, B. C. and Brent, M. R. (2009). Benchmarking regulatory network reconstruction with GRENDEL. Bioinformatics, 25(6):801-807. 3

[Hecker et al., 2009] Hecker, M., Lambeck, S., Toepfer, S., van Someren, E., and Guthke, R. (2009). Gene regulatory network inference: Data integration in dynamic models - A review. Biosystems, 96(1):86-103. 2, 29, 44 
[Heer et al., 2005] Heer, J., Card, S. K., and Landay, J. A. (2005). prefuse: a toolkit for interactive information visualization. In CHI '05: Proceedings of the SIGCHI conference on Human factors in computing systems, pages 421-430, New York, NY, USA. ACM. 58

[Hoheisel, 2006] Hoheisel, J. D. (2006). Microarray technology: beyond transcript profiling and genotype analysis. Nat Rev Genet, 7(3):200-210. 8

[Hovatta et al., 2005] Hovatta, I., Kimppa, K., Lehmussola, A., Pasanen, T., Saarela, J., Saarikko, I., Saharinen, J., Tiikkainen, P., Toivanen, T., Tolvanen, M., et al. (2005). DNA microarray data analysis. CSC, Scientific Computing Ltd, 2nd edition. 1, 7, 11, 16, 28

[Issue, 2005] Issue, S. (2005). Nonextensive statistical mechanics: new trends, new perspectives. Europhysics News, 36(6):185-231. 45

[Ivanov and Dougherty, 2006] Ivanov, I. and Dougherty, E. R. (2006). Modeling genetic regulatory networks: continuous or discrete? Journal of Biological Systems, 14(2):219-229. 3

[Jain et al., 2000] Jain, A. K., Duin, R. P. W., and Mao, J. (2000). Statistical pattern recognition: A review. IEEE TPAMI, 22(1):4-37. 4, 19

[Jeong et al., 2001] Jeong, H., Mason, S. P., Barabási, A.-L., and Oltvai, Z. N. (2001). Lethality and centrality in protein networks. Nature, 411(6833):41-42. 53

[Jeong et al., 2000] Jeong, H., Tombor, B., Albert, R., Oltvai, Z. N., and Barabási, A.-L. (2000). The large-scale organization of metabolic networks. Nature, 407:651-654. 33, 36, 53

[Kanehisa and Goto, 2000] Kanehisa, M. and Goto, S. (2000). KEGG: Kyoto Encyclopedia of Genes and Genomes. Nucleic Acids Research, 28(1):27-30. 44, 57

[Karlebach and Shamir, 2008] Karlebach, G. and Shamir, R. (2008). Modelling and analysis of gene regulatory networks. Nat Rev Mol Cell Biol, 9(10):770-780. 2, 3, 29, 44

[Kauffman et al., 2003] Kauffman, S., Peterson, C., Samuelsson, B., and Troein, C. (2003). Random Boolean network models and the yeast transcriptional network. PNAS, 100(25):14796-14799. 3

[Kauffman, 1969] Kauffman, S. A. (1969). Metabolic stability and epigenesis in randomly constructed genetic nets. Journal of Theoretical Biology, 22(3):437-467. 2, 11, 13, 62

[Kauffman, 1971] Kauffman, S. A. (1971). Chapter 5 gene regulation networks: A theory for their global structure and behaviors. volume 6 of Current Topics in Developmental Biology, pages 145-182. Academic Press. 33

[Kauffman, 1993] Kauffman, S. A. (1993). The origins of order: Self-organization and selection in evolution. Oxford University Press. 2, 13, 15, 33, 62, 67

[Kelemen et al., 2008] Kelemen, A., Abraham, A., and Chen, Y. (2008). Computational intelligence in bioinformatics. Springer. xvii, 12, 14, 15, 24, 29, 30

[Keles et al., 2002] Keles, S., van-der Laan, M., and Eisen, M. B. (2002). Identification of regulatory elements using a feature selection method. Bioinformatics, 18(9):1167-1175. 2

[Kim et al., 2010] Kim, D.-C., Wang, X., Yang, C.-R., and Gao, J. (2010). Learning biological network using mutual information and conditional independence. BMC Bioinformatics, 11(Suppl 3):S9. 68

[Kim et al., 2002] Kim, S., Li, H., Dougherty, E. R., Cao, N., Chen, Y., Bittner, M., and Suh, E. B. (2002). Can markov chain models mimic biological regulation. Journal of Biological Systems, 10(4):337-357. 2 
[Klamt et al., 2007] Klamt, S., Saez-Rodriguez, J., and Gilles, E. (2007). Structural and functional analysis of cellular networks with cellnetanalyzer. BMC Systems Biology, 1(1):2. 44

[Kuchaiev et al., 2010] Kuchaiev, O., Milenkovic, T., Memisevic, V., Hayes, W., and Przulj, N. (2010). Topological network alignment uncovers biological function and phylogeny. Journal of The Royal Society Interface, 7(50):1341-1354. 44

[Kumar and Varaiya, 1986] Kumar, P. R. and Varaiya, P. (1986). Stochastic Systems: Estimation, Identification, and Adaptative Control. Prentice Hall, New Jersey. 18

[Lacroix et al., 2008] Lacroix, V., Cottret, L., Thébault, P., and Sagot, M.-F. (2008). An introduction to metabolic networks and their structural analysis. IEEE/ACM Trans. Comput. Biol. Bioinformatics, 5(4):594-617. 44

[Lenas et al., 2009] Lenas, P., Moos, M., and Luyten, F. P. (2009). Developmental engineering: A new paradigm for the design and manufacturing of cell-based products. part ii. from genes to networks: Tissue engineering from the viewpoint of systems biology and network science. Tissue Engineering Part B: Reviews, 15(4):395-422. 44

[Li et al., 2004] Li, F., Long, T., Lu, Y., Ouyang, Q., and Tang, C. (2004). The yeast cell-cycle network is robustly designed. PNAS, 101(14):4781-4786. 3, 15

[Li and Lu, 2005] Li, L. M. and Lu, H. H. S. (2005). Explore biological pathways from noisy array data by directed acyclic boolean networks. Journal of Computational Biology, 12(2):170-185. 3

[Li et al., 2006] Li, S., Assmann, S. M., and Réka, A. (2006). Predicting essential components of signal transduction networks: A dynamic model of guard cell abscisic acid signaling. PLoS Biol, 4(10):e312. 3

[Liang et al., 1998] Liang, S., Fuhrman, S., and Somogyi, R. (1998). Reveal: a general reverse engineering algorithm for inference of genetic network architectures. In Proceedings of the Pacific Symposium on Biocomputing, pages 18-29. 2, 4, 28, 29, 39, 42, 45, 68

[Lopes et al., 2008a] Lopes, F. M., Cesar-Jr, R. M., and Costa, L. d. F. (2008a). AGN simulation and validation model. In Advances in Bioinformatics and Computational Biology, Proceedings, volume 5167 of Lecture Notes in Bioinformatics, pages 169-173. Springer-Verlag Berlin. 2, 5, 19, $31,39,59,66,89$

[Lopes et al., 2011a] Lopes, F. M., Cesar-Jr, R. M., and Costa, L. d. F. (2011a). Gene expression complex networks: synthesis, identification and analysis. Journal of Computational Biology. In Press, Accepted Manuscript. 5, 40, 59, 68, 76, 78, 89

[Lopes et al., 2009a] Lopes, F. M., de Oliveira, E. A., and Cesar-Jr, R. M. (2009a). Analysis of the GRNs inference by using Tsallis entropy and a feature selection approach. In Progress in Pattern Recognition, Image Analysis, Computer Vision, and Applications, Proceedings, volume 5856 of Lecture Notes in Computer Science, pages 473-480. Springer-Verlag Berlin. 14th Iberoamerican Congress on Pattern Recognition (CIARP 2009), Guadalajara, Mexico, NOV 15-18, 2009. 6, 66, 68,91

[Lopes et al., 2011b] Lopes, F. M., de Oliveira, E. A., and Cesar-Jr, R. M. (2011b). Inference of gene regulatory networks from time series by Tsallis entropies. BMC Systems Biology, 5(1):61. $6,68,91$

[Lopes et al., 2010] Lopes, F. M., Martins-Jr, D. C., Barrera, J., and Cesar-Jr, R. M. (2010). SFFSMR: a floating search strategy for GRNs inference. In Pattern Recognition in Bioinformatics, Proceedings, volume 6282 of Lecture Notes in Computer Science, pages 407-418. Springer Berlin / Heidelberg. 5th IAPR International Conference on Pattern Recognition in Bioinformatics (PRIB 2010), Nijmegen, The Netherlands, SEP 22-24, 2010. 6, 48, 51, 76, 82, 92 
[Lopes et al., 2011c] Lopes, F. M., Martins-Jr, D. C., Barrera, J., and Cesar-Jr, R. M. (2011c). An iterative feature selection method for GRNs inference by exploring its topology properties. Arxiv preprint arXiv:110\%.5000, abs/1107.5000v1:1-10. 6, 78, 93

[Lopes et al., 2008b] Lopes, F. M., Martins-Jr, D. C., and Cesar-Jr, R. M. (2008b). DimReduction - interactive graphic environment for dimensionality reduction. Technical report, Instituto de Matemática e Estatística da Universidade de São Paulo and Universidade Tecnológica Federal do Paraná. 5, 89

[Lopes et al., 2008c] Lopes, F. M., Martins-Jr, D. C., and Cesar-Jr, R. M. (2008c). Feature selection environment for genomic applications. BMC Bioinformatics, 9(1):451. xvii, 5, 10, 19, 21, 22, 31, $45,46,57,61,66,71,76,79,89$

[Lopes et al., 2009b] Lopes, F. M., Martins-Jr, D. C., and Cesar-Jr, R. M. (2009b). Comparative study of GRNs inference methods based on feature selection by mutual information. In 2009 IEEE International Workshop on Genomic Signal Processing and Statistics (GENSIPS 2009), pages 110-113, 345 E 47TH ST, New York, NY 10017 USA. IEEE Signal Proc Soc, IEEE. 7th IEEE International Workshop on Genomic Signal Processing and Statistics (GENSIPS 2009), Minneapolis, United States, MAY 17-19, 2009. 4, 5, 19, 45, 91

[Lu and Zhou, 2010] Lu, L. and Zhou, T. (2010). Link prediction in complex networks: A survey. Physica A: Statistical Mechanics and its Applications, In Press, Accepted Manuscript. 29

[Macintyre et al., 2010] Macintyre, G., Bailey, J., Gustafsson, D., Haviv, I., and Kowalczyk, A. (2010). Using gene ontology annotations in exploratory microarray clustering to understand cancer etiology. Pattern Recognition Letters, In Press, Corrected Proof:-. 44

[Mahalingam et al., 2005] Mahalingam, R., Shah, N., Scrymgeour, A., and Fedoroff, N. (2005). Temporal evolution of the arabidopsis oxidative stress response. Plant Molecular Biology, 57(5):709-730. 55

[Marbach et al., 2010] Marbach, D., Prill, R. J., Schaffter, T., Mattiussi, C., Floreano, D., and Stolovitzky, G. (2010). Revealing strengths and weaknesses of methods for gene network inference. Proceedings of the National Academy of Sciences, 107(14):6286-6291. 2, 29

[Margolin et al., 2006] Margolin, A., Basso, K. N., Wiggins, C., Stolovitzky, G., Favera, R., and Califano, A. (2006). ARACNE: An algorithm for the reconstruction of gene regulatory networks in a mammalian cellular context. BMC Bioinformatics, 7(Suppl 1):S7. 2, 4, 28, 30, 39, 68

[Markowetz and Spang, 2007] Markowetz, F. and Spang, R. (2007). Inferring cellular networks - a review. BMC Bioinformatics, 8(Suppl 6):S5. 2, 29

[Martins-Jr., 2008] Martins-Jr., D. C. (2008). Seleção de características e predição intrinsecamente multivariada em identificação de redes de regulação gênica. $\mathrm{PhD}$ thesis, Instituto de Matemática e Estatística da Universidade de São Paulo, Rua do Matão, 1010. xvii, 19, 24, 28, 31, 32, 33, 46

[Martins-Jr et al., 2008] Martins-Jr, D. C., Braga-Neto, U., Hashimoto, R. F., Dougherty, E. R., and Bittner, M. L. (2008). Intrinsically multivariate predictive genes. IEEE Journal of Selected Topics in Signal Processing, 2(3):424-439. 21, 32

[Martins-Jr et al., 2006] Martins-Jr, D. C., Cesar-Jr, R. M., and Barrera, J. (2006). W-operator window design by minimization of mean conditional entropy. Pattern Analysis 83 Applications, 9:139-153. 31, 45, 46

[Martins-Jr et al., 2010] Martins-Jr, D. C., Oliveira, E. A., Louzada, V. H., and Hashimoto, R. F. (2010). Inference of restricted stochastic boolean grn's by bayesian error and entropy based criteria. In 15th Iberoamerican Congress on Pattern Recognition (CIARP), Lecture Notes in Computer Science. Springer-Verlag. (to be appeared). 29 
[Mendes et al., 2003] Mendes, P., Sha, W., and Ye, K. (2003). Artificial gene networks for objective comparison of analysis algorithms. Bioinformatics, 19(Suppl 2):122ii-129. 2, 3

[Meyer et al., 2007] Meyer, P. E., Kontos, K., Lafitte, F., and Bontempi, G. (2007). Informationtheoretic inference of large transcriptional regulatory networks. EURASIP Journal on Bioinformatics and Systems Biology, 2007:1-9. 30, 39, 68

[Meyer et al., 2008] Meyer, P. E., Lafitte, F., and Bontempi, G. (2008). minet: A RBioconductor package for inferring large transcriptional networks using mutual information. BMC Bioinformatics, $9(1): 461.2,39,66$

[Milgram, 1967] Milgram, S. (1967). The small world problem. Psychology today, 2(1):60-67. 34

[Momoli, 2008] Momoli, M. M. (2008). Aspectos funcionais do gene thi1 em plantas selvagens e mutantes de Arabidopsis thaliana (Brassicaceae). PhD thesis, Departamento de Botânica do Instituto de Biociências da Universidade de São Paulo, Rua do Matão, 277. 56, 83, 94

[Narasimhan et al., 2009] Narasimhan, S., Rengaswamy, R., and Vadigepalli, R. (2009). Structural properties of gene regulatory networks: Definitions and connections. IEEE/ACM Trans. Comput. Biol. Bioinformatics, 6(1):158-170. 12, 33, 40, 44

[Nelson and Cox, 2004] Nelson, D. L. and Cox, M. M. (2004). Lehninger Principles of Biochemistry. W. H. Freeman, USA, 4th edition. 2, 7, 8, 83

[Newman, 2003] Newman, M. E. J. (2003). The structure and function of complex networks. SIAM Review, 45(2):167-256. 3, 12, 45

[Ott et al., 2005] Ott, S., Hansen, A., Kim, S.-Y., and Miyano, S. (2005). Superiority of network motifs over optimal networks and an application to the revelation of gene network evolution. Bioinformatics, 21(2):227-238. 45

[Pearl, 1988] Pearl, J. (1988). Probabilistic reasoning in intelligent systems: networks of plausible inference. Morgan Kaufmann. 12, 40

[Peng et al., 2005] Peng, H., Long, F., and Ding, C. (2005). Feature selection based on mutual information: criteria of max-dependency, max-relevance, and min-redundancy. IEEE TPAMI, 27(8):1226-1238. 4, 30

[Polanski and Kimmel, 2007] Polanski, A. and Kimmel, M. (2007). Bioinformatics. SpringerVerlag. 18

[Przytycka and Kim, 2010] Przytycka, T. and Kim, Y.-A. (2010). Network integration meets network dynamics. BMC Biology, 8(1):48. 44

[Pudil et al., 1994] Pudil, P., Novovičová, J., and Kittler, J. (1994). Floating search methods in feature-selection. Pattern Recognition Letters, 15(11):1119-1125. 21, 22, 31

[Quayle and Bullock, 2006] Quayle, A. and Bullock, S. (2006). Modelling the evolution of genetic regulatory networks. Journal of Theoretical Biology, 238(4):737-753. 3

[Rao et al., 2007] Rao, A., Hero III, A., States, D., and Engel, J. (2007). Using directed information to build biologically relevant influence networks. In Proc LSS Comput Syst Bioinform, pages 145156. 4,28

[Ray et al., 2009] Ray, S. S., Bandyopadhyay, S., and Pal, S. (2009). Combining multisource information through functional-annotation-based weighting: Gene function prediction in yeast. Biomedical Engineering, IEEE Transactions on, 56(2):229-236. 44 
[Ris et al., 2010] Ris, M., Martins-Jr, D. C., and Barrera, J. (2010). U-curve: A branch-and-bound optimization algorithm for u-shaped cost functions on boolean lattices applied to the feature selection problem. Pattern Recognition, 43(3):557-568. 21

[Sánchez and Thieffry, 2001] Sánchez, L. and Thieffry, D. (2001). A logical analysis of the drosophila gap-gene system. Journal of Theoretical Biology, 211(2):115-141. 3

[Schllit and Brazma, 2007] Schllit, T. and Brazma, A. (2007). Current approaches to gene regulatory network modelling. BMC Bioinformatics, 8(Suppl 6):S9. 2, 29

[Seok et al., 2010] Seok, J., Kaushal, A., Davis, R., and Xiao, W. (2010). Knowledge-based analysis of microarrays for the discovery of transcriptional regulation relationships. BMC Bioinformatics, 11(Suppl 1):S8. 44

[Serra et al., 2004] Serra, R., Villani, M., and Semeria, A. (2004). Genetic network models and statistical properties of gene expression data in knock-out experiments. Journal of Theoretical Biology, 227(1):149 - 157. 3

[Shalon et al., 1996] Shalon, D., Smith, S. J., and Brown, P. O. (1996). A DNA microarray system for analyzing complex DNA samples using two-color fluorescent probe hybridization. Genome Research, 6(7):639-645. 1, 7

[Shannon, 1948] Shannon, C. E. (1948). A mathematical theory of communication. Bell System Technical Journal, 27:379-423, 623-656. 23

[Shannon and Weaver, 1963] Shannon, C. E. and Weaver, W. (1963). The mathematical theory of communication. University of Illinois Press. 23

[Shen-Orr et al., 2002] Shen-Orr, S. S., Milo, R., Mangan, S., and Alon, U. (2002). Network motifs in the transcriptional regulation network of escherichia coli. Nature Genetics, 31(1):64-68. 33

[Shmulevich and Dougherty, 2007] Shmulevich, I. and Dougherty, E. R. (2007). Genomic Signal Processing. Princeton University Press, New Jersey. 1, 3, 12, 13, 15, 16, 17, 20, 41, 42

[Shmulevich et al., 2002a] Shmulevich, I., Dougherty, E. R., Kim, S., and Zhang, W. (2002a). Probabilistic boolean networks: a rule-based uncertainty model for gene regulatory networks. Bioinformatics, 18(2):261-274. 2, 3, 11, 17, 41

[Shmulevich et al., 2002b] Shmulevich, I., Dougherty, E. R., and Zhang, W. (2002b). From Boolean to probabilistic Boolean networks as models of genetic regulatory networks. Proceedings of the IEEE, 90(11):1778-1792. 3, 17, 41

[Shmulevich et al., 2005] Shmulevich, I., Kauffman, S. A., and Aldana, M. (2005). Eukaryotic cells are dynamically ordered or critical but not chaotic. PNAS, 102(38):13439-13444. 3

[Soinov et al., 2003] Soinov, L. A., Krestyaninova, M. A., and Brazma, A. (2003). Towards reconstruction of gene networks from expression data by supervised learning. Genome Biology, 4(1):R6. 2,39

[Somol et al., 2004] Somol, P., Pudil, P., and Kittler, J. (2004). Fast branch \& bound algorithms for optimal feature selection. IEEE TPAMI, 26(7):900-912. 21

[Somol et al., 1999] Somol, P., Pudil, P., Novovičová, J., and Paclík, P. (1999). Adaptive floating search methods in feature selection. Pattern Recognition Letters, 20:1157-1163. xvii, 21, 22

[Soranzo et al., 2007] Soranzo, N., Bianconi, G., and Altafini, C. (2007). Comparing association network algorithms for reverse engineering of large-scale gene regulatory networks. Bioinformatics, 23(13):1640-1647. 3 
[Steuer et al., 2002] Steuer, R., Kurths, J., Daub, C. O., Weise, J., and Selbig, J. (2002). The mutual information: detecting and evaluating dependencies between variables. Bioinformatics, 18(Suppl. 2):S231-S240. 28

[Strogatz, 2001] Strogatz, S. H. (2001). Exploring complex networks. Nature, 410(6825):268-276. 45

[Stuart et al., 2003] Stuart, J. M., Segal, E., Koller, D., and Kim, S. K. (2003). A gene-coexpression network for global discovery of conserved genetic modules. Science, 302(5643):249-255. 28, 36, 91

[Styczynski and Stephanopoulos, 2005] Styczynski, M. P. and Stephanopoulos, G. (2005). Overview of computational methods for the inference of gene regulatory networks. Computers $\mathcal{G}$ Chemical Engineering, 29(3):519-534. 2, 29

[Theodoridis and Koutroumbas, 2008] Theodoridis, S. and Koutroumbas, K. (2008). Pattern Recognition. Academic Press, USA, 4th edition. 4, 19

[Trepode et al., 2007] Trepode, N. W., Armelin, H. A., Bittner, M., Barrera, J., Gubitoso, M. D., and Hashimoto, R. F. (2007). A robust structural pgn model for control of cell-cycle progression stabilized by negative feedbacks. EURASIP Journal on Bioinformatics and Systems Biology, 2007(73109):1-11. 2

[Troyanskaya, 2005] Troyanskaya, O. G. (2005). Putting microarrays in a context: Integrated analysis of diverse biological data. Brief Bioinform, 6(1):34-43. 44

[Tsallis, 1988] Tsallis, C. (1988). Possible generalization of Boltzmann-Gibbs statistics. Journal of Statistical Physics, 52(1):479-487. 25

[Tsallis, 1998] Tsallis, C. (1998). Generalized entropy-based criterion for consistent testing. Phys. Rev. E, 58(2):1442-1445. 26

[Tsallis, 2001] Tsallis, C. (2001). I. Nonextensive Statistical Mechanics and Thermodynamics: Historical Background and Present Status. Lecture Notes in Physics, 560(3):3-98. 26

[Tsallis, 2004] Tsallis, C. (2004). What should a statistical mechanics satisfy to reflect nature? Physica D: Nonlinear Phenomena, 193(1-4):3-34. 26

[Tsallis, 2009a] Tsallis, C. (2009a). Nonadditive entropy: The concept and its use. The European Physical Journal A - Hadrons and Nuclei, 40:257-266. 23, 25

[Tsallis, 2009b] Tsallis, C. (2009b). Nonextensive statistical mechanics and nonlinear dynamics. In Interdisciplinary Aspects of Turbulence, volume 756 of Lecture Notes in Physics, pages 1-28. Springer Berlin / Heidelberg. 25

[Tsallis and Brigatti, 2004] Tsallis, C. and Brigatti, E. (2004). Nonextensive statistical mechanics: A brief introduction. Continuum Mechanics and Thermodynamics, 16:223-235. 25

[Tsallis et al., 2005] Tsallis, C., Gell-Mann, M., and Sato, Y. (2005). Extensivity and entropy production. Europhysics News, 36(6):186-189. 25, 27

[Ulitsky and Shamir, 2007] Ulitsky, I. and Shamir, R. (2007). Identification of functional modules using network topology and high-throughput data. BMC Systems Biology, 1(1):8. 44

[Van den Bulcke et al., 2006] Van den Bulcke, T., Van Leemput, K., Naudts, B., van Remortel, P., Ma, H., Verschoren, A., De Moor, B., and Marchal, K. (2006). Syntren: a generator of synthetic gene expression data for design and analysis of structure learning algorithms. $B M C$ Bioinformatics, 7(1):43. 3 
[Velculescu et al., 1995] Velculescu, V. E., Zhang, L., Vogelstein, B., and Kinzler, K. W. (1995). Serial Analysis of Gene Expression. Science, 270(5235):484-487. 1

[Vidal, 2005] Vidal, M. (2005). Interactome modeling. FEBS Letters, 579(8):1834-1838. Systems Biology. 44

[Voet et al., 2005] Voet, D., Voet, J., and Pratt, C. W. (2005). Fundamentals of Biochemistry: Life at the Molecular Level. John Wiley \& Sons, USA, 2nd edition. 2, 8

[Wahde and Hertz, 2000] Wahde, M. and Hertz, J. (2000). Coarse-grained reverse engineering of genetic regulatory networks. Biosystems, 55(1-3):129-136. 3

[Wang et al., 2009] Wang, Z., Gerstein, M., and Snyder, M. (2009). RNA-Seq: a revolutionary tool for transcriptomics. Nat Rev Genet, 10(1):57-63. 1

[Watts and Strogatz, 1998] Watts, D. J. and Strogatz, S. H. (1998). Collective dynamics of smallworld networks. Nature, 393:440-442. 33, 34, 35, 40, 91, 93

[Weaver et al., 1999] Weaver, D. C., Workman, C. T., and Stromo, G. D. (1999). Modeling regulatory networks with weight matrices. In Proceedings of the Pacific Symposium on Biocomputing, pages 112-123. 2, 39

[Webb, 2002] Webb, A. R. (2002). Statistical Pattern Recognition. John Willey \& Sons, 2nd edition. $19,20,37,54$

[Werhli and Husmeier, 2008] Werhli, A. V. and Husmeier, D. (2008). Gene regulatory network reconstruction by bayesian integration of prior knowledge and/or different experimental conditions. Journal of Bioinformatics and Computational Biology, 6(3):543-572. 44

[Wilk and Wlodarczyk, 2008] Wilk, G. and Wlodarczyk, Z. (2008). Example of a possible interpretation of Tsallis entropy. Physica A: Statistical Mechanics and its Applications, 387(19-20):48094813. 25

[Xiao, 2009] Xiao, Y. (2009). A tutorial on analysis and simulation of boolean gene regulatory network models. Current Genomics, 10:511-525. 2, 29

[Yu et al., 2006] Yu, H., Paccanaro, A., Trifonov, V., and Gerstein, M. (2006). Predicting interactions in protein networks by completing defective cliques. Bioinformatics, 22(7):823-829. 45

[Zhao et al., 2008] Zhao, W., Serpedin, E., and Dougherty, E. R. (2008). Inferring connectivity of genetic regulatory networks using information-theoretic criteria. IEEE/ACM TCBB, 5(2):262274. $2,4,28,39,68$

[Zhou et al., 2004] Zhou, X., Wang, X., Pal, R., Ivanov, I., Bittner, M., and Dougherty, E. R. (2004). A bayesian connectivity-based approach to constructing probabilistic gene regulatory networks. Bioinformatics, 20(17):2918-2927. 2, 39 


\section{Índice Remissivo}

adenosina trifosfato, 89

aditividade, 27

agrupamentos, 46

algoritmo de busca, 22, 47, 49

arabidopsis thaliana, 5, 57

ARACNE, 32

atratores, 16

bacia de atração, 16

bioinformática, 2, 21, 30, 41, 91

biologia computacional, 30

biologia sistêmica, 49

branch-and-bound, 23

cadeias de Markov, 20

circuito lógico, 2, 43

Claude Shannon, 25

cloroplasto, 88, 96

CLR, 32

CoD, 30

Constantino Tsallis, 27

dinâmica, 43, 49

dinâmica do sistema, 48

DNA microarrays, 1, 9, 41

DREAM, 2, 73

efeito nesting, 23, 33, 35

engenharia reversa, 2

entropia, 25, 27, 29, 46, 48, 49

entropia condicional, 25, 48

entropia condicional generalizada, 48

entropia condicional média, 26, 49

entropia condicional média generalizada, 49, 77

entropia conjunta, 25

entropia de Tsallis, 27

entropia generalizada de Tsallis, 27, 48, 94

entropia não extensiva, 28

espaço de estados da rede, 16

especificidade, 57

estado do sistema, 20

estados transientes, 16

expressão gênica, 2, 10, 13, 47, 57

expressões gênicas temporais, 2 extensividade, 27, 28

extração de características, 22

fotossíntese, 58,89

função critério, 22, 29, 47

função de transição, 20, 43

função estocástica, 20

glicólise, 58,88

grafo acíclico dirigido (DAG), 17

grafos, 14

hibridização competitiva, 10

hubs, 37

identificação de redes, 46

inferência de GRNs, 30

informação biológica, 46

informação mútua, 26

informação mútua generalizada, 28

Leonard Euler, 35

Ludwig Boltzmann, 25

média geométrica, 57

média proporcional, 57

maldição da dimensionalidade, 21

matriz de adjacência, 43, 56

matriz de confusão, 56

matriz de transição, 20

medida de similaridade, 56

mitocôndria, 88, 89, 96

MRNET, 32

Positive Predictive Value, 57

PPV, 57

precision, 57

predição, 49

predição intrinsecamente multivariada, 23, 50

propriedade small-world, 37

réplica biológica, 58

reação em cadeia da polimerase (PCR), 9

recall, 57

reconhecimento de padrões, 21 
rede bayesiana, 17

rede booleana $(\mathrm{BN}), 2,15$

rede booleana aleatória (RBN), 2, 15

rede booleana probabilística $(\mathrm{PBN}), 19$

rede de regulação gênica, 1

rede gênica artificial (AGN), 3, 42

rede gênica probabilística (PGN), 3, 20

redes small-world, 36

redes scale-free, 37

redes aleatórias (ER), 36

redes complexas, 35, 42, 47

redes de regulação gênica, 41

redes de relevância, 31

redes espaciais, 38

redes geográficas, 38

respiração, 58

respiração celular, 89

REVEAL, 31

RNA-Seq, 1

SAGE, 1

SBS, 23, 50

seleção de características, 4, 22, 47

sensibilidade, 57

SFFS, 23, 33, 35, 49, 79, 81, 93

SFFS-BA, 47, 49, 51, 81

SFFS-MCE, 33, 93

SFFS-MR, 47, 49, 79, 94

SFS, 23, 35, 49, 79, 81, 94

sistema dinâmico, 45

sistemas complexos, 17

sub-extensividade, 28

super-extensividade, 28

tamanho do ciclo, 17

teoria dos grafos, 35

tiamina, 57, 58, 61, 84, 89, 96

topologia, 3

trajetória, 16

vias metabólicas, 58

wrappers, 23 